\title{
Beyond static inequality
}

Citation for published version (APA):

Chongcharoentanawat, P. (2019). Beyond static inequality: public policies and economic mobility in Thailand. [Doctoral Thesis, Maastricht University]. ProefschriftMaken.

https://doi.org/10.26481/dis.20191216pc

Document status and date:

Published: 01/01/2019

DOI:

$10.26481 /$ dis.20191216pc

Document Version:

Publisher's PDF, also known as Version of record

\section{Please check the document version of this publication:}

- A submitted manuscript is the version of the article upon submission and before peer-review. There can be important differences between the submitted version and the official published version of record.

People interested in the research are advised to contact the author for the final version of the publication, or visit the DOI to the publisher's website.

- The final author version and the galley proof are versions of the publication after peer review.

- The final published version features the final layout of the paper including the volume, issue and page numbers.

Link to publication

\footnotetext{
General rights rights.

- You may freely distribute the URL identifying the publication in the public portal. please follow below link for the End User Agreement:

www.umlib.nl/taverne-license

Take down policy

If you believe that this document breaches copyright please contact us at:

repository@maastrichtuniversity.nl

providing details and we will investigate your claim.
}

Copyright and moral rights for the publications made accessible in the public portal are retained by the authors and/or other copyright owners and it is a condition of accessing publications that users recognise and abide by the legal requirements associated with these

- Users may download and print one copy of any publication from the public portal for the purpose of private study or research.

- You may not further distribute the material or use it for any profit-making activity or commercial gain

If the publication is distributed under the terms of Article $25 \mathrm{fa}$ of the Dutch Copyright Act, indicated by the "Taverne" license above, 


\section{Beyond Static Inequality: \\ Public Policies and \\ Economic Mobility in Thailand}

Patima Chongcharoentanawat 
Copyright (C) Patima Chongcharoentanawat 2019

\section{ISBN 978-94-6380-588-9}

Cover Design: Santi Hanjittrakan and ProefschriftMaken

Printing: ProefschriftMaken I | www.proefschriftmaken.nl

All rights reserved. No part of this publication may be reproduced, stored in retrieval system or transmitted, in any form or by any means, electronic, mechanical, photocopying, recording or otherwise, without prior permission of the author or the copyright-owning journals for previous published chapters. 


\section{Beyond Static Inequality: \\ Public Policies and \\ Economic Mobility in Thailand}

\section{DISSERTATION}

to obtain the degree of Doctor at Maastricht University, on the authority of the Rector Magnificus Prof. Dr. Rianne M. Letschert, in accordance with the decision of the Board of Deans, to be defended in public on Monday 16 December 2019 at 09:45 hours

$$
\text { by }
$$

\section{Patima Chongcharoentanawat}




\section{Supervisors}

Prof. Dr. Franziska Gassmann

Prof. Dr. Pierre Mohnen

\section{Assessment Committee}

Prof. Dr. Adam Szirmai (Chair)

Prof. Dr. Didier Fouarge

Dr. Britta Augsburg (Institute for Fiscal Studies, United Kingdom)

Dr. Miguel Niño-Zarazúa (UNU-WIDER, Finland) 


\section{Synopsis}

Upward economic mobility, a movement to a higher socioeconomic status, is a policy objective in its own right. It indicates the extent to which opportunity exists in society. In the presence of mobility, inequality is less problematic as individuals, through their own ability and effort, can rise into higher socioeconomic classes regardless of their backgrounds. However, research on economic mobility, in comparison to studies on mainstream static inequality indices, remains limited in developing countries due to the lack of longitudinal data. So far an abundance of literature on mobility has revealed that the opportunities for people, especially the ones at the bottom of the income spectrum, to move upward have become increasingly sparse. This phenomenon goes not only against the moral principles but may also lead to long-term economic inefficiency, persistence of inequality and disruption of social harmony. Hence, the impediment to mobility must be tackled in order to ensure that the equal opportunity to succeed remains achievable for all walks of life.

The purpose of this thesis is to understand economic mobility in the context of a developing economy and the role that social protection programs have played in promoting economic mobility. It does so by examining the extent and pattern of intragenerational income mobility, and by identifying factors driving mobility based on longitudinal data from Thailand. The study establishes causality linking participation in certain social protection programs which, in theory, have the potential to overcome mobility constraints including vocational training, microcredit and social pension, and changes in mobility outcomes by means of various impact evaluation methods using both absolute and relative mobility indicators.

Results gathered in this thesis suggest that Thailand still needs to overcome several challenges to transform the country into an inclusive and open society where everyone has an equal opportunity to prosper. In theory, social protection programs appear to be an obvious mobility-enhancing intervention to address the socioeconomic immobility. However, in practice, only the social pension program is found to impact beneficiaries along the outcome dimensions considered. The vocational training and the microcredit program do not play a role in fostering mobility. The thesis concludes that the implementation of social protection programs alone does not necessarily remove binding constraints to upward mobility. Program design and implementation matter. The effectiveness of the programs needs to be improved. Moreover, social protection should be regarded as an integral part of the wider system of social and economic support aiming to enhance productive capacity and promote upward mobility 



\section{Acknowledgements}

This thesis represents my four-year journey filled with tremendous effort, struggle, satisfaction, frustration, good times and bad times. There are enormous support and encouragement from many people behind every regression I ran and every sentence I wrote. Therefore, I would like to use the first pages of this book to acknowledge and extend my heartfelt appreciation to all those involved.

My deepest gratitude goes first of all to my supervisors, Prof. Dr. Franziska Gassmann and Prof. Dr. Pierre Mohnen, who play a central role in the completion of this thesis. Being supervised by the two distinguished professors has been something I always proudly brag about. I still remember how happy and relieved I was when both of them agreed to be my supervisors. People say that feeling insecure, unconfident and self-doubt is a part of PhD process. However, the fact that I have been in good hands overcame all those worries. Franziska, your thorough attentions, critical comments, challenging questions, constructive guidance and endless patience have broadened my intellectual horizon and decisively contributed to the success of this thesis project. Your immense knowledge and passion have also motivated and inspired me to be a better researcher. Thank you for being straightforward but so respectful and caring at the same time. Pierre, I am eternally thankful for your kindness. I still remember when the very first draft of my research proposal was so underdeveloped, you still encouraged me saying that at least I had a nice research title. I am deeply grateful for the time and effort you have made to teach me basic and advanced econometrics, derive equations and ensure the validity of all the models used in thesis, and even correct my grammar mistakes. I am also grateful for your swift responses (even at 11 pm on the weekend!) and your patience with the countless revisions of each paper. Working with you and Franziska is a truly invaluable learning experience.

I would also like to express my sincere gratitude to the members of the assessment committee, namely Prof. Dr. Adam Szirmai, Prof. Dr. Didier Fouarge, Dr. Britta Augsburg and Dr. Miguel Niño-Zarazúa for taking their precious time to review this thesis. Your insightful comments and useful feedbacks help further improve the quality of this thesis and provide a fertile ground for my future research. The thesis has also greatly benefited from the useful comments and suggestions I received at different workshops and conferences I attended and presented my research including the ADB-AGI workshop in Kitakyushu, the IZA World Labor conference in Berlin, the AASLE conference in Seoul, the NCDE conference in Copenhagen and the EEA-ESEM annual congress in Manchester.

UNU-MERIT has been my home away from home for the past years during which I have learned and grown so much, not only in academic research but in perspective on life. I 
would like to extend my gratitude to the director of the PhD program, Prof. Dr. Robin Cowan, for his support throughout the PhD process. Thank you for never rejecting my requests and for being a critical discussant of my papers at the internal conference for two years in a row. I am especially grateful to Prof. Dr. Adam Szirmai for his invaluable guidance both at the beginning and the end of this $\mathrm{PhD}$ trajectory. Eddy, I greatly appreciate your kind support especially at the early stage of this thesis project. Thank you for taking your time to listen to my research ideas, guide me towards relevant literature and help turning my ideas into more solid research questions. It is an honor and meaningful for me to have you as the chair of the assessment committee.

I am also thankful to Prof. Dr. Michael Cichon, Prof. Dr. Theophile Azomahou, Prof. Dr. Shayama Ramani, Prof. Dr. Ir. Eleonora Nillesen, Dr. Mindel van de Laar, Dr. Zina Nimeh, Dr. Nyasha Tirivayi, Dr. Micheline Goedhuys, Dr. Maty Konte and Dr. Stephan Dietrich for imparting their wisdom on me and for the fruitful and inspiring discussions especially at the beginning of my PhD study. A special thanks also goes to Dr. Paula Nagler and Dr. Bruno Martorano for giving me the opportunity to teach Public Policy Analysis during which I have considerably improved my quantitative skills necessary for my own research. I have learned a lot from working with you and teaching this course.

There is an endless list of UNU-MERIT administrative staffs to whom I am heavily indebted. I particularly thank Eveline for her support ever since day one. Eveline, I deeply appreciate all that you have done for me, ranging from taking care of all the visa, insurance, housing, and graduation process issues to always boosting my morale. My life in the Netherlands would be a whole lot harder without your kind help. I am also grateful to Marc for never getting tired of me knocking on his door asking for money. I am thankful to Herman for his willingness to help with all the IT issues and for the nice and professional photos; and Ad for kindly hunting down the books on my wishlist and allowing me to keep a pile of books as long as I need. A big thanks also to the reception team for the nicest Hoi every morning and the cleaning lady, Nancy, for keeping my desk clean even when I was away from the office.

I had the blessing sharing one of the most important chapters of my life with so many great people who have made my years in Maastricht so wonderful and memorable. I have always been proud of being a part of the 2015 batch with Bart, Joseph, Beatriz, Giulia, Victor, Danilo, Emmanuel, Kaleab, Halefom, Tamara and Rose. A big thanks to you all for helping each other going through the incredibly stressful assignments, presentations, exams and proposal defense in the first year and having been my good companions during all my years in Maastricht. In particular, I thank Bart (my personal lawyer) for teaching me how to deal with issues in a very direct (like a Dutch) but diplomatic way; Joseph (and his lovely wife, 
Mary) for always cooking me delicious Korean food; Bea for being the wonderful shopping buddy and for all the beauty tips; Giulia (a small girl with a big heart) for LaTex codes, the best aubergine parmigiana and numerous supportive conversations; Victor for always giving me useful tips for research and presentation; Danilo for trying to teach me how to cook (although it is not really successful); Emmanuel for being the superstar that you are; and Halefom and Kaleab for being the two coolest Ethiopian men alive.

I would also like to emphasize my thanks to Tamara and Rose for accepting to be my paranymphs and sharing with me this special moment. It is so meaningful to have both of you who sat beside me in our office 1.11 on the first day of my PhD study to stand next to me on the last day of this journey. Tamara, I am very appreciative of your kind help and support. Thank you for always making the time to listen to my concerns and trying your best to help me finding useful information and figuring out the best solutions. Also many thanks to you for cooking me countless delicious dinners, letting me be a couch potato at your place, watching Disney movies with me and taking me to many beautiful places. Rosie, like we have always told each other, despite all our differences, I am convinced that we were twin sisters in a past life. I have learned a lot from our stressful and non-stressful conversations and from being your friend. Thank you for suggesting tons of useful research tips, giving me advice on many of my econometric questions, being with me in all circumstances, and influencing me in many aspects.

I would like to mention some other special PhD colleagues and researchers with whom I have shared countless unforgettable coffee breaks, lunches, dinners, afterwork drinks, parties, movie nights, and interesting conversations on both work and non-work related topics. Anny (the co-founder of the small but awesome Asian club), I love working, talking, travelling and especially eating with you. Thank you for making the long days of work also beautiful and enjoyable. I will cherish every moment we spent together especially our wonderful trip in Malta. Sabrina, thank you for travelling to Copenhagen with me, making efforts to get me out of my bed, feeding me with the nicest vegan food that even the most adamant carnivores like me can fall in love with, and most gratefully, kindly proofreading this book. Alison, I am forever indebted to your kind support throughout the course of my $\mathrm{PhD}$ journey. Thank you for taking your time to read through countless versions of my proposal and always giving me the best advices. Arip, thank you for your willingness to help me out with my Stata questions and for having me over for lovely homemade dinners. Mira, thank you for reading my proposal and for your kind and practical suggestions that always made me feel more relieved. Also, Gideon (my inspirational officemate), Racky, Eszter (my burritos buddy), Clotilde, Lika, Tatenda, Davina, Elisa, Iman, Ortrun, Iulia, Michelle, Vasil, Janyl, Elvis, Nga, Solomon and Lorena, many thanks to all of you for your friendship and all the precious memories you have given me during my Maastricht years. 
Being away from home for so many years is never easy. I would like to thank many of the Thai students in Maastricht (TSAM) whom I had the pleasure to meet and be friends with especially p'Lek, Ploi, p'Por (and p'Martin), p'Som-O, Elizabeth, Wilai, FM, n'Ice, n'Paun, n'Beau, Nac and n'Jul for sharing my craving for Thai food, keeping up with hot topics in Thailand and giving me a hand in times of need. I am also thankful to the Pieters family ( $\mathrm{p}^{\prime}$ Nok, khun Paul and n'Than) for their delicious food and warmest hospitality. You all have made my life in Maastricht less lonely and even more memorable.

This thesis would have never happened without financial support from the Royal Thai Government Scholarship and intellectual support from the National Economic and Social Development Board (NESDB). I am grateful to have had several wonderful colleagues and bosses during my career at NESDB. Their accomplishments and strong dedication to make Thailand a better place have been my inspiration and made me become a better professional. In particular, I would like to express my gratitude to my boss ladies Mrs. Chutinart Wongsuban, Miss Jinanggoon Rojananan, and p'Pu Montip Sumpunthawong for their great support and understanding. Early in my career, I was also fortunate to have the opportunity to work with Mrs. Suwanee Khamman and Dr. Pattama Teanravisitsagool, another two incredible women whom I have looked up to and admired so much. Thank you for being inspirational bosses, role models and teachers. Working with you has been nothing but a rewarding experience.

I would also like to particularly thank Dr.Wanchat Suwankitti ( $\mathrm{p}^{\prime}$ Milo), the very first mentor in my civil service life. Thank you for your unending patience with my stubbornness and for being the open-minded, motivational and highly supportive boss that you are. I am forever grateful for all the opportunities you have given me and the efforts you have made to make certain that I will be able to pursue my $\mathrm{PhD}$. Access to data and program information is of utmost importance when conducting this research. I am thankful to Dr. Ouan Bhumisuk for his great assistance in data retrieval from the National Statistical Office (NSO). A big thank you needs to be extended to $\mathrm{p}^{\prime}$ Arm Pairat for his insightful suggestions on data manipulation and $\mathrm{p}^{\prime}$ Kung Angkana for her inside information on social protection programs in Thailand.

I am also fortunate to have found another family in the workplace. Words cannot adequately express the appreciation I have to my 4POD family (Dr. p'Dear Arnunchanog, Dr. p'Pearl Suphannada, Dr. p'Pai Thuttai, p'Oil Vanniya, and my dearest bae Pumpim Orachat) for constantly showering me with love and support. Thank you so much for your best advice, great encouragement and pleasant visits. A number of care packages filled with my favorite food, snacks and other sentimental stuff you have sent me over the past years 
did not only feed my stomach but also touch my heart. All the pictures and videos of the brightest rays of sunshine, Nalan and n'Fah, have also never failed to make me smile.

Much love and appreciation belong to all my beloved friends in Thailand who came to visit me and those who have been by my side even from all the way over there. I am particularly thankful to Piya and Tai (DDD) for being the lifelong bestest friends that one can find. Thank you for the wonderful and memorable trips we made together and for hilarious text messages in our group chat that always make me laugh even on a rough day. A huge thank you also goes to Palm and Parn (3Ps) for their positive influence, words of encouragement and nice visit. Living here by myself made me realize how lucky I was to have you both as my housemates back in Ann Arbor.

As a socioeconomic mobility researcher, I am fully aware that family plays an enormously important role in shaping one's life. Although I am not from the wealthiest class, I consider myself so lucky to have a large, loving and caring family who has always supported me in all of my endeavors. Na Aew and p'Hoek, you are the greatest aunt and uncle in law that one could ever ask for. Thank you for always taking good care of me and everyone in the family. My cousins, Korya, Pang, Dana and Kim (the artist who creates the beautiful and meaningful painting on the cover), thanks to you, I have never felt lonely despite being an only child. I hope I can inspire you in some way. J'Tu, you are my dearest aunt, my closest friend and my second mother. Thank you for always spoiling me and giving me so much love. Words are not sufficient to express my gratitude to what you have done for me. I would not be the person I am today without your kind love and support.

Finally but most importantly, none of the things I have achieved would have been possible without the unconditional love and endless support from my parents. Their strong belief in me has helped me through all the difficulties in life. Mama, I know these past years were not easy for you. Thank you for your patience and understanding with your only daughter who cannot always be there for you. Papa, the best man on earth who has never missed a single day to send me a blessing message every morning for the past four years and a half, thank you for all the sacrifices you have made for me and for giving me all the necessary tools to excel and get ahead in life. You always put me and my education first despite all odds. All that I am or will become, I owe it to you. I hope I have made you proud.

Patima (Pui) Chong Maastricht, October 15, 2019 

To all those beautiful people who have raised me - physically, intellectually and emotionally. You have helped me climb up the ladder! 



\section{Table of Contents}

List of Figures $\quad$ xiii

List of Tables $\quad$ xiv

List of Abbreviations $\quad$ xvi

Chapter 1 Introduction $\quad 1$

1.1 Background and Motivation 2

1.2 Multifaceted Concepts of Economic Mobility 5

1.3 Drivers of Mobility: Theoretical Background and Empirical Findings $\quad 7$

1.4 Potential Roles of Social Protection Programs 10

1.5 Objectives and Research Questions 12

1.6 Rationale of Case Study and Data Sources 14

$\begin{array}{lll}1.7 & \text { Organization of the Thesis } & 20\end{array}$

$\begin{array}{ll}\text { References } & 23\end{array}$

Chapter 2 Income Mobility in Thailand 27

2.1 Introduction 28

2.2 Economic Growth, Poverty and Inequality 29

2.3 Income Mobility 34

2.4 Drivers of Income Mobility 44

2.5 Conclusion and Policy Implications $\quad 61$

$\begin{array}{ll}\text { References } & 64\end{array}$

$\begin{array}{ll}\text { Chapter } 3 \text { Vocational Training and Upward Mobility: } & 67\end{array}$

$\begin{array}{ll}\text { Impact Heterogeneities and Policy Implications } & 67 \\ & 68\end{array}$

3.1 Introduction $\quad 68$

3.2 Evidence on Vocational Training 69

3.3 Thailand's Context and Vocational Training Program 72

$\begin{array}{ll}3.4 & \text { Data and Methods }\end{array}$

3.5 Results $\quad 85$

3.6 Conclusion and Discussion 96

$\begin{array}{ll}\text { References } & 101\end{array}$ 
Chapter 4 Microcredit and Upward Mobility:

the Evidence from the Thailand Village Fund

$\begin{array}{lll}4.1 & \text { Introduction } & 106\end{array}$

4.2 Thailand's Microcredit Market and the Village Fund 107

4.3 Evidence on Microcredit and the Village Fund 110

$\begin{array}{lll}4.4 & \text { Data and Methods } & 113\end{array}$

$\begin{array}{lll}4.5 & \text { Results } & 127\end{array}$

$\begin{array}{lll}4.6 & \text { Conclusion and Discussion } & 143\end{array}$

$\begin{array}{ll}\text { References } & 148\end{array}$

Chapter 5 Schooling Responses to Social Pension:

The Evidence from Thailand Old Age Allowance 153

$\begin{array}{lll}5.1 & \text { Introduction } & 154\end{array}$

$\begin{array}{lll}5.2 & \text { Theoretical Background } & 155\end{array}$

$\begin{array}{lll}5.3 & \text { Spillover Effects of Social Pensions } & 157\end{array}$

5.4 Thailand's Contexts and the Old Age Allowance Program 159

$\begin{array}{lll}5.5 & \text { Data } & 167\end{array}$

$\begin{array}{lll}5.6 & \text { Methods } & 172\end{array}$

$\begin{array}{lll}5.7 & \text { Results } & 179\end{array}$

$\begin{array}{lll}5.8 & \text { Conclusion and Discussion } & 191\end{array}$

$\begin{array}{ll}\text { References } & 200\end{array}$

$\begin{array}{ll}\text { Chapter } 6 \text { Conclusion } & 207\end{array}$

$\begin{array}{lll}6.1 & \text { Introduction } & 208\end{array}$

$\begin{array}{lll}6.2 & \text { Key Findings } & 209\end{array}$

6.3 Policy Implications 213

$\begin{array}{ll}6.4 \text { Contributions } & 216\end{array}$

6.5 Limitations and Future Research 219

6.6 Concluding Remarks 221

$\begin{array}{ll}\text { References } & 223\end{array}$

$\begin{array}{lr}\text { Valorisation Addendum } & 225\end{array}$

$\begin{array}{ll}\text { About the Author } & 227\end{array}$ 


\section{List of Figures}

Figure 2.1 GDP Growth and GDP Per Capita in Thailand (1988-2017) 29

Figure 2.2 Poverty Incidence in Thailand (1988-2017) 30

Figure 2.3 Income Inequality in Thailand (1988-2017) 31

Figure 2.4 Thailand's Growth Incidence Curve (GIC) (1988-2017) 32

Figure 2.5 Thailand's Growth Incidence Curve (GIC) at Each Time Period 33

Figure 2.6 Mean Share of Income Components over Total Household Income 36

Figure 2.7 Share of Household Income by Quintiles 37

Figure 2.8 FO Index and Components by Countries over Two-Year Period 41

Figure 2.9 FO Index (Directional Mobility) from 2005 to 2012 by Quintiles 42

Figure 5.1 Number of Old Age Population, OAA Beneficiaries and OAA 164 Budget (2006-2017)

Figure 5.2 The Distribution of Children Attending School by Age (0-24 years) 168

$\begin{array}{lll}\text { Figure 5.3 Education Expenditure (2009-2017) } & 197\end{array}$ 


\section{List of Tables}

Table 1.1 Non-Contributory Social Protection Programs in Thailand 16

Table 2.1 Thailand's FO Index and Components 40

Table 2.2 Transition Matrices by Income Quintiles (Percentage) 43

Table 2.3 Summary Statistics of Variables Used to Identify Drivers of Income 46 Mobility

Table 2.4 Drivers of Absolute Income Mobility (2005-2012) 48

Table 2.5 Drivers of Relative Income Mobility (2005-2012) 55

Table 2.6 Long-Run Equilibrium Impact of Key Drivers 60

Table 3.1 Baseline Statistics by Treatment and Control Group and 76

Descriptive Statistics of Training Programs

Table 3.2 Pre-Program Time Trends in Mobility Outcomes 81

Table 3.3 Impacts of Training by Difference in Difference with On-CommonSupport Observations

Table 3.4 Impacts of Training by Difference in Difference with Nearest Neighbor Matched Observations

Table 3.5 Impacts of Training on Upward Mobility by Endogenous Switching Regression (ESR)

Table 3.6 Heterogeneity of Effect by Participant and Program Characteristics 93

Table 4.1 Characteristics of Non-Borrowers, Borrowers and Loan Contracts 115

Table 4.2 Baseline Statistics by Treatment and Control Groups before Matching

Table 4.3 Baseline Statistics by Treatment and Control Groups after Nearest Neighbor Matching

Table 4.4 Pre-Program Time Trends in Mobility Outcomes 125

Table 4.5 Results of the Multinomial Logit Model (Marginal Effects) 129

Table 4.6 Results of the Hausman Test for the Independence of Irrelevant Alternatives (IIA)

Table 4.7 Impact of the VF on Upward Absolute and Relative Mobility 134

Table 4.8 Impact of the VF on Upward Labor Mobility 136

Table 4.9 $\quad P$-Values from Independent Estimations and Westfall-Young $\quad 137$ Adjusted $P$-Values 
Table 4.10 Differential Impact of Female Borrowers, Training Participants and Repeated Borrowers

Table 4.11 Impact of Loan Size on Mobility and Productive Decision-Making

Table 5.1 Number of Participants and Size of Pension Funds as of 2017

Table 5.2 Sample Size by Different Participant and Non-Participant Groups

Table 5.3 Summary Statistics

Table 5.4 Number and Percentage of School-Age Children Not Attending School by Age Group

Table 5.5 Impact of the OAA on Household Education Expenditure Per School-Age Child (2SLS)

Table 5.6 Impact of the OAA on Household Education Expenditure Per School-Age Child (Tobit Model)

Table 5.7 Impact of the OAA on the Share of Education Expenditure in Total Household Expenditure

Table 5.8 Impact of Co-Residing with OAA Pensioners on School Attendance

Table 5.9 Impact of the OAA on the Share of Education Expenditure in Total Household Expenditure by Income Decile 


\section{List of Abbreviations}

\begin{tabular}{|c|c|}
\hline 2SLS & Two-Stage Least Squares \\
\hline $\mathrm{AFC}$ & Asian Financial Crisis \\
\hline BAAC & Bank of Agriculture and Agricultural Cooperatives (Thailand) \\
\hline $\mathrm{CB}$ & Commercial Banks \\
\hline CPI & Consumer Price Index \\
\hline CSG & Child Support Grant (Thailand) \\
\hline DD & Difference in Difference \\
\hline DSD & Department of Skill Development, Ministry of Labour (Thailand) \\
\hline ECM & Error Correction Model \\
\hline ESR & Endogenous Switching Regressions \\
\hline $\mathrm{FO}$ & Fields and Ok Index \\
\hline GIC & Growth Incidence Curve \\
\hline GPF & Government Pension Fund (Thailand) \\
\hline GSB & Government Savings Bank (Thailand) \\
\hline IV & Instrumental Variable \\
\hline NESDB & National Economic and Social Development Board (Thailand) \\
\hline NSF & National Savings Fund (Thailand) \\
\hline NSO & National Statistical Office (Thailand) \\
\hline OAA & Old Age Allowance (Thailand) \\
\hline OECD & Organisation for Economic Co-operation and Development \\
\hline OLS & Ordinary Least Squares \\
\hline PCA & Principal Component Analysis \\
\hline PVD & Provident Funds (Thailand) \\
\hline RMF & Retirement Mutual Fund (Thailand) \\
\hline SDGs & Sustainable Development Goals \\
\hline SEA & South East Asia \\
\hline SES & Socio-Economic Survey (Thailand) \\
\hline SES-Panel & Socio-Economic Panel Survey (Thailand) \\
\hline SSF & Social Security Fund (Thailand) \\
\hline UHCCS & Universal Health Care Coverage Scheme (Thailand) \\
\hline VF & Village Fund (Thailand) \\
\hline
\end{tabular}




\section{Chapter 1}

\section{Introduction}




\subsection{Background and Motivation}

In one of his powerful and inspiring speeches, President Barack Obama stated that "If you work hard and meet your responsibilities, you can get ahead, no matter where you come from, what you look like, or who you love" (Trotter, 2013). The First Lady, Michelle Obama, also emphasized the spirit of the American dreams with the motivational message "With hard work and a good education, anything is possible - even becoming president" (ECMC Foundation, 2017). In a similar fashion, Nick Clegg, the Deputy Prime Minister of the United Kingdom, announced the government intention to make the country a fair and open society, one in which every individual is free to prosper. In his captivating speech Clegg had said "What matters most is the person you become, not the person you were born" (Jowit, 2012). The ideology of the connection between effort and reward embraced in western cultures is also found to be valid on the other side of the world. The widely shared belief and norm that hard work will always pay off have been rooted in Asian values, have shaped Asians' behaviors toward success and have been a great source of aspiration for Asian people to achieve their goals.

However, substantial obstacles to move upward faced by people especially ones from disadvantaged backgrounds raises the question, "Does the world work like that in reality, particularly for this current generation?". Unfortunately, a growing body of literature substantiates the concern that such a hopeful and dynamic society may no longer be within reach. The prospects of getting ahead, especially for those at the low end, are increasingly elusive. Children from disadvantaged backgrounds are likely to spend their whole life as deprived in terms of income, education, occupation and health status. A recent study reveals that in OECD countries, children from a poor family would need at least 150 years to reach the average income level while in some developing countries such as Brazil, Colombia and South Africa, it could take as long as 300 years (OECD, 2018a).

This stalled mobility goes not only against moral principles but may also lead to quantifiable detrimental consequences. From an economic perspective, lack of mobility undermines motivations, innovations and efficiency. People at the bottom whose talents and skills could potentially contribute to economic growth will not progress and potential businesses created by poor people will never come into existence (OECD, 2018a; Rama, Beteille, Li, Mitra, \& Newman, 2015). In other words, the disadvantaged groups in an immobile society will continually remain a burden waiting for assistance instead of becoming a potential resource to be tapped. At the same time, stagnant societies, where there is no hope for change, may 
lead to segregation between the advantaged and disadvantaged groups which in turn threaten social cohesion and may eventually lead to political unrest (ibid). Hence, impaired mobility necessitates effective policy interventions to change the rules, level the playing field and promote an environment conducive to upward mobility.

Social protection has been widely recognized as a powerful tool to alleviate deprivation and insure the poor against risks. The positive impact of social protection on poverty reduction is so abundantly documented that the Sustainable Development Goals (SDGs) adopted by governments, calls for the implementation of social protection programs in the fight against poverty. The social protection agenda has recently expanded from a modest beginning as a short-term intervention to mitigate vulnerability and deprivation to a more ambitious focus on promoting the livelihoods of the poor so they can become self-reliant, move to a higher income trajectory and escape poverty in a sustainable manner. Furthermore, social protection is expected to transform society by emancipating the poor, changing the power disequilibrium, and enhancing social equity. Therefore, social protection policies appear to be a potential mechanism to foster mobility.

So far an abundance of academic research and policy discussions on the equal, fair and just society have focused on the extent of inequality of development outcomes between the rich and the poor derived from cross-sectional data. While this remains relevant, traditional inequality measures observed at one point in time cannot capture the mobility of individuals and are thus insufficient to properly capture the dynamism in society. By contrast, mobility indicators drawn from longitudinal data can identify who moves up the ladder, who moves down and who remains in the same position. Moreover, while there is no common agreement regarding the optimal level of inequality, the need to promote equality of opportunity is widely recognized (OECD, 2018a). Unlike static inequality which primarily emphasizes disparity of outcomes, mobility measures observe whether people progress and thus highlight the extent of opportunity that the society has offered (Forde \& Zeuner, 2009; Rama et al., 2015). Furthermore, with a high degree of mobility, inequality would be less of a concern because inequality together with the prospect of mobility will incentivize people's behavior and equalize longer term outcomes (Fields, 2008a; Krugman, 1992; OECD, 2018a; Rama et al., 2015). Therefore, more research on dynamic mobility of individuals or groups of individuals is necessary to complement the perspective on distributional patterns and consequences.

As aforementioned, a study of mobility could offer more insight that would not have been provided by traditional static inequality studies based on cross-sectional data. Among the 
existing literature on mobility, however, most studies focus on developed countries. Very little literature is available from developing world because of the lack of longitudinal data particularly at the national coverage level (Brand-Weiner \& Francavilla, 2015; Fields, Hernández, Freije, \& Puerta, 2007). In addition, although evidence of the role that social protection plays in poverty alleviation is robust, the existing body of literature is not informative enough to convince us that social protection programs foster mobility. The vast majority of existing evaluation studies rely on cross-sectional data and thus fail to trace the dynamic improvement of beneficiaries' status over time (Browne, 2015). Besides, a rigorous evaluation of social protection programs regarding their potential to trigger transformation needs to consider a change of beneficiaries' position in relation to others in society (Devereux \& McGregor, 2014). This relative change, however, has rarely been explored in existing quantitative evaluation studies.

The primary purpose of this thesis project is to understand economic mobility in the context of a developing economy and the role that social protection programs have played in promoting economic mobility. It does so by examining the extent and pattern of mobility, and identifying factors driving and inhibiting mobility based on longitudinal data from Thailand. The study establishes causality linking participation in certain social protection programs which are expected to overcome mobility constraints including vocational training, microcredit and social pension, to changes in mobility outcomes using both absolute and relative mobility indicators. Results and implications derived from this study may serve as a useful guide to formulate policies, both in Thailand and other developing countries, aiming to foster mobility and assist the country toward a fairer and more inclusive society where everyone has an opportunity to succeed.

This chapter provides the background knowledge for the remainder of the thesis. The chapter is structured as follows. Section 1.2 describes the main concepts and definitions of economic mobility which are used in this work. Section 1.3 summarizes theories and empirical findings with regard to factors associated with economic mobility whereas section 1.4 discusses the potential role that social protection programs play in driving economic mobility. The subsequent section (section 1.5) presents the objectives and primary research questions that this thesis attempts to answer. Section 1.6 justifies the rationale for choosing Thailand as a case study, briefly reviews major social protection programs in Thailand and explains the two main data sets used in this thesis. The last section (section 1.7) contains the overview and organization of the thesis. 


\subsection{Multifaceted Concepts of Economic Mobility}

Studies on economic mobility are concerned with quantifying the degree to which economic status of individuals or groups of individuals change over two or more points in time. In the literature on mobility, economic status is often measured by income (Fields, 2010). Hence, income mobility is the central focus of this thesis when the term economic mobility is mentioned. Income mobility can be examined from the within-lifetime perspective, which is referred to as intragenerational mobility, or can be explained as mobility between generations, or intergenerational mobility (Jäntti \& Jenkins, 2015; OECD, 2018a). In other words, while intragenerational income mobility looks at income change within the life time, intergenerational income mobility compares economic status of (grand)parents and their children.

The notion of income mobility is multi-dimensional. According to Fields (2006, 2008b; 2007), income mobility can be categorized into six concepts: non-directional income movement, directional income movement, positional movement, share movement, mobility as time independence and mobility as an equalizer of longer-term incomes. First, non-directional income movement measures the magnitude of income change without regard to the direction. Income gains and income losses are weighted equally. Therefore, the non-directional movement indicates the degree of income flux or fluctuations of income. Second, unlike the non-directional concept, directional income movement differentiates between upward and downward mobility. Higher income will increase directional movement while lower income will decrease it.

Third, the notion of positional movement refers to changes of the position in the income distribution. The position means income rank and is often measured by individuals' or households' quintiles, deciles or centiles in the income distribution. Thus, positional movement is commonly referred to as rank change. Fourth, mobility as share movement traces changes in shares of total income. Unlike positional movement, share movement is concerned with change in income ratios rather than change in income positions. Shares of total income will change if income of an individual or household increases or decreases relative to others. Therefore, it is possible that a person/household experiences upward share movement even if her income falls because the decrease of her income is smaller than that of others within the income distribution.

Fifth, mobility as time independence examines the degree to which current income is determined by initial income. Income mobility through the lens of the time-independence 
concept is highest if current income and past income are not correlated to each other. Finally, mobility as an equalizer of longer-term incomes probes if income changes have led to more equal distribution of longer-term incomes, in comparison to the distribution of initial income. As exemplified in Field (2008b), an income change of an individual $x$ and y $(x, y)$ from $(1,3)$ to $(1,5)$ would increase non-directional and directional income mobility of y but disequalize the distribution of income because the income gap between $\mathrm{x}$ and $\mathrm{y}$ becomes larger.

The first four mobility concepts (non-directional, directional, positional and share mobility) describe mobility as a movement. The income movement can also be further classified into absolute and relative mobility. Absolute mobility is concerned with changes in absolute wellbeing, without comparisons with others (OECD, 2018a; Woolard \& Klasen, 2005). Relative mobility, on the other hand, is associated with changes in individual or household's standing in comparison to the standing of others (Fields, 2008b). As can be noted, while nondirectional and directional movement are absolute mobility concepts, positional and share movement are relative ones.

Each mobility concept is essentially different and the extent and pattern of mobility will entirely depend on which concept is being applied (Fields, 2006, 2008b). In this thesis, income mobility is measured through the movement perspective because the opportunity to get ahead is of particular interest in this study. Both absolute and relative income mobility are covered. For absolute income mobility, a strong emphasis is placed on directional income mobility since the direction of movement matters when examining the impacts of policy interventions. With regard to relative income mobility, only positional income movement is examined. The neglect of share movement is justified by the fact that in a large sample size, individual income shares as well as changes in their income shares might be so small that share movement is negligible and have no intuitive interpretation (Fields et al., 2007).

As aforementioned, greater income mobility indicates higher equality of opportunity since individuals, through their own talents and efforts, have a higher chance to move up the ladder. Income mobility is thus desirable from the fairness and social welfare standpoint (Jäntti \& Jenkins, 2015; OECD, 2018a). However, there are two counter arguments that would make income mobility socially undesirable. First, excessive income mobility particularly over the short period of time may be seen as income risk and economic insecurity which is unappealing for risk-averse people (ibid). To prevent this confusion, this thesis focuses on directional income mobility instead of non-directional movement to make 
certain that higher income mobility reflects individuals/households' advancement. Besides, particular attention is paid to the long-term analysis to avoid any confusion between income mobility and transitory income shocks.

The second argument against mobility is that for positional income mobility or rank change, when some people move up, there must be some people who move down. Therefore positional income mobility may be considered as a zero-sum game (OECD, 2018a). In this regard, the justification would be that "a great variety of situations can occur within this zero-sum game" (OECD, 2018a, p. 70). The number of people experiencing upward mobility may not necessarily be equal to those moving downward and the size of income change between upward and downward mobility may not always be identical (ibid). Moreover, from a policy viewpoint, positional movement taking place at the bottom of the income spectrum is also different from positional movement at the middle or the top of the distribution. Positional income mobility is socially desirable if people at the low end experience upward positional income mobility since such mobility would reduce inequality in the long term.

\subsection{Drivers of Mobility: Theoretical Background and Empirical Findings}

The mechanism through which income mobility takes place is essential for policy design and formulation. There are four main theories explaining who is likely to move up, who is falling behind and how income mobility happens (Fields \& Puerta, 2010). The first theory is the theory of cumulative advantage. The theory of cumulative advantage is developed from the Matthew Effect in science which posits that scientific contributions by scientists of renown tend to gain more recognition than contributions made by less eminent scientists (Merton, 1968). This disproportionate credit in the reward system of science is driven by the higher ability of famous scientists to attract resources such as funding, collaboration opportunities and talents to work for them (DiPrete \& Eirich, 2006; Merton, 1968). The Matthew Effect has also been applied to the economic context to explain the condition under which "a favorable relative position becomes a resource that produces further relative gains" (DiPrete \& Eirich, 2006, p.1). Individuals with higher income to begin with are more likely to accumulate human capital, own physical assets and get access to social and political connections, all of which are useful to secure and even promote their privileged status (DiPrete \& Eirich, 2006; 
Fields \& Puerta, 2010). This cumulative advantage of people from wealthier backgrounds would impede income mobility especially among those at the bottom.

The second theory explaining income mobility is the theory of poverty traps. According to this theory, the inability of poor individuals or households to invest in human capital (nutrition, health care and education) to accumulate physical assets and to access credit markets will undermine their productive capacity (Carter \& Barrett, 2006; Chronic Poverty Research Center, 2004). In turn, their low level of productive capacity will trap people who are initially poor in persistent deprivation. This theory of poverty traps complements the theory of cumulative advantage in the sense that while the latter explains why rich people tend to get richer, the notion of poverty traps explains why the poor may become poorer.

Providing further explanation for the pattern of income mobility is the theory of skill-biased technological change. Technological progress together with trade openness and globalization has improved the productivity of skilled workers, caused relative demand shift toward such labor categories and has eventually boosted earnings of workers with relatively more skills in a more than proportional way compared to workers with less skills (Autor, Katz, \& Krueger, 1998; Gottschalk, 1997; Johnson, 1997). Accordingly, the skill-biased technological change would allow individuals with high human capital and physical capital endowments complementary to new technologies to disproportionately benefit from technological change and move up on the socioeconomic ladder (Autor et al., 1998; Fields \& Puerta, 2010).

The final theory is the theory of the regression to the mean. Unlike the three theories discussed above, this theory supports the idea of the reversal of fortune. The theory of the regression to the mean was first introduced by Galton (1886) who finds that the gap of height between tall and short individuals will be smaller in the following generations because the transmission of height is not perfect. Although children of tall parents tend to be higher than average, they are found to be shorter than their parents. In the same fashion, short parents also appear to have children who are taller than them. As a result, the children' height is closer to the population mean height than that of their parents'. Becker and Tomes (1986) explain the extent of intergenerational earning mobility based on the idea of the regression to the mean. They substantiate that parents, due to parental altruism, will maximize their children's welfare by investing in human capital and passing on physical wealth to their children. Therefore, children from rich families are more likely have an endowment higher than average and are expected to earn more than children from poorer backgrounds. However, since rich parents may have more than one child, the investment spent on and the bequest given to each child is lower making the expected earning of rich children regress 
down to the mean. At the same time, poor families tend to have higher marginal rates of return from investment in human capital, a fact which in turn lifts the expected earnings of poor children up to the mean. In this way, the earnings gap between rich and poor children will become closer, relative to the gap between rich and poor parents. The authors claim that earning inequality between the rich and the poor disappears in three generations. The rate of convergence depends on the inheritability of endowments and the capital constraints on investments in children.

As mentioned before, the implications for the pattern of income mobility derived from the aforementioned theories are somewhat inconsistent. While the theories of cumulative advantage, poverty traps and skill-biased technological changed hypothesize that people from better-off backgrounds are more likely to sustain their good fortune, the theory of the regression to the mean supports an idea that goes in the opposite direction (Fields \& Puerta, 2010). However, one common agreement stands out; the extent of income mobility relies considerably on individuals' productive capacity, which is measured by human capital and physical asset.

The crucial role of human capital and physical capital in driving upward income mobility is also backed up by a growing number of empirical findings. For example, Aristei and Perugini (2015) examine absolute household income mobility from 2004 to 2006 in 25 European countries. The authors observe that short-term absolute income mobility of the households is driven by human capital characteristics of the household head including education and work experience. In the same vein, a recent study on income mobility by the OECD (2018a) indicates that labor market transitions are a key driver of both absolute and relative income mobility among working-age population in OECD countries. A transition from non-employment to employment is associated with upward income mobility while a transition from employment to non-employment is a primary factor of downward income mobility.

With regard to the evidence from less developed economies, Fields et al. (2003) analyze determinants of absolute household income mobility in Indonesia, South Africa, Spain and Venezuela. They conclude that despite different years of observation, macroeconomic conditions and income levels, the four countries under investigation have a common determinant of absolute income mobility which is the employment status of the household head. Households whose heads are formally employed, or at least employed, are more likely to move up the ladder. Income mobility in South Africa is scrutinized in more detail by Woolard and Klasen (2005) using panel data covering the most populous province in 
South Africa, KwaZulu-Natal, from 1993 to 1998. The results indicate that large household size, low level of education of the household head, and insufficient possession of physical assets are the key factors trapping households in poverty. A similar finding is obtained for the case of Vietnam. Brand-Weiner and Francavilla (2015) establish that having members participating in the labor market, regardless of the form, is found to drive both absolute and relative upward income mobility of Vietnamese households. Finally, Shi et al. (2010) examine long-term absolute income mobility of households in rural China from 1989 to 2006. They suggest that human capital characteristics of household members such as average years of schooling, sector of employment and physical capital measured by number of durables owned by a household are positively associated with upward income mobility.

\subsection{Potential Roles of Social Protection Programs}

The role of social protection schemes in improving well-being of beneficiaries has risen to prominence in the late 1990s during which its boundaries have expanded from public policies aiming at protecting people against risks in rich countries to a development policy agenda in developing economies (Barrientos, Hulme, \& Shepherd, 2005). Moreover, in recent years, there has been a growing interest in the graduation approach which highlights the productive role of the programs in improving the capacities of beneficiaries, lifting them to higher income trajectories and facilitating a sustainable transition out of poverty (Devereux \& Sabates-Wheeler, 2015; Samson, 2015). The movement of social protection policies towards a more productive perspective is fully aligned with the concept of upward mobility and emphasizes the role of social protection programs in promoting economic mobility. This section provides definitions of social protection and its expected contributions in each functional component. This background information proffers a deeper understanding of the linkages between social protection programs and economic mobility that is the core interest of this thesis.

Drawing from the one of the most commonly cited conceptual frameworks by Devereux and Sabates-Wheeler (2004) from the Institute of Development Studies (IDS), social protection can be defined as a set of interventions that aim to reduce socioeconomic risks and vulnerabilities, improve livelihoods, and enhance the social status and rights of the poor, vulnerable and marginalized groups. Devereux and Sabates-Wheeler (2004) classify social protection into four main functions. The protective function aims to alleviate deprivation of the chronic poor and extremely vulnerable by lifting their living standards at least to the minimal sufficient level and providing them with access to basic services (Arnold, Conway, 
\& Greenslade, 2011). The interventions under this category include social assistance such as social pensions and disability allowances as well as social services such as orphanages, feeding programs and refugee camps. The preventive function refers to interventions attempting to prevent livelihood shocks from having catastrophic impacts on the poor and vulnerable (Arnold et al., 2011; Asfaw et al., 2014). The preventive interventions are generally provided in the form of social insurance such as unemployment benefits, health insurance and informal saving groups.

The promotive function seeks to improve income, human capital and physical assets which in turn enhances the productive capacities of disadvantaged people through a variety of livelihood-enhancing programs such as school feeding, microfinance and skill development programs (Arnold et al., 2011; Asfaw et al., 2014). Finally, the transformative function attempts to address power imbalances that trap people in poverty and enhance social equity through the programs that empower the excluded groups to be able to claim their rights and access to economic opportunities (ibid). There may be overlaps between functions because some interventions may have more than one area of contribution (Devereux \& Sabates-Wheeler, 2004; Gassmann, 2014). For instance, there is growing evidence indicating that social assistance programs could simultaneously protect the poor from deprivation, prevent them against irreversible damages from calamitous shocks, promote their productive capacity and transform society toward more inclusion and less discrimination.

Another framework proposed by the World Bank (2012) identifies the objectives of social protection programs in a similar fashion. The first objective is equity which aims to protect poor individuals and households from extreme deprivation, losses of human capital and intergenerational transmission of poverty. This in turn contributes to equality of opportunity for the current and future generations. Cash transfers and school feeding programs serve as examples of interventions under the objective of equity. Resilience is the second objective constituting the goals of social protection in the World Bank framework. Resilience can be enhanced by insuring the poor and vulnerable against welfare slumps from economic shocks through interventions such as unemployment insurance, elderly pensions and public works programs. The last objective is to provide opportunity by means of investing in human capital, enabling the accumulation of physical capital and ensuring access to productive employment. As can be noted, the two social protection frameworks are in line with each other. Devereux and Sabates-Wheeler's protective function conforms to the World Bank's equity objective while the prevention function is consistent with the objective of resilience. The promotive and transformative role of Devereux and Sabates- 
Wheeler are also covered in the opportunity objective of the World Bank framework (Gassmann, 2014).

In particular, the promotive and transformative functions or the opportunity objective reflect the productive role of social protection in fostering upward income mobility. This productive impact could take place both within and between generations. In regard to the intragenerational context, for example, skill training programs could improve labor productivity while microcredit programs allow borrowers to accumulate physical assets for productive activities. Moreover, additional resources from social assistance allow the poor to afford better nutrition, healthcare and education, all of which lead to a higher level of human capital (ILO, 2010; Mideros, Gassmann \& Mohnen, 2013). Furthermore, regular and reliable transfers from social assistance could facilitate labor market participation, relieve credit constraints, provide access to productive assets and promote income-generating activities (Alderman \& Yemtsov, 2012; Barrientos, 2012; Mideros, Gassmann, \& Mohnen, 2013). In this way, social protection programs could increase income, improve living standards and foster upward income mobility among the beneficiaries.

The productive impact of social protection could also be expanded to the next generation. For instance, a cash transfer to the elderly or social pension program could allow households to invest in children's nutrition, development, health and education which in turn raises human capital of children living with elderly recipients (Arnold et al., 2011). Moreover, the regular and reliable stream of income from social assistance could increase families' living standard and make children feel less compelled to work in order to support their family (Barrientos \& Lloyd-Sherlock, 2002). By improving human capital of the next generation, social protection would therefore promote upward intergenerational income mobility and lead to a break in the intergenerational transmission of poverty.

\subsection{Objectives and Research Questions}

Despite the importance of complementing the traditional static inequality with the more dynamic perspective for a richer discussion about income distribution, research on economic mobility has been scarce in less developed nations (Brand-Weiner \& Francavilla, 2015; Fields, Hernández, Freije, \& Puerta, 2007). At the same time, a number of studies claim that social protection programs have the potential to promote economic mobility by removing constraints to mobility such as underdeveloped human capital and lack of physical assets. However, evidence of such a "productive" role of social protection 
programs has not been well documented. Most social protection evaluation studies do not provide evidence based on panel data and thus fail to examine the dynamic improvement of participants over time (Browne, 2015). Moreover, evidence of the transformative function of social protection programs has not been sufficiently explored.

The objective of this thesis is to fill these knowledge gaps by examining the degree and pattern of absolute and relative intragenerational income mobility in the context of a developing country and evaluate the role that social protection programs have played in fostering income mobility. Thailand serves as the case study to explore these research objectives. The rationale of choosing Thailand as the country of investigation is discussed in section 1.6. Motivated by the scientific and societal significance of income mobility, relevant conceptual frameworks and lacunas in the literature described in the previous sections, the main research questions of this thesis are identified as follows

(1) To what extent does intragenerational income mobility, in both absolute and relative terms, take place in Thailand? [Chapter 2]

(1.1) What are underlying factors that determine absolute intragenerational income mobility? [Chapter 2]

(1.2) What are drivers of relative intragenerational income mobility? [Chapter 2]

(2) To what extent and under what conditions do social protection programs in Thailand contribute to upward socioeconomic mobility? [Chapter 3, 4 and 5]

(2.1) To what extent do the vocational training program and the microcredit program contribute to upward intragenerational mobility? [Chapter 3 and 4]

(2.2) To what extent does the social pension program have implications for upward intergenerational mobility? [Chapter 5]

The three programs of interest - vocational training, microcredit and social pension - are chosen based on their potential contributions to upward mobility. Vocational training aims to impart job skills which increase human capital and labor productivity of participants, enabling them to generate higher income and move up the ladder. Microcredit could lead to the possession of productive assets which also facilitate upward income mobility. Lastly, the selection of the social pension program is justified by its probable impact on intergenerational mobility. As discussed, the reliable source of income from social pension could be used to support human capital development of co-residing children and hence reduce the likelihood of intergenerational transmission of poverty. 


\subsection{Rationale of Case Study and Data Sources}

Thailand is an upper-middle-income country in South East Asia (SEA) with a poverty rate of 7.9 percent and a Gini coefficient, measuring the level of income inequality, of 0.45 as of 2017 (National Economic and Social Development Board [NESDB], 2018d). Income mobility is of particular relevance in Thailand for several reasons. First, despite having been recognized as one of the most successful countries in the world in terms of poverty eradication, inequality reduction remains a big challenge. The country's performance in poverty eradication is remarkable. The number of those categorized as poor has declined from 34 million persons in 1988 to 5.3 million persons in 2017 while the incidence of poverty has plummeted from 65.2 percent to 5.3 percent (ibid). Yet, the reduction of income inequality, as measured by the Gini index, has been sluggish and the income gap between the rich and the poor remains large, meaning that the benefit from economic development is not equally distributed. The income share of the richest 10 percent is 19 times higher than that of the poorest 10 percent group, compared to 8.5 times in OECD countries (NESDB, 2018d). This issue of inequality has been of great concern to the Thai people, scholars and policy makers. Given the inseparable linkage between income inequality and income mobility, a better insight - based on rigorous empirical evidence - into income mobility is an important stepping-stone in tackling the problem of inequality.

Second, until recently, income mobility has emerged in the national goals and policy direction. The creation of equal opportunity and a just society is prioritized as one of the six key pillars in the 20-years national strategy (from 2018 to 2037) which aims to move Thailand toward a high-income country with "security, prosperity and sustainability" (NESDB, 2018a). Moreover, one of the objectives listed in this national strategy framework is to "create an inclusive society that moves forward without leaving anyone behind through the realization of the full potential of all members of society" (OECD, 2018b) implying that the attempt is being made to increase economic mobility. Nevertheless, the number of existing studies on income mobility in Thailand is too small to generate credible evidence that could help formulate policies and inform policy decisions. Therefore, a deeper understanding of mobility is needed for effective policy formulations to achieve Thailand's objective of creating an inclusive and just society.

Third, Thailand is a fast developing country that invests considerably in social protection, both through contributory and non-contributory programs. For the contributory system, in which the direct contribution made by beneficiaries or their employers is required (Behrendt 
\& Hagemejer, 2018), social security in Thailand provides coverage in a number of areas including medical care, sickness benefits, maternity benefits, retirement pensions, invalidity pensions, survivors' benefits, family allowances and unemployment benefits. The ILO report on social protection in SEA indicates that "Thailand is the only Member State with a comprehensive scope of social security legal coverage with at least one statutory program in each social security policy area" (Ong \& Peyron Bista, 2015). The non-contributory social protection programs, which are at the central interest of this thesis, are referred to as social protection programs that do not require direct contribution from beneficiaries in order to receive the benefit from the programs (Behrendt \& Hagemejer, 2018). Unlike many other developing countries whose programs are donor-funded pilots, most of the noncontributory social protection programs in Thailand are implemented at the national level, institutionalized in the national legislation and financed by government revenues.

Table 1.1 presents a brief outline of the major non-contributory social protection programs in Thailand. As illustrated, the Thai government has provided nearly comprehensive noncontributory social protection to the poor and vulnerable throughout the life course. Considering that not much progress has been made regarding the reduction of income inequality, it is thus interesting to study to what extent these social protection programs have succeeded so far in fostering upward mobility. This thesis highlights vocational training, microcredit (the Village Fund) and social pension (the Old Age Allowance) programs which, according to the aforementioned theories, have the potential to do so.

The final justification of locating the analyses in Thailand is the availability of data. Research on mobility requires data sets in which the same observations can be observed over multiple time periods. Moreover, establishing causal relationships between social protection programs and mobility requires detailed information regarding program participation and characteristics of beneficiaries. Furthermore, since the programs of interest are implemented nationwide, a nationally representative data set is preferable. The Socio-Economic Panel Survey (SES-Panel) is a nationally representative household panel survey data conducted by the National Statistical Office (NSO) using the two-stage stratified sampling strategy. The analyses of income mobility and the impact evaluation of vocational training and the VF are based on this data set. 


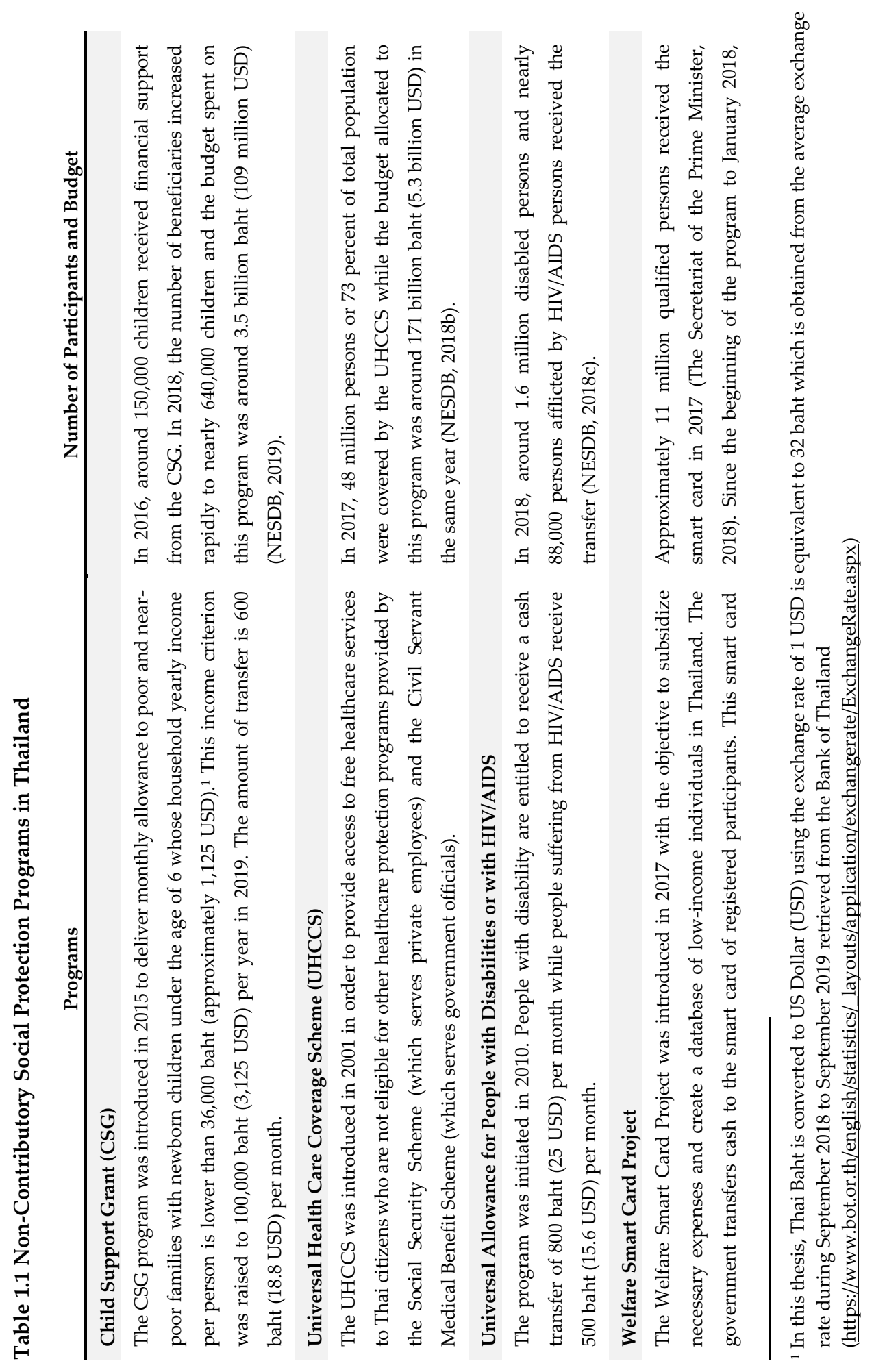




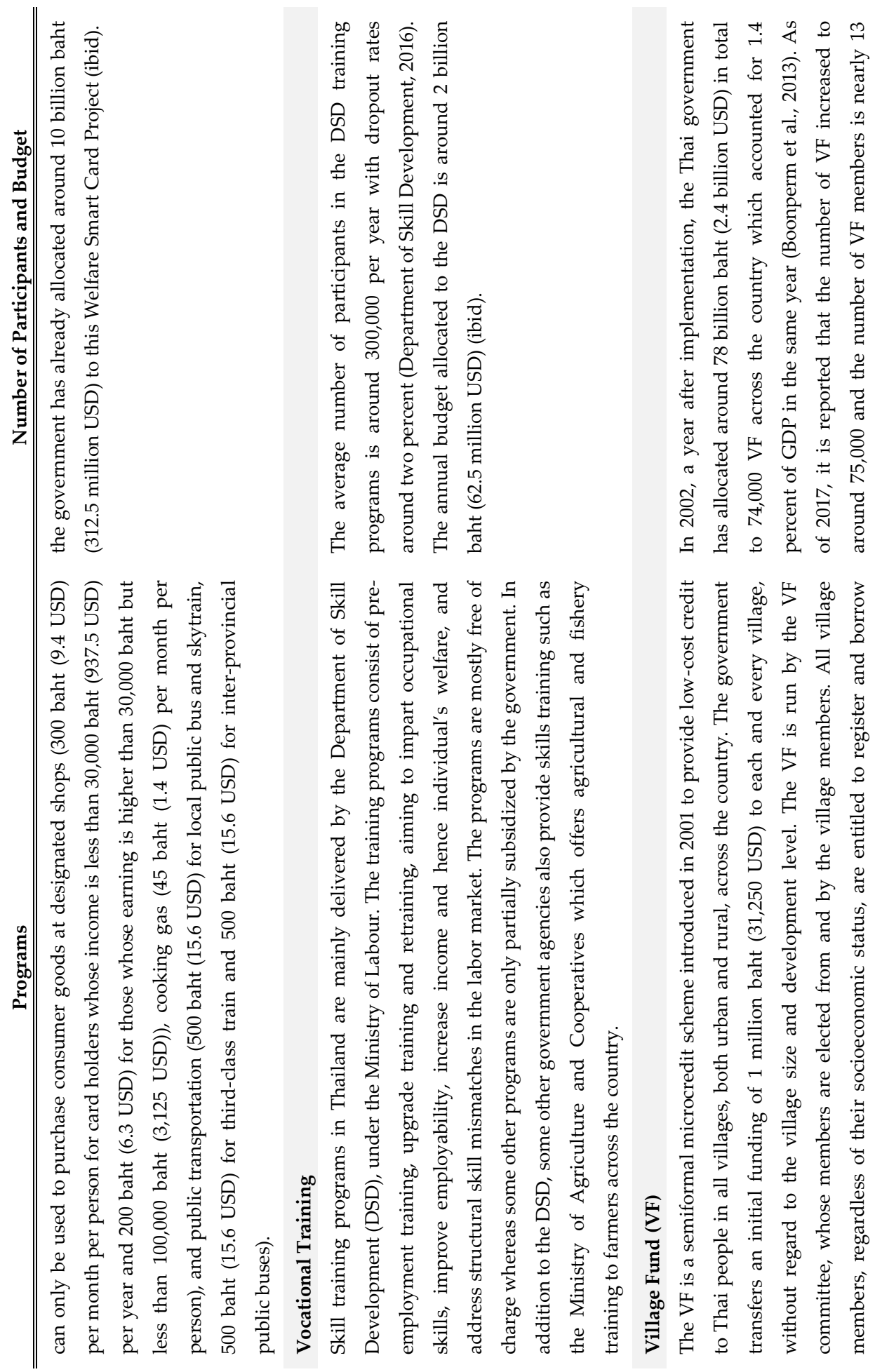




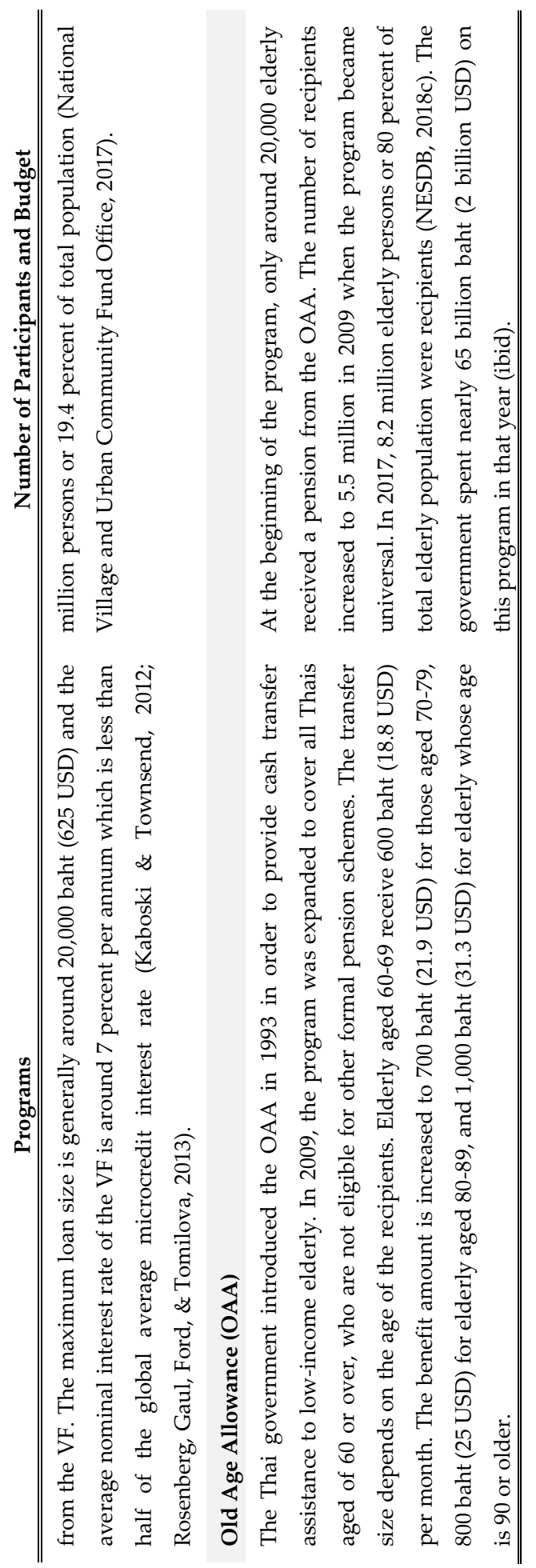


The SES-Panel comprises five waves, of which the first wave was conducted in 2005 and the following waves were in 2006, 2007, 2010 and 2012. The first survey in 2005 covers 6,000 households or 21,450 individuals from all regions of Thailand (Bangkok Metropolitan, Central, North, Northeast and South), both urban and rural. The data set contains detailed information of households and household members' characteristics such as age, gender, income, expenditure, location of residence, education, assets, employment status as well as participation in vocational training and VF program which can be used to draw conclusions about the extent, pattern and underlying factors of income mobility in Thailand and the effectiveness of the vocational training and the VF in promoting mobility.

This thesis also utilizes the cross-sectional Household Socioeconomic Survey (SES) because the information on the OAA is not available in the SES-Panel. The use of cross-sectional data is justified by the fact that the outcomes of interest in the impact assessment of the OAA are the investment in human capital of children living with beneficiaries which implies intergenerational mobility, not the actual mobility indicators used in other estimations. The SES is a repeated cross-sectional household survey which is nationally and regionally representative. Although both the SES and SES-Panel are conducted by the NSO and follow the same two-stage stratified sampling strategy, these two data sets are independent from each other and have different questionnaires.

The SES is exceptional in its breadth and level of detail. It was conducted every two years between 1988 and 2006. Since 2007, the SES has been collected on an annual basis but the information on income-related variables is available in the odd years only. For example, the SES in 2007 contains both household income and expenditure while the SES in 2008 provides only expenditure-related information. In addition to the income and expenditurerelated variables, the SES includes details of households and household members' characteristics and most importantly, OAA participation status. The SES covers around 40,000-50,000 households or more than 120,000 individuals in each survey. It is worth noting that both the SES-Panel and the SES are not available to the public and can only be obtained from the NSO upon request, generally with access fees.

Even though all the estimations conducted in this dissertation are based on Thailand's data and the implications are drawn with the specific Thai context in mind, the insights and lessons learned derived from this research may provide a useful guide to other developing countries, especially the ones whose socioeconomic and institutional environments are comparable to Thailand, in replicating the successes and avoiding the mistakes in promoting upward mobility. 


\subsection{Organization of the Thesis}

This thesis comprises four empirical papers which are presented in Chapter 2, 3, 4 and 5. Chapter 2 examines the extent and pattern of income mobility in Thailand and identifies factors associated with income mobility. The results from Chapter 2 set the stage for social protection programs evaluated in the subsequent chapters. Chapter 3 and 4 evaluate the impact of vocational training and microcredit, respectively, on upward intragenerational mobility using several impact evaluation methods. The last paper (Chapter 5) attempts to draw a conclusion of the impact of the social pension program on intergenerational mobility proxied by the household investment in co-residing children's education. A brief overview of the chapters is presented as follows

Chapter 2 shows that share of earners in a household and their possession of productive assets are the most important factors underlying absolute and relative intrageneration income mobility. The chapter begins with the background knowledge of economic circumstance, poverty incidence and income distribution in Thailand using both static and dynamic indicators. Regarding the static indicators, conventional development indices including poverty rate and the Gini coefficients of Thailand over the past three decades are reported. The Growth Incidence Curve (GIC) in each time period is also presented to further visualize the distribution of income. For the dynamic indicators, which are the central interest of this thesis, the extent and pattern of absolute and relative income mobility in the short, medium and long term are examined. The chapter identifies key drivers of income mobility using OLS and instrumental variable methods for absolute income mobility and an ordered logit model for relative income mobility. Finally, the chapter discusses the potential policy options to strengthen factors facilitating income mobility which make a case for the selection of social protection programs evaluated in the following chapters.

Chapter 3 presents the first impact evaluation of vocational training in Thailand. Vocational training is among the most common active labor market policies aiming to improve job skills, increase employability and productivity and hence foster upward mobility of participants. Despite having been in operation for several decades, the impact of vocational training in Thailand has never been measured. This chapter evaluates the impact of vocational training program in Thailand on various upward mobility indicators in both absolute and relative measurements including wage, aggregate labor income, expenditure and labor mobility in the short, medium and long term. It is found that Thailand's vocational training program does not impact participants along the outcome dimensions 
considered. The results are derived from both exogenous treatment effect method (propensity score matching with difference in difference) and endogenous treatment effect method (endogenous switching regressions) which work under different assumptions. The heterogeneity of effects with respect to individual and program characteristics is also examined to answer the important policy questions: 1) For whom does the training works? and 2) Which type of training works best? The results suggest that a more tailored training program that takes into account backgrounds and preferences of participants; and a program that keeps up with the demand for labor of the labor market and is provided in close cooperation between public and private sectors is more likely to associate with better mobility outcomes.

Chapter 4 evaluates the impact of the VF which is the largest microcredit program in Thailand initiated and initially funded by the government. Microcredit could foster upward mobility of borrowers by relieving credit constraints, facilitating investment in physical capital and promoting income-generating activities. However, there is increasing evidence that a number of microcredit programs fail to deliver this promise. Although some attempts have been made in measuring the impact of the VF, the results remain inconclusive and not informative enough for policy decisions. This chapter contributes to the VF and microcredit literature by measuring the impact of the VF on upward economic mobility using both propensity score matching with difference in difference and the Heckman selection model to obtain the results. It is found that the VF does not foster upward income, expenditure, productive asset and labor mobility, both in absolute and relative terms. Moreover, the chapter investigates whether the VF impacts vary across population subgroups including female borrowers, trained borrowers and repeated borrowers. The results suggest that while trained borrowers have higher mobility outcomes, significant heterogeneity by gender and frequency of borrowing are not observed. In addition to the impact assessment, the chapter also examines characteristics of VF borrowers, in comparison to other lending sources, to deepen the understanding of the selection process of the VF which may in turn affect the impact of the program.

Chapter 5 turns the attention to the role that a social protection program, or a social pension program, could play in fostering upward intergenerational mobility. A regular and reliable income from social pension increases financial resources and allows households to invest in education of school-age members. As education is associated with earning ability and other positive characteristics such as better networks, improved health status and greater longevity, social pensions could break intergenerational transmission of poverty and 
promote intergeneration mobility. This chapter examines the effect of the OAA, the universal social pension program in Thailand, on household investment in education of coresiding children. Outcome of interests include both household education expenditure and school attendance. Various econometric methods suiting data and estimation contexts are employed to obtain the results including instrumental variable with 2SLS, tobit model, fractional probit model and bivariate probit regressions. The results suggest that the secure source of income from the OAA promotes school attendance and, though small in magnitude, increases the share of household expenditure that is contributed to education.

Chapter 6, the concluding chapter, highlights the main findings and implications from the previous chapters and offers policy implications that are drawn from the thesis. In summary, the thesis substantiates that social protection programs have the potential to foster upward economic mobility in theory. However, in practice, only having social protection programs in place is not enough to change mobility prospects. The thesis argues that the fragmented social protection programs must be harmonized and these harmonized programs should be considered as a part of the wider system of social and economic support, together with other quality basic services especially in the realm of education, aiming to enhance productive capacity and promote upward mobility. Besides presenting the academic and policy contributions of the thesis, this chapter also discusses research limitations and outlines avenues for future research. 


\section{References}

Alderman, H., \& Yemtsov, R. (2012). Productive Role of Social Protection. Background Paper for the World Bank 2012-2022 Social Protection and Labor Strategy. Social Protection and Labor Discussion Paper, The World Bank, No.1203.

Aristei, D., \& Perugini, C. (2015). The drivers of income mobility in Europe. Economic Systems, 39(2), 197-224. https://doi.org/10.1016/j.ecosys.2014.06.007

Arnold, C., Conway, T., \& Greenslade, M. (2011). Cash Transfers: Literature Review. London: Department for International Development (DFID).

Asfaw, S., Tirivayi, N., Knowles, M., Davis, B., \& Demeke, M. (2014). Risk Management and the Productive Role of Social Protection. Food and Agriculture Organization of the United Nations (FAO).

Autor, D. H., Katz, L. F., \& Krueger, A. B. (1998). Computing inequality: Have computers changed the labor market? QUARTERLY JOURNAL OF ECONOMICS, 113(4), 1169-1213. https://doi.org/10.1162/003355398555874

Barrientos, A. (2012). Social Transfers and Growth: What Do We Know? What Do We Need to Find Out? World Development, 40(1), 11-20. https://doi.org/10.1016/j.worlddev.2011.05.012

Barrientos, A., Hulme, D., \& Shepherd, A. (2005). Can Social Protection Tackle Chronic Poverty? The European Journal of Development Research, 17(1), 8-23. https://doi.org/10.1080/09578810500066456

Barrientos, A., \& Lloyd-Sherlock, P. (2002). Non-contributory pensions and social protection. Social Protection Sector, International Labor Office Geneva, Discussion paper 12, 31.

Becker, G. S., \& Tomes, N. (1986). Human Capital and the Rise and Fall of Families. Journal of Labor Economics, 4(3, Part 2), S1-S39. https://doi.org/10.1086/298118

Behrendt, C., \& Hagemejer, K. (2018). Introduction: Social Transfers. International Labour Organization (ILO).

Brand-Weiner, I., \& Francavilla, F. (2015). Income mobility in times of economic growth: The case of Vietnam. OECD Working Paper No.328. Retrieved from http://www.oecdilibrary.org/development/income-mobility-in-times-of-economicgrowth_5jrp0hz8thjl-en

Boonperm, J., Haughton, J., \& Khandker, S. R. (2013). Does the Village Fund matter in Thailand? Evaluating the impact on incomes and spending. Journal of Asian Economics, 25, 3-16. https://doi.org/10.1016/j.asieco.2013.01.001

Browne, E. (2015). Social Protecton: Topic Guide. UK:GSDRC, University of Birmingham.

Carter, M. R., \& Barrett, C. B. (2006). The economics of poverty traps and persistent poverty: An asset-based approach. Journal of Development Studies, 42(2), 178-199. https://doi.org/10.1080/00220380500405261 
Chronic Poverty Research Center. (2004). The chronic poverty report 2004-05. Institute for Development Policy \& Management, University of Manchester.

Department of Skill Development. (2016). Summary Statistics of Vocational Training Program. Retrieved from Ministry of Labour website: http://www.dsd.go.th/DSD/Stat

Devereux, S., \& Sabates-Wheeler, R. (2004). Transformative social protection. Institute of Development Studies.

Devereux, S., \& Sabates-Wheeler, R. (2015). Graduating from Social Protection? Editorial Introduction. IDS Bulletin, 46(2), 1-12. https://doi.org/10.1111/1759-5436.12124

DiPrete, T. A., \& Eirich, G. M. (2006). Cumulative Advantage as a Mechanism for Inequality: A Review of Theoretical and Empirical Developments. Annual Review of Sociology, 32(1), 271-297. https://doi.org/10.1146/annurev.soc.32.061604.123127

ECMC Foundation. (2017). Michelle Obama Delivers Final Speech: “With hard work and a good education anything is possible." Retrieved from https://www.ecmcfoundation.org/informed/2017/michelle-obama-delivers-finalspeech-with-hard-work-and-a-good-education-anything-is-possible

Fields, G. S. (2006). The Many Facets of Economic Mobility. Cornell University ILR School Working Paper. Retrieved from https://digitalcommons.ilr.cornell.edu/articles/230/

Fields, G. S. (2008a). A brief review of the literature on earnings mobility in developing countries. Cornell University ILR School Working Paper. Retrieved from http://digitalcommons.ilr.cornell.edu/workingpapers/101

Fields, G. S. (2008b). Income Mobility. Cornell University ILR School Working Paper. Retrieved from https://digitalcommons.ilr.cornell.edu/articles/453/

Fields, G. S. (2010). But that's not what economic mobility is! Cornell University ILR School Working Paper. Retrieved from https://digitalcommons.ilr.cornell.edu/workingpapers/155/

Fields, G. S., Cichello, P. L., Freije, S., Menendez, M., \& Newhouse, D. (2003). Household Income Dynamics: A Four-Country Story. The Journal of Development Studies, 40(2), 30-54. https://doi.org/10.1080/00220380412331293757

Fields, G. S., Hernández, R. D., Freije, S., \& Puerta, M. L. S. (2007). Intragenerational income mobility in Latin America. Economía, 7(2), 101-154.

Fields, G. S., \& Puerta, M. L. S. (2010). Earnings Mobility in Times of Growth and Decline: Argentina from 1996 to 2003. World Development, 38(6), 870-880. https://doi.org/10.1016/j.worlddev.2010.02.001

Forde, I., \& Zeuner, D. (2009). Financial incentives to promote social mobility. BMJ: British Medical Journal, 339(7720), 544-546.

Galton, F. (1886). Regression towards mediocrity in hereditary stature. Journal of the Anthropological Institute of Great Britain and Ireland, 15, 246-263. 
Gassmann, F. (2014). The business case for social protection in Sub-Saharan Africa: Concept note on the research agenda. Retrieved from https://includeplatform.net/wpcontent/uploads/2014/10/concept-note_Social-Protectionv6mar14.pdf

Gottschalk, P. (1997). Inequality, Income Growth, and Mobility: The Basic Facts. Journal of Economic Perspectives, 11(2), 21-40. https://doi.org/10.1257/jep.11.2.21

International Labour Organization (ILO). (2010). Effects of non-contributory social transfers in developing countries: A conpendium. ILO Working Paper, Social Security Department.

Jäntti, M., \& Jenkins, S. P. (2015). Income Mobility. In A. B. Atkinson \& F. Bourguignon, Handbook of Income Distribution (Vol. 2A, pp. 807-935). Retrieved from http://linkinghub.elsevier.com/retrieve/pii/B9780444594280000114

Johnson, G. E. (1997). Changes in Earnings Inequality: The Role of Demand Shifts. Journal of Economic Perspectives, 11(2), 41-54. https://doi.org/10.1257/jep.11.2.41

Jowit, J. (2012). Nick Clegg rails against British snobbery. The Guardian. Retrieved from https://www.theguardian.com/politics/2012/may/22/nick-clegg-british-classsnobbery

Kaboski, J. P., \& Townsend, R. M. (2012). The impact of credit on village economies. American Economic Journal: Applied Economics, 4(2), 98.

Krugman, P. (1992). The Rich, the Right, and the Facts. The American Prospect, 11, 19-31.

Merton, R. K. (1968). The Matthew Effect in Science. Science, 159(3810), 56-63.

Mideros, A., Gassmann, F., \& Mohnen, P. (2013). Estimation of rates of return on social protection: Making the case for non-contributory social transfers in Cambodia. UNU-MERIT Working Papers, 63.

National Economic and Social Development Board, Office of the Prime Minister. (2018a). National Strategy 2018-2037 (Summary) (in Thai). Retrieved from https://www.nesdb.go.th/download/document/SAC/NS_SumPlanOct2018.pdf

National Economic and Social Development Board, Office of the Prime Minister. (2018b). Social and Quality of Life Database System - Healthcare Protection. Retrieved from http://social.nesdb.go.th/SocialStat/StatReport_Final.aspx?reportid=1302\&template $=1 \mathrm{R} 1 \mathrm{C} \&$ yeartype $=\mathrm{M} \&$ subcatid $=46$

National Economic and Social Development Board, Office of the Prime Minister. (2018c). Social and Quality of Life Database System - Income Security. Retrieved from http://social.nesdb.go.th/SocialStat/StatReport_Final.aspx?reportid=175\&template= 1R2C\&yeartype $=$ M\&subcatid $=47$

National Economic and Social Development Board, Office of the Prime Minister. (2018d). Thailand's Poverty and Inequality Report 2017 (in Thai). Bangkok, Thailand.

National Economic and Social Development Board, Office of the Prime Minister. (2019). Poverty and Inequality in Thailand. Presented at the The presentation of Thailand's 
poverty and inequality situation to Bangladesh Social Welfare Council, Bangkok, Thailand.

National Village and Urban Community Fund Office. (2017). The Village and Urban Community Fund: Progress Report (in Thai). Presented at the Bangkok, Thailand. Bangkok, Thailand.

OECD (Ed.). (2018a). A broken social elevator? how to promote social mobility. Paris: OECD Publishing.

OECD. (2018b). Multi-dimensional Review of Thailand: Volume 1. Initial Assessment. OECD Development Pathways, OECD Publishing, Paris. https://doi.org/10.1787/9789264293311-en

Ong, C. B., \& Peyron Bista, C. (2015). The state of social protection in ASEAN at the dawn of integration. Bangkok: International Labour Organization (ILO).

Rama, M., Beteille, T., Li, Y., Mitra, P., \& Newman, J. L. (2015). Addressing Inequality in South Asia. Retrieved from The World Bank website: https://openknowledge.worldbank.org/handle/10986/20395

Rosenberg, R., Gaul, S., Ford, W., \& Tomilova, O. (2013). Microcredit Interest Rates and Their Determinants 2004-2011 (No. 7). CGAP.

Samson, M. (2015). Exit or Developmental Impact? The Role of 'Graduation' in Social Protection Programmes. IDS Bulletin, 46(2), 13-24. https://doi.org/10.1111/17595436.12125

Shi, X., Liu, X., Nuetah, A., \& Xin, X. (2010). Determinants of household income mobility in rural China. China \& World Economy, 18(2), 41-59.

The Secretariat of the Prime Minister. (2018). Welfare Measures: The innovation for Poverty Reduction (in Thai) [Thai Khu Fai quarterly journal (April-June 2018)]. Retrieved from https://spm.thaigov.go.th/FILEROOM/spmthaigov/DRAWER004/GENERAL/DATA0000/00000438.PDF

Trotter, J. K. (2013). The Full Text of President Obama's 2013 State of the Union Address. The Atlantic. Retrieved from https://www.theatlantic.com/politics/archive/2013/02/fulltext-president-obama-2013-state-of-the-union-address/318416/

Woolard, I., \& Klasen, S. (2005). Determinants of Income Mobility and Household Poverty Dynamics in South Africa. Journal of Development Studies, 41(5), 865-897. https://doi.org/10.1080/00220380500145313

World Bank. (2012). Resilience, Equity and Opportunity: The World Bank's Social Protection and Labor Strategy 2012-2022. Washington D.C.: The World Bank. 


\section{Chapter 2}

Income Mobility in Thailand 


\subsection{Introduction}

Thailand is one of the fast-developing countries in the world. The extraordinary economic growth especially between 1965 and 1996, during which the average growth rate was approximately over 7 percent per annum, has moved Thailand from a low- to middle income country status (Warr, 1999). The country's performance in poverty reduction is remarkable. Thailand managed to achieve the MDGs target of halving the proportion of people living in poverty since 2003. Moreover, over the three most recent years that the data is available (from 2013 to 2015), not even one person in Thailand lives under the 1.9 USD international poverty line (World Bank, 2017c). In spite of the substantial improvement in poverty reduction, income inequality has remained a great concern. Income inequality, measured by the Gini Coefficient, has gradually improved during the last decade but the rate at which it declines is sluggish and fitful. Moreover, according to the Global Wealth Databook report (Credit Suisse, 2017), Thailand was ranked as one of the world' most unequal countries in terms of wealth inequality, together with Russia and India. It is found that while the richest 10 percent holds as much as almost 80 percent of the country's total wealth, the poorest decile only holds 0.1 percent. As wealth generates income and higher income tends to contribute to higher wealth status, the problem of income inequality in Thailand is probably more serious than what is reported by the conventional Gini index.

Unlike a snapshot picture of inequality based on the traditional inequality indices, a measure of income mobility traces dynamic improvements of agents, either individuals or households, and identifies who is moving up, who is falling behind and who is standing still (Woolard \& Klasen, 2005). In the presence of mobility, inequality is less problematic as individuals have an opportunity to rise into higher socioeconomic classes regardless of what class they were born into. However, the study of income mobility has been uncommon in developing countries, including Thailand, due to the lack of longitudinal data (Fields, Hernández, Freije, \& Puerta, 2007). Research on mobility in Thailand has been scarce compared to static inequality studies. Existing research that put dynamic movement into perspective has generally focused on an occupational transition out of agriculture (see e.g. Chawanote \& Barrett, 2014) or a transition into and out of poverty (see e.g. Sakondhavat, 2013).

This chapter attempts to contribute to the scarce existing literature on mobility in Thailand by examining income mobility in both absolute and relative terms. In addition, key factors associated with income mobility will also be identified. The remainder of this chapter is 
organized as follows. Section 2.2 provides information on economic circumstances, poverty and inequality in Thailand over the last 30 years. Section 2.3 and section 2.4 explain data, methods and obtained results of income mobility and key drivers underlying mobility. The last section (section 2.5) concludes and discusses the results.

\subsection{Economic Growth, Poverty and Inequality}

Thailand's economic performance can be broadly divided into three main periods. The first period is between the late 1950s and 1996 during which Thailand enjoyed its economic prosperity with the average GDP growth rate of over 7 percent per year. The source of extraordinary economic growth was not from the quality of labor but rather from the growing capital stock due to domestic and foreign direct investment (Warr, 1999). Following a decade of enjoyment of high economic growth, Thailand became the epicenter of the Asian Financial Crisis (AFC) of mid-1997. The Thai economy exhibited a negative GDP growth and GDP per capita appeared to collapse from 1997 to 1998. After the crisis, it has been the period of recovery with an average growth rate of 4 percent between 1999 and 2017. GDP per capita has also been on a rising trend, although at a slower rate compared to the precrisis era.

Figure 2.1 GDP Growth and GDP Per Capita in Thailand (1988-2017)

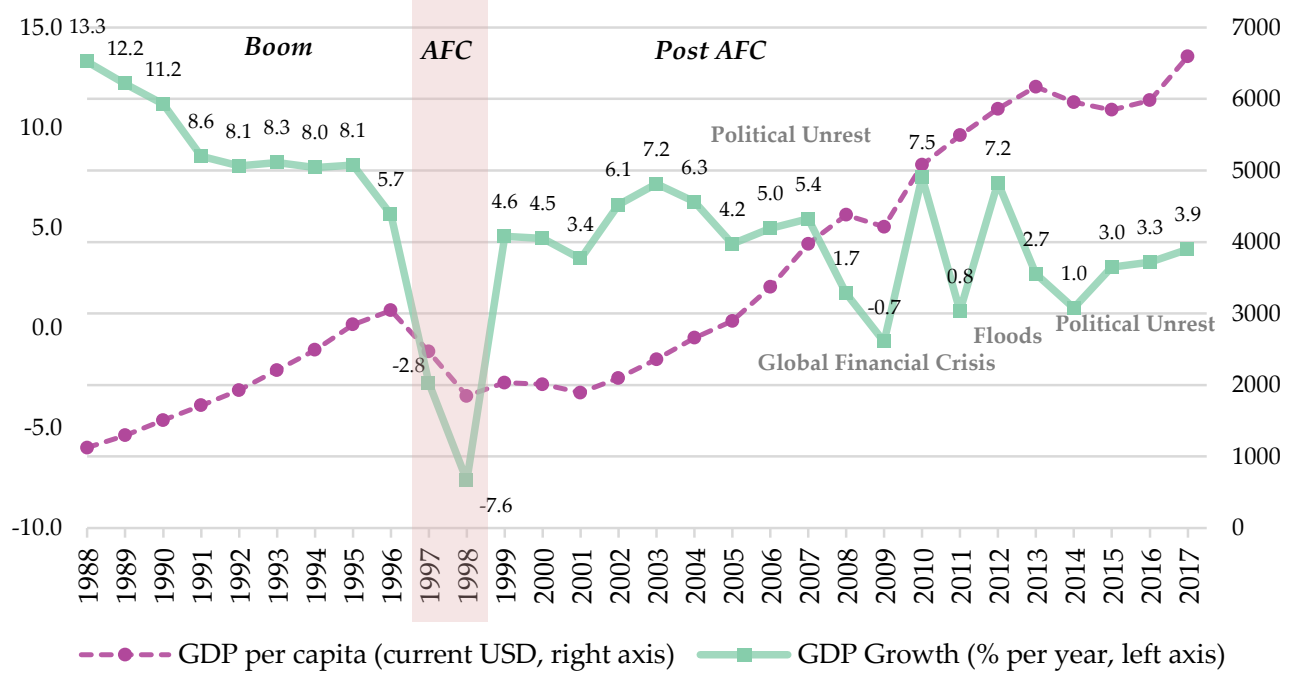

Source: World Development Indicators (World Bank, 2017a, 2017b) 
Thailand's national poverty line is calculated from the total of the food poverty line and the non-food poverty line. The food poverty line is derived from the amount of money needed to purchase the minimum calorie and protein requirement whereas the non-food poverty line is calculated from the cost of possessing nine non-food items including clothing and footwear, shelter, fuel and light, household goods, medical care, personal care, transportation, communication and education (Jitsuchon, Plangpraphan, \& Kakwani, 2006). The poverty incidence in Thailand presented in Figure 2.2 is the proportion of population living below the national poverty line (percentage of total population). In the case of Thailand, macroeconomic circumstances have a significant impact on poverty incidence. The high-growth rate during the economic boom had led to a striking poverty reduction from 65 percent in 1988 to 35 percent in 1996 and the number of poor was almost reduced by half, as depicted in Figure 2.2. The poverty rate began to increase during the crisis, 19971998, and returned to its downward trend afterwards. During the post-crisis period, however, despite the global economic crisis between 2008 and 2009 and the ongoing political unrest since 2005, Thailand still manages to gradually reduce its poverty rate to around 8 percent in 2017.

Figure 2.2 Poverty Incidence in Thailand (1988-2017)

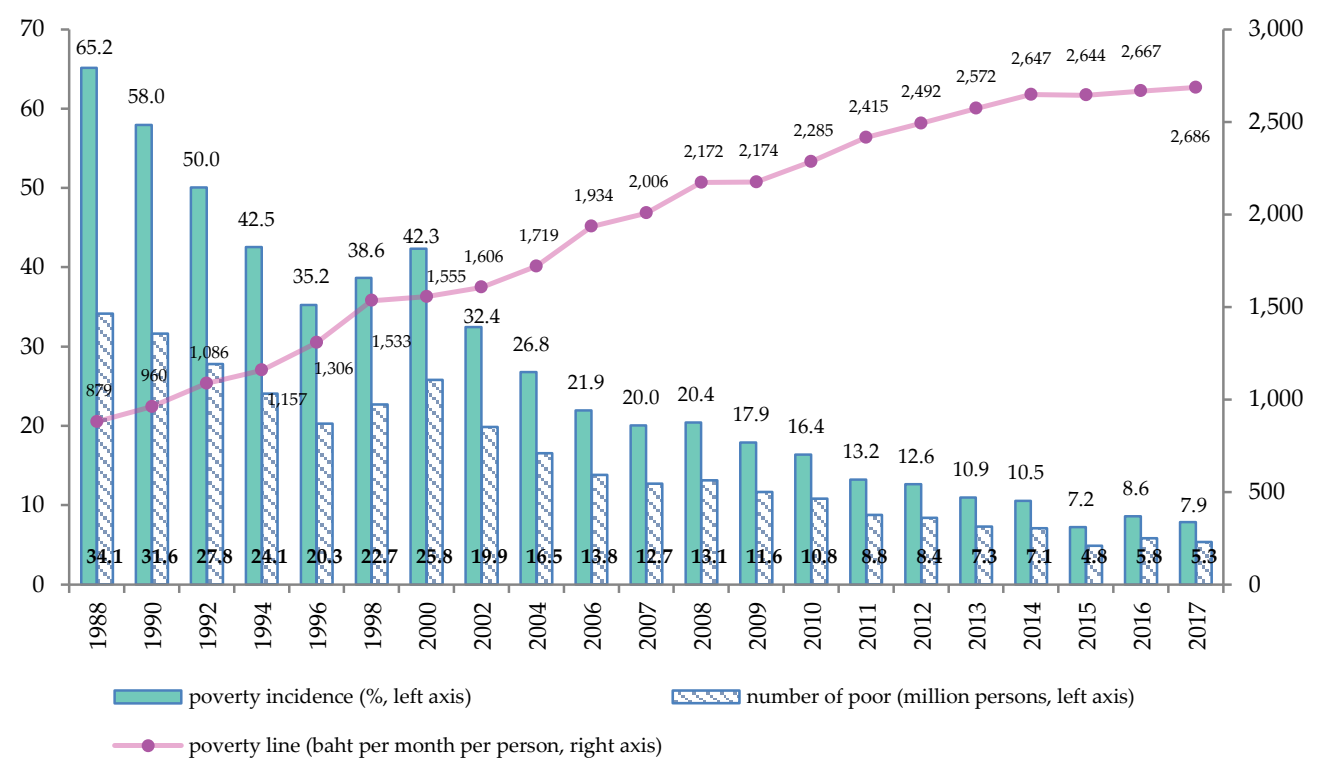

Source: Thailand's Poverty and Inequality Report 2017 (National Economic and Social Development Board [NESDB], 2018) 
As mentioned before, the exceptional economic growth has been considered as the main driver of Thailand's remarkable poverty eradication. Nevertheless, as the source of growth particularly during the economic boom period was mainly attributable to physical and financial capital which poor households often lack access to, it is thus interesting to study whether the benefits of growth have been equally distributed. Figure 2.3 presents income inequality, measured by the income Gini coefficient, in Thailand from 1988 to 2017. Overall, income inequality has sluggishly decreased by 3.4 percentage point over the past 30 years. When zooming in on income inequality in a particular period of time, it is found that inequality was relatively higher during the economic boom, and appeared to be lower after the crisis especially over the last decade. Figure 2.3 also exhibits the difference of income inequality between rural and urban areas. The Gini coefficient is found to be higher in urban areas for the entire period, meaning that income inequality has been slightly higher in urban areas.

Figure 2.3 Income Inequality in Thailand (1988-2017)

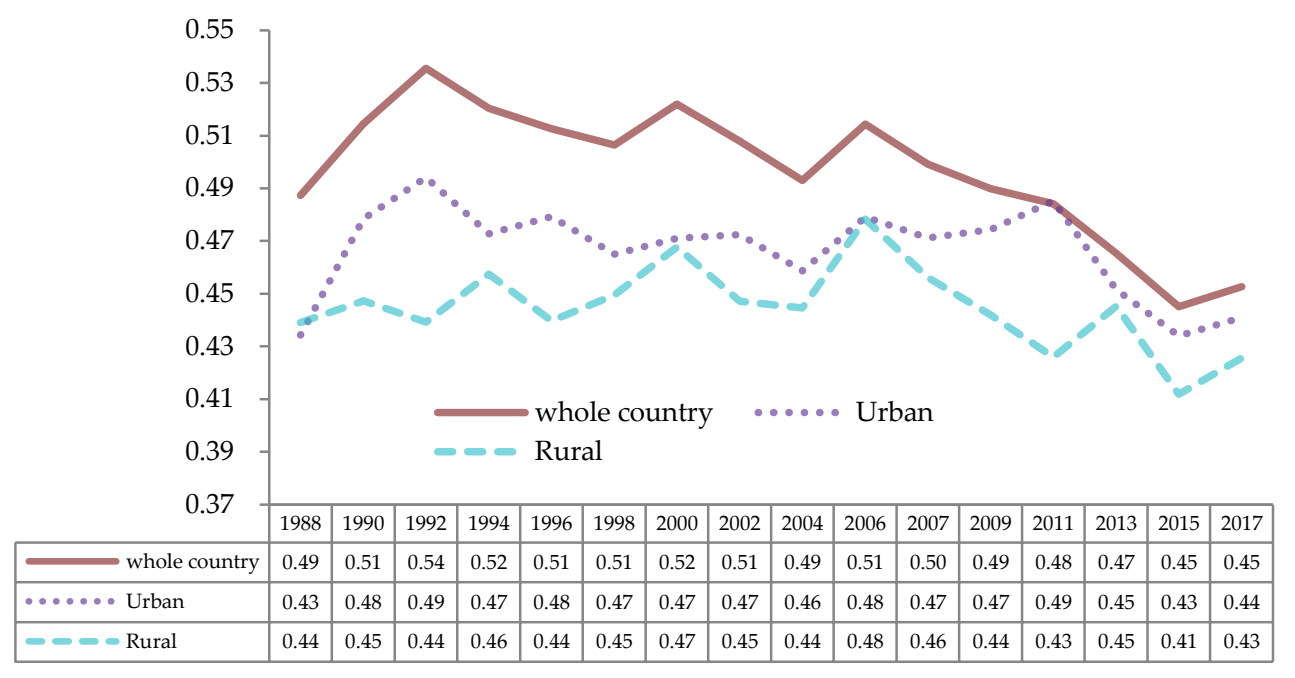

Source: Thailand's Poverty and Inequality Report 2017 (NESDB, 2018)

In addition to the static Gini index, the Growth Incidence Curve (GIC) is constructed to further visualize how income has been distributed during the last three decades. GIC assesses the extent to which income growth, over the two given periods, varies across income quantiles ranked from poorest to richest (Ravallion \& Chen, 2003). Figure 2.4 shows the GIC between 1988 and 2017 for each income percentile constructed from the crosssectional Household Socioeconomic Survey (SES) which is the nationally representative 
household survey conducted by the National Statistical Office (NSO). Income refers to an average monthly household income including wage and salaries, agricultural income, business income and non-working income. Income is converted to real value using the consumer price index (CPI) with the base year of 2015 obtained from Bureau of Trade and Economic Indices, Ministry of Commerce (2018) and equivalised by the OECD-modified scale, where the first adult is given the weight 1.0, each additional adult member 0.5 and each child member younger than 14 years has the weight 0.3 , to address the variation in household size and demographic structure (OECD, 2009).

\section{Figure 2.4 Thailand's Growth Incidence Curve (GIC) (1988-2017)}

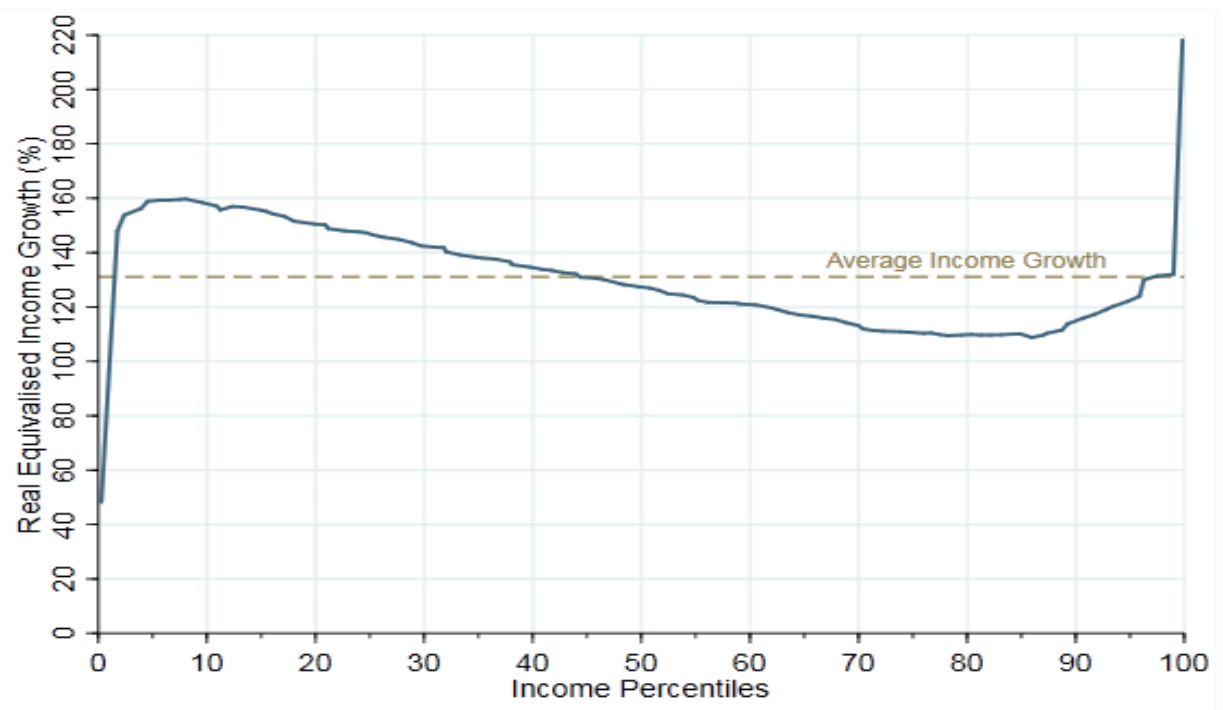

Source: Author's own estimation based on SES 1988 and 2017

According to Figure 2.4, the 1988-2017 GIC is positive at all percentile points, indicating that all households have benefited from growth, and poverty has fallen from 1988 to 2017. The negatively sloping GIC suggests that economic growth has been pro-poor and inequality has declined. However, the poorest and the richest percentiles have benefited disproportionately from growth. The bottom 40 percent has enjoyed an income growth that was relatively faster than for an average household, with the exception of the first poorest percentile. Moreover, GIC also increases sharply for the richest percentile, implying that the very rich households have enjoyed the highest rate of growth. This pattern of Thailand's GIC is consistent with the elephant curve of global inequality and growth between 1980 and 2016 presented in Alvaredo et al. (2017). The elephant curve illustrates that, at the global 
level, the growth rate appears to be low for the poorest countries, gets higher around the $20^{\text {th }}$ to $60^{\text {th }}$ percentile, turns to be lower again around the $70^{\text {th }}$ to $90^{\text {th }}$ percentile, and becomes highest for the richest countries.

\section{Figure 2.5 Thailand's Growth Incidence Curve (GIC) at Each Time Period}
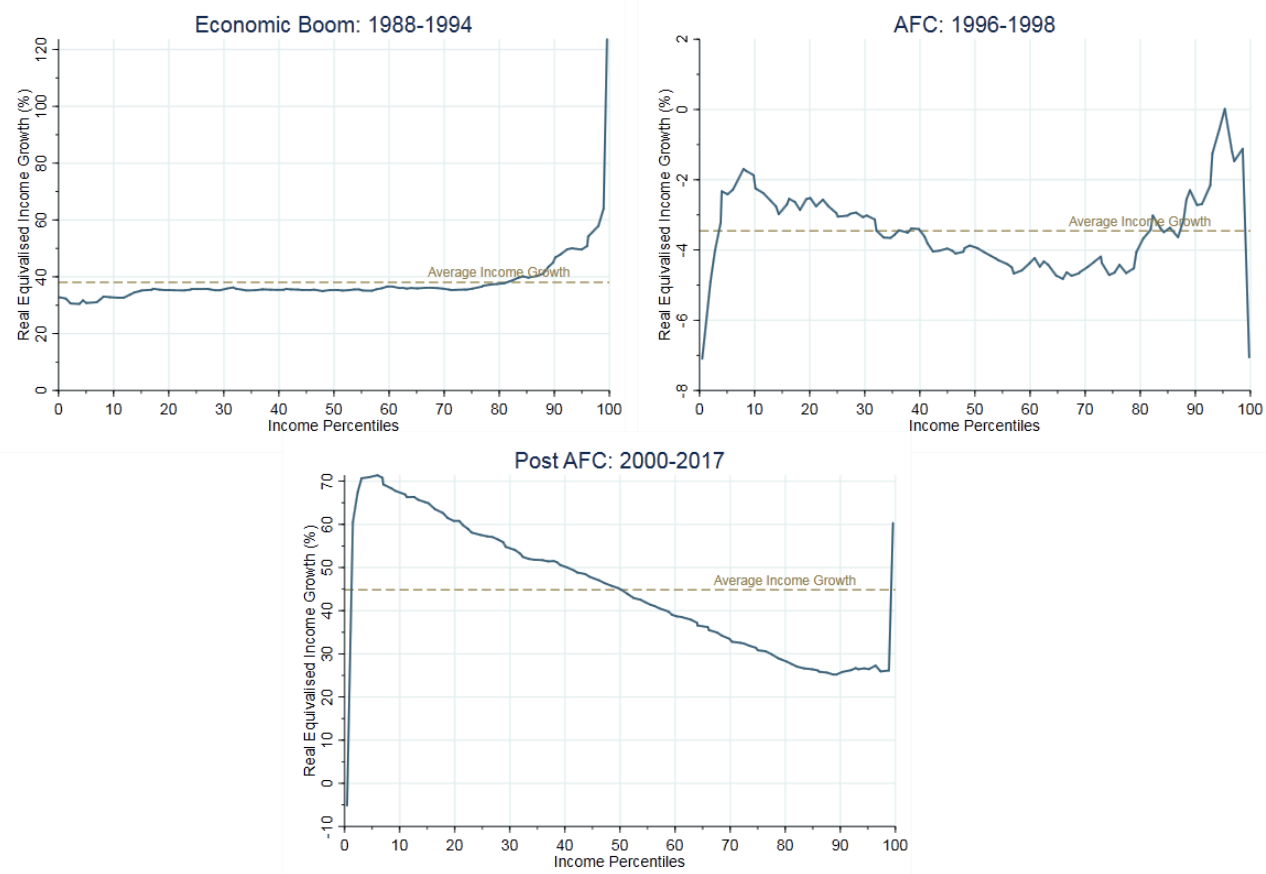

Source: Author's own estimation based on SES 1988, 1994, 1996, 1998, 2000 and 2017

Notes: AFC actually took place from 1997 to 1998. However, the SES was conducted every two years from 1988 until 2006. As the survey is not available in 1997 and 1999, the 1996-1998 GIC is thus used to represent GIC during the economic crisis and the 2000-2017 GIC represents the post$\mathrm{AFC}$ or the recovery period.

Figure 2.5 presents GIC for three different periods of time: the economic boom, the AFC and the post-AFC period. During the economic boom (1988-1994), economic growth led to poverty alleviation as GIC was above zero at all percentile points. However, inequality rose as economic growth appeared to favor households at the top 20 percent over poorer households. This finding is consistent with the results from the Gini coefficient, which also suggests a higher income inequality during the economic boom.

The GIC between 1996 and 1998 reveals an increasing poverty incidence during the economic crisis since GIC was negative for all percentiles. An implication of income inequality remains ambiguous as both the poor households (from $4^{\text {th }}$ to $33^{\text {th }}$ percentile) and 
the very rich households (from $82^{\text {nd }}$ to $99^{\text {th }}$ percentile) were less affected by economic slump, in comparison to average households. The Gini index in this period was also found to be similar to the pre-crisis level. After the AFC period (2000-2017), economic growth has been relatively more pro-poor as, apart from the poorest percentile, the bottom 50 percent households have enjoyed income growth more than most of the richer households. The negatively sloped GIC also demonstrates a declining income inequality during this postcrisis period. As can be seen, distribution of income growth is found to be different in a different period of time. However, there is one common conclusion standing out, the poorest percentile ( $1^{\text {st }}$ percentile) has benefited least from growth, regardless of which time period is being considered.

\subsection{Income Mobility}

The Gini coefficient and GIC discussed in the previous section provide an overview of the extent to which income has been distributed in Thailand over the past decades. However, since both the Gini index and GIC are drawn from the cross-sectional data, where it is not possible to precisely identify who is getting ahead and who is falling behind, these analyses can, at best, display "net changes" of development outcomes at one particular point in time. Therefore, this conventional static approach needs to be complemented by the dynamic analysis of income mobility that provides richer insights of how households/individuals move along the income distribution. Nevertheless, due to the absence of appropriate panel data, the study of income mobility in Thailand remains poorly documented.

Chawanote and Barrett (2014) analyze occupational transition from farm to non-farm activities of employed individuals living in rural areas over the period of 2005 to 2010 . They find that individuals changing from farm to non-farm employment earn higher incomes, while those moving in the opposite direction end up earning less income. Moreover, education levels, total working months, asset ownership and size of an agricultural land owned by a household are associated with higher earnings, which indicates the significant complementarity of human and physical capital in fostering upward earning mobility in rural Thailand. Similarly, Cherdchuchai and Otsuka (2006) examine long-term changes of income components of rural households and determinants underlying the changes from 1987 to 2004. The authors observe a shift of primary source of household income from farm to non-farm. This structural shift of household income toward non-farm sources has led to a lesser importance of land and agricultural technologies and the growing importance of education attainment in driving income mobility among rural households. 
Another study of income mobility in Thailand examines the transition into and out of poverty. Sakondhavat (2013) analyzes the pattern and factors explaining poverty dynamics in the rural village in the northeast and central region of Thailand from 1988 to 2009. She finds that a larger proportion of households have escaped from poverty than have fallen into it. Moreover, the proportion of households moving into and out of poverty is higher than households trapped in poverty. The author also suggests that education of working members, cultivated and irrigated areas and physical agricultural assets are key factors lifting households out of poverty.

As can be noted, past studies have generally focused on occupational transition out of agriculture and transition into and out of poverty. Furthermore, they have mainly focused on rural areas. This chapter contributes to the small existing literature on income mobility in Thailand by examining the incidence and determinants of the movement of household income through the entire income distribution (not limited to poverty threshold), in both rural and urban areas, and irrespective of household's occupation.

\subsubsection{Data}

Income mobility in this chapter is derived from the Thailand Socioeconomic Panel Survey (SES-Panel) which is a nationally representative longitudinal survey. Although the SESPanel is also carried out by NSO, this survey is independent from the regular cross-sectional SES used to construct the Gini index and the GIC, and has different questionnaires. The data set comprises five waves, of which the first one was conducted in 2005 and the following waves in 2006, 2007, 2010 and 2012. The first survey in 2005 covered 6,000 households from all regions of Thailand (Bangkok Metropolitan, Central, North, Northeast and South), both from urban and rural areas. Like many other panel survey data, SES-Panel also suffers from substantial attrition. The attrition rate at household level is approximately 30 percent.

The probit regression, using attrition dummy as dependent variable and household and household members' characteristics as explanatory variables, is conducted to examine whether or not the SES-Panel data is subject to attrition bias. The results suggest a statistically significant correlation between the probability of attrition and some socioeconomic characteristics such as expenditure, age and education. The problem of attrition bias is thus addressed by generating the inverse probability weight, which gives more weight to households having similar initial characteristics to households who 
subsequently dropped off, and including it in all estimations. The details of each step of the calculation are presented in Baulch and Quisumbing (2011).

To the best of my knowledge, there are two studies that examine mobility in Thailand using the SES-Panel data set. Chawanote and Barrett (2014) employ four waves of data $(2005,2006$, 2007 and 2010) restricted to rural areas to examine occupation mobility from agriculture to rural non-farm employment. Another study conducted by Urzainqui (2017) focuses on validating two different synthetic panel methods used in generating poverty dynamics. The SES-Panel 2006 and 2007 is employed to analyze his results.

\section{Figure 2.6 Mean Share of Income Components over Total Household Income}

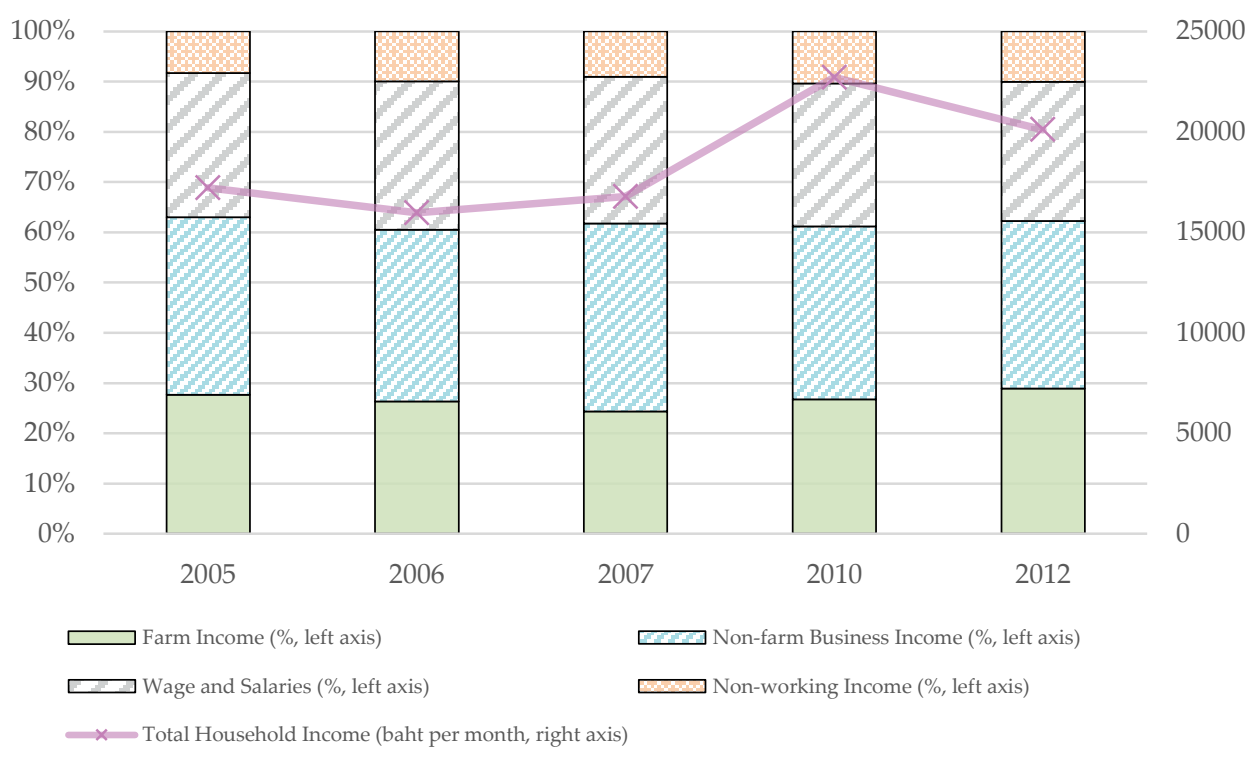

Source: Author's own estimation based on SES-Panel 2005, 2006, 2007, 2010 and 2012

In this chapter, the data is restricted to households that present in all five waves (balanced panel) which are 4,193 households per wave in total. Total household income includes wages and salaries, agricultural income, business income and non-working income. In the SES-Panel survey, agricultural income was recorded as average annual income while other sources of income were recorded as average monthly income. The annual agricultural income is then converted to a monthly basis in order to obtain the average total household income per month. The average total household income is inflated by the 2015 CPI and 
equivalised by the OECD-modified scale (OECD, 2009). ${ }^{2}$ As presented in Figure 2.6, the average real equivalised monthly household income was relatively constant from 2005 to 2007, increased significantly in 2010 and slightly declined in 2012. The proportion of income sources does not change much throughout the course of the year. Non-farm business income, including income from self-employment, has been the major income source, followed closely by income from wage and salaries, income from agricultural activities and non-working income.

\section{Figure 2.7 Share of Household Income by Quintiles}

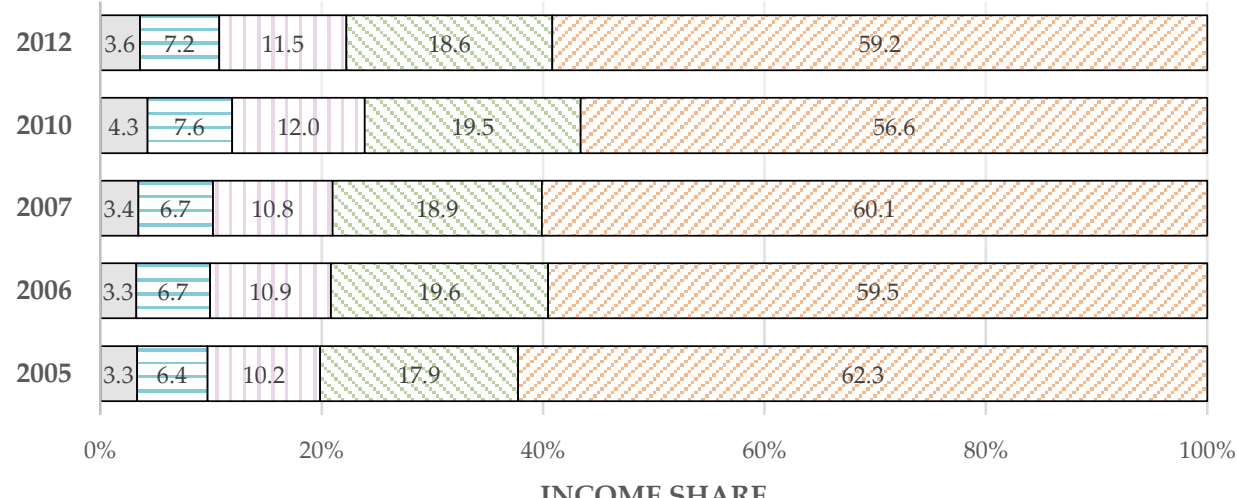

$\square \mathrm{Q} 1$ (Poorest) $\square \mathrm{Q} 2 \quad \square \mathrm{Q} 3 \quad \square \mathrm{Q} 4 \quad \square \mathrm{Q} 5$ (Richest)

Source: Author's own estimation based on SES-Panel 2005, 2006, 2007, 2010 and 2012

When considering the share of household income by quintiles as presented in Figure 2.7, it is found that there is a moderate decline in income of the richest 20 percent over the period of seven years. Income share of the poorest has also increased slightly from 2005 to 2012. However, the income gap between the richest quintile and the poorer quintile has remained large, and the income distribution has been highly skewed. The richest 20 percent holds an income share greater than the poorer 80 percent households combined. At the same time,

\footnotetext{
${ }^{2}$ The OECD-modified scale was first proposed by Hagenaars, de Vos and Zaidi (1994). Unlike the old scale, the OECD-modified scale assumes that children aged 14 and over have the same living cost as adults. The selection of this equivalence scale is guided by previous studies on income mobility such as Brand-Weiner and Francavilla (2015) who studied income mobility in Vietnam. The OECDmodified scale is also used in several studies on welfare and income redistribution in Thailand such as the National Transfer Account of Thailand (Lowhachai, 2018).
} 
while households in the richest quintile own, approximately, as much as 60 percent of total income, the poorest households have an income share lower than 5 percent.

\subsubsection{Absolute Income Mobility}

Absolute income mobility refers to the magnitude of income changes between two periods, without comparing to income changes of others. It is mainly concerned with changes in absolute well-being (Woolard \& Klasen, 2005). Absolute income mobility is commonly estimated by the Fields and Ok (1999) mobility index or FO index due to its conformity to desirable axioms including scale invariance, symmetry and subgroup decomposability. The FO index measures the average growth of income and can be written as

$$
F O=\frac{1}{n} \sum_{i=0}^{n}\left|\ln \left(\frac{y_{t}}{y_{t-1}}\right)\right|
$$

where $y$ is household income and $\mathrm{n}$ is the number of households during the period under study. As can be seen from equation (1), both upward and downward income movement increases the FO indicator. The higher value of the FO index indicates the higher level of mobility. Hence, the FO index is considered as non-directional income mobility index which measures income flux, without regard to direction of change. The FO index is decomposable into two mobility components, growth component or $G\left(y_{t-1}, y_{t}\right)$ and transfer component or $T\left(y_{t-1}, y_{t}\right)$, as follows

$$
F O=G\left(y_{t-1}, y_{t}\right)+T\left(y_{t-1}, y_{t}\right)=\frac{1}{n} \sum_{i=0}^{n} \ln \left(\frac{y_{t}}{y_{t-1}}\right)+\frac{2}{n} \sum_{i \in L} \ln \left(\frac{y_{t}}{y_{t-1}}\right)
$$

where $\mathrm{L}$ is losers or households whose income decreases during the period of study. The first component (growth component) mirrors directional income mobility of which the negative value indicates downward movement and the positive value of the index is a sign of upward mobility. This component can be interpreted as an average social utility due to growth (Aristei \& Perugini, 2015). In other words, it is the part of absolute mobility which is driven by an increase in a country's wealth or structural mobility (Brand-Weiner \& Francavilla, 2015). The second component (transfer component) is social utility due to transfers from losers (L) to gainers or average social utility that has changed hands (Ayala \& Sastre, 2008). This term is multiplied by two because the loss of losers would be gained by 
winners (ibid). The transfer component indicates the redistribution of the existing wealth or exchange mobility (Brand-Weiner \& Francavilla, 2015).

Table 2.1 presents absolute income mobility in Thailand measured by the FO index and its growth and transfers component in the short term (2005-2006), medium term (2005-2007) and long term (2005-2010 and 2005-2012), ${ }^{3}$ in both urban and rural areas. According to the results, absolute income mobility measured by the FO index increases over time. With the exception of the period from 2005 to 2010, absolute income mobility is mainly driven by the transfer component or the redistribution of existing wealth. In general, the share of growth and transfer component in driving income mobility are associated with GDP growth. A country with high GDP growth tends to exhibit a higher proportion of growth component (Brand-Weiner \& Francavilla, 2015). Considering that the average GDP growth rate of Thailand during the period under study is actually not low ${ }^{4}$, the dominance of the transfer component may signify that economic growth does not reach households, and GDP per capita may not be sufficient to reflect actual household welfare.

When the growth component or directional mobility is particularly considered, it is found that in the short term, an average income movement is welfare decreasing since the FO index is negative. The directional FO index becomes positive in the medium term and appears to be highest from 2005 to 2010. Over the course of seven years (2005-2012), however, the directional FO index declines, yet remains positive, indicating the lesser degree of upward mobility in comparison to the five-year period (2005-2010). With regard to the variation of mobility between administrative areas, it is observed that the extent of mobility is generally higher in rural areas. Given that income mobility may lead to longterm inequality (Rama et al., 2015), the higher mobility in rural areas derived from the FO index is in line with the lower inequality in rural areas obtained from the Gini coefficient.

\footnotetext{
${ }^{3}$ In some studies, "long-term mobility" is referred to as a movement of income between generations (intergenerational mobility), across different stages of life or over an extended period of time. However, as the SES-Panel which is the only nationally representative panel data available in Thailand was only conducted from 2005 to 2012, the notion of "long-term mobility" in this thesis is referred to as intragenerational income mobility over the period of 5-7 years. The notion of "long-term mobility" is used to differentiate the findings of 2005-10,12 from those obtained during 2005-2006 and 2005-2007 which are denoted as "short-term mobility" and "medium-term mobility", respectively. The readers thus need to be cautious that, in comparison to other studies that can access to the longer panel data, the notion of "long-term mobility" mentioned in this chapter and throughout this thesis might not be able to reflect considerable income change given the shorter period of time considered.

${ }^{4}$ GDP growth from 2005 to 2006, 2005 to 2007 and 2005 to 2012 is approximately 4.6 percent, 4.9 percent and 3.9 percent respectively (World Bank, 2017a).
} 
Table 2.1 Thailand's FO Index and Components

\begin{tabular}{rcccc} 
& Short Term & Medium Term & \multicolumn{2}{c}{ Long Term } \\
\cline { 2 - 5 } & $\mathbf{2 0 0 5 - 2 0 0 6}$ & $\mathbf{2 0 0 5 - 2 0 0 7}$ & $\mathbf{2 0 0 5 - 2 0 1 0}$ & $\mathbf{2 0 0 5 - 2 0 1 2}$ \\
\hline \hline All Households & & & & \\
Total FO Index (Non-Directional) & 0.551 & 0.565 & 0.700 & 0.715 \\
Growth Component (Directional) & -0.038 & 0.011 & 0.410 & 0.215 \\
Transfer Component & 0.589 & 0.554 & 0.290 & 0.500 \\
Urban Households & & & & \\
Total FO Index (Non-Directional) & 0.495 & 0.522 & 0.656 & 0.675 \\
Growth Component (Directional) & -0.058 & 0.012 & 0.308 & 0.107 \\
Transfer Component & 0.553 & 0.510 & 0.348 & 0.568 \\
Rural Households & & & & \\
Total FO Index (Non-Directional) & 0.578 & 0.584 & 0.719 & 0.731 \\
Growth Component (Directional) & -0.028 & 0.008 & 0.460 & 0.288 \\
Transfer Component & 0.606 & 0.576 & 0.259 & 0.443 \\
\hline \hline
\end{tabular}

Source: Author's own estimation based on SES-Panel 2005, 2006, 2007, 2010 and 2012

As aforementioned, the FO index is the most common indicator used to estimate income mobility. Past research on income mobility also employs this index to measure the extent of mobility in some other countries where the panel data is available. For example, Aristei and Perugini (2009) estimate the FO index from 2004 to 2006 in 25 European countries. Likewise, Brand-Weiner and Francavilla (2015) measure income mobility in Vietnam during the same period of time using the same FO index. The FO index is also used to assess income mobility from 2003 to 2005 in rural China (Jinqi, Guang-Sheng, \& Qiang, 2009). In order to examine what Thailand has achieved in terms of income mobility, it is thus interesting to compare the results of Thailand's FO index with that of other countries. The medium-term FO index (2005-2007) is used to benchmark with similar indicators in other countries since the 20052007 time period is comparable to the time period used in the aforementioned studies (twoyears period). 


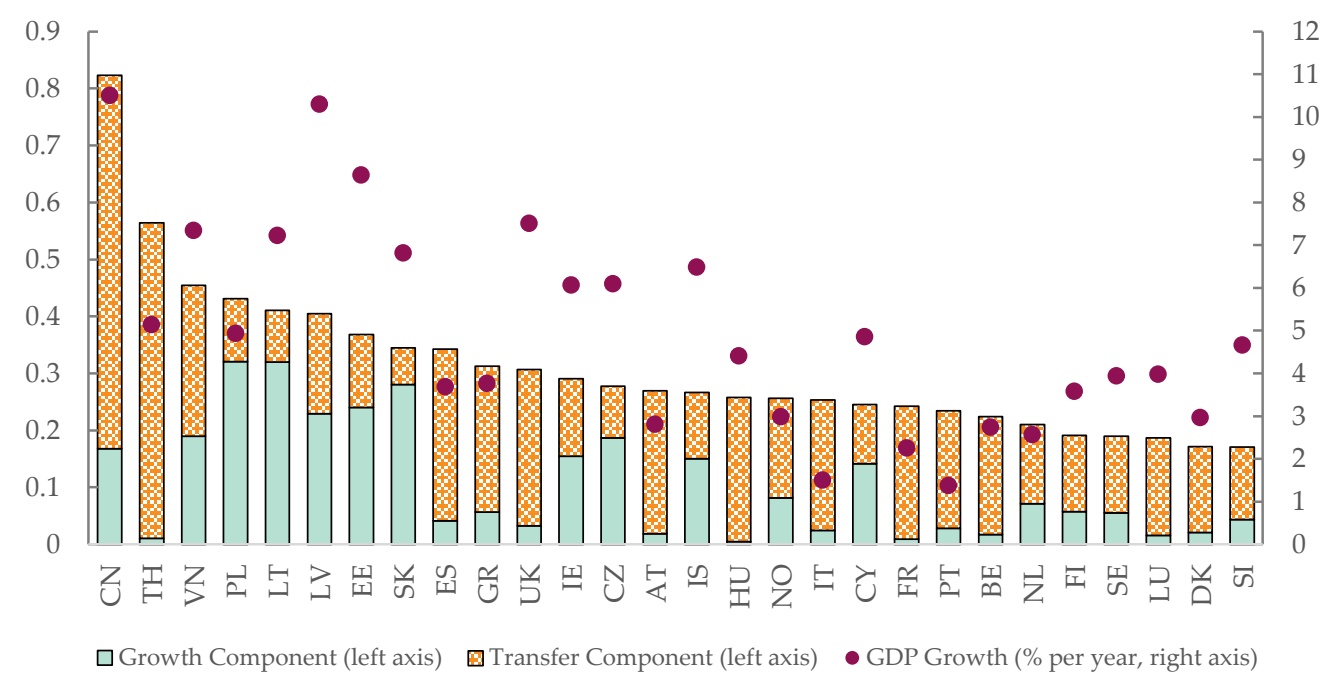

Sources: This chart is extended from Brand-Weiner and Francavilla (2015). The FO index for Thailand is obtained from author's own estimation based on SES-Panel 2005 and 2007, for European countries from Aristei and Perugini (2015), for Vietnam from Brand-Weiner and Francavilla (2015), and for China from Jinqi, Guang-Sheng and Qiang (2009). GDP growth is obtained from World Development Indicators (World Bank, 2017a).

Notes: The FO indices of all countries are estimated for the period of two years but the years of observation are different due to data availability. The FO index for Thailand is estimated from 2005 to 2007, the FO index in European countries and Vietnam are from 2004-2006, and the FO index for China is from 2003-2005.

Figure 2.8 presents the FO index and its decomposition into growth and transfer sources of each country, plotted against the country's average GDP growth. The chart is extended from Brand-Weiner and Francavilla (2015, p. 14). The results emphasize that absolute income mobility in Thailand is mainly driven by the transfer component. As can be seen, Thailand is ranked as the second most mobile country, after China, when it comes to non-directional income movement. However, the country is found to be among the most immobile countries when the direction of income movement is taken into consideration. Moreover, in comparison to other countries whose average GDP growth is similar to Thailand such as Poland and Cyprus or even lower than Thailand such as Italy and Portugal, the proportion of growth component in Thailand's absolute income mobility is substantially lower, indicating that the role of growth in driving mobility is exceptionally limited.

Having the transfer component as the leading component of absolute income mobility raises a concern that inequality will be exacerbated if losers are those at the bottom of the income 
distribution. Therefore, the growth component of the FO index or directional income movement by quintiles is particularly considered in order to examine who exactly are the losers. Surprisingly, Figure 2.9 shows that during the period under study (2005-2012), the poorest 20 percent households experience the highest degree of upward absolute income mobility. The extent of upward absolute income mobility is found to decreases as income rank increases. The result implies that richest households are losers and wealth is transferred from richer to poorer households.

Figure 2.9 FO Index (Directional Mobility) from 2005 to 2012 by Quintiles

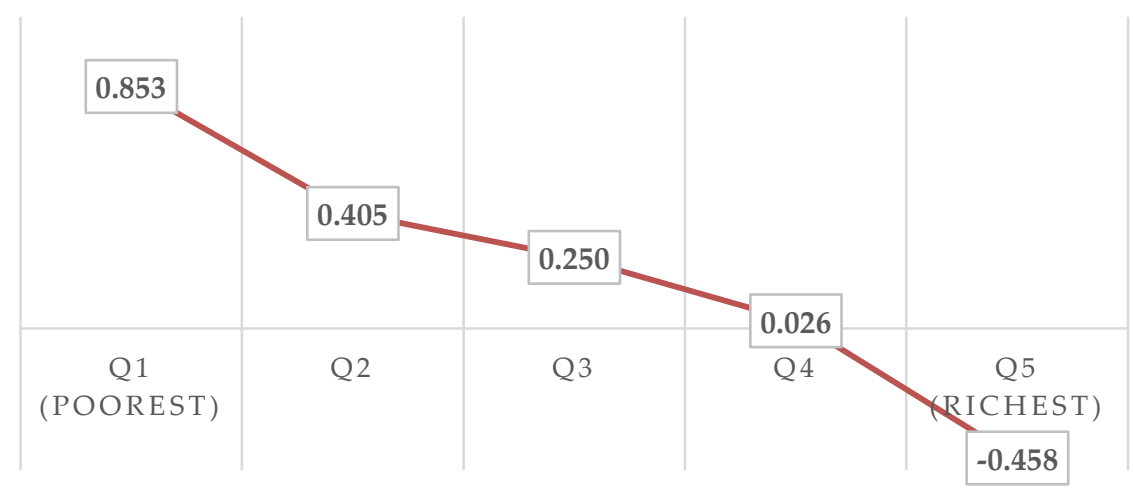

Source: Author's own estimation based on SES-Panel 2005 and 2012

\subsubsection{Relative Income Mobility}

Absolute income mobility needs to be complemented by relative income mobility measurement to fully reflect the picture of income mobility in Thailand. In this study, relative income mobility refers to changes in income position of households between two periods and is estimated by means of transition matrices. The transition matrix approach firstly allocates households into income quintile groups. Relative income mobility is then estimated by calculating the percentage of households moving up, moving down and staying in the same income ranking. 
Table 2.2 Transition Matrices by Income Quintiles (Percentage)

\begin{tabular}{|c|c|c|c|c|c|c|c|c|c|c|}
\hline All & \multicolumn{5}{|c|}{ Short-Term Relative Mobility } & \multicolumn{5}{|c|}{ Medium-Term Relative Mobility } \\
\hline Households & \multicolumn{5}{|c|}{ 2006 Quintile } & \multicolumn{5}{|c|}{2007 Quintile } \\
\hline $\begin{array}{c}2005 \\
\text { Quintile }\end{array}$ & 1 & 2 & 3 & 4 & 5 & 1 & 2 & 3 & 4 & 5 \\
\hline 1 & 52.92 & 28.84 & 11.56 & 5.60 & 1.07 & 51.01 & 29.08 & 12.99 & 5.01 & 1.91 \\
\hline 2 & 28.25 & 37.19 & 21.45 & 9.42 & 3.69 & 30.27 & 33.25 & 23.00 & 9.77 & 3.69 \\
\hline 3 & 12.77 & 22.20 & 37.35 & 20.88 & 6.80 & 11.34 & 24.58 & 34.49 & 20.64 & 8.95 \\
\hline 4 & 4.05 & 9.18 & 22.65 & 43.27 & 20.86 & 5.24 & 10.01 & 21.33 & 43.50 & 19.90 \\
\hline 5 & 2.03 & 2.63 & 6.92 & 20.88 & 67.54 & 2.15 & 3.10 & 8.11 & 21.12 & 65.51 \\
\hline All & \multicolumn{10}{|c|}{ Long-Term Relative Mobility } \\
\hline Households & \multicolumn{5}{|c|}{2010 Quintile } & \multicolumn{5}{|c|}{2012 Quintile } \\
\hline $\begin{array}{c}2005 \\
\text { Quintile }\end{array}$ & 1 & 2 & 3 & 4 & 5 & 1 & 2 & 3 & 4 & 5 \\
\hline 1 & 47.32 & 28.96 & 13.71 & 7.27 & 2.74 & 44.93 & 27.18 & 15.02 & 8.22 & 4.65 \\
\hline 2 & 29.68 & 32.06 & 21.33 & 11.56 & 5.36 & 27.18 & 31.82 & 21.10 & 13.35 & 6.56 \\
\hline 3 & 15.16 & 23.27 & 30.07 & 20.17 & 11.34 & 16.59 & 22.20 & 26.49 & 21.72 & 13.01 \\
\hline 4 & 5.84 & 11.80 & 23.24 & 38.38 & 20.74 & 7.75 & 12.87 & 23.72 & 32.90 & 22.77 \\
\hline 5 & 2.03 & 3.94 & 11.58 & 22.67 & 59.79 & 3.58 & 5.97 & 13.60 & 23.87 & 52.98 \\
\hline Urban/ & \multicolumn{5}{|c|}{ Urban Households } & \multicolumn{5}{|c|}{ Rural Households } \\
\hline Rural & \multicolumn{5}{|c|}{2012 Quintile } & \multicolumn{5}{|c|}{2012 Quintile } \\
\hline $\begin{array}{c}2005 \\
\text { Quintile }\end{array}$ & 1 & 2 & 3 & 4 & 5 & 1 & 2 & 3 & 4 & 5 \\
\hline 1 & 56.04 & 23.81 & 9.52 & 7.69 & 2.93 & 42.06 & 23.82 & 17.38 & 10.94 & 5.79 \\
\hline 2 & 24.81 & 30.00 & 20.74 & 15.56 & 8.89 & 25.48 & 28.05 & 22.27 & 15.20 & 8.99 \\
\hline 3 & 9.59 & 22.88 & 31.73 & 24.72 & 11.07 & 15.78 & 23.67 & 27.08 & 21.32 & 12.15 \\
\hline 4 & 5.54 & 13.65 & 23.62 & 29.15 & 28.04 & 11.26 & 16.67 & 21.00 & 27.92 & 23.16 \\
\hline 5 & 4.06 & 9.59 & 14.39 & 22.88 & 49.08 & 5.38 & 7.74 & 12.26 & 24.73 & 49.89 \\
\hline
\end{tabular}

Source: Author's own estimation based on SES-Panel 2005, 2006, 2007, 2010 and 2012

Table 2.2 presents relative household income mobility in the form of transition matrices. The numbers on the diagonal indicate the share of households preserving their rank in the income distribution. The numbers above the diagonal represent the percentage of households experiencing upward mobility while the numbers below the diagonal refer to households undergoing downward mobility. The results suggest that relative income mobility in Thailand is quite modest. Relative income mobility increases once the time horizon is expanded. However, even over the period of seven years, as much as 45 percent 
of households remains stuck in the poorest quintile and 53 percent secures their richest position. Moreover, for households who were in the middle of the income distribution (quintile 3) in 2005, the proportion of those falling behind is higher than the proportion of those who could manage to climb up, regardless of what time duration is being considered. This finding implies that although poor households experience upward directional income movement in absolute term, there is still a sticky floor at the bottom and sticky ceiling at the top when positional movement is taken into consideration.

When long-term relative mobility between urban and rural households is differentiated, it is apparent that urban households are more stagnant. The results are in line with the findings from absolute mobility measurement that households in rural areas have higher mobility than those living in urban areas. This finding is indeed counterintuitive since rural residents are usually thought to be left behind. However, recent studies also suggest these counterintuitive results. A study from the Opportunity Insights project (Chetty et al., 2018) shows that opportunities to move upward are not necessary lower for children from rural areas. They conclude that greater social capital, more stable family structure and the opportunity to grow up around adults with positive characteristics are more important for upward mobility of children than macroeconomic conditions of the area. Another study by Weber et al. (2018) also confirms these unusual findings. The authors find that absolute mobility in non-metropolitan counties of USA is higher than in metropolitan counties. Nevertheless, my results of higher absolute and relative mobility in rural area presented so far are derived from purely descriptive statistics. These results needs to be confirmed by the more rigorous econometric regressions to further examine whether living location is significantly correlated with absolute and relative income mobility. These analyses are presented in the following sections.

\subsection{Drivers of Income Mobility}

Apart from the extent and pattern of income mobility, the factors associated with income mobility are also of considerably importance particularly from a policy viewpoint. This section attempts to identify drivers of both absolute income mobility (income change) and relative income mobility (rank change) using a micro mobility method to obtain the results. For absolute income mobility, direction of movement matters when identifying factors underlying the movement. Therefore, the directional component (or growth component) of the FO index is used as the outcome of interest. The analyses are based on the seven year 
horizon, from 2005 to 2012, of income mobility since the long-term income mobility is more relevant to household welfare than the short-term fluctuations of household income.

\subsubsection{Drivers of Absolute Income Mobility}

Following the standard practice in the benchmark studies on determinants of income mobility by Field et al. (2003), Woolard and Klasen (2005), and Aristei and Perugini (2015), the form of the empirical model used to examine determinants of absolute income mobility is as presented in equation (3).

$$
\ln \left(\frac{y_{i 2012}}{y_{i 2005}}\right)=f\left(\ln y_{i 2005}, H_{i 2005}, \Delta H_{i}, K_{i 2005}, \Delta K_{i}, R_{i 2005}, \Delta R_{i}\right)
$$

where $y$ represents real equivalised household income in the respective year. $\ln \left(\frac{y_{2012}}{y_{2005}}\right)$ is income change of household $i$ between 2005 and 2012 which corresponds to the directional FO index presented in equation (2). Factors influencing the income change are categorized into human assets of household $i$, physical capital assets owned by the household and other characteristics reflecting the environment in which the household locates. Human capital variables $(H)$ include variables indicating quantity and quality of human capital resources of the household namely household size, share of working-age males and females, share of elderly members, share of child members, share of earners, and characteristics of household head including age, gender, education and employment status. Physical capital variables (K) consist of size of land owned by the household, a binary variable indicating whether the household has debt or not, and an asset index which represents resources used to support income-generating activities of a household. ${ }^{5}$ Variables indicating the location of residence including administrative area (rural and urban) and geographical region (Bangkok Metropolitan, Central, North, Northeast, South) are put in the category of other household characteristics $(R)$. The delta operator $(\Delta)$ denotes change in certain corresponding timevarying variables over the period of seven years. Moreover, since income mobility may also

\footnotetext{
${ }^{5}$ The asset index is constructed by Principal Component Analysis (PCA) method which can combine a number of variables into one single index according to their relative importance (Fry, Firestone, \& Chakraborty, 2014). A total of 13 productive durable items recorded as continuous variables, for which the data is available, are used to construct the index including landline phone and fax, computer, internet access, mobile phone, motorcycle, bike, car, pickup truck, Thai etan truck (a small truck used for agricultural works in Thailand), traditional plough, tractor, boat and six-wheeled truck or larger vehicles.
} 
rely on the initial endowments, the real equivalised household income in natural logarithms in $2005\left(\ln y_{i 2005}\right)$ is thus also included in the model specification. Table 2.3 summarizes the means and standard deviations of variables used in the estimation models.

Table 2.3 Summary Statistics of Variables Used to Identify Drivers of Income Mobility

\begin{tabular}{|c|c|c|}
\hline & Mean & $\begin{array}{r}\text { Standard } \\
\text { Deviation }\end{array}$ \\
\hline \multicolumn{3}{|l|}{ Income Variables } \\
\hline Real equivalised household income in 2005 ( $\left.\ln y_{2005}\right)$ & 9.163 & 1.005 \\
\hline Change in real equivalised household income $\left(\ln y_{2012}-\ln y_{2005}\right)$ & 0.209 & 0.952 \\
\hline \multicolumn{3}{|l|}{ Human Capital Variables in $2005\left(H_{2005}\right)$} \\
\hline Household size & 3.683 & 1.721 \\
\hline Share of working-age male & 0.296 & 0.220 \\
\hline Share of working-age female & 0.347 & 0.224 \\
\hline Share of children (age $<15)$ & 0.208 & 0.205 \\
\hline Share of elderly & 0.149 & 0.266 \\
\hline Share of earners & 0.553 & 0.289 \\
\hline Female headed household & 0.296 & 0.457 \\
\hline Age of household head & 50.636 & 13.051 \\
\hline Squared age of household head & $2,734.306$ & $1,376.286$ \\
\hline \multicolumn{3}{|l|}{ Education of household head } \\
\hline Never been to school & 0.045 & 0.207 \\
\hline Primary & 0.689 & 0.463 \\
\hline Lower secondary & 0.081 & 0.272 \\
\hline Upper secondary & 0.063 & 0.243 \\
\hline Vocational education & 0.051 & 0.220 \\
\hline Higher education & 0.071 & 0.256 \\
\hline \multicolumn{3}{|l|}{ Employment status of household head } \\
\hline Unemployed or inactive & 0.157 & 0.364 \\
\hline Unpaid family workers & 0.025 & 0.156 \\
\hline Self-employed & 0.365 & 0.481 \\
\hline Employee & 0.349 & 0.477 \\
\hline Employer & 0.104 & 0.306 \\
\hline \multicolumn{3}{|l|}{ Physical Capital Variables in $2005\left(K_{2005}\right)$} \\
\hline Size of land owned & 3.647 & 4.696 \\
\hline Having debt & 0.696 & 0.460 \\
\hline Asset index & -0.430 & 1.229 \\
\hline \multicolumn{3}{|l|}{ Other Household Characteristics in $2005\left(R_{2005}\right)$} \\
\hline Rural household & 0.664 & 0.472 \\
\hline
\end{tabular}




\begin{tabular}{|c|c|c|}
\hline & Mean & $\begin{array}{r}\text { Standard } \\
\text { Deviation }\end{array}$ \\
\hline \multicolumn{3}{|l|}{ Region } \\
\hline Bangkok Metropolitan & 0.163 & 0.370 \\
\hline Central & 0.200 & 0.400 \\
\hline North & 0.211 & 0.408 \\
\hline Northeast & 0.301 & 0.459 \\
\hline South & 0.124 & 0.330 \\
\hline \multicolumn{3}{|c|}{ Change Variables between 2005 and $2012(\Delta H, \Delta K, \Delta R)$} \\
\hline Change in household size & -0.036 & 1.544 \\
\hline Change in share of children $($ age $<15)$ & -0.064 & 0.214 \\
\hline Change in share of elderly & 0.096 & 0.256 \\
\hline Change in share of earners & 0.022 & 0.331 \\
\hline \multicolumn{3}{|l|}{ Change in employment status } \\
\hline Not moving & 0.712 & 0.453 \\
\hline Downward moving & 0.216 & 0.412 \\
\hline Upward moving & 0.072 & 0.258 \\
\hline Change in asset index & 0.584 & 1.078 \\
\hline \multicolumn{3}{|l|}{ Change in area of residence (rural-urban) } \\
\hline Not moving & 0.879 & 0.326 \\
\hline Urban to rural & 0.013 & 0.112 \\
\hline Rural to urban & 0.109 & 0.311 \\
\hline Number of Households & \multicolumn{2}{|c|}{4,193} \\
\hline
\end{tabular}

Source: Author's own estimation based on SES-Panel 2005 and 2012

The reported initial income $\left(\ln y_{i 2005}\right)$ included in equation (3) may result in the biased estimates of coefficients due to the correlation of errors in the reported income over time (Woolard \& Klasen, 2005). Therefore, in addition to the Ordinary Least Squares (OLS) regression, equation (3) is additionally estimated with the instrumental variable (IV) and Two Stages Least Square (2SLS) approach to address the possible endogeneity of reported income. The initial income is instrumented by real equivalised household expenditure in natural logarithm in 2005, other additional household and household head characteristics, and assets ownership such as types of home ownership and the number of the bedroom. The selection of these variables is guided by previous studies on determinants of income mobility including Field et al. (2003), Aristei and Perugini (2015) and Brand-Weiner and Francavilla (2015).

As shown in Table 2.4, the Wooldridge's endogeneity score test (presented in the third last low of the table) rejects the null hypothesis of exogeneity, confirming that the IV approach is 
necessary to address the problem of endogeneity. Besides, the high value of the F-statistic on the instrument (the second last row of the table), which is equal to 132.6, indicates that the IV regression does not have a problem of weak instrument. With regard to the assumption of exclusion restriction, the selection of instruments in this analysis follows previous practice used in the aforementioned studies. The instruments such as household expenditure, the number of bedroom and types of home ownership in 2005 are expected not to have direct relationship with income mobility. However, it would be remiss not to note that there is also a possibility that the assumption of exclusion restriction is not satisfied and the endogeneity of reported income is not fully addressed.

Table 2.4 Drivers of Absolute Income Mobility (2005-2012)

\begin{tabular}{|c|c|c|c|c|}
\hline & \multicolumn{2}{|c|}{ OLS } & \multicolumn{2}{|c|}{ IV-2SLS } \\
\hline & Coefficient & $\begin{array}{l}\text { Standard } \\
\text { Error }\end{array}$ & Coefficient & $\begin{array}{l}\text { Standard } \\
\text { Error }\end{array}$ \\
\hline $\begin{array}{l}\text { Real equivalised household income in } 2005 \\
\left(\ln y_{2005}\right)\end{array}$ & $-0.735^{* * *}$ & 0.017 & $-0.543^{* * *}$ & 0.035 \\
\hline \multicolumn{5}{|l|}{ Human Capital Variables in $2005\left(H_{2005}\right)$} \\
\hline Household size & $-0.022^{* *}$ & 0.009 & -0.014 & 0.009 \\
\hline Share of working-age male & -0.400 & 0.663 & -0.068 & 0.875 \\
\hline Share of working-age female & -0.309 & 0.664 & 0.005 & 0.875 \\
\hline Share of children $($ age $<15)$ & -0.137 & 0.675 & 0.188 & 0.885 \\
\hline Share of elderly & -0.466 & 0.669 & -0.073 & 0.880 \\
\hline Share of earners & $0.739^{* * *}$ & 0.070 & $0.600^{* * *}$ & 0.072 \\
\hline Female headed household & 0.001 & 0.028 & 0.004 & 0.028 \\
\hline Age of household head & $-0.019 * *$ & 0.007 & $-0.018^{* *}$ & 0.007 \\
\hline Squared age of household head & $0.000^{* *}$ & 0.000 & $0.000^{* *}$ & 0.000 \\
\hline \multicolumn{5}{|c|}{ Education of household head (never been to school = reference) } \\
\hline Primary & $0.120^{* *}$ & 0.060 & 0.089 & 0.059 \\
\hline Lower secondary & $0.146^{*}$ & 0.076 & 0.077 & 0.077 \\
\hline Upper secondary & $0.207^{* *}$ & 0.073 & $0.124^{*}$ & 0.074 \\
\hline Vocational education & $0.258^{* * *}$ & 0.077 & $0.172^{* *}$ & 0.078 \\
\hline Higher education & $0.440^{* * *}$ & 0.075 & $0.302^{* * *}$ & 0.078 \\
\hline \multicolumn{5}{|c|}{ Employment status of household head (unemployed and inactive $=$ reference) } \\
\hline Unpaid family workers & 0.116 & 0.080 & 0.091 & 0.082 \\
\hline Self-employed & $0.080^{*}$ & 0.046 & 0.058 & 0.047 \\
\hline Employee & -0.035 & 0.046 & -0.011 & 0.046 \\
\hline Employer & 0.123 & 0.077 & 0.033 & 0.080 \\
\hline
\end{tabular}




\section{OLS}

IV-2SLS

\begin{tabular}{|c|c|c|c|c|}
\hline & & & \multirow[b]{2}{*}{ Coefficient } & \multirow[b]{2}{*}{$\begin{array}{l}\text { Standard } \\
\text { Error } \\
\end{array}$} \\
\hline & Coefficient & $\begin{array}{l}\text { Standard } \\
\text { Error } \\
\end{array}$ & & \\
\hline \multicolumn{5}{|l|}{ Physical Capital Variables in $2005\left(K_{2005}\right)$} \\
\hline Size of land owned (ln) & $0.006^{* *}$ & 0.003 & $0.008^{* *}$ & 0.003 \\
\hline Having debt & 0.010 & 0.027 & -0.015 & 0.028 \\
\hline Asset index & $0.237^{* * *}$ & 0.014 & $0.166^{* * *}$ & 0.017 \\
\hline \multicolumn{5}{|l|}{ Other Household Characteristics in $2005\left(\boldsymbol{R}_{2005}\right)$} \\
\hline Rural household & $-0.065^{* *}$ & 0.030 & -0.049 & 0.031 \\
\hline \multicolumn{5}{|l|}{ Region $($ Bangkok Metropolitan = reference) } \\
\hline Central & $0.095^{* *}$ & 0.039 & $0.146^{* * *}$ & 0.041 \\
\hline North & 0.008 & 0.040 & $0.072^{*}$ & 0.042 \\
\hline Northeast & -0.043 & 0.041 & 0.014 & 0.043 \\
\hline South & $0.191^{* * *}$ & 0.047 & $0.230^{* * *}$ & 0.047 \\
\hline \multicolumn{5}{|c|}{ Change Variables between 2005 and $2012(\Delta H, \Delta K, \Delta R)$} \\
\hline Change in household size & -0.015 & 0.010 & -0.013 & 0.010 \\
\hline Change in share of children (age $<15)$ & $0.170^{* *}$ & 0.081 & $0.172^{* *}$ & 0.082 \\
\hline Change in share of elderly & $-0.167^{* *}$ & 0.059 & $-0.170^{* *}$ & 0.060 \\
\hline Change in share of earners & $0.797^{* * *}$ & 0.062 & $0.786^{* * *}$ & 0.063 \\
\hline \multicolumn{5}{|c|}{ Change in employment status (not moving = reference) } \\
\hline Downward moving & $-0.094^{* *}$ & 0.040 & $-0.085^{* *}$ & 0.040 \\
\hline Upward moving & 0.054 & 0.050 & 0.054 & 0.049 \\
\hline Change in asset index & $0.177^{* * *}$ & 0.012 & $0.161^{* * *}$ & 0.013 \\
\hline \multicolumn{5}{|c|}{ Change in area of residence (not moving = reference) } \\
\hline Urban to rural & $-0.184^{*}$ & 0.110 & $-0.195^{*}$ & 0.113 \\
\hline Rural to urban & -0.031 & 0.035 & -0.043 & 0.036 \\
\hline Constant & $7.260^{* * *}$ & 0.714 & $5.188^{* * *}$ & 0.978 \\
\hline R-squared & 0.437 & & 0.416 & \\
\hline \multicolumn{3}{|c|}{ Wooldridge's endogeneity score test ( $p$-value in Standard Error column) } & 36.234 & 0.000 \\
\hline F-Statistics ( $p$-value in Standard Error column) & & & 132.609 & 0.000 \\
\hline Number of households & 4,193 & & 4,193 & \\
\hline
\end{tabular}

Source: Author's own estimation based on SES-Panel 2005 and 2012

Notes: The results are obtained from the model presented in equation (3) with OLS and IV-2SLS method conducted at household level. The null hypothesis of the Wooldridge's score tests is that reported income is exogenous. Since the test statistics is highly significant, the null hypothesis of exogeneity is rejected. Coefficients in bold denotes significant result. Robust standard errors are reported and ${ }^{*} p<0.1,{ }^{* *} p<0.05,{ }^{* * *} p<0.001$. 
Table 2.4 presents the results from the absolute income mobility regressions, using reported initial income (OLS approach) and instrumented income (IV-2SLS approach). The results obtained with the OLS and IV methods are nearly similar. The most important findings derived from both methods are that the share of earners, the possession of productive assets and the changes in these two factors are the most important factors underlying absolute intragenerational income mobility in Thailand from 2005 to 2012. When considering the results in details, it is found that households starting with higher income in 2005 tend to experience a negative income change seven years later. The results suggest that a 1 percent increase in base year income of a household is associated with a 0.5 percent decrease in income change of the household (or 0.7 percent if the OLS method is applied). This finding implies that there is a regression of income towards the mean among the sample households considered during the period under study. Although this sounds counterintuitive, the results are in line with previous studies (see e.g. Aristei \& Perugini, 2015; Brand-Weiner \& Francavilla, 2015; Fields et al., 2003; Woolard \& Klasen, 2005), which assert that "low income does not impede income mobility" (Brand-Weiner \& Francavilla, 2015) and "neither a cumulative mechanism nor a low income trap is in place" (Aristei \& Perugini, 2015).

The finding of positive (negative) income change among the poor (rich) obtained from the absolute income mobility regressions is in line with the negative slope of the directional FO index by quintiles presented in Figure 2.9 which also suggests that absolute income mobility decreases as income rank increases. Fields et al. (2002) offer a number of possible justifications for this counterintuitive result. For instance, the macroeconomic and political conditions may have disproportionately benefitted the initially poorer households than the richer households. The negatively sloping GIC curve from 2000 to 2017 presented in Figure 2.5 seems to support this argument. Moreover, it might also be the case that households with low reported income in the initial year experience a transitory negative income shock in that initial year. Their income in the subsequent year, when they have already recovered from income shock, thus appears as a relatively large increase in income. Furthermore, the negative relationship between the initial income and absolute income mobility might be simply due to the measurement error in income which cannot be fully addressed by the current IV approach.

Although low income trap is not in place, poor initial human capital and physical capital are still found to lead to the poverty trap. Human capital variables of a household are found to have a positive association with upward absolute income mobility. Larger household size is associated with negative income change. However, the impact of household size on income 
mobility vanishes when initial income is instrumented. Among various human capital variables included in the model, the share of earner stands out. A larger share of earners and increase in that share are highly and strongly associated with positive income change. The magnitude of the share of earners' impact decreases with the IV approach but remains large, compared to other variables, and statistically highly significant. Other variables reflecting composition of household including share of working-age male, working-age female, elderly and child member have no significant relationship with income change. Nevertheless, a change in share of children is found to have a positive correlation while a change in share of elderly has a negative correlation with upward income mobility.

These results on change in the share of children and that of elderly are inconsistent with the study by Woolard and Klasen (2005) which report a negative relationship between share of children and absolute income mobility. The dissimilarities of the results might be partly driven by the different time periods considered. While Woolard and Klasen (2005) analyze income mobility in South Africa from 1993 to 1998, this study looks at mobility during the period from 2005 and 2012. Moreover, Woolard and Klasen (2005) explain that the higher share of children indicates larger household size. As in their study, household size is found to be strongly negatively related with income mobility, an increase in the share of children would lead to a decreasing income change. However, in this study, the relationship between household size and absolute income mobility is relatively weaker. As discussed, the significant role of household size even vanishes when initial income is instrumented. Furthermore, the positive impact of change in the share of children observed in this study is probably due to fact that the presence of children motivates their parents to work and earn more in order to support the children. According to Edin and Kefalas (2011), children provide motivation and purpose in life stalled by uncertainty and failure. Having children may thus be considered as an opportunity to demonstrate maturity and personal achievement. As a consequence, a higher share of children is found to lead to upward absolute income mobility.

Regarding the share of elderly, Woolard and Klasen (2005) suggest that a higher share of elderly is associated with positive income change particularly in rural areas because old-age pension income is an important income sources for households. Nevertheless, the amount of pension income in Thailand is small in comparison to other sources of household income. Considering that a higher share of elderly may imply a lower share of earners, which is found to be the most important driver of income mobility, the higher pension income that households may receive from having a higher share of elderly members may not be able to 
offset the loss from forgone working income. Hence, the positive change in the share of elderly is associated with downward absolute income mobility of a household.

With respect to characteristics of the household head, no significant variation between male and female headed households is observed. There is a non-linear relationship between age of household head and absolute income mobility. The prospect of upward absolute income mobility is decreasing with age but with a slower rate when the household head is getting older. As summarized in Aristei and Perugini (2015) who observe the similar pattern in European countries, young workers tend to have less job stability due to the lower degree of tenure, while older workers may have greater difficulty in acquiring new skills and adapting to changes. As a result, younger workers tend to have higher income mobility. As expected, education of household head is also positively correlated with absolute income mobility. This relationship is found to be stronger for higher levels of education. Employment status of household head plays a minor role. Having an employed head does not seem to be statistically different from having an unemployed or inactive one, with an exception of self-employed head but the difference is only significant at the 10 percent. However, the downward transition to lower employment status is negatively related with absolute income mobility.

The possession of physical capital is also found to have a positive association with absolute income mobility. The amount of land owned by a household is positively associated with upward absolute income mobility. Similarly, possessing productive durables and increase in the level of possession, measured by the asset index and change in the asset index respectively, are also positively correlated with absolute income mobility. With regard to area of residence, households living in the central and southern parts of the country tend to have higher income mobility experience, compared to those living in the capital city and surroundings. The negative relationship between rural residence and absolute income mobility seems to be incompatible with the higher rate of mobility found by the descriptive FO index presented in the previous section, which indicates that households in rural area are more mobile. However, the importance of being a rural household becomes insignificant when estimated by the IV approach. Moreover, although moving from urban to rural area is found to decrease income mobility by almost 20 percent, the result is only significant at the 10 percent level. Therefore, the inconclusive association between location of residence and absolute income mobility in Thailand leaves room for future research to examine whether the prospects of mobility is tied to the area of residence. 
The two estimations of determinants of absolute income mobility (OLS and IV-2SLS) are additionally replicated with merely households in the bottom 40 percent of the income distribution. It is found that the determinants of absolute income mobility for the entire population, as presented above, and the determinants of absolute income mobility for the bottom 40 percent are quite similar; no significant difference is discerned.

\subsubsection{Drivers of Relative Income Mobility}

We now turn our attention to the determinants of relative income mobility. The rank movement of the bottom 40 percent households is the main focus of this study because mobility of the disadvantaged group would reflect the extent to which opportunity truly exists in the society. Moreover, the three social protection programs that are empirically evaluated in the next chapters, although open for participants from all income levels, seem to target their effort on those at the low end of the income spectrum. Referring to the transition matrices presented in table 2.2, the attempt is made to identify factors that are associated with the positional movement of households, who begin with the first and second poorest income quintile in 2005, to the higher (same/lower) quintile positions in 2012. The ordered logistic regression is used to account for the ordinal dependent variable which is the income quintile of households in 2012. The same model specification used for the absolute income mobility (or income change) regressions presented in equation (3), is also applied for this relative income mobility (or rank change) regressions. The ordered logit model regression is estimated separately for the 2005 poorest (households moving out of quintile 1) and second poorest quintile households (households moving out of quintile2).

Table 2.5 presents the results obtained from the two ordered logit regressions. As can be noted, drivers of the transition out of the first poorest quintile are not always identical to drivers of the transition out of the second quintile. Moreover, some factors driving absolute income mobility are not strong enough to foster relative income mobility, which highlights the importance of examining drivers of both concepts of income mobility. Nevertheless, the results from the relative income mobility regressions suggest a similar conclusion obtained from the absolute income mobility regressions that the share of earners, the possession of productive assets and the changes in these two variables are the most important factors associated with relative income mobility.

When considering the results of each variable in more details, it is found that for households in the poorest quintile in 2005 , the higher initial income is positively associated with the 
probability of upward movement to the higher income positions. This positive association is in line with the relative mobility measured by transition matrices presented in Table 2.2 which also indicate the sticky floor at the bottom. However, since the initial income is not found to be significant for household departing from the second poorest quintile, this finding implies that the relative income trap may only exist among the poorest of the poor.

These results obtained from relative income mobility regressions appear to contradict to the negative relationship between initial income and upward absolute income mobility discussed earlier. A possible explanation for these inconsistent results is that during the period of 2005 to 2012, households who have less income to begin with have experienced a significant positive income change. However, that positive income change is not sufficient to move the initially poor households to the higher income quintile ranks due to the large income gap between the low income quintiles and the higher income quintiles. This explanation is supported by the large discrepancy of income share between each income quintile especially the poorest and the richest households presented in Figure 2.7.

With regard to factors related to human capital, in line with absolute income mobility regressions, the share of earners is found to be highly significant in explaining relative income mobility. The higher share of earners and increase in the share of earners lead to the higher chance of moving up to the higher income ranks. On the contrary, the lower share of earners or the decrease in the share is found to increase the likelihood of remaining in the low positions or moving down to the lower position. The non-linear relationship between age and income rank change is only found for the transition out of the second poorest quintile. By contrast, the importance of household head's education in explaining relative income mobility is mainly realized in households departing from the poorest quintile. Apart from the share of earners, age and education, other human capital variables explaining absolute income mobility including household size, and change in the share of children and elderly members, do not seem to have a significant association with upward relative income mobility. However, employment status of household head, which is not significant in explaining income change, is found to be associated with the transition out of the poorest quintile. Entrepreneurship, both self-employed and especially employer, is positively correlated with upward movement to higher income positions among the poorest 20 percent households. 


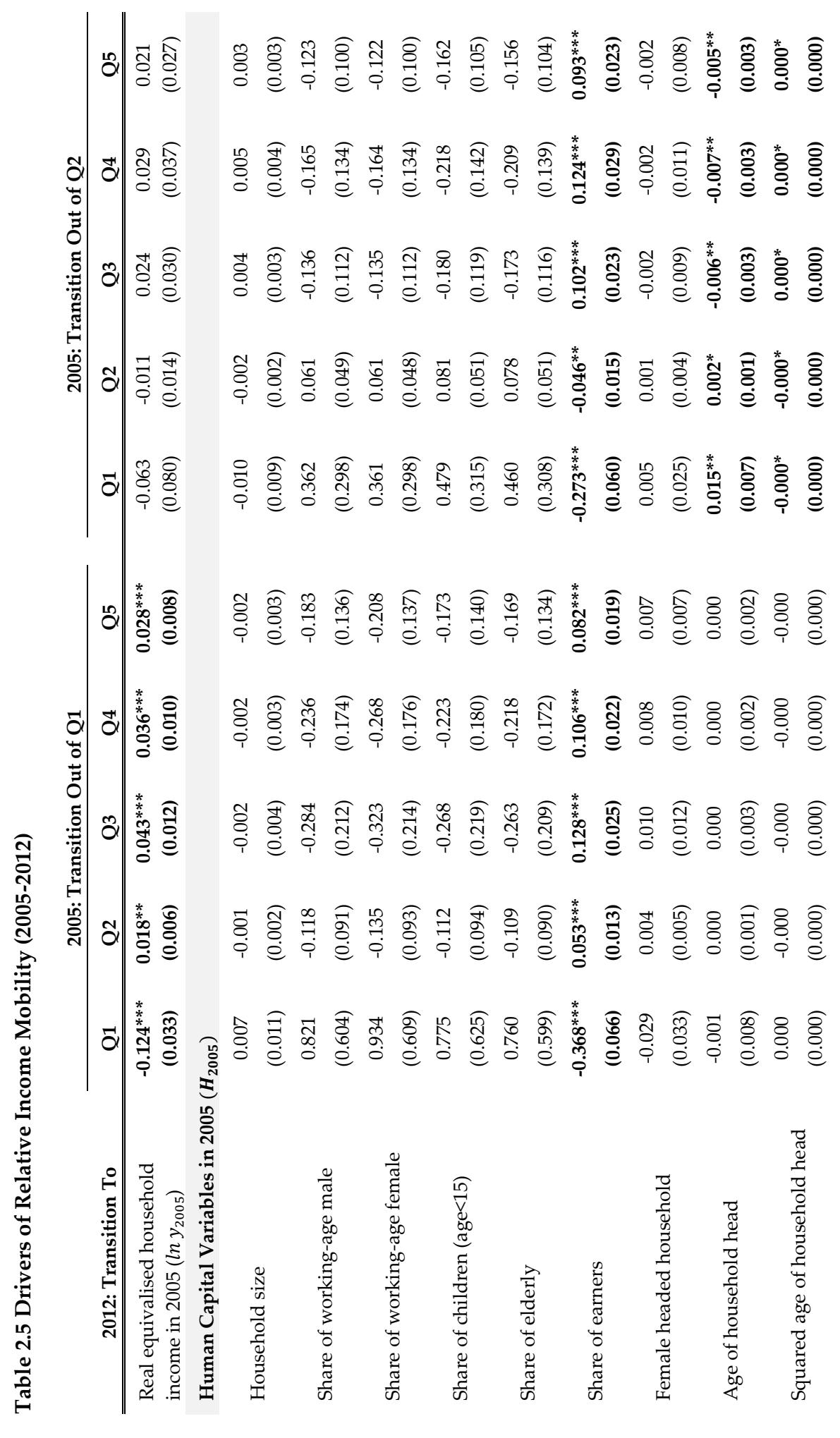




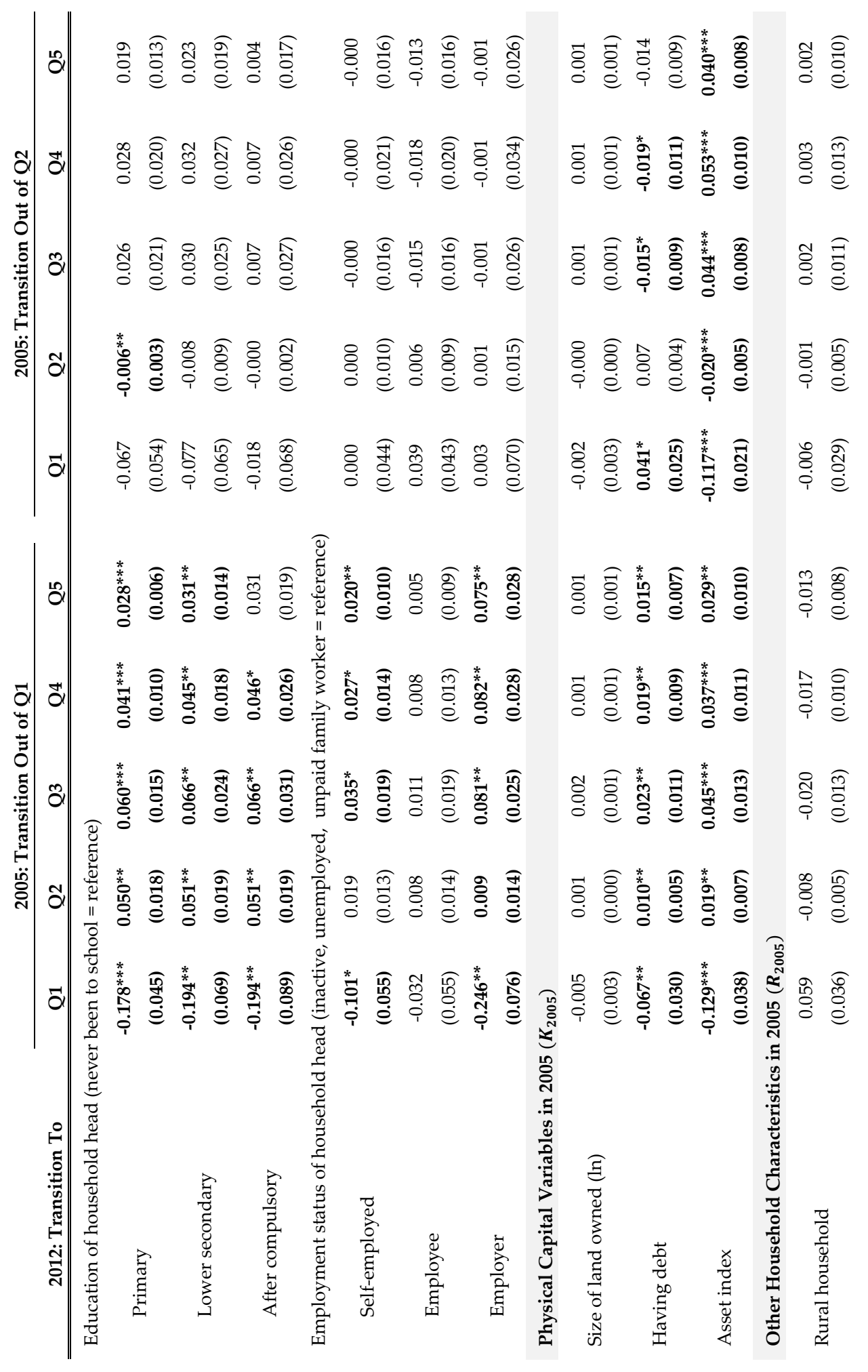




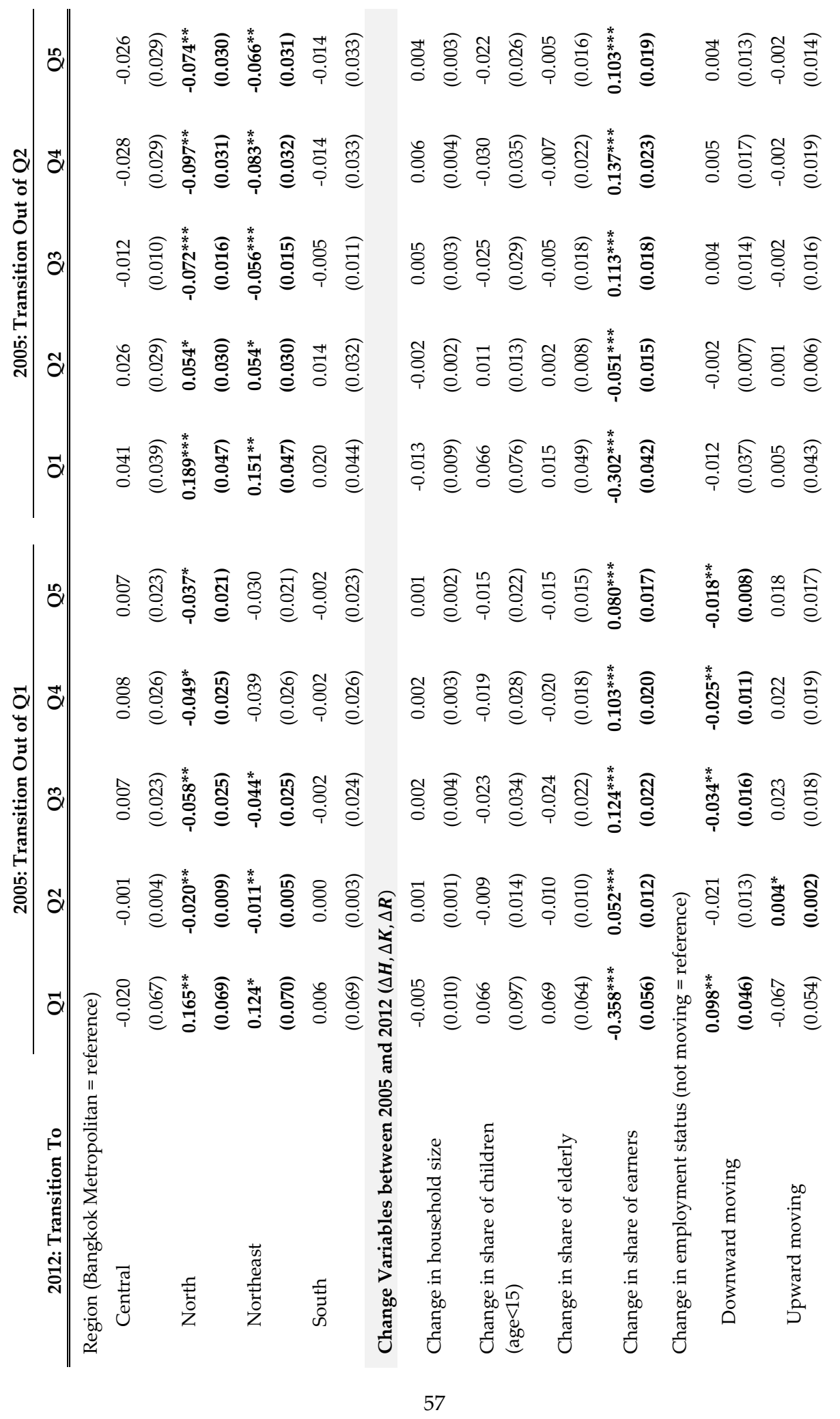




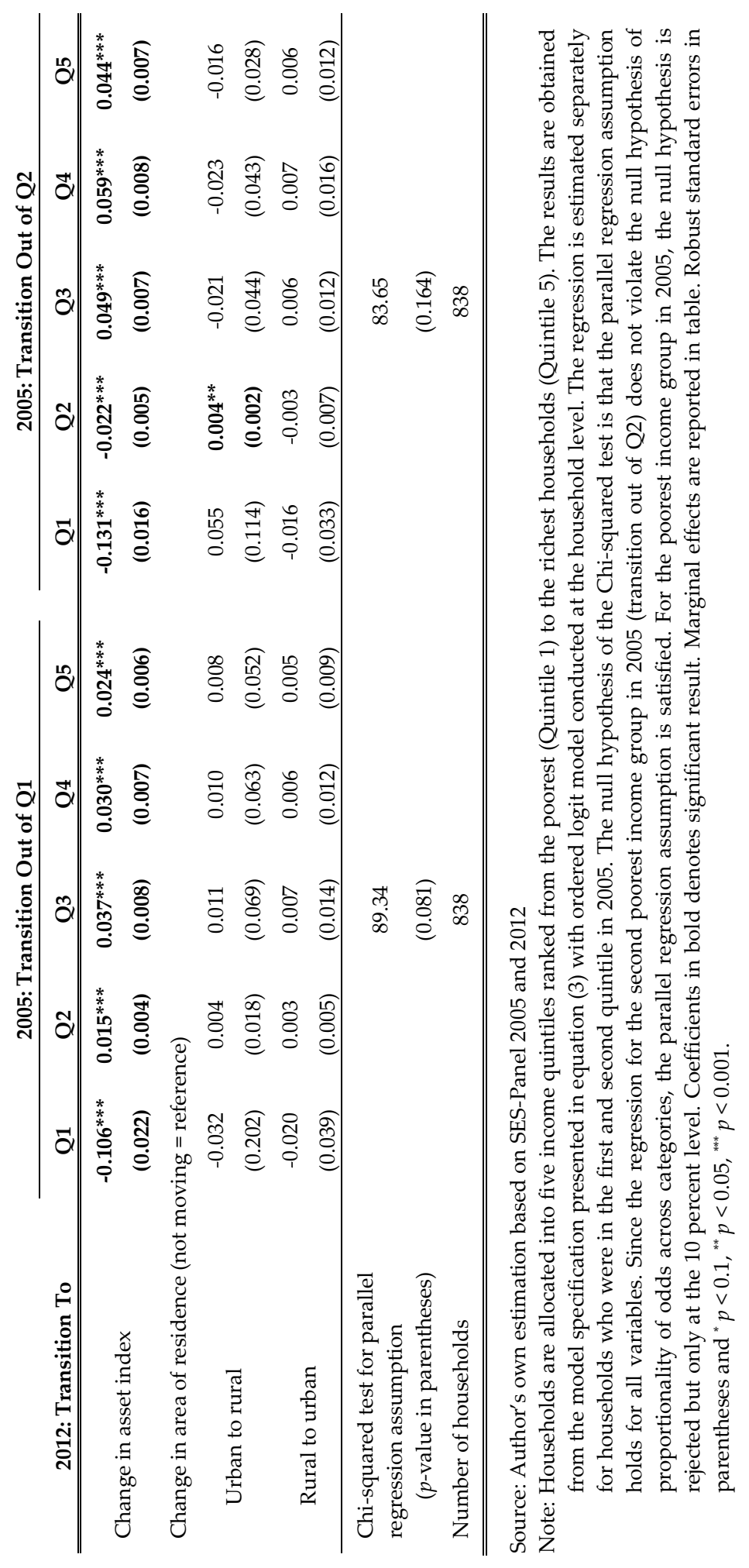


With respect to physical capital variables, the asset index and change in the index are positively correlated with income rank change, as expected. A household owning productive durables has higher chance to move upward to higher income ranks and downward otherwise. The result is highly significant at the one percent level. Interestingly, incurring a debt is positively correlated with the transition out of the poorest quintile to higher income quintiles. Considering that the poorest households are normally subject to credit constraints, having a debt may indicate that households have access to credit allowing them to invest in productive durables, conduct income-generating activities and thus move to higher income positions. The inverse relationship of debt and relative income mobility is found for the transition out of the second quintile. However, the result is not consistent among each response category and only significant at the 10 percent level

The proportional odds assumption, also known as the parallel regression assumption, is the key assumption underlying the ordered logit model. The assumption requires that the relationship between dependent and independent variable does not vary with different response categories. As shown by the Chi-squared statistics result presented in Table 2.5, the regression for the households moving from the second poorest quintile does not violate the null hypothesis of proportionality of odds across categories. The proportional odds assumption for all variables in this estimation is thus satisfied. For households moving from the poorest quintile, the null hypothesis is rejected but only at the 10 percent level. According to Kim (2003), the proportional odds assumption is strong and the rejection of the null is not informative. Therefore, violation of the proportional odds assumption does not always mean that the results obtained from the ordered logit model are invalid. To further verify the results, the binary logit model for each response category is conducted. It is found that the results from the two methods, ordered logit model and binary logit model, are nearly identical.

\subsubsection{Equilibrium Impact of Key Drivers}

According to the results, share of earners, asset index and change in these two factors play the most crucial role in driving Thailand's income mobility, both in absolute and relative terms, during the period 2005 to 2012. As long-term income mobility has led to a decrease in long-term inequality (Khor \& Pencavel, 2008), it is interesting to examine the impact of these two key factors beyond the seven years horizon. This section seeks to evaluate the long-run equilibrium impact of share of earners and productive asset index on income mobility using 
the Error Correction Model (ECM) as a framework of estimation. Following the ECM developed by Davidson, Hendry, Srba and Yeo (1978); and Engle and Granger (1987), the long-run equilibrium impact can be derived as follows

$$
\begin{gathered}
\ln y_{t}=\gamma_{1} \ln y_{t-1}+\theta_{0} X_{t}+\theta_{1} X_{t-1}+\varepsilon_{t} \\
\ln y_{t}-\ln y_{t-1}=\gamma_{1} \ln y_{t-1}-\ln y_{t-1}+\theta_{0} X_{t}+\theta_{1} X_{t-1}+\varepsilon_{t}+\theta_{0} X_{t-1}-\theta_{0} X_{t-1} \\
\ln \left(\frac{y_{t}}{y_{t-1}}\right)=\left(\gamma_{1}-1\right) \ln y_{t-1}+\theta_{0} \Delta X+\left(\theta_{0}+\theta_{1}\right) X_{t-1}+\varepsilon_{t}
\end{gathered}
$$

As can be noted, equation (6) conforms to the model specification used to identify drivers of income mobility presented in equation (3) where $\mathrm{X}$ includes human capital variable $(H)$, physical capital variable $(K)$ and other characteristics reflecting environment in which the household operates $(R)$. Equation (6) can be rewritten as

$$
\Delta \ln y=\theta_{0} \Delta X+\left(\gamma_{1}-1\right)\left[\ln y_{t-1}-\frac{\left(\theta_{0}+\theta_{1}\right)}{\left(1-\gamma_{1}\right)} X_{t-1}\right]+\varepsilon_{t}
$$

At the equilibrium, change in income $(\Delta \ln y)$ and change in factors driving mobility $(\Delta X)$ is equal to zero. Therefore, the long-run equilibrium relationship between income mobility and factors fostering mobility is determined by the term $\frac{\left(\theta_{0}+\theta_{1}\right)}{\left(1-\gamma_{1}\right)}$.

Table 2.6 Long-Run Equilibrium Impact of Key Drivers

\begin{tabular}{lllll} 
& \multicolumn{2}{c}{ OLS } & \multicolumn{2}{c}{ IV } \\
\cline { 2 - 5 } & Coefficient & Standard Error & Coefficient & Standard Error \\
\hline \hline Share of earners & $\mathbf{1 . 0 0 6 ^ { * * * }}$ & 0.095 & $\mathbf{1 . 1 0 4 ^ { * * * }}$ & 0.134 \\
Asset index & $\mathbf{0 . 3 2 2 ^ { * * * }}$ & 0.017 & $\mathbf{0 . 3 0 5 ^ { * * * }}$ & 0.023 \\
\hline Number of Households & $\mathbf{4 , 1 9 3}$ & & $\mathbf{4 , 1 9 3}$ & \\
\hline \hline
\end{tabular}

Source: Author's own estimation based SES-Panel 2005 and 2012

Notes: The results are obtained from the term $\frac{\left(\theta_{0}+\theta_{1}\right)}{\left(1-\gamma_{1}\right)}$ in equation $(7)$ and the value of $\left(\theta_{0}+\theta_{1}\right)$ and $\left(1-\gamma_{1}\right)$ are obtained from the regression used to identify drivers of absolute income mobility presented in equation (3). Coefficients in bold denotes significant result. Robust standard errors are reported and ${ }^{*} p<0.1{ }^{* *} p<0.05,{ }^{* * *} p<0.001$.

Table 2.6 presents the long-term equilibrium correlation of absolute income mobility and two key drivers including share of earners and asset index. As reported in the table, the long-run equilibrium impacts of both factors are highly significant. Moreover, the size of the impact is higher compared to the impact obtained from the period of seven years. The long- 
term equilibrium results highlight the importance of share of earners and asset index in fostering income mobility of households over time.

\subsection{Conclusion and Policy Implications}

Despite the remarkable success in poverty reduction, income inequality has remained a big challenge in Thailand. Existing evidence for the use of policy decisions is mostly based on cross-sectional data which can only portray the static information of inequality at best and thus fail to fully reflect the evolution of Thailand's inequality. This chapter complements the cross-sectional approach of income inequality by analyzing inequality through the longitudinal lens, using the nationally representative household panel survey data to examine the extent and the factors of income mobility.

The results from the FO index suggest that the degree of absolute income mobility in Thailand is high by international standards. However, when the direction of income mobility is taken into account, Thailand is among the most immobile countries. Absolute income mobility is mainly driven by the redistribution of already existing wealth from losers to gainers. The results from absolute income mobility suggest that poor households experience positive income change and thus be the gainers in this redistribution. However, the results from relative income mobility shows that the poorest 20 percent households still have limited opportunities to climb up the ladder to higher income positions due to the large income gap between each income rank. It is found that more than 60 percent of households beginning with the lowest income rank is found to be trapped in the same position or can only move to the second poorest income position at best.

These results necessitate the creation of a facilitating environment in which upward income mobility remains attainable especially for the poor and disadvantaged households. In other words, factors associated with upward mobility need to be strengthened. The analyses of the drivers of absolute and relative household income mobility suggest that share of earners and productive assets are the two most important factors that could level the playing field. This finding is consistent with the theories and empirical findings on mobility discussed in Section 1.3 that the extent of economic mobility relies considerably on human capital and physical capital accumulations.

The first factor, share of earners, is found to be the most influential determinant of both upward income change and rank change. Having members working and earning increases income of a household and the probability for the household to move up to the higher 
income positions. Hence, policies to foster income mobility need to target their effort on improving the ability to participate in labor market and generate higher income. Among the policies that can be implemented to tackle this problem, vocational training program which aims to improve job skills, productivity and employability of participants and hence increase household's share of earners, has been the most common active labor market interventions for the government in many countries including Thailand (McKenzie, 2017). However, despite having been in operation for decades, the extent to which Thailand's vocational training program could help promote advancement of participants remains unknown. Chapter 3 seeks to give answers to this question by examining the impact of vocational training program on absolute and relative income mobility.

Another important factor in explaining absolute and relative income mobility is the asset index.Productive assets facilitate the initiatives and expansions of income-generating activities. This in turn fosters upward income mobility of households. Moreover, there is evidence that incurring a debt and working as an entrepreneur, either self-employed or employer, is one of the pathways for the poorest households to climb up the ladder to higher income ranks. These findings can be translated into numerous policy options, one of which is microcredit program. Microcredit has become the most popular instrument to relieve credit constraint, promote investment and enhance development outcomes of participants during the past decades. In Thailand, the Village Fund is the single largest microcredit program which has been the most important source of credit for low-income households (Haughton, Khandker, \& Rukumnuaykit, 2014). The program is initiated and initially funded by the government with an attempt to provide access to credit and promote income-generating activities especially among the poor households. The performance of Thailand's Village Fund, which is expected to facilitate investment in productive asset, business creation, business expansion and thus upward economic mobility, is evaluated in Chapter 4.

It is important to be noted that the analyses presented in this chapter are subject to some limitations and need to be considered with cautions. As discussed earlier, the SES-Panel used in this study suffers from substantial attrition. The problem of attrition bias is already addressed by the inverse probability weight which is a common method used to handle longitudinal analyses. It is found that the results are robust to the inverse probability weight as nearly similar findings are obtained when the analyses are conducted with and without including this weight. However, it might be the case that attrition is linked to job opportunities and economic mobility in a way that cannot be captured by the current 
method. This caveat needs to be taken into consideration when interpreting the results. Moreover, the results derived from the analyses of determinants of income mobility conducted in this chapter imply the association rather than the causation. Therefore, the results may not be sufficiently convincing to use as a basis for explicit policy recommendations.

Despite all these limitations, the results presented in this chapter provide fertile ground for potential interventions that can increase mobility prospects. The main contribution of this chapter is to set the stage by providing the overview picture of income mobility and credible evidence of factors associated with mobility. The next chapters will zoom in on the effectiveness of program interventions that aim to directly strengthen key drivers of income mobility identified in this chapter. 


\section{References}

Alvaredo, F., Chancel, L., Piketty, T., Saez, E., \& Zucman, G. (2017). The Elephant Curve of Global Inequality and Growth. AEA Papers and Proceedings, 108. https://doi.org/10.1257/pandp.20181073

Aristei, D., \& Perugini, C. (2015). The drivers of income mobility in Europe. Economic Systems, 39(2), 197-224. https://doi.org/10.1016/j.ecosys.2014.06.007

Ayala, L., \& Sastre, M. (2008). The structure of income mobility: empirical evidence from five UE countries. Empirical Economics, 35(3), 451-473. https://doi.org/10.1007/s00181-007-0172-z

Baulch, B., \& Quisumbing, A. R. (2011). Testing and Adjusting for Attrition in Household Panel Data [CPRC Toolkit Note]. Chronic Poverty Research Centre.

Brand-Weiner, I., \& Francavilla, F. (2015). Income mobility in times of economic growth: The case of Vietnam. OECD Working Paper No.328. Retrieved from http://www.oecdilibrary.org/development/income-mobility-in-times-of-economicgrowth_5jrp0hz8thjl-en

Bureau of Trade and Economic Indices, Ministry of Commerce. (2018). Thailand Consumer Price Index. Retrieved from http://www.price.moc.go.th/price/cpi/index_new_all.asp

Chawanote, C., \& Barrett, C. B. (2014). Farm and Non-farm Occupational and Earnings Dynamics in Rural Thailand. Charles H. Dyson School of Applied Economics and Management, Cornell University Working Paper.

Cherdchuchai, S., \& Otsuka, K. (2006). Rural income dynamics and poverty reduction in Thai villages from 1987 to 2004. Agricultural Economics, 35(s3), 409-423. https://doi.org/10.1111/j.1574-0862.2006.00187.x

Chetty, R., Friedman, J. N., Hendren, N., Jones, M. R., \& Porter, S. (2018). The Opportunity Atlas: Mapping the Childhood Roots of Social Mobility. U.S. Census Bureau.

Credit Suisse. (2017). Global Wealth Databook 2017. Retrieved from Credit Suisse Research Institute website: file:///Users/PatimaChong/Downloads/global-wealthdatabook.pdf

Davidson, J. E. H., Hendry, D. F., Srba, F., \& Yeo, S. (1978). Econometric modelling of the aggregate time-series relationship between consumers' expenditure and income in the United Kingdom. The Economic Journal, 88(352), 661-692.

Edin, K., \& Kefalas, M. (2011). Promises I can keep: Why poor women put motherhood before marriage. University of California Press.

Engle, R. F., \& Granger, C. W. J. (1987). Co-integration and error-correction: Representation, estimation, and testing. Econometrica, 55(2), 251-276. 
Fields, G., Cichello, P. L., Freije, S., Menendez, M., \& Newhouse, D. (2002). For Richer or For Poorer? Evidence from Indonesia, South Africa, Spain and Venezuela. Cornell University ILR School Working Paper.

Fields, G. S., Cichello, P. L., Freije, S., Menendez, M., \& Newhouse, D. (2003). Household Income Dynamics: A Four-Country Story. The Journal of Development Studies, 40(2), 30-54. https://doi.org/10.1080/00220380412331293757

Fields, G. S., Hernández, R. D., Freije, S., \& Puerta, M. L. S. (2007). Intragenerational income mobility in Latin America. Economía, 7(2), 101-154.

Fields, G. S., \& Ok, E. A. (1999). Measuring Movement of Incomes. Economica, 66(264), 455471. https://doi.org/10.1111/1468-0335.00183

Fry, K., Firestone, R., \& Chakraborty, N. (2014). Measuring Equity with Nationally Representative Wealth Quintiles. Washington, DC: PSI.

Hagenaars, A., de Vos, K., \& Zaidi, A. (1994). Poverty Statistics in the Late 1980s: Research Based on Micro-data. Office for Official Publications of the European Communities. Luxembourg.

Haughton, J., Khandker, S. R., \& Rukumnuaykit, P. (2014). Microcredit on a Large Scale: Appraising the Thailand Village Fund: Appraising the Thailand Village Fund. Asian Economic Journal, 28(4), 363-388. https://doi.org/10.1111/asej.12041

Jinqi, J., Guang-Sheng, Z., \& Qiang, L. (2009). The Income Mobility in Rural China: Measurement and Decomposition. SSRN Electronic Journal. https://doi.org/10.2139/ssrn.1645842

Jitsuchon, S., Plangpraphan, J., \& Kakwani, N. (2006). Thailand's New Official Poverty Line. Thailand Development Research Institute.

Khor, N., \& Pencavel, J. (2008). Measuring Income Mobility, Income Inequality, and Social Welfare for Households of the People's Republic of China. ADB Economics Working Paper Series, 47.

Kim, J.-H. (2003). Assessing practical significance of the proportional odds assumption. Statistics \& Probability Letters, 65(3), 233-239. https://doi.org/10.1016/j.spl.2003.07.017

Lowhachai, S. (2018). The National Transfer Accounts 2013 (in Thai). Bangkok, Thailand: National Economics and Social Development Board, Office of the Prime Minister.

McKenzie, D. (2017). How Effective Are Active Labor Market Policies in Developing Countries? A Critical Review of Recent Evidence. Policy Research Working Paper, (WPS8011), 32.

National Economic and Social Development Board, Office of the Prime Minister. (2018). Thailand's Poverty and Inequality Report 2017 (in Thai). Bangkok, Thailand.

OECD. (2009). What Are Equivalence Scales. Retrieved from http://www.oecd.org/els/soc/OECD-Note-EquivalenceScales.pdf 
Rama, M., Beteille, T., Li, Y., Mitra, P., \& Newman, J. L. (2015). Addressing Inequality in South Asia. Retrieved from The World Bank website:

https://openknowledge.worldbank.org/handle/10986/20395

Ravallion, M., \& Chen, S. (2003). Measuring pro-poor growth. Economics Letters, 7.

Sakondhavat, A. (2013). Understanding poverty dynamics using a mixed-method study: evidence from the rural village in the northeast and central regions of Thailand (University of Sussex). Retrieved from http://sro.sussex.ac.uk/46488/

Urzainqui, D. G. (2017). Poverty Transitions Without Panel Data? An Appraisal of Synthetic Panel Methods. Presented at the Seventh ECINEQ Meeting, New York. Retrieved from http://www.ecineq.org/ecineq_nyc17/FILESx2017/CR2/p447.pdf

Warr, P. G. (1999). What Happened to Thailand? The World Economy, 22(5), 631-650. https://doi.org/10.1111/1467-9701.00222

Weber, B., Fannin, J. M., Miller, K., \& Goetz, S. (2018). Intergenerational mobility of lowincome youth in metropolitan and non-metropolitan America: A spatial analysis. Regional Science Policy and Practice, 10(2), 87-101.

Woolard, I., \& Klasen, S. (2005). Determinants of Income Mobility and Household Poverty Dynamics in South Africa. Journal of Development Studies, 41(5), 865-897. https://doi.org/10.1080/00220380500145313

World Bank. (2017a). GDP growth (annual \%). Retrieved from https://data.worldbank.org/indicator/NY.GDP.MKTP.KD.ZG?locations=TH

World Bank. (2017b). GDP per capita (current US\$). Retrieved from https://data.worldbank.org/indicator/NY.GDP.PCAP.CD?locations=TH

World Bank. (2017c). Poverty headcount ratio at $\$ 1.90$ a day (2011 PPP) (\% of population). Retrieved from https://data.worldbank.org/indicator/SI.POV.DDAY?locations=TH 


\section{Chapter 3}

Vocational Training and Upward Mobility:

Impact Heterogeneities and Policy Implications 


\subsection{Introduction}

The insufficient development of human capital has been described as one of the critical constraints to the prospect for upward mobility (Woolard \& Klasen, 2005). Among various policy options, vocational training is the obvious policy response to address this limitation. In this thesis, vocational training refers to training to prepare a person to work in a job that requires a particular set of skills. It is held outside of the regular schooling system and excludes apprenticeships and staff trainings by firms. Vocational training, which aims to impart skills and enable participants to be more productive, has long been the common policy expected to augment human capital and move people upward.

However, the empirical evidence regarding the effectiveness of vocational training has been inconclusive as there is a substantial variation in training impact depending on characteristics of programs and participants (Borkum et al., 2015; Maitra \& Mani, 2013). An insight into impact heterogeneity is thus crucial to improve the effectiveness of training programs. Nevertheless, most of the studies to date have simply focused on the overall impact of a particular program. The most important questions, for whom the training works best and which type of training are the most effective, have rarely been answered. Therefore, the existing body of literature is not informative for policy design. Moreover, the econometric evaluation of training programs has been mostly derived from advanced economies. The evidence from developing countries remains relatively smaller. On top of that, the existing literature from developing countries hardly captures changes that take place in the informal sector. Hence, the results do not represent the real impact of training programs in developing economies.

The objective of this chapter is to fill these knowledge gaps by using a large-scale vocational training program in Thailand as a case study. Although vocational training has been provided to Thai workers for decades, studies on vocational training in Thailand have been simply institutional assessments or program monitoring report. No rigorous impact evaluation has been conducted. In this chapter, the impact of training on economic and social mobility is examined by both exogenous and endogenous treatment effect approaches. With regard to economic mobility, in addition to the impact on income, this chapter also considers the impact on wage which is quite common in previous training evaluations and household expenditures which may better reflect changes in individual's living standards. Moreover, this chapter breaks new ground by not only looking at absolute but also relative changes, which are measured by the change of position in the earnings and 
expenditure distribution. This approach is justified by the fact that people tend to assess their living conditions by comparing themselves to others and develop their preference based on what others have and want (Pavlopoulos, 2007, p. 16). Therefore, absolute measurements may be insufficient to portray the improvement of individuals. To the best of my knowledge, examining the impact of training participation on relative mobility has never been done before. Last but not least, the heterogeneity of impact with respect to participants and programs characteristics is discovered. The results provide a better understanding of which component is associated with greater success and hence can be used as a policy guideline to improve the effectiveness of human capital development by means of vocational training program.

The data set used in this chapter is drawn from the Thailand Socio-economic Panel Survey (SES-Panel) which, to my knowledge, has never been used in any impact evaluation studies. This panel data set covers seven years and contains rich information of training and individuals' socioeconomic characteristics and thus allows for the evaluation of training impact as well as its heterogeneity in the short term, medium term and long term, and capture changes that occurred in both formal and informal sector. The remainder of the chapter is structured as follows. Section 3.2 summarizes previous findings of the impact of vocational training in both developed and developing countries. Section 3.3 outlines Thailand's context and detail of vocational training in Thailand. Section 3.4 describes data and methodology used in this study. Section 3.5 presents the results of the empirical analysis. The last section (section 3.6) concludes the results and discusses the policy implications.

\subsection{Evidence on Vocational Training}

\subsubsection{Overall Effects of Training}

During the past decades, many evaluation studies of vocational training have been carried out. Most of these evaluations have been concentrated in developed nations (Cho et al., 2015; Hirshleifer et al., 2015), both in USA and Europe. Many studies claim that training programs in these countries, on average, have a positive but small impact on labor market outcomes in the short term but the long-term impact has been inconclusive. Kluve (2010) observes that 38 out of 70 training evaluations in Europe report a small but significant shortterm positive impact on employment. Heckman et al. (1999) in reviewing evaluations of training programs in North American and European countries conclude that training 
programs have a moderate positive impact on participants' earnings, at best, but the impact is likely to dissipate in the long term. In contrast, Card et al. (2010), based on a metaanalysis, conclude that training programs are likely to have a positive impact on earnings and employment in the medium and long term.

However, the results from developed countries may not be applicable in the context of developing countries due to the larger informal sector, greater skill gap, and weaker administrative capacity to implement the training programs (Betcherman, Dar, \& Olivas, 2004). In comparison to the evidence from developed countries, very little literature is available from the developing world, most of it comes from Latin America and the Caribbean (LAC) (Puerta, 2010). Ibarraran and Rosas Shady (2008) review evaluation studies of training programs in seven Latin American countries. They conclude that, on average, the impact of training programs in LAC is slightly larger than the results discovered in developed countries. Recent studies from LAC have also tried to address the long-term impact of training which has been a crucial gap in the literature. Attanasio et al. (2015) merge experimental data with administrative information to examine the longer-term impact of the Columbian training program. They found that after ten years, the impact of training on earnings and probability to work in the formal sector remained positive and significant. Another evaluation study by Ibarraran et al. (2015) claims that despite the disappointing impact on labor earnings and quantity of employment, the training program in the Dominican Republic is found to increase the quality of employment, measured as the probability of being a formal employee, in the long run. Although evaluation studies from LAC give an insight into training impacts in the context of developing countries, most of the LAC programs target the youth, and not the general working-age population.

Maitra and Mani (2013), instead of looking at youth, evaluate the impact of the training program for women living in poor neighborhoods in India. They conclude that participants are likely to work more and earn more relative to their non-participant counterparts. These positive effects are realized in both short term ( 6 months after the program) and medium term (18 months after the training). Hirshleifer et al. (2015) attempt to examine the result of vocational training beyond the medium term by examining the impact of Turkey's training program on the unemployed population in general and uncover changes up to three years after the program. After merging experimental data with social security records, they find no statistically significant impact of training on earnings and employment. The impact on formality of employment is positive and significant but disappears within three years. Although this study sheds further light on the long-term impact of vocational training in 
developing country, the social security data they used does not capture changes that occurred in the informal sector. It might be the case that earnings actually increased but participants remained in the informal sector in which the data was not recorded. Therefore, the results may not represent the real impact of training in developing economies.

\subsubsection{Training Effects for Specific Groups}

The existing evidence shows that the impact of vocational training varies from program to program. The main general conclusion emerging from the overall result is that the effectiveness of the program depends considerably on characteristics of participants and types of training (see e.g. Heckman et al., 1999; Ibarraran \& Rosas Shady, 2008). However, little evidence exists on what specific features drive such heterogeneous results (Betcherman et al., 2004; Maitra \& Mani, 2013; McEntaffer, 2015). ${ }^{6}$ Heterogeneity of effect by gender, among several individual characteristics, has received most attention. Many studies conclude that female participants, on average, do better than males especially in the long run (Greenberg et al., 2003; McEntaffer, 2015; Osikominu, 2013). Osikominu (2013) examines heterogeneity of training impact by pre-specified skill and education. He finds that participants with higher occupational skill and degree of education gain less in terms of earnings but more in terms of employment. By contrast, Hirshleifer et al. (2015) do not observe any variation of impacts with respect to gender, age, cognitive ability, education and personality traits (measured by work centrality and tenacity).

The existing evidence is much more scarce regarding heterogeneity due to program characteristics. Greenberg et al., (2003) by means of a meta-analysis, found no significant variation of impact by program cost, implying that more expensive training does not guarantee better outcome. Hirshleifer et al. (2015) observe only limited and non-robust heterogeneity by course length and quality of teacher. Strong heterogeneity is only found by type of provider. Training programs tend to have more impact when they are provided by private provider, but this distinction is significant only in the short run.

\footnotetext{
${ }^{6}$ Some studies also try to provide evidence regarding the impact heterogeneity by means of a metaanalysis but their findings are based on Active Labor Market Policies as a whole, not only vocational training (see e.g. Card, Kluve, \& Weber, 2015; Crépon \& van den Berg, 2016).
} 


\subsection{Thailand's Context and Vocational Training Programs}

Thailand is a middle income country with a poverty rate of 7.9 percent and a Gini coefficient, measuring the level of income inequality, of 0.45 in 2017 (National Economic and Social Development Board [NESDB], 2018). In the same year, out of 56 million people aged 15 years or older, around 38 million are in the labor market. In other words, the labor force participation rate is around 68 percent (NESDB, 2017). The unemployment rate has been very low at about one percent over the last decade (National Statistical Office [NSO], 2017b). However, like many other developing countries, the quality of employment has long been a critical issue. Thailand has a large informal economy and more than half of employment takes place in the informal sector. In 2016, around 55.6 percent of Thai workers are informal with uncertain earnings and no protection from social security (NSO, 2016).

Moreover, Thailand also faces the challenge of an ageing workforce as more than 50 percent of Thai workers are older than 40 years (NESDB, 2017b). The working age population is expected to decrease rapidly by 2040, and at a faster pace than in other developing countries in East Asia and Pacific (World Bank, 2016). Furthermore, the average salary of workers in Thailand is low and the decrease in labor supply, due to factors such as an ageing population, does not seem to result in higher salary. In addition to the institutional factors that have contributed to this wage rigidity, the low quality of labor supply is also to be mentioned. In 2017, around 60 percent of Thai workers have education only at lower secondary level or below (NSO, 2017a). Therefore, an investment in human capital aiming to increase workers' skills, productivity and thus earnings level has been the priority for the Thai government.

Although Thailand has managed to achieve most of the Millennium Development Goals on gender equality in 2015 (NESDB, 2015), the Thai labor market is not that friendly for women. As of April 2018, around 60 percent of women of working age participate in the labor force, compared to 77 percent of male labor force participation (NSO, 2018). Although the wage gap between male and female workers has narrowed over the past decades due to an improvement in skills and education of female workers, the gender wage gap remains large when informal and self-employed workers are taken into account (Warunsiri Paweenawat, Vechbanyongratana, \& Yoon, 2017). The discrimination against women in a number of industries also resulted in a lower wage of female workers compared to their male counterparts (Bui \& Permpoonwiwat, 2015). 
The Department of Skill Development (DSD), under the Ministry of Labour, is the main agency delivering the public vocational training program for the population in Thailand since around 1953. Its objectives are to improve human capital, increase individual welfare and address structural skill mismatches in the labor market. DSD provides services through its 12 regional and 68 provincial training centers across the country. The training program comprises pre-employment training, upgrade training and retraining, aiming to increase earnings and employability of participants. The duration of training varies from course to course, ranging from six hours to longer than two months. The training courses offered cover a wide range of skills and occupations such as computer, electronics, constructions, craft production and cooking. These courses are mostly delivered in the classroom setting. Some courses also offer a brief on-the-job training after classroom training. Target participants are those with low socioeconomic status such as informal labor, elderly and low income workers. However, the participation in a training program is entirely voluntary. Between 2009 and 2013, the average number of participants was around 300,000 per year with dropout around two percent (DSD, 2016).

In addition to the DSD, many other government agencies also offer programs related to vocational training. For example, the Ministry of Agriculture and Cooperatives provides agricultural and fishery training to farmers nation-wide. Local administrative units also provide skills training to their residents that fit the local context and community needs. Most of the programs are free of charge and some are partly subsidized by the government. Although the government has been a major provider of vocational training courses, it has encouraged private institutions to participate in skills training provision through various measures. For example, there are a number of public-private partnership projects that provide training to the unemployed, laid off workers and new graduates (Smiti, 2009). Moreover, the government also offers low-cost credit from which poor and unemployed workers can borrow to finance their vocational training programs offered by private providers (Jitsuchon et al., 2009).

\subsection{Data and Methods}

\subsubsection{Data}

In order to examine the impact of training and its heterogeneity, this chapter requires a data set that contains information of training participants (and non-participants) such as income, age, gender, education and employment status; and details of the training such as course 
content, course length and course provider. Moreover, as the outcome of interest is mobility, the data set needs to be longitudinal. The Thailand Socio-Economic Panel Survey (SESPanel) is a nationally representative longitudinal survey conducted by the National Statistical Office (NSO). The data set comprises five waves, of which the first one was conducted in 2005. The survey in 2005 contains some questions in which the interviewers asked respondents to recall their information up to 12 months prior to the interview. For example, respondents were asked "Have you ever attended a training program during the last 12 months?". Therefore, the survey in 2005 also contains information about the situation in 2004. This is also the case for the follow up surveys which were conducted in 2006, 2007, 2010 and $2012 .^{7}$

In this analysis, training participation in 2006 is used as the treatment variable, and 2005 is used as the baseline. Changes that occurred from 2005 to 2006, or within a year after the training, are perceived as a short-term effect. A change from 2005 to 2007 or between 1-2 years post-training is a medium-term effect. Lastly, changes that occurred between 2005 and 2010 (4-5 years after training) and 2005 and 2012 (6-7 years after training) are considered as long-term impacts. The first survey in 2005 covered 6,000 households or 21,450 individuals from both rural and urban areas in all regions: Bangkok Metropolitan, Central, North, Northeast, and South. The attrition rate of surveyed individuals during 2005 to 2012 is 27.7 percent which is comparable to other surveys used in training evaluations in developing countries such as the Dominican Republic (38 percent) and Malawi (46 percent) (as cited in Hirshleifer et al., 2015, p. 8). The potential problem of attrition bias is addressed by including the inverse probability weight, which assigns more weight to individuals having similar characteristics to individuals which are subsequently drop off, in all estimations.

The data is trimmed by excluding all individuals below the age of 15 years because the analyses focus on work-related issues and any worker aged less than 15 is perceived as an illegal child laborer in Thailand. People who participated in training in 2005 are dropped from the analysis so that 2005 can be used as the pre-treatment period (baseline). Moreover, those from the control group attending trainings after 2006 are also excluded so that the analyses can make the causal inference about the effect of training in 2006 which is used as the treatment variable. The information on training status in the SES-Panel is not available in 2010 and 2012. Hence, only the members of the control group that became treated in 2007

\footnotetext{
7 The retrospective questions are applied in section 3 (household agricultural income) of the householdlevel record; and section 1 (training experience), section 2 (health and healthcare services), section 3 (employment), section 4 (income), section 5 (saving, expenditure, debt) and section 6 (migration) of the individual-level record.
} 
are dropped. It is acknowledged that this choice of sample selection may also bias the results. However, the number of individuals participating in training in 2007 (but not before) is only 56 or approximately 0.6 percent of the total observations in control group. Therefore, this study argues that the bias from dropping these 56 individuals should be minimal. After excluding all these observations, the panel is then balanced by keeping only observations that can be observed in all five waves. The final balanced sample size consists of 10,485 individuals per wave of which 406 observations are treated and 10,079 observations are non-treated.

Table 3.1 provides summary statistics of the trimmed and balanced panel data set classified by training participation. As can be seen from the "unmatched observations" column, individuals from treatment and control group are statistically highly different in several aspects such as age, rural/urban setting, education, labor force status, wage, expenditure and labor mobility. Training participants appear to be better off than their non-participants counterparts in all outcomes being considered. For example, the average wage of nonparticipants is less than half of their participant counterparts. However, as training participation is voluntary, the differences might be due to the unobserved factors such as motivation and talents. Therefore, rigorous econometric methods are required in order to spell out the impact of the training program.

\subsubsection{Defining and Measuring Upward Mobility}

As described in Chapter 1, mobility studies are concerned with quantifying the movement of individuals or households' socioeconomic status between two or more points in time. The analyses can take place either in inter- or intragenerational contexts, however, due to data availability, this chapter focuses on intragenerational mobility. Research on mobility has centered on income, also known as economic mobility and labor market status, also known as social mobility (see e.g. Fields, 2006; Fields et al., 2003; Rama et al., 2015). Concerning economic mobility, outcomes of interest used in this chapter include both absolute income mobility, measured by directional movement or income level per capita in natural logarithms, and relative income mobility, measured by positional movement or changes in income ranking. ${ }^{8}$ In short, an individual is moving upward if he/she achieves a higher income or moves to a higher income rank in a subsequent period.

\footnotetext{
${ }^{8}$ According to Fields' definition (2006), directional movement examines the direction and magnitude of income changes between two periods. Positional movement measures changes of the position in the income distribution.
} 


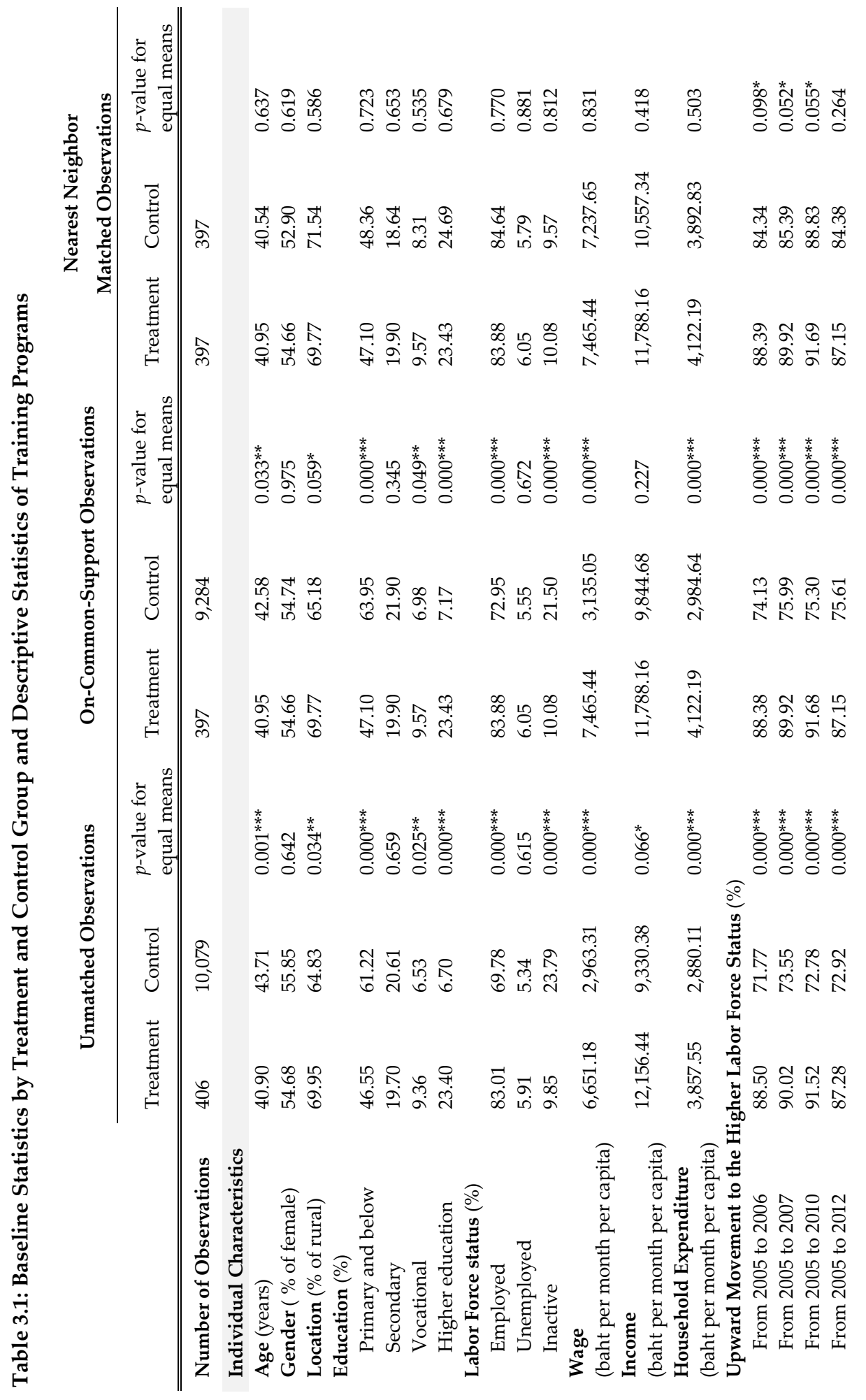




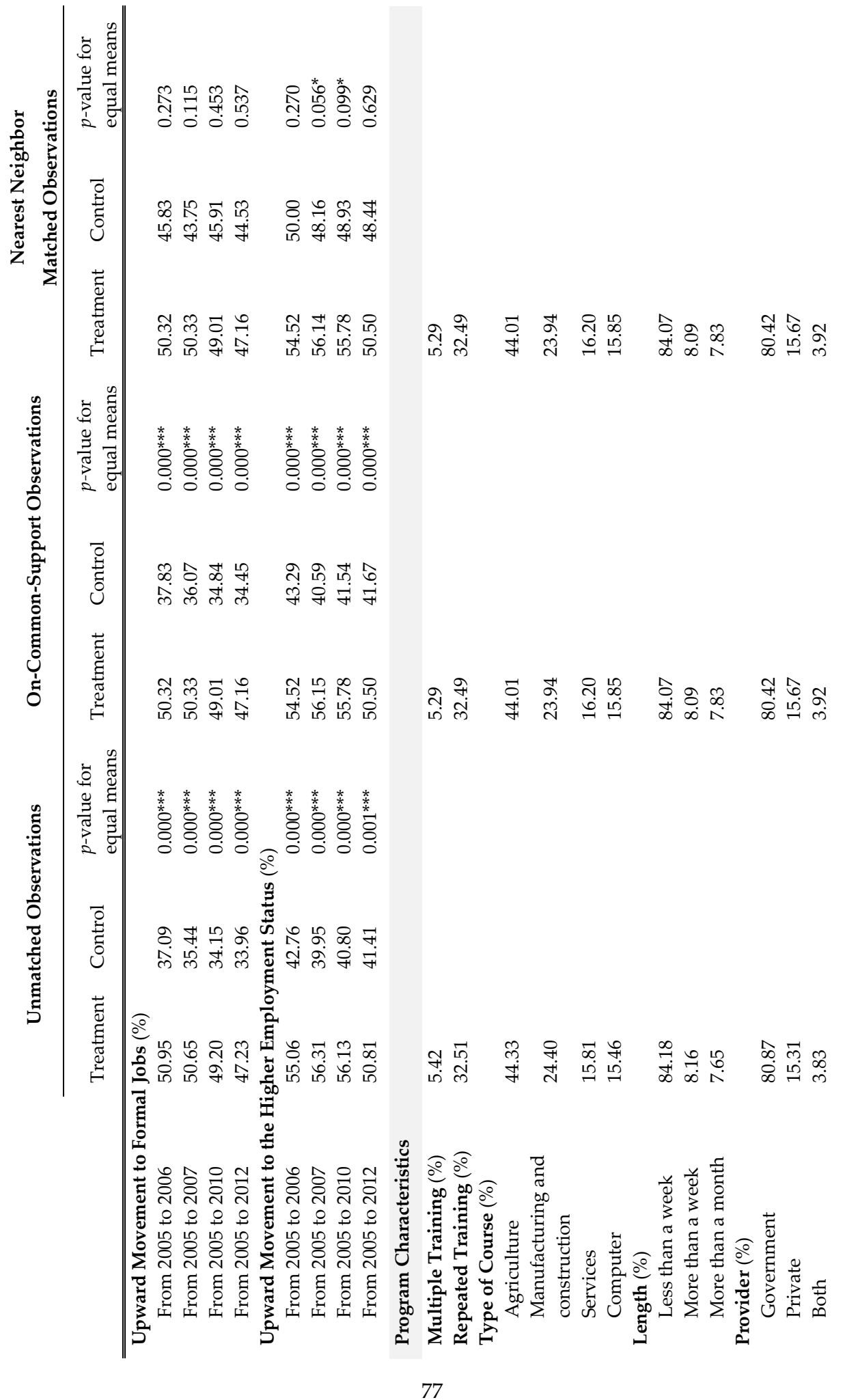




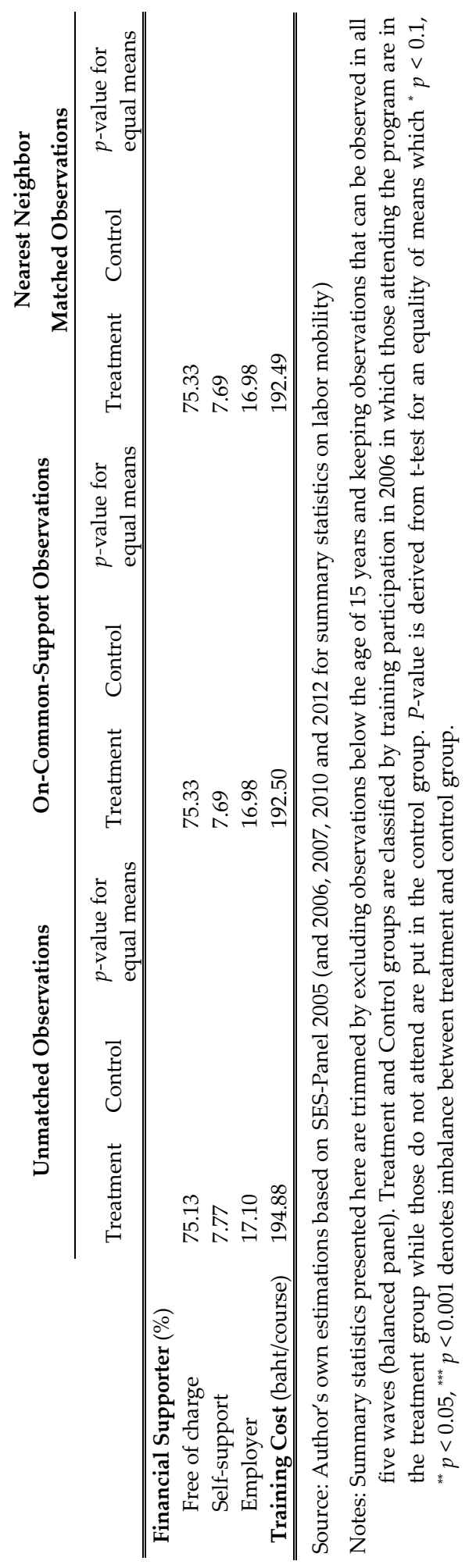


In addition to income mobility, this chapter also includes wage mobility and expenditure mobility in the evaluation. Wage refers exclusively to return from wage employment while income is the total of all returns from working including wage, agricultural income and business income for each individual. Household expenditures per capita include all living expenses such as food, housing, clothing and transportation divided by household size. Expenditure mobility can directly reflect changes in an individual's living standard.

Regarding labor mobility, most studies use the transition between labor market states such as inactivity, unemployment, self-employment, informal employment and formal employment to compute mobility across various positions (e.g. Tansel \& Kan, 2011; Verme et al., 2014). In this chapter, three indicators are used to reflect upward labor mobility. The first indicator is an improvement in labor force status which is categorized, in an ascending order, as inactivity, unemployment and employment. The second indicator is a transition to formal employment which measures the prospect of upward movement from being informally employed to a formal employee. The final indicator is an improvement in employment status which is categorized, in an ascending order, as unpaid family worker, informal self-employed/informal employee, formal self-employed/formal employee and employer. While the first indicator indicates the impact of training on employment prospects or the quantity of employment, the other two indicators are used to track changes in terms of quality of employment which is also a major problem of labor markets in developing countries.

\subsubsection{Estimation Methodology}

This section describes the econometric models used to identify the treatment effect and its heterogeneity. Due to the fact that vocational training in Thailand is offered to the general working-age population and participation is on a voluntary basis, a problem of selection bias is likely to occur. As anticipated, the summary statistics in Table 3.1 show that a person with higher socioeconomic status is more likely to attend the training. The treatment group has higher levels of education, tends to be more employed and has higher wage, income and expenditure. Rigorous econometric methods for impact evaluation are thus necessary to address this potential problem of selection bias.

This chapter employs two different methods to examine the aggregate impact of vocational training on upward mobility, i.e. difference in difference (DD) and endogenous switching regressions (ESR). Following the method suggested by the World Bank Handbook on 
Impact Evaluation (Khandker, Koolwal, \& Samad, 2010), the propensity score is firstly estimated to exclude outliers, who fall outside the common support region, from the analysis. The propensity score is calculated by probit model of the probability of participation in training conditional on observable characteristics of individuals or $P(X)=$ $\operatorname{Pr}\{\mathrm{T}=1 \mid \mathrm{X}\}$ where $\mathrm{T}$ indicates training participation in 2006 which is equal to " 1 " for participant and "0" for non-participants (Khandker et al., 2010). Individual characteristics at baseline (2005) or $X$ that are likely to influence training participation includes age, gender, level of education, urban/rural setting, region (Bangkok Metropolitan, Central, North, Northeast, and South), employment status and health condition. By keeping only observations that remain in the common support region, the sample reduces to 9,681 observations, of which 397 observations are treated and 9,284 observations are non-treated. Table 3.1 provides baseline characteristics of these "on-common-support" observations categorized by their treatment status.

However, as can be seen from Table 3.1, there are still serious imbalances between participants and non-participants in various aspects including age, rural/urban setting, education, labor force status, wage expenditure and labor mobility. Therefore, the one-toone nearest neighbor matching without replacement is further performed to ensure that treatment and control group become more comparable at the pre-intervention baseline. This nearest neighbor matching step reduces the sample size to 794 individuals of which half of the final matched observations belongs to the treatment group and the other half are the control group. The treatment and control groups are then more comparable as presented in Table 3.1. Although the incidences of upward transition to the higher labor force status and higher employment status of treatment and control group are statistically different, the differences are only significant at the 10 percent level. After that, the difference-in-difference regressions are applied to both on-common-support observations and nearest neighbor matched samples to estimate the impacts of vocational training programs in Thailand;

$$
\ln y_{i t}=a_{0}+a_{1} T_{i 1}+a_{2} t+a_{3} T_{i 1} t+a_{4} X_{i t}+u_{i t}
$$

where $y_{i t}$ is wage, income or expenditure. $\mathrm{t}$ is time which is equal to " 0 " in the year prior to training (2005) and " 1 " in the post-training year. $X_{i t}$ is a set of control variables including age, gender, level of education, location of residence (urban or rural), region, employment status, household size (in case of expenditure), and borrowing status (to control for any potential confounding effect from having better access to physical capital). The coefficient of 
the interaction term between treatment and time $\left(a_{3}\right)$ is the treatment effect (Khandker et al., 2010).

The probit model is also used to examine the impact of training on the probability of positive movement of the position in the wage, income and expenditure distribution, and labor market status. The dependent variable $\left(g_{i t}\right)$ takes the value " 1 " if an individual moves upward to higher ranking position, moves to a better labor market status, or maintains the highest status. On the other hand, $g_{i t}$ takes the value " 0 " if an individual experiences downward mobility or remains stuck in the low status.

$$
\operatorname{Pr}\left(g_{i t}=1\right)=\Phi\left(c_{0}+c_{1} T_{i 1}+c_{2} t+c_{3} T_{i 1} t+c_{4} X_{i t}+v_{i t}\right)
$$

The difference in difference method is supposed to be valid as long as the unobservable characteristics that may influence upward mobility are time invariant. In other words, participant and non-participant groups must have a parallel trend in their outcomes (Khandker et al., 2010).

Following Attanasio et al. (2010) and Canelas and Niño-Zarazúa (2019), the parallel trend assumption is tested using data from 2005 which is used as pre-treatment period in this study. As presented in Table 3.2, the outcome trends between treatment and control are not statistically different implying that the parallel trend assumption is plausible.

Table 3.2 Pre-Program Time Trends in Mobility Outcomes

Treatment ${ }^{*}$ Year 2005

\begin{tabular}{lc}
\hline \hline Absolute Mobility & -0.076 \\
Wage & $(0.180)$ \\
& 0.129 \\
Income & $(0.169)$ \\
& 0.006 \\
Expenditure & $(0.062)$ \\
Relative Mobility & -0.012 \\
Wage rank & $(0.028)$ \\
& 0.045 \\
Income rank & $(0.037)$ \\
& 0.044 \\
Expenditure rank & $(0.028)$
\end{tabular}




\begin{tabular}{lc}
\hline \hline Labor Mobility & \\
Labor force status & 0.030 \\
& $(0.024)$ \\
Formality of employment & 0.054 \\
& $(0.041)$ \\
Employment status & 0.056 \\
& $(0.041)$
\end{tabular}

Notes: Coefficients are estimated using nearest neighbor matching and difference in difference approach. Control variables as discussed in equation (1) are included but not shown here. Marginal effects are reported for relative and labor mobility. Standard errors in parentheses and ${ }^{*} p<0.1,{ }^{* * *} p<0.05,{ }^{* * *} p<0.001$.

Moreover, the propensity score matching in the first step, particularly the nearest neighbor matching, provides a more comparable treatment and control group before the program starts. Furthermore, during 2005 to 2012, there are no macroeconomic or policy changes, to my knowledge, that affects the treatment and control group differently. Therefore, it is convincing that the parallel trend assumption is not violated. However, since vocational training in Thailand is based on voluntary registration, some unobservable factors such as motivation and aspiration in life that affect both outcomes and decision to participate are likely to change over time. Therefore, this chapter employs another method to examine the aggregate impact of vocational training in Thailand.

Unlike DD for which treatment status is given, the endogenous switching regressions (ESR) approach assumes that selection into treatment is endogenous; hence unobservables that influence training participation are not independent of unobservables that affect outcomes (Maddala, 1983). Accordingly, ESR can address selection that is due to both observable and unobservable factors. Individuals, based on certain characteristics, are self-selected into two different regimes: participants and non-participants. The outcome equations are then estimated separately according to their regime, meaning that covariates are allowed to affect the outcome differently. Consequently, the unobservables in the selection (or choices) of training participation are taken into account in outcome equations and the possible selection bias is thus addressed. The model consists of two outcome equations and a selection equation that determines which regime applies.

Drawing from Maddala (1983) and Cameron and Trivedi (2005, p. 556), the impact of vocational training on absolute income, wage and expenditure mobility is estimated by the following regressions 
Regime1

(participant):

$$
\operatorname{lny}_{1 i t+1}=\beta_{1}{ }^{\prime} X_{1 i t+1}+u_{1 i t+1}
$$

Regime2

(non-participant):

$$
\ln y_{2 i t+1}=\beta_{2}{ }^{\prime} X_{2 i t+1}+u_{2 i t+1}
$$

Selection

Equation:

$$
y_{3 i t}=\pi^{\prime} Z_{i t-1}+\varepsilon_{i t}
$$

$$
y=\left\{\begin{array}{l}
\ln y_{1 i t+1} \text { if } y_{3 i t}>0 \\
\ln y_{2 i t+1} \text { if } y_{3 i t} \leq 0
\end{array}\right.
$$

where $\mathrm{t}-1$ is time at baseline or year 2005, $\mathrm{t}$ is time when training takes place or in year 2006 and $t+1$ is post-training period or in year 2006 (but after the training takes place), 2007, 2010 or 2012, the error terms in equations (3), (4) and (5) have mean zero and variance-covariance matrix

$$
\operatorname{Cov}\left(u_{1 i t+2}, u_{2 i t+2}, \varepsilon_{i t+1}\right)=\left[\begin{array}{ccc}
\sigma_{11} & \cdot & \sigma_{1 \varepsilon} \\
\cdot & \sigma_{22} & \sigma_{2 \varepsilon} \\
\sigma_{1 \varepsilon} & \sigma_{2 \varepsilon} & 1
\end{array}\right]
$$

where the variance of the error term in the selection equation (5) or $\sigma_{\varepsilon}^{2}$ is assumed to be equal to 1 for reasons of identification. $\sigma_{11}$ and $\sigma_{22}$ denote the variances of the error terms in the outcome equations (3) and (4). $\sigma_{1 \varepsilon}$ and $\sigma_{2 \varepsilon}$ are the covariances of the error terms in equation (3), and (4) respectively, with equation (5). The covariance between the error terms in equations (3) and (4) cannot be identified and is therefore reported as a dot because $\ln y_{1 i t+1}$ and $\ln y_{2 i t+1}$ are never observed at the same time.

In equation (5), $y_{3 i t}$ is a binary variable denoting training participation. If an individual participates in training program in 2006, $y_{3 i t+1}$ will equal " 1 " and will be placed in regime1 (participant). Regime2 (non-participant) will be applied if $y_{3 i t}$ takes the value " 0 ". $Z_{i t-1}$ are baseline characteristics used to model selection into training including age, gender, level of education, location of residence (urban or rural), employment status, region and health condition. These variables are the same set as the ones used to estimate propensity score in DD approach. $y_{1 i t+1}$ and $y_{2 i t+1}$ in the outcome equation (3) and (4) denote absolute wage, income or expenditure of participants and non-participants, respectively, in the posttraining period. $X_{1 i t+1}$ and $X_{2 i t+1}$ are control variables in the post-training year, most of which are used as explanatory variables in the DD regression for the on-common-support matched samples, including age, gender, level of education, rural/urban setting, region, 
employment status, household size (in case of expenditure), and borrowing status. Following Heckman et al. (2001) and Di Falco et al. (2011), the treatment effect on the treated evaluated at the means of the variables is then calculated by equation $(6)^{9}$ as follows

$$
\text { Treatment Effect on the treated }=\left(\beta_{1}{ }^{\prime}-\beta_{2}{ }^{\prime}\right) \bar{X}_{1 i t+1}+\left(\sigma_{1 \varepsilon}-\sigma_{2 \varepsilon}\right) \frac{\varphi\left(\pi \prime \bar{Z}_{i t-1}\right)}{\Phi\left(\pi \prime \bar{Z}_{i t-1}\right)}
$$

where bars over the variables denote averages. For the impact on relative income, wage and expenditure mobility as well as labor mobility, outcome variables are coded as binary variables. The dependent variable takes the value " 1 " if individuals experience upward mobility or secure the highest status and " 0 " otherwise. A bivariate probit model is then constructed as follows

$$
\begin{gathered}
y_{i t+1}^{*}=\beta_{1}{ }^{\prime} X_{1 i t+1}+v_{1 i t+1} \\
y_{3 i t}^{*}=\pi^{\prime} Z_{i t-1}+\varepsilon_{i t}
\end{gathered}
$$

where $y_{i t+1}^{*}=1\left[y_{1 i t+1}^{*}>0\right]$ represents upward mobility and $y_{3 i t}^{*}=1\left[y_{3 i t}^{*}>0\right]$ represents training and where $v_{1 i t+1}$ and $\varepsilon_{i t}$ follow a bivariate normal distribution with variances equal to 1 and correlation equal to $\mathrm{Q}$. Using a conditional distribution from a bivariate distribution (Greene, 2012) and following Lokshin and Sajaia (2011, p. 371), the effects of the vocational training program on the treated for relative and labor mobility evaluated at the means of the variables are obtained by equation $(7)^{10}$ as follows

$$
\begin{aligned}
& P(\text { upward mobility } \mid \text { training })-P(\text { upward mobility } \mid \text { not training }) \\
& =\frac{P(\text { upward mobility } \cap \text { training })}{P(\text { training })} \\
& -\frac{P(\text { upward mobility } \cap \text { not training })}{P(\text { not training })}
\end{aligned}
$$

Treatment effect of the treated $=\frac{\Phi_{2}\left(\beta_{1^{\prime}} X_{1 i t+1}, \pi \prime Z_{i t-1}, \sigma_{1 \varepsilon}\right)-\Phi_{2}\left(\beta_{2^{\prime}} X_{2 i t+1}, \pi \prime Z_{i t-1}, \sigma_{2 \varepsilon}\right)}{\Phi\left(\pi \prime Z_{i t-1}\right)}$

The same set of regressors $\left(X_{1 i t+1}\right.$ and $\left.X_{2 i t+1}\right)$ used in the case of absolute income, wage and expenditure mobility are also used in the two outcome equations but some control variables

\footnotetext{
${ }^{9}$ It is worth nothing that individual-specific components have not been taken into account.

${ }^{10}$ Like in equation (6), in this equation, the individual-specific unobserved effects have not been addressed.
} 
at baseline $\left(X_{1 i t-1}\right.$ and $\left.X_{2 i t-1}\right)$ are also included to account for environmental changes during the two periods of time.

As mentioned at the beginning, the main objective of this chapter is to generate evidence that is informative for training policy design and implementation. This chapter aims to examine impact heterogeneity and give answers to the question: do certain types of participant benefit more and do particular types of training work better than others? Equation (8) is used to estimate heterogeneity of impact by individual and program characteristics.

$$
\ln y_{i t}=\alpha_{0}+\alpha_{1} T_{i 1}+\alpha_{2} t+\alpha_{3} T_{i 1} t+\alpha_{4} X_{i t}+\gamma T_{i 1} t I_{i 0}+\delta T_{i 1} t P_{i 1}+v_{i t}
$$

Equation (8) is extended from equation (1) by adding the interaction of treatment, time, and individual characteristics at baseline $\left(T_{i 1} t I_{i 0}\right)$ and the interaction of treatment, time and program characteristics $\left(T_{i 1} t P_{i 1}\right)$ to the DD regression. The difference-in-difference effect is now a linear function of the variables included in $I_{i 0}$ and $P_{i 1}$. In this equation, $\mathrm{y}_{\mathrm{it}}$ is wage, income or household expenditure per capita. $\mathrm{T}$ is treatment variable and $\mathrm{t}$ is time which is equal to " 0 " in the year prior to training (2005) and " 1 " in the post-training year. $\mathrm{I}_{\mathrm{i} 0}$ includes variables for individual characteristics before the start of training, i.e. baseline characteristics, including gender, living area (urban or rural), age, education and labor force status (inactive, unemployed or employed). $\mathrm{I}_{\mathrm{i} 0}$ also includes variables indicating tenacity measured by whether the individual attends more than one training course (multiple training) and whether he/she participates in two consecutive years, both 2006 and 2007 (repeated training). $\mathrm{P}_{\mathrm{i} 1}$ consists of variables related to the training program, including type of course, type of provider, course length, financial supporter, and training costs reported by participants. Descriptive statistics of characteristics of training are presented in Table 3.1. The nearest neighbor matched observations are used to estimate heterogeneity of impact where treatment and control group are made comparable as also presented in Table 3.1.

\subsection{Results}

This section discusses the results of the estimations presented in the previous section. It begins with the overall treatment effects of vocational training on upward mobility. Then the heterogeneity of impacts is examined with respect to pre-specified individual characteristics and types of training. 


\subsubsection{Impacts on Upward Mobility}

Table 3.3 presents the impact of vocational training in Thailand on absolute, relative and labor mobility using on-common-support observations with a DD approach. According to the results, there is no statistically significant impact of vocational training on either absolute wage or income mobility in any of the time horizons. However, participation in training increases absolute expenditure mobility, and hence individual's living standards, by 11.3 percent within a year after training. However, the result is only significant at the 10 percent level. A similar effect is found in the medium term when the impact slightly decreases to 10.7 percent. Nevertheless, these positive and significant results do not persist in the long run. ${ }^{11}$

In line with absolute mobility outcomes, it is observed that vocational training has no significant impact on the probability of positive wage and income rank change. However, although the impact on expenditures is positive and significant, the impact is not large enough to move participants upward to a higher expenditure ranking position. The effectiveness of training on upward labor mobility is also disappointing. There is no statistically significant evidence, for any time duration, that training participation contributes to more employment, measured as the transition to a higher labor force status. Likewise, no positive impact is found on the quality of employment, neither for the transition to formality nor for the upward movement to a higher employment status.

As a robustness check, DD on the nearest neighbor matched samples is also conducted. As presented in Table 3.4, the results between the two matching methods are consistent as both models find no significant impact of training on wage and income, both absolute and relative terms, and labor mobility. The only exception is the impact on absolute expenditure mobility in the short and medium term. While the on-common-support observations show that training participation significantly contributes to higher household expenditure, the impact on expenditure vanishes when the statistically significant differences between participants and non-participants are addressed before examining the impact of vocational training.

11 Equation (1) and (2) are also estimated using the whole sample without on-common-support restriction and nearest neighbor matching (10,485 individuals of which 406 observations are treated and 10,079 are non-treated). Control variables in this case include both the variables used in the calculation of propensity score (probit model) and those used in the DD regressions. It is found that the results from the entire sample are similar to the ones from the on-common-support observations. 


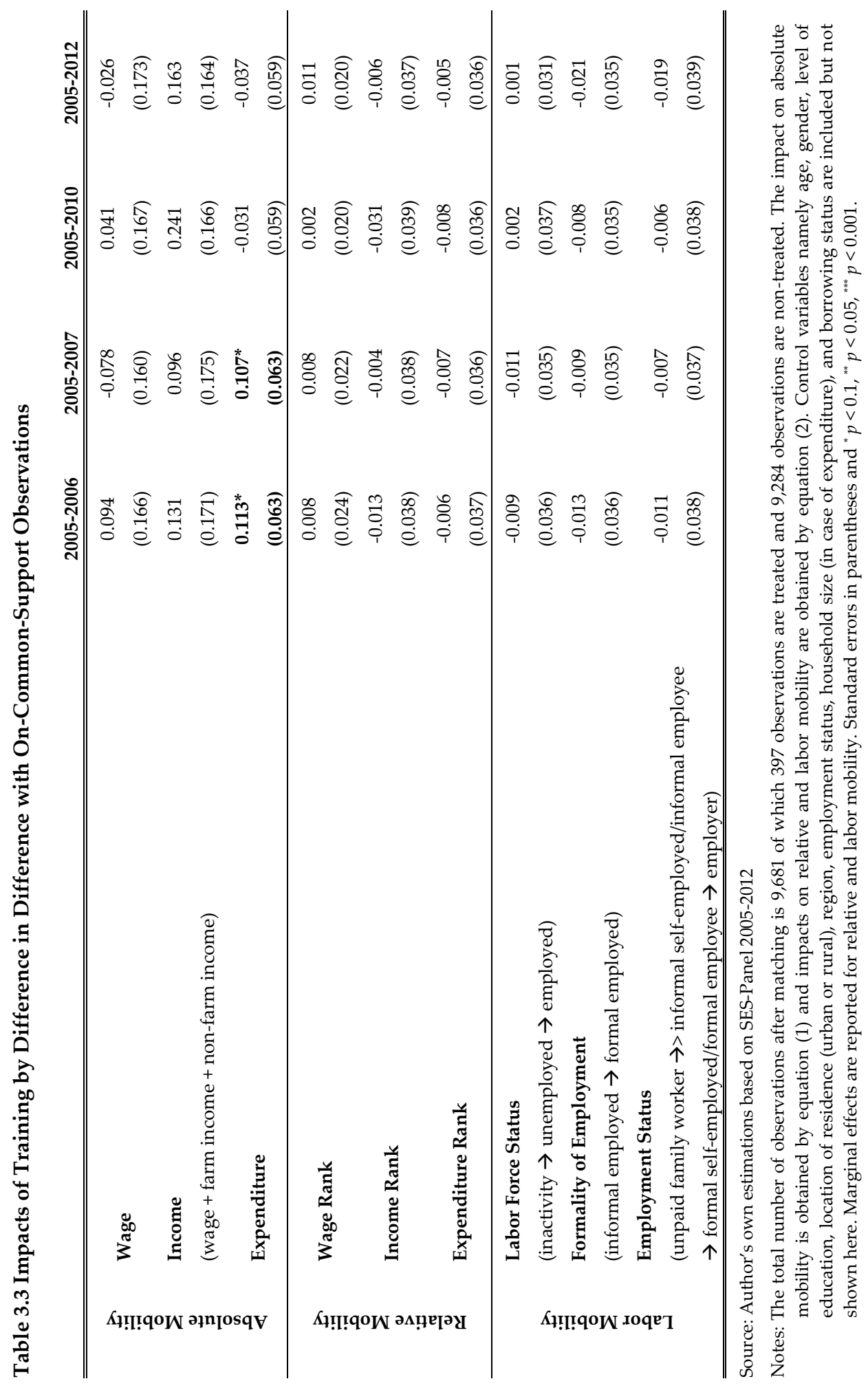




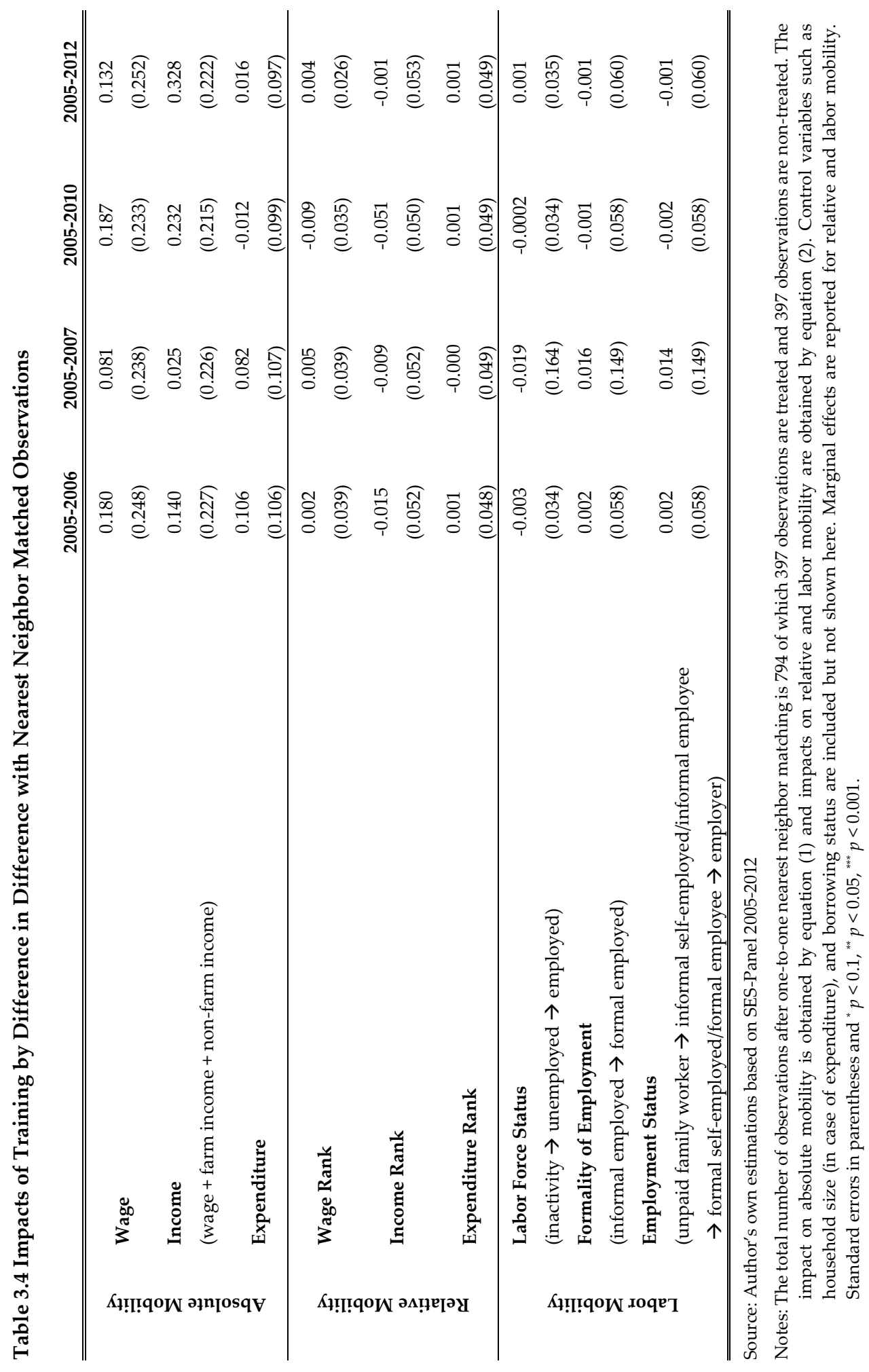




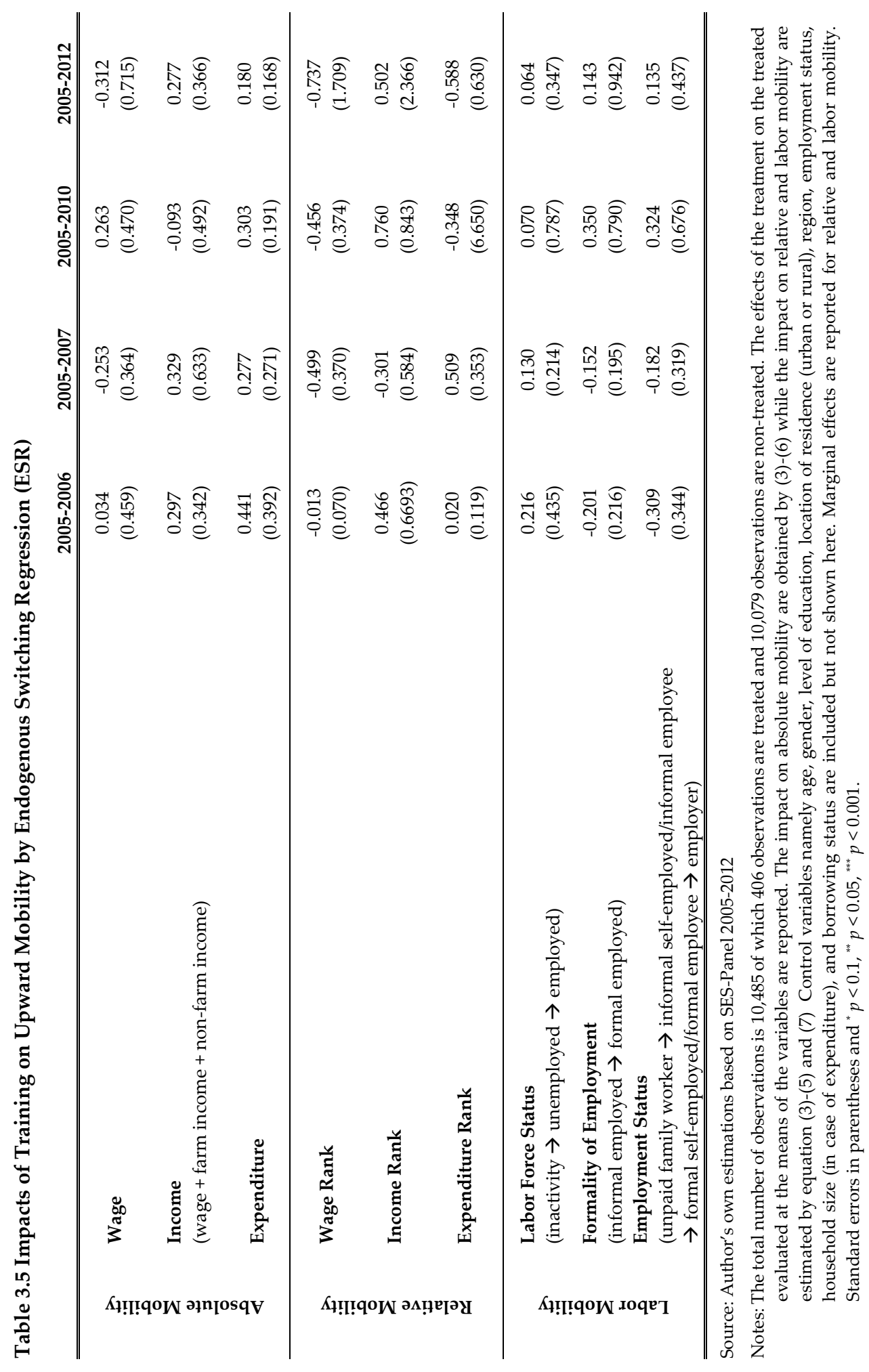


Moreover, the impact of vocational training is further estimated using other matching methods such as radius matching. It is found that most of the results from nearest neighbor matching are in line with radius matching implying that the reported results are robust to different matching technique. Furthermore, the analyses of training impacts are additionally replicated using 2006 as baseline and 2007 as treatment with nearest neighbor matching and difference in difference method. The 2006-2007 results are identical to those of 2005-2006 implying that the zero impacts of training on mobility outcomes considered in the short term are robust and the common trend assumption is likely to be satisfied.

The results obtained with the nearest neighbor matching and DD approach are also robust when comparing to the results obtained by ESR which are presented in Table 3.5. As can be seen, vocational training does not play a part in fostering upward absolute, relative and labor mobility when the endogeneity of decision to participate in training program is taken into account.

\subsubsection{Heterogeneity by Participant Characteristics}

As summarized in section 3.2.2, existing literature suggests that training impact depends considerably on characteristics of participants and types of training. The empirical findings presented in this chapter support such argument. The results suggest that although the overall impacts of training program are disappointing, significant heterogeneous effects across population subgroups are empirically observed. Table 3.6 presents heterogeneity of training effects by participant characteristics. As can be seen, the results on the heterogeneity by gender is different from previous studies, which claim that female participants benefit more from training especially in the long run (see e.g. Greenberg et al., 2003; McEntaffer, 2015; Osikominu, 2013). In this study, it is found that male participants, on average, do better than their female counterparts in the short term, medium term and long term, for wage and expenditure mobility. However, no significant variation is observed when the outcome of interest is income mobility. The results also suggest that vocational training is more effective in fostering wage and expenditure mobility for those living in urban area. In the medium term (2005-2007), however, urban residents seem to benefit less from training in terms of income but the impact is significant only at the 10 percent level.

The variation across age groups is mixed. There is some evidence indicating that when the dependent variable is absolute wage mobility, participants aged 25-39 are found to benefit most from the program but the impact only materializes in the short run. However, when 
income and expenditure mobility are particularly considered, participants aged 40-59 benefit most from training in the short and medium term. In the long run, the elderly (60 or above) appear to be the least affected in terms of wage and income mobility. All things considered, it is difficult to conclude at what age should people attend vocational training. The only conclusion that can be drawn is that vocational training appears to be the least effective for youth (aged 15-24) in the short and medium term and for elderly in the long term.

There is a complementary effect between initial human capital, measured by degree of education, and training. The overall finding suggests that participants with a higher degree of education, especially vocational education and higher education, do better than those that have attended only primary school or less. The results are particularly compelling when the dependent variable is wage mobility as the magnitude of the impact is highest for all time horizons. These findings contrast sharply with previous findings from Germany which, with respect to earnings, report a substitution effect between education and training (Osikominu, 2013). Concerning heterogeneity by labor force status, there is no significant difference between participants who are already employed before the start of training and those who are not. However, participants who are economically inactive before the training are found to benefit less than those who have already been active in the labor market.

This chapter also examines whether attending more than one training program within a year, yields better outcomes. The result suggests that the null hypothesis of equality between participants attending only one program and those attending more than one program cannot be rejected, implying that having participants to attend multiple programs does not necessarily foster the program impact on upward mobility. Finally, this study further examines if there is any significant difference between those attending the training only in 2006 and those attending in two consecutive years (2006 and 2007). It is found that participants who attend training in both years do better in all absolute mobility indicators but the impact on income and expenditure mobility does not appear to persist after 2007 when the repeated training does not take place.

\subsubsection{Heterogeneity by Program Characteristics}

Table 3.6 also presents heterogeneity of training effect by program characteristics. With regard to types of training, the courses of training are categorized into four main categories including agriculture, manufacturing and construction, services, and computers. 
Participants who have attended a computer training course do considerably better than others especially when it comes to wage mobility. Regarding the role of training duration, the obtained results are somewhat similar to Card et al. (2010) who report that longer courses do not differ from shorter courses. This study finds that although longer training courses are found to be more effective than shorter courses, in terms of expenditure mobility, in the long run, the evidence is weak as the positive result is significant only at the 10 percent level and does not persist beyond five years post-training. Considering the role of training provider, in line with Hirshleifer et al. (2015), it is found that the training has a stronger impact when offered by private institutions in comparison to government agencies. However, private providers are found to significantly differ from public providers only if the outcome variable is expenditure mobility. When wage and income mobility are particularly considered, a partnership between public and private agencies in training provision leads to a larger impact in the medium term.

With regard to heterogeneity by financial supporter, there is no statistically significant evidence suggesting that participants who finance themselves are different from those attending the training for free. Unsurprisingly, training participants who are financed by their employers appear to be more effective in terms of upward wage mobility in the short, medium and long term. The reason might be that employers know what skills they need and develop career paths based on the skills obtained from vocational training. However, this heterogeneity does not persist beyond $4-5$ years after the program. Last but not least, the role of training costs in driving upward mobility is examined. The results are comparable to Greenberg (2003) in that there is almost no significant variation of impact by program cost. The only exception is in 2005-2010 during which a positive and significant association between training cost and upward income mobility is found but the magnitude of the impact is small and negligible. Nevertheless, the reader should keep in mind that the information on program cost analyzed in this heterogeneity analysis is based on the selfreported information in the SES-Panel household survey. Therefore, it reflects the participation cost paid by participants which is likely to be different from the actual cost of the program especially for the subsidized training programs. 


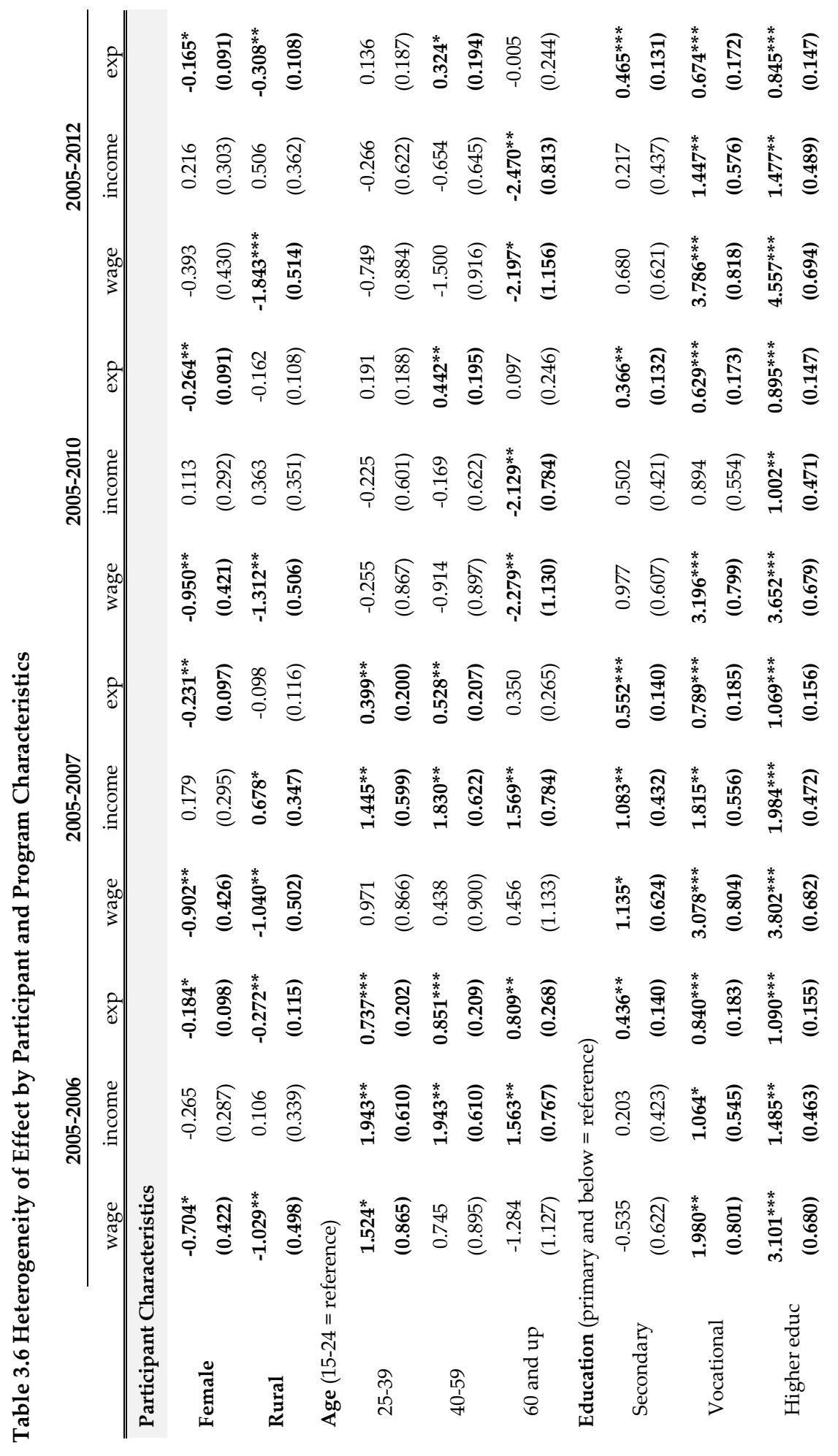




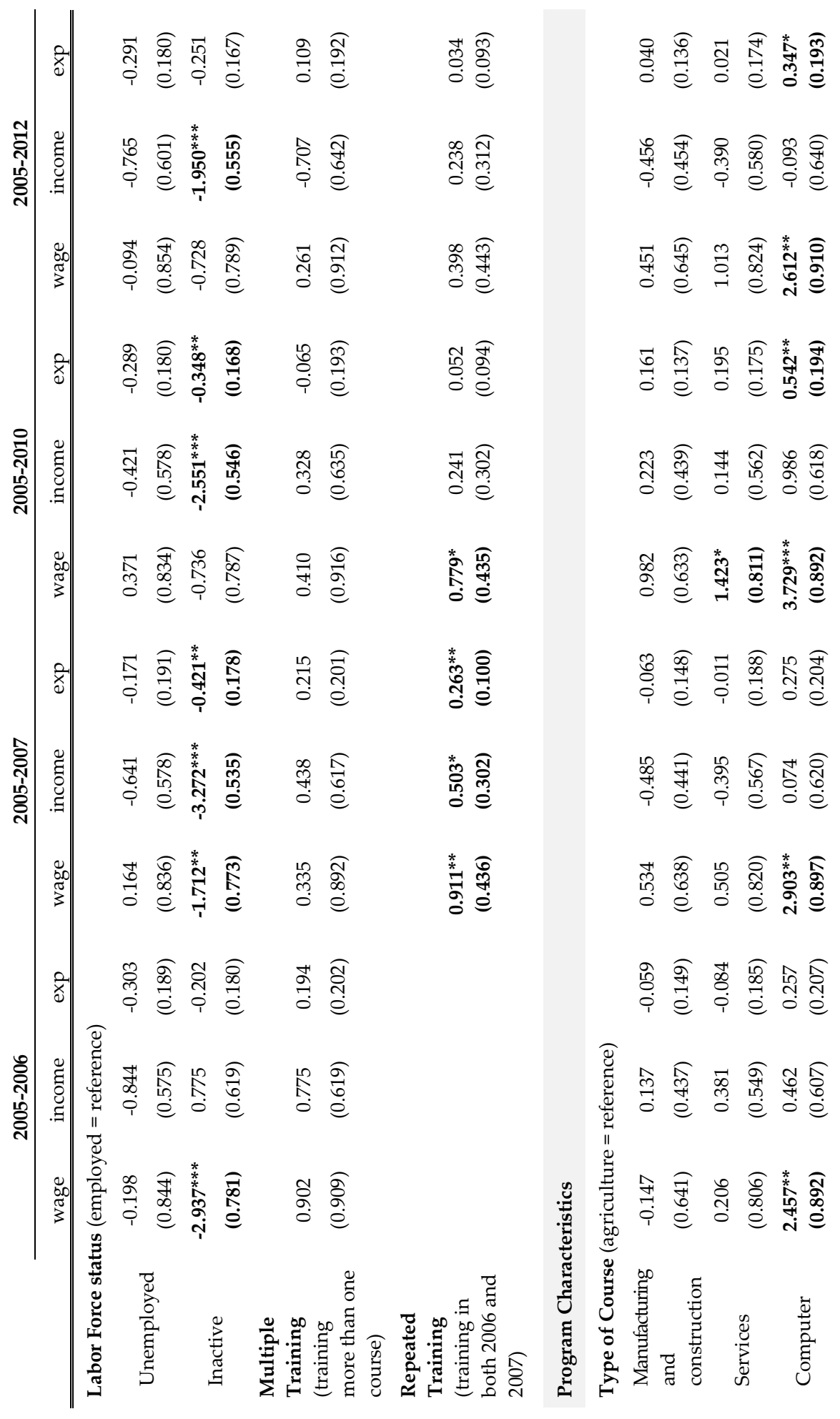




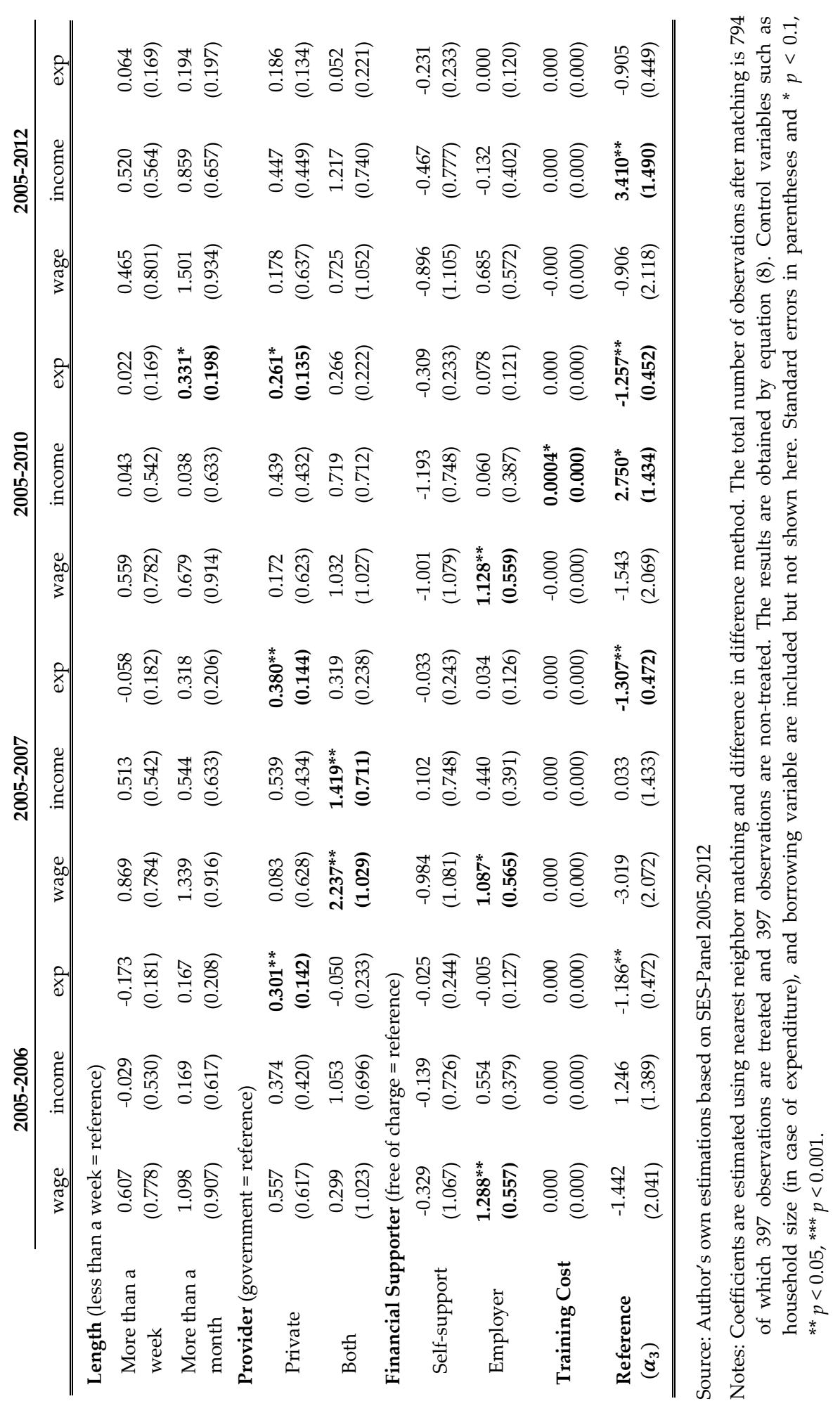


The robustness of the results is checked, in both heterogeneities by participant and program characteristics, by performing DD with various matching methods such as radius matching and running equation (8) with various specifications such as removing treatment $(\mathrm{T})$ and time (t) variables as well as adding/removing control variables. It is found that most of the results are robust to different matching methods and specifications.

Moreover, since three different outcomes (wage, labor income and expenditure) are used in the heterogeneity analyses, the multiple hypothesis testing is also conducted to prove that the significant heterogeneities are not observed by chance among different outcomes that are being analyzed at the same time. As guided by Gibson, McKenzie and Stillman (2011) and Kling, Liebman and Katz (2007), the bootstrapped estimates of adjusted p-values using a modification of the free step-down algorithm of Westfall and Young (1993) is calculated to correct for the multiple testing. ${ }^{12}$ The results suggest that the significant heterogeneities by gender and by age groups vanish after accounting for multiple hypothesis testing. However, the significant heterogeneities by level of education, labor force status, location of residence (rural/urban) and type of training course remain significant.

\subsection{Conclusion and Discussion}

According to the theoretical reasoning and empirical evidence discussed in Chapter 1, human capital is one of the most critical factors underlying upward economic mobility. Over the past decades, the Thai government has invested considerably in vocational training programs, the important social protection scheme with the promotive and transformative capabilities, in order to increase human capital of participants, improve their welfare and lift them to higher socioeconomic status. It is therefore interesting to examine if the program meets all these expectations.

This chapter provides the first quantitative evaluation of vocational training in Thailand using a unique panel data set to analyze the training impact on upward mobility in the short, medium and long term. Various treatment effect methods that work under different assumptions are conducted. Starting from propensity score matching with DD, both oncommon-support observations and nearest neighbor matched observations are used to

\footnotetext{
12 The selection of this approach is due to that it is a family-wise comparison method which allows for the individual examination of each outcome and does not assume that each outcome is independent from each other. More detailed discussions of this method in comparison to others are presented in Gibson, McKenzie and Stillman (2011) and Kling, Liebman and Katz (2007).
} 
confine treatment and control group. In comparison to the on-common-support restriction, the nearest neighbor matching reduces the risk of bias at the expense of higher variance due to smaller sample size. To thoroughly assess the impact of training, ESR is also applied. While DD assumes that treatment assignment is given and relies its accuracy on the parallel trend assumption, ESR allows for endogenous treatment, that is, when treatment assignment is not independent of outcomes.

Despite the different assumptions, all approaches suggest a common conclusion, which is that there is no credible evidence for the positive impact of Thailand vocational training program on upward mobility of participants in terms of earnings and employment, both in absolute and relative terms. The result is quite disappointing but not so much different from many previous training evaluation studies which found only modest impacts, at best. The unpromising results of training effectiveness in Thailand might be due to a mismatch between skills acquired from training and labor market demand. The quality of training is also an important issue which hampers trainings to facilitate upward mobility.

The only significant impact of training is obtained when the outcome variable is expenditures. However, this desirable result on expenditures is only significant at the 10 percent level and merely realized when a DD approach with on-common-support observations is employed. In other words, vocational training is found to foster absolute expenditure mobility when the significant difference between treatment and control group at baseline is ignored or the endogeneity of decisions to participate in a vocational training is disregarded. The potential explanation might be that people who voluntarily participate in a training program are more likely to succeed even without training due to their superior characteristics especially the unobservable ones such as motivation and ability. Therefore, once these factors are taken into account by ensuring that treated and controlled observations are comparable from the start or applying the endogenous approach, the positive and significant impact vanishes.

Although the impact of training on absolute expenditure mobility is weakly significant and derived from the on-common-support matching method of which treatment and control group remain unbalanced at baseline, the fact that the (weakly) significant results can only be observed in the short and medium term still worth discussing. Vocational training is normally predicted to have small or negative short-term effects but becomes more positive in the long run. The reason is that during training, participants may spend less time and effort on working and finding jobs resulting in prolonged unemployment and unfavorable labor market outcomes in the short run (Card et al., 2015). This lock-in effect is found 
empirically in Card et al. (2010), Attanasio et al. (2015), Ibarraran et al. (2015). The reverse finding in Thailand, which is in line with Heckman et al. (1999) and Hirshleifer et al. (2015), is probably because the training length, in general, is not long enough to realize the lock-in effect. Moreover, the training content might be so specific that the return to such a training course may disappear in the long run when technology and demand for labor change. Furthermore, employers may use training participation to indicate greater productivity of employees or job applicants. Since the role of this signaling and screening effect may become less important in the long run, the impact of training is relatively more favorable in the short term.

As discussed, participation in vocational training does not lead to upward mobility. Therefore, further analysis is needed to fully understand the impact of training and to design more effective policies that mitigate the potential negative effects and enhance the positive impact of training on upward mobility. One possible way of doing so is to examine impact heterogeneity to discover what program and participant characteristics are associated with greater (and lesser) success. This chapter shows the heterogeneity of training impacts derived from nearest neighbor matching with difference in difference method. According to the results, among several groups of participants, women, rural residents, youth (aged 15-24) and elderly (60 or above), low-educated workers, and economically inactive persons are found to benefit less from vocational training. Therefore, policies to foster upward mobility need to target their efforts on these marginalized groups.

With regard to the heterogeneity by gender, training courses have to be more female friendly by offering skills training for jobs that are suitable for female workers. However, the limited opportunities for women in Thailand's labor market may not be overcome simply by providing vocational training. There might also be factors that hinder women from advancing their career such as perception of women in traditional Thai society, family commitments, and occupational segregation. Moreover, protective legislations for women such as mandated maternal benefit may lead to unfair hiring practices against women because it increases the cost of employment of women (Hansatit, 2014). Therefore, structural and institutional barriers preventing women from a decent and well-paid job also need to be removed.

Moreover, training should be more customized to serve different age groups. For the youth, in addition to the classroom training, a different training setting that provides hands-on experience such as apprenticeship and on-the-job training may be more effective for the transition from school to work. It is also more common for seniors to remain working even 
after retirement. Some people may continue their primary occupation after their retirement and some may choose different vocations. In any case, vocational training programs need to provide up-to-date skills for senior participants so that they can stay in the labor force and contribute to national economic and social development especially in the context of an ageing population.

The strong complementary effect between education and training suggests that investment in formal education, both in terms of quantity and quality, should continue to be a priority. However, for those who have already dropped out and are unlikely to get back to the formal education system, vocational training must take into account participants' prior knowledge and experience. The training program must also address their barriers to learning as the low educated participants may lack motivation and encounter some impeding factors such as family obligations that prevent them from achieving success in training program (Cedefop, 2016). Regarding participants who are inactive before the start of training, simply providing vocational skills may not be sufficient. Other active labor market policies such as employment counselling and job search assistance are needed to complement the training program. The results also show that repeated training is associated with better upward mobility outcomes. Accordingly, the same training program, probably with more advanced contents, should be offered to the same participants every year or on a regular basis.

The results obtained from this study also suggest a number of important policy implications with respect to program features. As can be seen, a computer training course has larger effects compared to other types of training. This is not surprising as computer skills have become an essential requirement for career advancement in Thailand during the past decades. Therefore, computer skills training should be offered more. At the same time, other types of training such as agriculture, manufacturing and services, should be redesigned to better fit the current country context and keep up with the demand for labor. As private providers and public-private partnerships are found to be more effective than the courses offered by government agencies alone, the government should continue to support private institutions and consider working more with them in designing and providing skill development programs. Furthermore, improving a connection with businesses may also help widen employment opportunity for training participants, thereby enhancing the effectiveness of training program. Last but not least, the empirical results imply that training is more effective when it is sponsored by employers. Therefore, the government should incentivize employers to support their employees both by funding the training cost and 
providing opportunity for job promotion based on skills that employees can be equipped by attending the training program.

The presented results and conclusions are derived from the rigorous methods with the justified assumptions. However, it must be admitted that there are some limitations in this study, mainly due to the lack of data, which call for further research. First, as there is no available data for the quality of training, to my knowledge, this analysis cannot ensure that the quality of training courses delivered are consistent across training centers and groups of participants. Second, as mentioned earlier, vocational training in Thailand has been offered for decades. Due to data availability, however, this study can only control for the year 2005, which is used as the baseline, and make sure that during the past 12 months, at least, before the training takes place, not any person in the sample participates in vocational training. There might be the case that subjects in the control group did participate in vocational training long before 2005 resulting in the bias which cannot be addressed by the current data set.

Finally, although the disappointing results on the impact of training programs are in line with existing literature and several explanations can be used to justify the result, the zero impact, which is found, might simply be because the sample size used in this analysis is too small. Unlike previous training evaluation studies in developing countries, which analyze the impact based on administrative data, this study makes use of survey data to ensure that changes that occur in the informal sector are captured in the analysis. Unfortunately, in the data set used in this analysis, only a small number of training participants were surveyed. Moreover, it might also be the case that people who dropped out from the program responded to the survey that they never attended the program. Hence, this study may have difficulty discerning the training impact resulting in an unpromising outcome of Thailand's vocational training program. The results presented in this chapter thus need to be considered and interpreted with cautions. 


\section{References}

Attanasio, O., Fitzsimons, E., Gomez, A., Gutiérrez, M. I., Meghir, C., \& Mesnard, A. (2010). Children's Schooling and Work in the Presence of a Conditional Cash Transfer Program in Rural Colombia. Economic Development and Cultural Change, 58(2), 181210. https://doi.org/10.1086/648188

Attanasio, O., Guarín, A., Medina, C., \& Meghir, C. (2015). Long Term Impacts of Vouchers for Vocational Training: Experimental Evidence for Colombia. Retrieved from National Bureau of Economic Research website: http://www.nber.org/papers/w21390

Betcherman, G., Dar, A., \& Olivas, K. (2004). Impacts of active labor market programs: New evidence from evaluations with particular attention to developing and transition countries. Retrieved from http://info.worldbank.org/etools/docs/library/251019/day6DiscussionPaperSeries04 02April6Se1.pdf

Borkum, E., Mamun, A., Marco, L., \& Mubeen, M. K. (2015). Evaluation of the Vocational Training Grant Fund in Namibia: Baseline Report (No. 40233.241). Mathematica Policy Research.

Bui, M.-T. T., \& Permpoonwiwat, C. K. (2015). Gender Wage Inequality in Thailand: A Sectoral Perspective. International Journal of Behavioral Science, 10(2), 19-36.

Cameron, A. C., \& Trivedi, P. K. (2005). Microeconometrics: Methods and Applications. Cambridge, UK: Cambridge University Press.

Canelas, C., \& Niño-Zarazúa, M. (2019). Schooling and Labor Market Impacts of Bolivia's Bono Juancito Pinto Program. Population and Development Review. https://doi.org/10.1111/padr.12270

Card, D., Kluve, J., \& Weber, A. (2010). Active Labour Market Policy Evaluations: A MetaAnalysis. The Economic Journal, 120(548), F452-F477. https://doi.org/10.1111/j.14680297.2010.02387.x

Card, D., Kluve, J., \& Weber, A. (2015). What Works? A Meta Analysis of Recent Active Labor Market Program Evaluations. IZA Discussion Paper, IZA DP No.9236. Retrieved from http://ftp.iza.org/dp9236.pdf

Cedefop. (2016). Improving career prospects for the low educated: The role of guidance and lifelong learning.

Cho, Y., Mobarak, A. M., Orozco, V., \& Wolfson, D. (2015). Gender Differences in The Effects of Vocational Training: Constraints on Women and Dropout Behavior. Retrieved from http://elibrary.worldbank.org/doi/abs/10.1596/1813-9450-6545

Crépon, B., \& van den Berg, G. J. (2016). Active Labor Market Policies. Annual Review of Economics, 8(1), 521-546. https://doi.org/10.1146/annurev-economics-080614-115738

Department of Skill Development. (2016). Summary Statistics of Vocational Training Program. Retrieved from Ministry of Labour website: http://www.dsd.go.th/DSD/Stat 
Di Falco, S., Veronesi, M., \& Yesuf, M. (2011). Does Adaptation to Climate Change Provide Food Security? A Micro-Perspective from Ethiopia. American Journal of Agricultural Economics, 93(3), 829-846. https://doi.org/10.1093/ajae/aar006

Fields, G. S. (2006). The Many Facets of Economic Mobility. Cornell University ILR School Working Paper. Retrieved from https://digitalcommons.ilr.cornell.edu/articles/230/

Fields, G. S., Cichello, P. L., Freije, S., Menendez, M., \& Newhouse, D. (2003). Household Income Dynamics: A Four-Country Story. The Journal of Development Studies, 40(2), 30-54. https://doi.org/10.1080/00220380412331293757

Gibson, J., McKenzie, D., \& Stillman, S. (2011). The Impacts of International Migration on Remaining Household Members: Omnibus Results from A Migration Lottery Program. The Review of Economics and Statistics, 93(4), 1297-1318.

Greenberg, D. H., Michalopoulos, C., \& Robins, P. K. (2003). A meta-analysis of governmentsponsored training programs. Industrial \& Labor Relations Review, 57(1), 31-53.

Greene, W. H. (2012). Econometric Analysis (Seventh Edition). Pearson Education Limited.

Hansatit, P. (2014). A study on gender inequality in Thailand: career experience of Thai female managers (Southern Cross University). Retrieved from https://epubs.scu.edu.au/cgi/viewcontent.cgi?article=1403\&context=theses

Heckman, J. J., Lalonde, R. J., \& Smith, J. A. (1999). The Economics and Econometrics of Active Labor Market Programs. Handbook of Labor Economics, 3.

Heckman, J., Tobias, J. L., \& Vytlacil, E. (2001). Four Parameters of Interest in the Evaluation of Social Programs. Southern Economic Journal, 68(2), 210. https://doi.org/10.2307/1061591

Hirshleifer, S., McKenzie, D., Almeida, R., \& Ridao-Cano, C. (2015). The Impact of Vocational Training for the Unemployed: Experimental Evidence From Turkey. The Economic Journal, 126(597), 2115-2146. https://doi.org/10.1111/ecoj.12211

Ibarrarán, P., Kluve, J., Ripani, L., \& Rosas, D. (2015). Experimental evidence on the long-term impacts of a youth training program. Retrieved from https://papers.ssrn.com/sol3/papers.cfm?abstract_id=2655085

Ibarraran, P., \& Rosas Shady, D. (2008). Evaluating the impact of job training programmes in Latin America: evidence from IDB funded operations. Journal of Development Effectiveness, 1(2), 195-216.

Jitsuchon, S., Planpraphan, J., Vajragupta, Y., \& Methakunavut, N. (2009). Social Investment under the Changes in Social Structure and Transformation to a Knowledge-Based Society. Retrieved from Thailand Development Research Institute website: http://tdri.or.th/research/social-investment/

Khandker, S., Koolwal, G., \& Samad, H. (2010). Handbook on Impact Evaluation: Quantitative Methods and Practices. https://doi.org/10.1596/978-0-8213-8028-4

Kling, J. R., Liebman, J. B., \& Katz, L. F. (2007). Experimental Analysis of Neighborhood Effects. Econometrica, 83-119. 
Kluve, J. (2010). The effectiveness of European active labor market programs. Labour Economics, 17(6), 904-918. https://doi.org/10.1016/j.labeco.2010.02.004

Lokshin, M., \& Sajaia, Z. (2011). Impact of interventions on discrete outcomes: Maximum likelihood estimation of the binary choice models with binary endogenous regressors. The Stata Journal, 11(3), 368-385.

Maddala, G. S. (1983). Limited-Dependent and Qualitative Variables in Econometrics. Cambridge, UK: Cambridge University Press.

Maitra, P., \& Mani, S. (2013). Learning and earning: Evidence from a randomized evaluation in India. Fordham University, Department of Economics, Discussion Paper Series, 2. Retrieved from http://papers.ssrn.com/sol3/papers.cfm?abstract_id=2341125

McEntaffer, M. J. (2015). The Promise of Worker Training: New Insights into the Effects of Government Funded Training Programs. University of Nebraska.

National Economic and Social Development Board, Office of the Prime Minister. (2015). Thailand Millenium Development Goals 2015 (in Thai). Retrieved from http://social.nesdb.go.th/social/Portals/0/MDG\%20Thailand\%2020150825.pdf

National Economic and Social Development Board, Office of the Prime Minister. (2017). Social and Quality of Life Database System - Thailand Labor Force. Retrieved from http://social.nesdb.go.th/SocialStat/StatSubDefault_Final.aspx?catid=2

National Economic and Social Development Board, Office of the Prime Minister. (2018). Thailand's Poverty and Inequality Report 2017 (in Thai). Bangkok, Thailand.

National Statistical Office, Ministry of Information and Communication Technology. (2016). Informal Labor in 2016. Retrieved from http://service.nso.go.th/nso/web/survey/surpop2-2-4.html

National Statistical Office, Ministry of Information and Communication Technology. (2017a). Summary report on Thailand labor force survey as of January 2017 (in Thai). Retrieved from http://service.nso.go.th/nso/nsopublish/themes/files/lfs60/reportJan.pdf

National Statistical Office, Ministry of Information and Communication Technology. (2017b). The Labor Force Survey. Retrieved from http://service.nso.go.th/nso/web/statseries/statseries04.html

National Statistical Office, Ministry of Information and Communication Technology. (2018). Summary report on Thailand labor force survey as of April 2018 (in Thai).

Osikominu, A. (2013). Quick Job Entry or Long-Term Human Capital Development? The Dynamic Effects of Alternative Training Schemes. The Review of Economic Studies, 80(1), 313-342. https://doi.org/10.1093/restud/rds022

Pavlopoulos, D. (2007). Wage Mobility Patterns in Europe (Tilburg University). Retrieved from https://pure.uvt.nl/portal/en/publications/wage-mobility-patterns-ineurope(916ddc9e-ef9c-45ad-bc4b-4cb6e6cbad99).html 
Puerta, M. L. S. (2010). Labor Market Policy Research for Developing Countries: Recent Examples from the Literature What do we know and what should we know? Retrieved from Citeseer website:

http://citeseerx.ist.psu.edu/viewdoc/download?doi=10.1.1.163.1431\&rep=rep1\&typ $\mathrm{e}=\mathrm{pdf}$

Rama, M., Beteille, T., Li, Y., Mitra, P., \& Newman, J. L. (2015). Addressing Inequality in South Asia. Retrieved from The World Bank website:

https://openknowledge.worldbank.org/handle/10986/20395

Smiti, P. (2009). Thailand's Perspective on Skills Training in the Workplace. Retrieved from Department of Skill Development, Ministry of Labour website:

http://www.ilo.org/wcmsp5/groups/public/@asia/@robangkok/documents/meetingdocument/wcms_120566.pdf

Tansel, A., \& Kan, E. O. (2011). Labor Mobility Across The Formal/Informal Divide in Turkey: Evidence From Individual Level Data. Retrieved from http://ssrn.com/abstract=1978291

The World Bank. (2016). Thailand Economic Monitor - June 2016: Aging Society and Economy. Retrieved from http://www.worldbank.org/en/country/thailand/publication/thailand-economicmonitor-june-2016-aging-society-and-economy

Verme, P., Barry, A. G., Guennouni, J., \& Taamouti, M. (2014). Labor Mobility, Economic Shocks, and Jobless Growth: Evidence from Panel Data in Morocco. The Poverty Reduction and Economic Management Department, Middle East and North Africa Region, The World Bank, (Policy Research Working Paper 6795).

Warunsiri Paweenawat, S., Vechbanyongratana, J., \& Yoon, Y. (2017). Is Thailand's labour market really woman friendly? Revisiting the declining gender wage gap. Presented the Labor and Human Capital, Bank of Thailand, Bangkok, Thailand. Retrieved from https://www.pier.or.th/wpcontent/uploads/2017/08/workshop2017_Labor_Jessica.pdf

Westfall, P., \& Young, S. (1993). Resampling-Based Multiple Testing: Examples and Methods for P-Value Adjustment. New York: Wiley.

Woolard, I., \& Klasen, S. (2005). Determinants of Income Mobility and Household Poverty Dynamics in South Africa. Journal of Development Studies, 41(5), 865-897. https://doi.org/10.1080/00220380500145313 


\section{Chapter 4}

Microcredit and Upward Mobility:

The Evidence from the Thailand Village Fund 


\subsection{Introduction}

Physical capital endowment is an important determinant of welfare development and socioeconomic upward mobility (Fields, 2001; Woolard \& Klasen, 2005). Among various kinds of intervention, microcredit ${ }^{13}$ has been a popular program to address credit constraints, increase physical capital investment, promote income-generating activities and foster positive mobility outcomes. Following the rapid expansion of microcredit throughout the world, many evaluation studies have been carried out. However, the evidence has been mixed and debated. While several research suggest a positive impact of microcredit (e.g. Augsburg, De Haas, Harmgart, \& Meghir, 2015; Banerjee, Duflo, Glennerster, \& Kinnan, 2015), many other studies observe zero impact or even negative impact of the program (e.g. Karlan \& Zinman, 2011; Van Rooyen, Stewart, \& de Wet, 2012). These contested empirical findings have led to the widespread skepticism and controversy over the contribution of microcredit programs.

Scholars point to an increase in the commercialization of the industry as a one of the most important causes of microcredit failure (Dichter \& Harper, 2007; Milana \& Ashta, 2012). They argue that commercial microcredit providers usually charge relatively high interest rates and hence exploit their clients. Moreover, the existence of microcredit, or microfinance at large, may lead to institutional barriers to sustainable local economic and social development. Therefore, a higher degree of state intervention and local community engagement have been proposed as potential solutions to the disappointing results of microcredit (Bateman \& Chang, 2009). However, to the best of my knowledge, there is no study so far that proves this hypothesis empirically. This chapter contributes to this ongoing discussion by studying the large-scale, government-supported microcredit initiative in Thailand.

The Village and Urban Community Fund program, which is often called the Village Fund (VF), has been in operation since 2001 after the Thai government decided to inject 1 million baht (31,250 USD) to each and every one of the 77,000 villages in Thailand. This initiative has made the VF one of the world largest government microfinance programs (Boonperm, Haughton, \& Khandker, 2013; Kaboski \& Townsend, 2012; Menkhoff \& Rungruxsirivorn, 2011). The design of the VF is also exceptional in that it promotes local community

\footnotetext{
${ }^{13}$ This thesis narrowly focuses on the role of a small loan offered by microcredit program. Unlike microcredit, microfinance refers to a broader spectrum of financial services such as loans, deposit, saving, insurance and remittances.
} 
engagement by allowing each village to manage the program on its own. Due to its unusual size and attractive design, there were some attempts to evaluate the effectiveness of the VF. However, the existing research on the VF only presents impacts up to 2007 while the Thai government continues to allocate enormous resources to the program. Moreover, the data used in those studies are either drawn from some specific areas in which the sample size cannot represent the impact at the national level (e.g. Kaboski \& Townsend, 2011; Menkhoff \& Rungruxsirivorn, 2011), or are too short to detect any long-term impact of the program (e.g. Boonperm et al., 2013; Chandoevwit \& Ashakul, 2008).

This chapter aims to provide fresh evidence on the VF by using data from a panel survey which has never been used in any microcredit evaluation study to analyze the impact of the VF on mobility outcomes. The Thailand Socioeconomic Panel Survey (SES-Panel) is a nationally representative survey data covering seven years (2005-2012). It contains rich information of individual characteristics and their borrowing information. Hence, access to this data set allows this chapter to analyze the impact, and its heterogeneity, of the VF in the short, medium and long term. Moreover, characteristics of VF borrowers, compared to other lending institutions, are also examined to further deepen the understanding of the program.

The rest of the chapter is structured as follows. Section 4.2 provides an overview of microcredit in Thailand and the VF. Section 4.3 briefly summarizes findings of existing literature on both the VF and other microcredit programs in other countries. Section 4.4 explains detail of the data set and methodologies used in this study. The subsequent section (section 4.5) presents the results obtained from the analysis and the last section (section 4.6) concludes and discusses the results.

\subsection{Thailand's Microcredit Market and the Village Fund}

\subsubsection{Microcredit in Thailand}

In Thailand, the government has been a major provider of microcredit servicing low-income individuals and households. Political parties often promote greater access to low-cost credit to gain popularity among voters. Hence, the interest rates have been kept low and thus made it difficult for private microfinance institutions to compete. This prominent characteristic distinguishes Thailand from many other middle-income countries (Bird et al., 2011). Financial institutions in Thailand that offer microloans can be broadly classified into three main categories: formal, semiformal and informal institutions (Bird et al., 2011; Lewis, 
Tambunlertchai, Suesuwan, Adair, \& Hickson, 2013; Tambunlertchai, 2017). Each category differs in their legal status and the extent of regulation to which it is subject to.

Formal microfinance institutions refer to financial institutions that have a clear legal status, operate under prudential regulations and are controlled by financial authorities, either the Bank of Thailand or Ministry of Finance. In addition to the commercial banks (CB), the stateowned special financial institutions (SFIs) such as the Bank for Agriculture and Agricultural Cooperatives (BAAC) and the Government Saving Bank (GSB) are also under this category. In comparison to the $\mathrm{CB}$, the state-owned SFIs tend to provide financial access to lowincome individuals. The BAAC focuses on providing affordable credit to individual farmers and agricultural cooperatives. As more than one-third of the Thai workforce is in the agricultural sector, the BAAC has been the major financial provider especially in the rural area. Unlike the BAAC, the GSB prioritizes low-income customers living in urban areas and aims to promote saving habit among Thai people (Bird et al., 2011; Lewis et al., 2013; Tambunlertchai, 2017).

Semiformal institutions generally hold a legal status but are not controlled by financial authorities nor subject to prudential regulations. Microfinance institutions falling into this category include cooperative and occupational groups, saving groups for production and the VF. Cooperative and occupational groups typically offer financial services only to their members who have the same occupation or live in the same area (Bird et al., 2011; Lewis et al., 2013; Tambunlertchai, 2017). Lastly, informal microfinance institutions, such as saving groups and self-organizing funeral funds, are usually initiated by local community. They do not hold legal status and are not under regulations (ibid). Apart from these three main microfinance types, there are also several informal credit sources from which people can borrow such as informal private moneylenders, neighbors, relatives and friends.

As financial inclusion has been the priority of the Thai government, Thai people generally have good access to financial services. According to Bird et al. (2011, p. 5), more than 90 percent of Thai households have access to financial services, at least from one source, and 64 percent of Thai households had borrowed from at least one of the three types of financial institutions mentioned earlier. Moreover, 72 percent of households are able to receive credit when they need one. Tambunlertchai (2017, p. 286) also shows that 61 percent of total credit volume of microloans are provided by formal microfinance institutions. The semiformal microfinance institutions account for 35 percent of total microloans and the remaining four percent are from informal institutions. 


\subsubsection{The Village Fund (VF)}

In 2001, the Thai government introduced The Village and Urban Community Funds project and transferred the initial funding, 1 million baht (31,250 USD), to nearly 80,000 villages across the country. The size of that transfer alone accounts for about 1.5 percent of GDP in that year (Kaboski \& Townsend, 2011). The objectives of this project are to provide affordable and sustainable credit access to Thai people in rural and urban communities so that people can use this money for business investment, career development, job creation, consumption smoothing and/or welfare improvement (Wichianlert, 2015). Moreover, the government also aims to promote community learning, managing skills and self-reliance among the village members through this program (Chandoevwit \& Ashakul, 2008).

To establish the Village Fund and receive the initial funding from the government, the village needs to set up the VF committees, elected from and by community residents, draft its own regulations, which has to be in line with the broad guideline given by the central government, and submit the application to the concerned government agencies (Chandoevwit \& Ashakul, 2008). The elected VF committees are in charge of all lending policies including interest rate, maximum loan amounts and terms of loans. However, according to the Village Fund Act, the maximum loan size cannot be higher than 20,000 baht (625 USD). In some few cases, it is also possible to receive loans higher than 20,000 baht but it must not exceed 50,000 baht (1,562.5 USD) (Kaboski \& Townsend, 2012). Repayment is required to be made within one year and borrowers are eligible for a repeat loan only if their former loan is fully repaid (ibid).

The interest rate is also set by the VF committees but it needs to be a positive rate in order to maintain the revolving fund. The interest rate is found to vary from 2 to 12 percent (Kaboski \& Townsend, 2012). In general, the average nominal interest rate is around 7 percent per annum which is less than half of the global average microcredit interest rate (Kaboski \& Townsend, 2012; Rosenberg et al., 2013). The VF committees may require collateral to take up loans but they generally ask only for third party guarantors. Those who cannot make the repayment in time, the VF committees may punish by charging higher interest rate, putting that borrower on the blacklist and/or asking guarantors to pay for the loans instead (Menkhoff \& Rungruxsirivorn, 2011). With regard to the lending decision, the VF committees will decide who and how much they can borrow. Although the government aims to alleviate credit constraints of the low-income individuals and households through the VF, all village members, regardless of their social and economic status, are eligible to 
borrow from this program (Boonperm et al., 2013). Moreover, there are no specific rules regarding the purpose of borrowing. However, the reasons behind the purpose together with the ability to repay are often used as lending criteria (Kaboski \& Townsend, 2011).

The government has also promised to provide additional funding to the VF that receives high ratings from the audit and evaluation team, often the local teaching colleges. But the VF has also been threatened with cuts from other sources of government transfer and the provision of other types of assistance in case the VF fails or the funds are abused (Kaboski \& Townsend, 2012). According to the National Village and Urban Community Fund Office (2017), as of 2017, there are 75,000 Village Funds remaining in operation and the government has already allocated more than 267 billion baht ( 8.3 billion USD) to this program.

\subsection{Evidence on Microcredit and the Village Fund}

Due to the growing number of microcredit programs over the last decades, numerous impact assessments of microcredit have been conducted. According to Khandker, Khalily and Samad (2016), there are two strands of literatures on the impact of microcredit: non-RCT and RCT-based research. The first strand of studies employs observational data to evaluate the impact of microcredit programs. In this category, microcredit is usually found to have an important role in economic, social and human development. For example, the results based on the 20-year-long panel household survey data in Bangladesh suggest that microcredit increases income, expenditure and assets as well as labor supply and educational outcomes for both men and women (Khandker \& Samad, 2014). Microcredit programs in Indonesia are also found to increase income and empower female borrowers (Panjaitan-Drioadisuryo $\&$ Cloud, 1999). In addition, Imai et al. (2012) examine the impact of microcredit on poverty at the macro level, using cross-country panel data during 2003-2007. They find that countries with higher microfinance institutions' gross loan portfolios per capita are associated with lower levels of poverty.

Results from research in the RCT-based category are, however, ambiguous. The evidence from Bosnia and Herzegovina indicates that microcredit leads to higher self-employment activities and larger business inventories but has no impact on overall household income (Augsburg et al., 2015). Similarly, Attanasio et al. (2015) conduct a microcredit experiment in Mongolia during 2008-2011 and find that a joint-liability microcredit program targeted at women promotes entrepreneurship and food consumption. However, they do not observe any impact on income and total working hours. While these studies suggest positive results 
on certain outcome variables, a number of studies find no positive impact on important outcomes at all. For instance, Tarozzi, Desai, and Johnson (2015) assess the impact of microcredit in Ethiopia. They do not find any evidence supporting the beneficial role of microcredit on income, employment, education, and women empowerment. The research from Mexico suggests similar results. By evaluating the impact of Compartamos Banco, the largest microcredit program in Mexico and Latin America, Angelucci, Karlan, and Zinman (2015) conclude that the microcredit program has no transformative impact on critical development outcomes including income, expenditure, entrepreneurship, labor supply, and subjective well-being.

Similar to the results from other microcredit programs, the existing evidence on the VF is also mixed and inconclusive. Chandoevwit and Ashakul (2008) evaluate the impact of the VF on income, expenditure and poverty ratio of the rural households by employing the panel component of the 2002-2004 cross-sectional Socioeconomic Survey ${ }^{14}$ (SES) with propensity score matching and difference in difference method. The authors conclude that the VF has no significant impact on poverty reduction among rural households. They only find a positive impact on agricultural income of rural households living in the central region. However, non-consumption expenditure among those living in the north and the south appears to increase which is probably attributable to the higher expenditure on interest payment.

However, Boonperm et al. (2013) find different results, despite the use of the same data. The results obtained from their fixed effects model indicate that the VF slightly increases both income and expenditure of the rural households by 1.4 and 3.5 percent, respectively. Moreover, the VF is found to be pro-poor as the impacts are stronger among the lower income and expenditure quantiles. The inconsistent findings between Chandoevwit and Ashakul (2008) and Boonperm et al. (2013) raise the question about the real impact of the VF. Nevertheless, even if the two studies came up with uniform results, no definite conclusion of the $\mathrm{VF}^{\prime}$ impact can be drawn from these two studies because the underlying data is confined to rural households only but the program is offered to both urban and rural communities. Moreover, the timespan of the data is too short to detect any long-term impact, which is crucial for microcredit evaluation, as business prosperity may need time to realize.

\footnotetext{
${ }^{14}$ The Socioeconomic Survey (SES) is a nationally representative survey data conducted by the National Statistics Office since 1988. It is a cross-sectional data but in 2004, 5,755 households living in the rural area, that had been interviewed in 2002, were resurveyed (Boonperm et al., 2013).
} 
Another impact assessment of the VF is conducted by Kaboski and Townsend (2012) using the exceptionally long panel data set, the Townsend Thai data (1997-2007). The authors find that the introduction of the VF increases consumption especially on housing and vehicle repairs, meat and alcohol. However, these increases in consumption are not sustained in the long run. Business and labor market incomes increase, but business creation and expansion unexpectedly remain stable. One explanation of this peculiar result is that the sample size might be too small to detect any change in business investment, which is often small and unstable. This might be the case as although the Townsend Thai data is exceptionally long, this data set is only surveyed in four small provinces of Thailand. To confirm the results, in their parallel paper, Kaboski and Townsend (2011) also employ the structural model to predict and evaluate the impact of the VF. As a consequence, similar results are obtained.

The results from Kaboski and Townsend $(2011,2012)$ cast doubt among a number of scholars. According to Banerjee (2013), "there is clear evidence that as long as the credit is reasonably priced, it leads to business creation and/or some amount of expansion. The one exception to this is the Thailand study, but that is the only place where the process of selecting borrowers is almost entirely a black box" (p.508). His argument sounds reasonable as the decision to lend depends entirely on the VF committees and it tends to vary from village to village. However, there were some attempts trying to identify the common characteristics of those willing to apply for the credit and finally managing to receive credit from the VF. Menkhoff and Rungruxsirivorn (2011) employ a multinomial logit model with data from the Vulnerability in Southeast Asia project, which was implemented in three provinces located in the northeast of Thailand in 2007. They report that households with lower socioeconomic status are more likely to obtain credit from the VF, compared to other lending institutions. Moreover, the VF borrowers seem to share common characteristics in terms of income, assets, landholding, occupation and education with those borrowing from informal moneylenders. Boonperm et al. (2013) obtain similar results even though different data and method are used. By conducting a probit model to predict the probability of receiving credit from the VF, they conclude that the VF borrowers differ considerably from their non-borrower counterparts. Most of them are farmer and self-employed living in the northeast region. The VF borrowers also appear to have lower income and expenditure and poorer access to the health care services.

This chapter aims to fill the aforementioned research gaps and contribute to the ongoing discussion of microcredit and, in particular, the VF by answering the following research questions: 
(1) What are common characteristics of VF borrowers, in comparison to other lending sources?

(2) To what extent does the VF facilitate employment, promote income-generating activities and foster upward mobility of borrowers?

i. To what extent does the impact vary across population subgroups: female borrowers, training participants and repeated borrowers?

ii. How does the amount of the loan affect success/failure in fostering upward mobility and promoting productive activities?

The multinomial logit model is employed to answer the first research question while the second questions are examined by propensity score matching with difference in difference and Heckman Selection Models.

\subsection{Data and Methods}

\subsubsection{Data}

The Thailand Socioeconomic Panel Survey (SES-Panel) is a nationally representative longitudinal survey data conducted by the National Statistical Office (NSO). The first survey was conducted in 2005. For some sections, respondents are asked to recall their information backward up to 12 months prior to the interview. Therefore, the survey in 2005 also contains information in relation to 2004. This is also the case for the follow up surveys, which were conducted in 2006, 2007, 2010 and 2012. In total, five data waves are available so far. The first survey in 2005 covered 6,000 households including 21,450 individuals from all regions of Thailand (Bangkok Metropolitan, Central, North, Northeast and South), both from urban and rural areas. The data set contains rich information of individual characteristics such as age, gender, income, expenditure and employment status; and details of loan contracts such as source of borrowing, purpose of borrowing, interest rate charged and repayment period. The attrition rate of surveyed individuals from 2005 to 2012 is 27.7 percent. The inverse probability weight which is straightforward and commonly used in microcredit studies (e.g. Khandker \& Samad, 2014) is applied to all estimations in order to account for the potential problem of attrition bias.

In addition, although there is no explicit rule regarding the minimum age of borrowers, the data is restricted to people of working age and above by excluding individuals below the age of 15 years. Moreover, individuals who obtained credit in 2005, regardless of the lending 
source, are also dropped. This step excludes 2,795 observations (from 21,450 observations) in 2005 from the sample. It is acknowledged that this choice of sample selection may bias the results. However, this is justified by the fact that the VF was in place before the SES-Panel was collected meaning that the real baseline is not available. Dropping individuals with credit in 2005 thus allows the analyses to use 2005 as the pre-treatment baseline. The panel is then balanced by keeping only the observations that have information in all five waves. The final balanced sample size consists of 8,994 individuals per wave.

\subsubsection{Choice of Credit Sources}

Following the classification of financial institutions by Bird et al. (2011), Lewis et al. (2013), and Tambunlertchai (2017), and the number of observations available, lending institutions are divided into four different groups. The first group is formal financial institutions including commercial banks (CB) and the specialized state financial institutions namely Bank of Agriculture and Agricultural Cooperatives (BAAC) and Government Savings Bank (GSB). The semiformal institutions are divided into two groups. The VF is put into a separate group as their borrower characteristics are of this chapter's interest. Other semiformal institutions such as cooperatives and occupational groups are combined in the third group. The SES-Panel data does not contain information on informal financial institutions. However, there is some information available about informal sources of credit such as relatives, neighbors and informal moneylenders. Hence, these informal credit sources are grouped into the last category.

To sum up, the four groups of lending sources in this analysis are (1) formal sources i.e. CB, BAAC and GSB, (2) the VF, (3) cooperatives and occupational groups, and (4) informal sources. The descriptive statistics of borrowers, at baseline, classified by lenders as well as the descriptive statistics of non-borrowers are presented in Table 4.1. As can be seen, individuals with lower socioeconomic status tend to borrow from the VF and informal sources. The summary statistics of loan contracts by choices of lenders are also presented in the same table. In line with previous studies (e.g. Kaboski \& Townsend, 2012; Menkhoff \& Rungruxsirivorn, 2011), the VF appear to have the lowest interest rate and offer the smallest loan size, compared to other sources. 


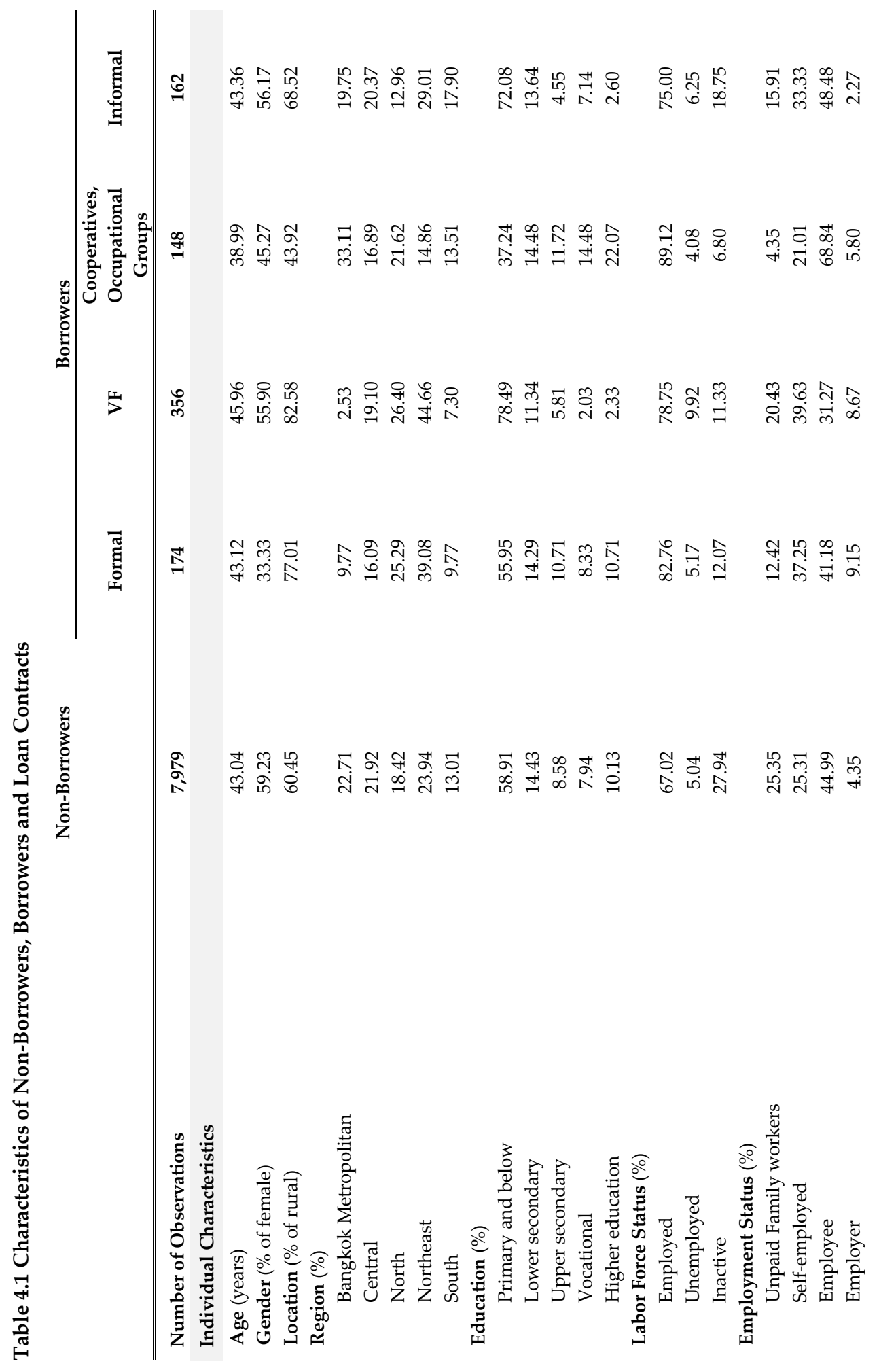




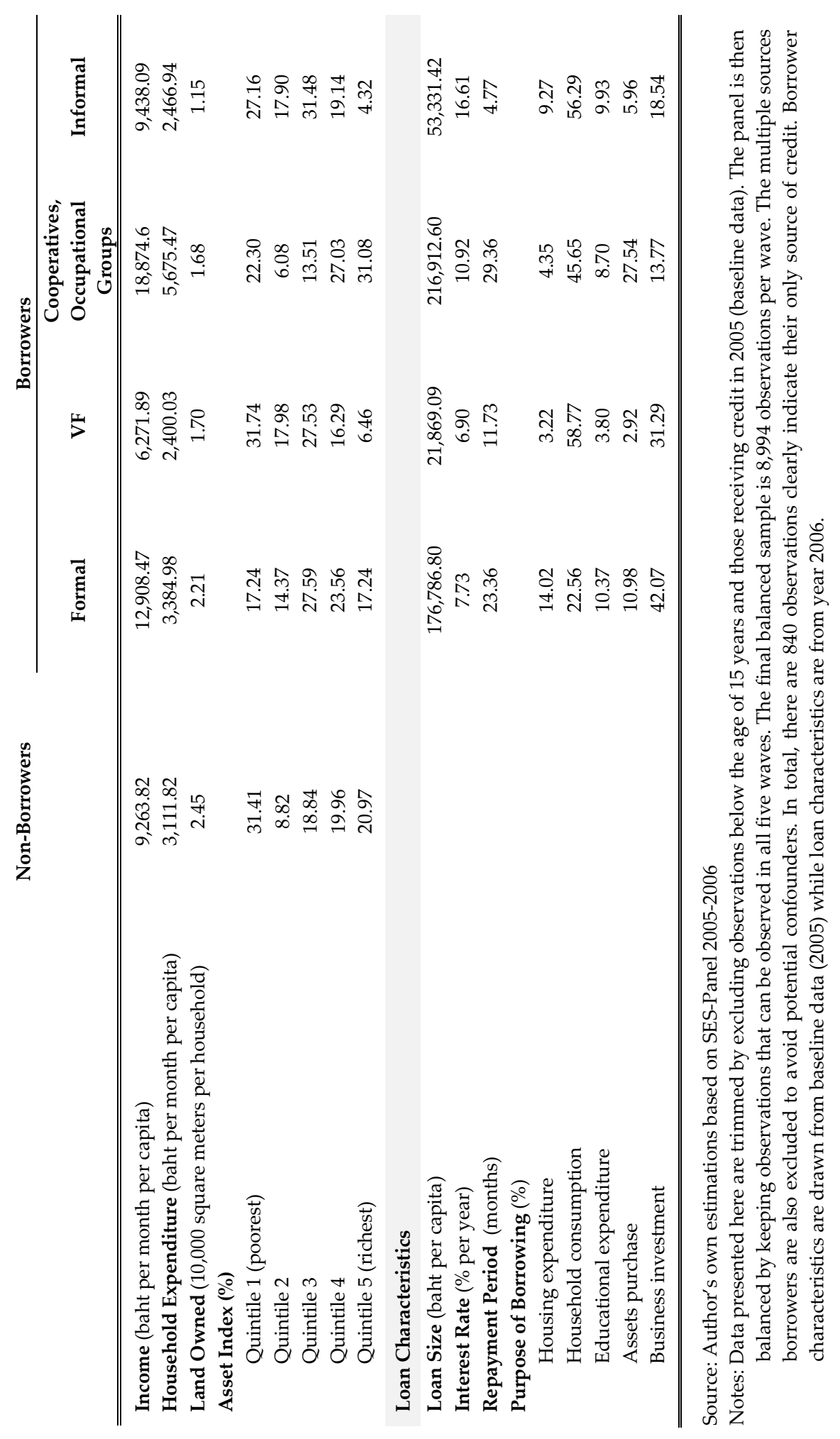


An asset index is also constructed to represent resources that can be used to support income-generating activities. The asset index is constructed by Principal Component Analysis (PCA) which can combine a number of variables into one single index according to its relative importance (Fry, Firestone, \& Chakraborty, 2014). Items included in the asset index are mainly productive durables. These items are recorded as continuous variables indicating the number of that item owned by a household. The selection of the items is guided by previous relevant studies (e.g. Moser \& Felton, 2007; Salia, 2014) and the availability of the data. ${ }^{15}$ After that, the asset index is normalized to a range between zero and one (0-1) using the min-max scaling method ${ }^{16}$ to avoid negative values of the index. The asset index is established at the household level as the assets used to construct the index are normally owned and consumed by the household. This study then assumes that individuals living in the same household are equivalent in terms of assets. Finally, quintiles are used to illustrate the proportion of individuals that fall into each asset quintile. ${ }^{17}$

As the lending source is the dependent variable in this analysis, a multinomial response model is appropriate. In comparison to multinomial probit models, multinomial logit models are simpler and less likely to experience practical limitations (Wooldridge, 2010) as it does not require computing integration. Therefore, the following multinomial logit model is applied in order to examine the common characteristics of the VF borrowers, compared to other credit sources;

$$
\operatorname{Pr}\left(y_{i t}=k\right)=\frac{\exp \left(\alpha_{k} X_{i t-1}\right)}{\sum_{m=1}^{4} \exp \left(\alpha_{m} X_{i t-1}\right)}
$$

where $y_{i t}$ is a categorical dependent variable denoting the individual's choice of lenders. $X_{i t-1}$ is a set of control variables, lagged by one period, that may influence the individual's choice of credit sources including age, gender, level of education, labor force status (employed, unemployed, inactive) and employment status of employed individuals (self-

\footnotetext{
${ }^{15} \mathrm{~A}$ total of 13 productive durable items, of which the data is available, are used to construct the index including landline phone and fax, computer, internet access, mobile phone, motorcycle, bike, car, pickup truck, Thai etan truck, traditional plough, tractor, boat and six-wheeled truck or larger vehicles.

${ }^{16}$ The min-max scaling is calculated by $X_{\text {normalized }}=\frac{X-X_{\min }}{X_{\max }-X_{\min }}$

${ }^{17}$ Asset index quintiles is calculated using only observations in the final balanced sample, not the entire population, since this chapter would like to focus the impact only on our target group. However, all estimations are also replicated using asset index quintiles that are generated from the entire population to further verify the robustness of the results and no significant differences between the two methods are observed.
} 
employed, employee, employer), location of residence (rural/urban), geographical region (Bangkok Metropolitan, Central, North, Northeast, and South), income, expenditure, asset index, land owned and loan purposes.

The study firstly examines how individuals sort themselves into different lending programs in 2006 using individual characteristics in 2005 to ensure that the observed characteristics, which may influence the choice of lenders, reflect the situation before program participation. Individuals borrowing from more than one lending source (166 individuals in total) are also excluded from the analysis to control for potential confounders. The final number of observations used for the analysis in 2006 is 840. In addition, the results for 2012 are also provided, using the characteristics from 2010, since data in 2011 is not available, to analyze how this decision changes over time. After excluding multiple-sources borrowers, the final sample size used for the analysis in 2012 is 720 observations.

\subsubsection{Impact Assessment}

To analyze the impact of the VF, a binary variable indicating borrowing status in 2006 is used as the treatment variable and 2005 as the baseline. Those who do not borrow in 2006 but do borrow in subsequent years $(2007,2010$ or 2012) are excluded from the analyses so that the analyses can make the causal inference about the effect of the VF in 2006 which is used as the treatment variable. Then, individuals who receive credit from the VF, and nothing else, in 2006 are considered as treated observations. It would be remiss not to note that the exclusion of observations may induce another source of bias to the results. However, since the complementarity between programs is also of interest of this thesis, the impact assessment in this chapter applies the similar estimation design as conducted in Chapter 3 so that the impact of training and the VF can be compared and considered in a similar fashion.

In total, there are 356 treated observations in the analysis. With regard to the control group, two different definitions are applied in this study. The first control group are non-borrowers or individuals who do not obtain credit from any source at all. There are a total of 6,458 observations of this non-borrowing control group in the final balanced sample. The second control group are non-VF borrowers or those who obtain credit from other lending sources but not from the VF. This group comprises 544 observations. The balance test of the treatment and both control groups at baseline are presented in Table 4.2. 


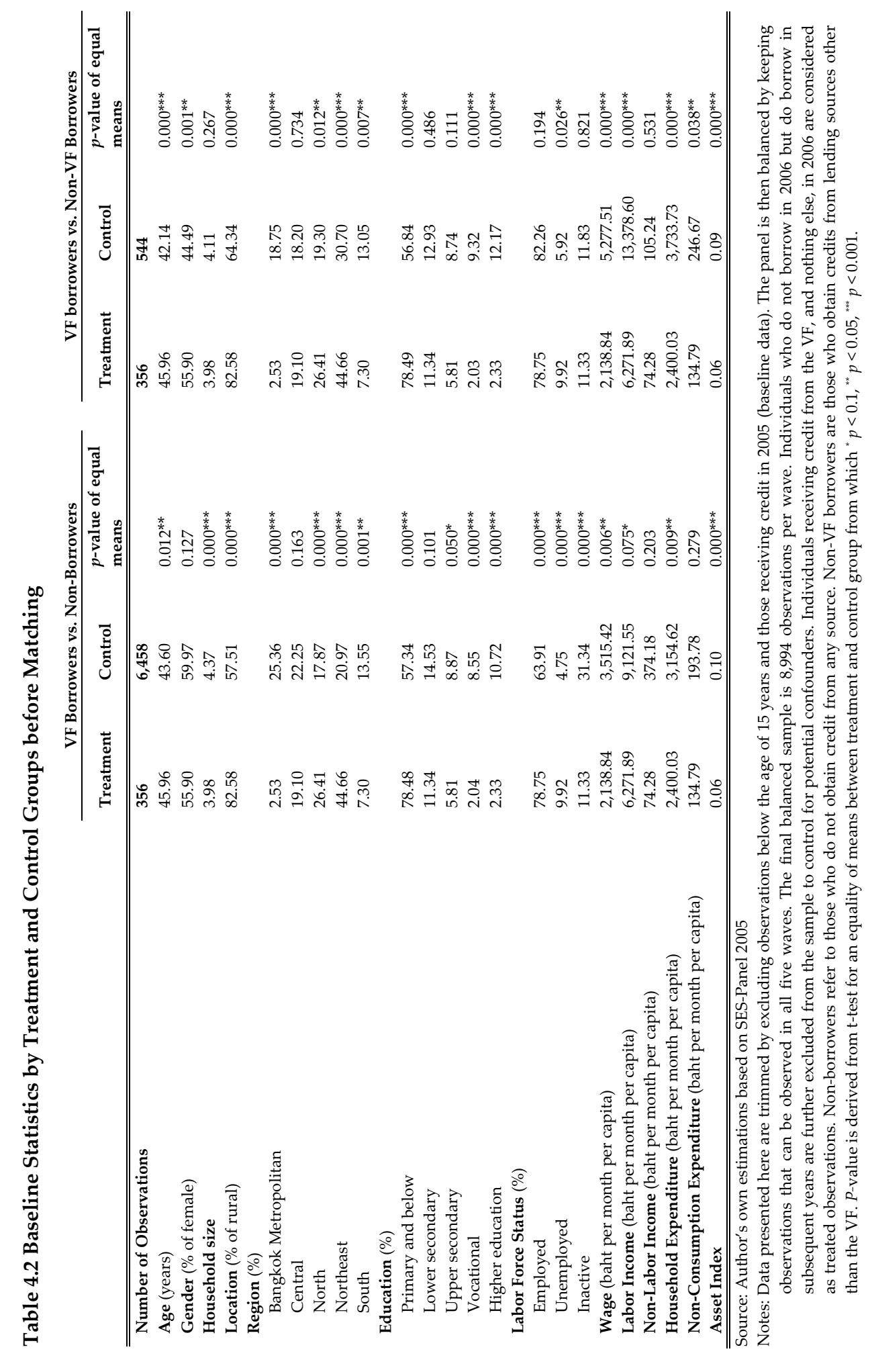


As can be seen, there are serious imbalances between treated and controlled observations at the pre-intervention baseline in several characteristics.

With regard to the outcome variables, this chapter examines the impact of the VF on upward mobility through three main outcomes of interest. First, this study measures the impact of the VF on absolute mobility with respect to income per capita, household expenditure per capita and asset index. With regard to income variables both labor and nonlabor income are considered. Labor income refers to the total of all returns from labor supply including wage, farm income, and non-farm income. Farm income in this data set was collected at household level. It is converted to individual level by dividing the total household farm-income by the number of household members at the age of 15 years or older. This is justified by the fact that workers aged less than 15 years is considered as an illegal child laborer in Thailand. Therefore, income of those younger than 15 years should be only from transfers, not labor activities. Non-labor income, in this study, refers to payment received from any source other than work including public transfers, rent income, interest and dividend. A per adult income is measured on monthly basis and is transformed to natural logarithm.

Expenditure is also used as a dependent variable in order to reflect changes in an individual's living standard. Household expenditures include all living expenses namely housing, food, drinks, tobacco, health, education, transportation, recreation/entertainment, personal and social expenditure, transfer to other households, and other non-consumption expenditure. In the Thailand SES-Panel, information on household expenditure is collected at individual level. However, it is recognized that some expenses, especially housing and food, should be measured at household level. Therefore, housing and food expenditure are converted to household level by adding amounts of housing and food expenses paid by all household members and divide it by household size to get the household expenditure per capita. To assess the impact of the VF on different types of expenditure, this chapter also examines the impact on non-consumption expenditure separately. This non-consumption expenditure is reported in one single variable and includes expenditure on tax, insurance premium, contribution to social security, interest payment, lottery and gambling. Like income, expenditure is also measured on a monthly basis and converted to natural logarithm. Finally, the asset index which is constructed from productive durables is used to measure whether borrowing from the VF increase resources used to support incomegenerating activities. 
Second, this study analyzes the effect of the VF on upward relative income, expenditure and asset mobility defined as a positional movement in income, household expenditure and asset index ranking. An individual is moving upward if he/she moves to higher income, expenditure or asset index ranking in a subsequent period. An evaluation of microcredit on relative mobility, to my knowledge, has never been studied before. Third, the impact of the VF on income-generating activities or labor mobility is examined. A number of indicators are constructed to reflect changes in labor mobility including an improvement in labor force status, a transition to formal employment, business creation and business expansion. The first two indicators, improvement in labor force status and formality of employment, indicate the degree to which the VF facilitates job search and career development. The latter two indexes, on the other hand, reflect the impact of the VF on self-employment and entrepreneurial activities. Labor force status is categorized, in an ascending order, as inactivity, unemployment and employment. A transition to formal employment measures the prospect of upward movement from being informally employed to a formal employee. Business creation is measured as a transition to entrepreneur, either employer or selfemployed. Lastly, business expansion is measured by natural logarithm of business and agricultural expenditure, and growth rate of farm and non-farm business income.

Regarding econometric models used to evaluate the impact of the Village Fund on the outcome variables of interest, the balance test in Table 4.2 suggests that the treatment and control group are significantly different in several dimensions. A person with lower socioeconomic status is more likely to borrow from the VF. The treatment group appears to have lower income, lower expenditure and fewer assets, compared to both the nonborrowers and non-VF borrowers. There are several alternatives to address this potential problem of selection bias. For example, Kaboski and Townsend (2012) and Boonperm et al. (2013) apply instrumental variable with fixed effect model, using the inverse number of households in the village as an instrument, in their study. However, due to the availability of data, this analysis does not have sufficient information to generate valid instruments. Therefore, propensity score matching with difference in difference method is used to examine the impact of the VF on upward mobility.

Propensity scores are calculated by the probability of borrowing from the VF conditional on observable characteristics of individuals (Khandker, Koolwal, \& Samad, 2010) or $P(X)=$ $\operatorname{Pr}\{T=1 \mid X\}$ where $\mathrm{T}$ indicates the VF participation in 2006 . $\mathrm{T}$ is equal to " 1 " for treated individuals and " 0 " for individuals in control groups. $X$ is a set of individual characteristics at baseline (2005) that are likely to influence borrowing decision including age, gender, 
urban-rural setting, region, education, labor force status and household size. The treatment and control groups are then matched by one-to-one nearest neighbor matching without replacement, which is the most common and straightforward matching technique and not subject to the problem of choosing optimal width of caliper (Caliendo \& Kopeinig, 2008).

The final matched sample of the VF borrowers is 341, which is also equal to the final matched sample of the non-borrowers and the non-VF borrowers. The balance test and descriptive statistics of the matched sample are presented in Table 4.3. As can be seen, the treatment and control groups become more comparable in all observed dimensions. Although gender, age, fraction of people with primary education or less and labor income of VF and Non-VF borrowers are found to be statistically different, the difference is only significant at the 10 percent level. Moreover, the three variables are included in the difference in difference regressions as control variables to take into account this (weakly) imbalanced baseline. The matched samples are applied to the following difference in difference equation to obtain the impact of the VF on absolute income, expenditure and asset mobility and business expansion:

$$
y_{i t}=a_{0}+a_{1} T_{i 1}+a_{2} t+a_{3} T_{i 1} t+a_{4} X_{i t}+u_{i t}
$$

where $y_{i t}$ is the natural logarithm of income, household expenditure, and business expenditure, and the asset index. $t$ is the time which is equal to " 0 " at the baseline (2005) and " 1 " in the year after borrowing from the VF (2006, 2007, 2010 or 2012). $X_{i t}$ is a set of control variables which may associate with the dependent variable and were not strongly balanced such as gender and age. Other variables that were not used to calculate the propensity score are also included such as training participation, total volume of land owned, a dummy variable indicating whether individuals borrow in subsequent years (repeated borrower) and a dummy variable for individuals borrowing from multiple sources. The coefficient of the interaction term between treatment and time $\left(a_{3}\right)$ is the treatment effect (Khandker et al., 2010). 


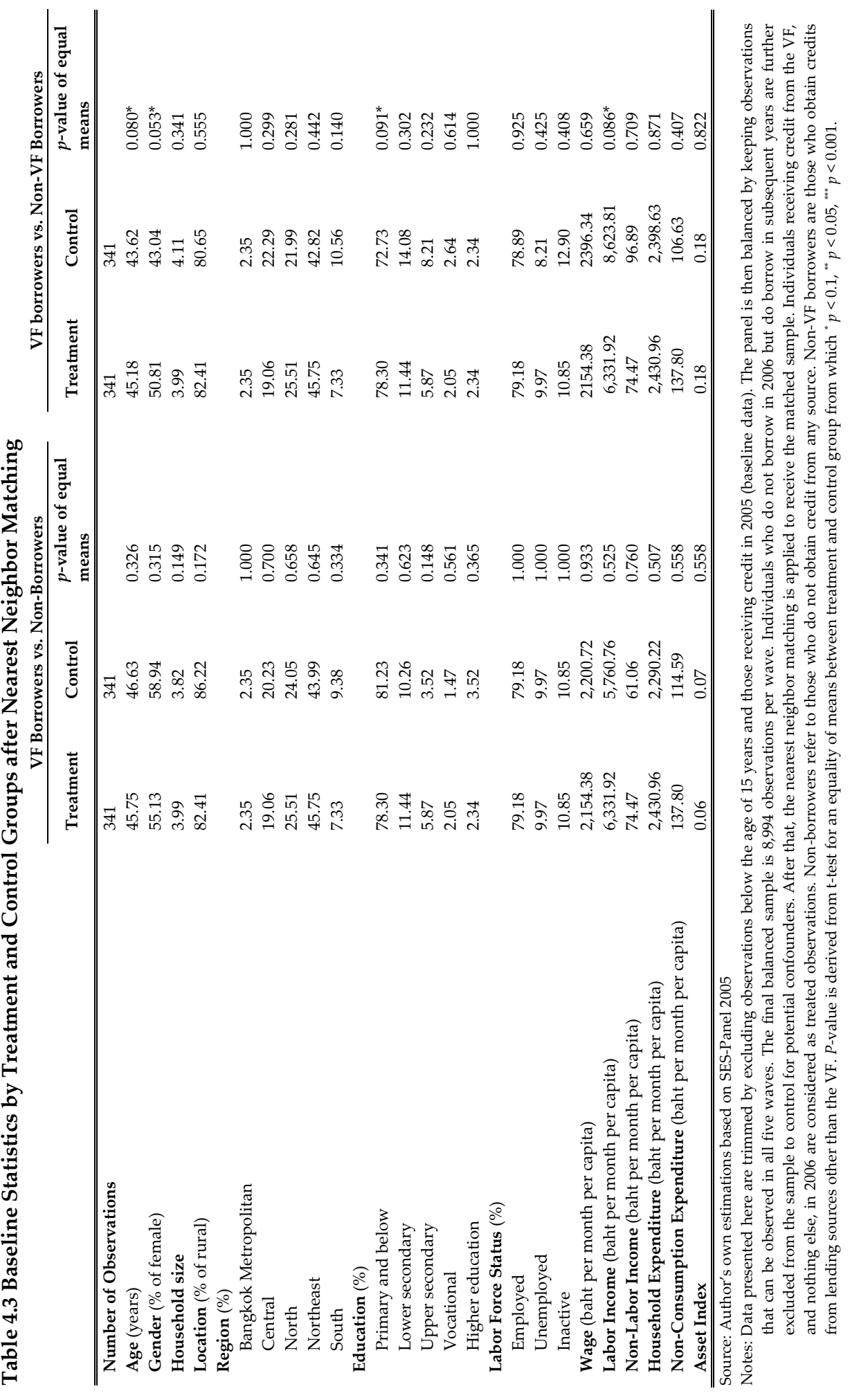


The logit model is also conducted to examine the impact of the VF on relative mobility with respect to income, expenditure and asset quintiles; and labor mobility. In equation (3), with regard to relative income, expenditure, and asset quintiles mobility, the dependent variable $\left(g_{i t}\right)$ takes the value " 1 " if an individual moves upward to higher income, expenditure and asset quintiles ranking position, and " 0 " otherwise. For labor mobility, $g_{i t}$ is equal to " 1 " if an individual moves to a better labor force status, make a transition from an informal to formal labor, or become an employer or self-employed. $g_{i t}$ is also equal to " 1 " if he/she maintains the highest status. On the other hand, $g_{i t}$ takes the value " 0 " if an individual experiences downward mobility or remains stuck in the low status.

$$
\operatorname{Pr}\left(g_{i t}=1\right)=\frac{1}{1+e^{-\left(c_{0}+c_{1} T_{i 1}+c_{2} t+c_{3} T_{i 1} t+c_{4} X_{i t}+v_{i t}\right)}}
$$

In addition, equation (2) is extended by adding interaction of treatment, time, and individual characteristics at baseline $\left(T_{i 1} t I_{i 0}\right)$ to further examine whether the VF impact vary across population subgroups. The impact heterogeneity is obtained by the following equation

$$
\operatorname{lny}_{i t}=\alpha_{0}+\alpha_{1} T_{i 1}+\alpha_{2} t+\alpha_{3} T_{i 1} t+\alpha_{4} X_{i t}+\gamma T_{i 1} t I_{i 0}+\varepsilon_{i t}
$$

where $\mathrm{I}_{\mathrm{i} 0}$ are variables for individual characteristics which its impact heterogeneity are of particular interest including gender, training participation and a dummy variable indicating whether or not an individual is a repeated borrower, or those who borrow in consecutive years. For example, repeated borrowers in 2007 are ones who continues borrowing in both 2006 and 2007 and repeated borrowers in 2012 are ones who borrows in 2006, 2007, 2010 and 2012. The impact assessments utilize all five waves of the SES-Panel $(2005,2006,2007,2010$ and 2012). Changes that occurred from 2005 to 2006, or within a year after borrowing, are perceived as a short-term impact. A change from 2005-2007, or between 1-2 years after borrowing, is treated as a medium-term effect. Lastly, changes that occurred between 2005 and 2010, 4-5 years after borrowing, and 2005 and 2012, 6-7 years after borrowing, are considered as long-term impacts.

The difference in difference method relaxes the assumption of selection only on observable characteristics. However, its validity relies on the assumption that unobservable factors that may influence program participation and outcomes of interest or "the selection bias" are time-invariant (Khandker et al., 2010). In other words, it requires that in the absence of the 
VF, the treatment and control groups have parallel trend in outcomes. In this study, the propensity score matching in the first step gives us a comparable, in terms of individual characteristics, treatment and control group. Moreover, there are no changes at the macro level, either in terms of policy or macroeconomic conditions, to my knowledge, that affect the borrowers and non-borrowers differently. Therefore, the parallel trend assumption is plausible. As guided by Attanasio et al. (2010) and Canelas and Niño-Zarazúa (2019), the parallel trend assumption is also formally examined using data from 2005 which is considered as the pre-treatment period in this chapter. The results presented in Table 4.4 suggest that the outcome trends between treatment and control are not statistically different. The parallel trend assumption is thus likely to hold true.

Table 4.4 Pre-Program Time Trends in Mobility Outcomes

\begin{tabular}{|c|c|c|}
\hline & $\begin{array}{c}\text { Treatment*Year } 2005 \\
\text { (non-borrowers) }\end{array}$ & $\begin{array}{c}\text { Treatment*Year } 2005 \\
\text { (non-VF borrowers) }\end{array}$ \\
\hline \multicolumn{3}{|l|}{ Absolute Mobility } \\
\hline Labor Income & $\begin{array}{l}-0.187 \\
(0.123)\end{array}$ & $\begin{array}{l}-0.026 \\
(0.110)\end{array}$ \\
\hline Wage & $\begin{array}{c}0.061 \\
(0.197)\end{array}$ & $\begin{array}{c}0.022 \\
(0.203)\end{array}$ \\
\hline Business income & $\begin{array}{c}0.210 \\
(0.190)\end{array}$ & $\begin{array}{l}-0.029 \\
(0.225)\end{array}$ \\
\hline Agricultural income & $\begin{array}{c}0.044 \\
(0.111)\end{array}$ & $\begin{array}{l}-0.154 \\
(0.098)\end{array}$ \\
\hline Non-Labor Income & $\begin{array}{l}-0.102 \\
(0.111)\end{array}$ & $\begin{array}{c}0.115 \\
(0.120)\end{array}$ \\
\hline Household Expenditure & $\begin{array}{c}0.026 \\
(0.069)\end{array}$ & $\begin{array}{l}-0.065 \\
(0.080)\end{array}$ \\
\hline Food, drink and tobacco & $\begin{array}{l}-0.057 \\
(0.058)\end{array}$ & $\begin{array}{l}-0.061 \\
(0.054)\end{array}$ \\
\hline Non-consumption expenditure & $\begin{array}{c}0.015 \\
(0.196)\end{array}$ & $\begin{array}{l}-0.139 \\
(0.200)\end{array}$ \\
\hline Asset Index & $\begin{array}{l}-0.004 \\
(0.005)\end{array}$ & $\begin{array}{l}-0.007 \\
(0.005)\end{array}$ \\
\hline \multicolumn{3}{|l|}{ Relative Mobility } \\
\hline Labor Income Rank & $\begin{array}{c}0.006 \\
(0.022)\end{array}$ & $\begin{array}{l}-0.004 \\
(0.020)\end{array}$ \\
\hline Expenditure Rank & $\begin{array}{c}0.032 \\
(0.052)\end{array}$ & $\begin{array}{l}-0.053 \\
(0.050)\end{array}$ \\
\hline Asset Quintiles Rank & $\begin{array}{l}0.0150 \\
(0.036)\end{array}$ & $\begin{array}{c}0.031 \\
(0.036)\end{array}$ \\
\hline \multicolumn{3}{|l|}{ Labor Mobility } \\
\hline Labor Force Status & $\begin{array}{c}0.033 \\
(0.043)\end{array}$ & $\begin{array}{l}-0.043 \\
(0.031)\end{array}$ \\
\hline Formality of Employment & $\begin{array}{l}-0.036 \\
(0.027)\end{array}$ & $\begin{array}{c}0.030 \\
(0.024)\end{array}$ \\
\hline
\end{tabular}




\begin{tabular}{lcc}
\hline \hline Business Creation & 0.002 & -0.007 \\
Business Expansion & $(0.039)$ & $(0.034)$ \\
\multirow{2}{*}{ Business expenditure } & -0.100 & \\
& $(0.176)$ & 0.164 \\
Agricultural expenditure & -0.215 & $(0.245)$ \\
& $(0.144)$ & -0.191 \\
Growth rate of business income & 0.444 & $(0.136)$ \\
& $(0.442)$ & 0.334 \\
Growth rate of agricultural income & -0.048 & $(0.832)$ \\
& $(0.218)$ & -0.116 \\
\hline \hline
\end{tabular}

Notes: Coefficients are estimated using nearest neighbor matching and difference in difference approach. Control variables as discussed in equation (2) are included but not shown here. Marginal effects are reported for relative mobility, labor force status, formality of employment and business creation. Standard errors in parentheses and ${ }^{*} p<0.1,{ }^{* *} p<0.05,{ }^{* * * *} p<0.001$.

With difference in difference method, the impact of the VF is obtained by examining whether program participation leads to upward mobility. In other words, a binary treatment variable, borrow or not borrow, is used to analyze the impact. However, it is also interesting to see if the amount of credit matters. Following the approach used in Ibrahim and Bauer (2013), the Heckman Selection Model is applied to this analysis. Heckman's model (1976, 1979) comprises two steps of estimations. The first step is a selection equation describing program participation conditional on observable characteristics of an individual. The second step estimates determinants of an outcome of interest by including the inverse Mill ratio $(\lambda)$ obtained from the selection equation, as another explanatory variable to address a potential problem of selection bias and possible omitted variables (Akotey \& Adjasi, 2016).

$$
\begin{aligned}
& \text { Selection } \\
& \text { equation: } \\
& \text { Outcome } \\
& \qquad \begin{array}{c}
\operatorname{Pr}\left(y_{1 i t}=1\right)=\Phi\left(\pi Z_{i t-1}+u_{1 i t}\right) \\
\text { equation: }
\end{array} \\
& y_{2 i t}=\beta_{0}+\beta_{1} \text { Loansize }_{i t}+\beta_{2} X_{i t}+\beta_{3} \lambda_{i t}+u_{2 i t}
\end{aligned}
$$

where

$$
\begin{gathered}
u_{1} \sim N(0,1) \text { and } u_{2} \sim N(0, \sigma) \\
\operatorname{Corr}\left(u_{1} u_{2}\right)=\rho
\end{gathered}
$$

In this chapter, the Heckman Selection Model is applied to the final balanced and trimmed data before matching. The results in 2006, 2007, 2010 and 2012 are all examined to see if the role of loan size changes over time. In equation (5), $y_{1 i t}$ is a binary variable denoting 
program participation. It is equal to " 1 " for those borrowing from the VF (VF borrower) and “ 0 ” for non-borrowers.

$Z_{i t-1}$ denotes individual characteristics which are likely to influence decision of a person to apply for the VF, the VF to grant credit and that person to take credit from the VF including age, gender, urban-rural setting, region, education, labor force status and household size. It is worth noting that variables used to model program participation here are similar to the ones we use in the matching step of difference in difference method. $Z$ is also lagged by one period to ensure that individual characteristics are before the start of the program. However, as data in 2008, 2009 and 2010 are not available, $\mathrm{Z}$ needs to be lagged by three periods in 2010 and two periods in 2012. Therefore, the results in 2010 is obtained by using the uptake of the VF $\left(y_{1 i t}\right)$ in 2010 and characteristics $\left(Z_{i t-1}\right)$ in 2007 while the results in 2012 is estimated from the uptake of the VF $\left(y_{1 i t}\right)$ in 2012 and characteristics $\left(Z_{i t-1}\right)$ in 2010.

Equation (6) is the outcome equation where $y_{2 i t}$ denotes income, expenditure, business expansion, in natural logarithm, and asset index. Loansize Lit $_{\text {is }}$ an amount of loan, also in natural logarithm, which a borrower receives from the VF. $X_{i t}$ is control variables such as age, gender, education, marital status, urban-rural setting, gender, household size, labor force status, occupation, amount of land owned, and training participation. $\lambda_{i t}$ is an inverse Mill ratio which is calculated by $\lambda_{i t}=\frac{\varphi\left(\pi \hat{Z}_{i t-1}\right)}{\Phi\left(\pi \hat{Z}_{i t-1}\right)}$ (Akotey \& Adjasi, 2016; Heckman, 1979).

\subsection{Results}

This section presents the results obtained from the estimations explained in the previous section. It starts with the results from multinomial logit model which examine what are common characteristics of VF borrowers. Then the impacts of the VF on borrowers' socioeconomic upward mobility are presented.

\subsubsection{Characteristics of VF Borrowers}

Table 4.5 presents common characteristics of the VF borrowers relative to the other three lending sources. In 2006, the results suggest that older women living outside of Bangkok Metropolitan are more likely to borrow from the VF. According to the results, getting one year older and being female increase the average probability of a person to apply for the VF, the VF to grant credit and that person to take credit from the VF by 0.003 and 0.07 , respectively. Moreover, it is observed that the VF are more common among low educated 
borrowers (those obtaining primary education or below) than borrowers with vocational and higher education. Having higher education decreases the average probability to apply and obtain credit from the VF by 0.25 , in comparison to those with only primary education or below. However, a size of land and amount of assets that a person occupies have no impact on a decision to borrow and receive credit from the VF. Similarly, income and household expenditure of VF borrowers is not statistically different from other credit sources. Furthermore, urban-rural setting, labor force status (inactive, unemployed or employed) and employment status (unpaid family workers, self-employed, employee or employer) do not seem to play a role in the decision to borrow and take credit from the VF in 2006. The results also suggest an interesting result regarding loan purpose. It is found that the VF borrowers tend use the obtained credit for household consumption than for business investment. Nevertheless, they prefer to use credit for business investment over housing expenditure and assets purchase.

The estimation in 2012 is also conducted, using borrower characteristics in 2010, to further examine how these results change over time. The results indicate that the VF remains common to an individual with low socioeconomic status, defined by residential area (region), education, labor force status and income. Borrowers living outside of the capital city and surroundings continue to borrow from the VF. Moreover, labor status is found to have greater role as the VF borrowers tend to be unemployed than employed. However, while the VF borrowers continue to borrow to consume than to invest, they are found to be more employer than inactive, unemployed and unpaid family workers. At the same time, while household expenditure and amount of asset and land owned remain insignificant, the VF borrowers in 2012 are found to have lower income, in comparison to borrowers from other credit sources.

It is recognized that the multinomial logit model assumes the independence of irrelevant alternatives (IIA). This chapter therefore conducts the Hausman test to ensure that the assumption of IIA is not violated. As presented in Table 4.6, the null hypothesis that IIA holds for the multinomial logit model in both 2006 and 2012 cannot be rejected. Therefore, the assumption of IIA holds for these estimations. 


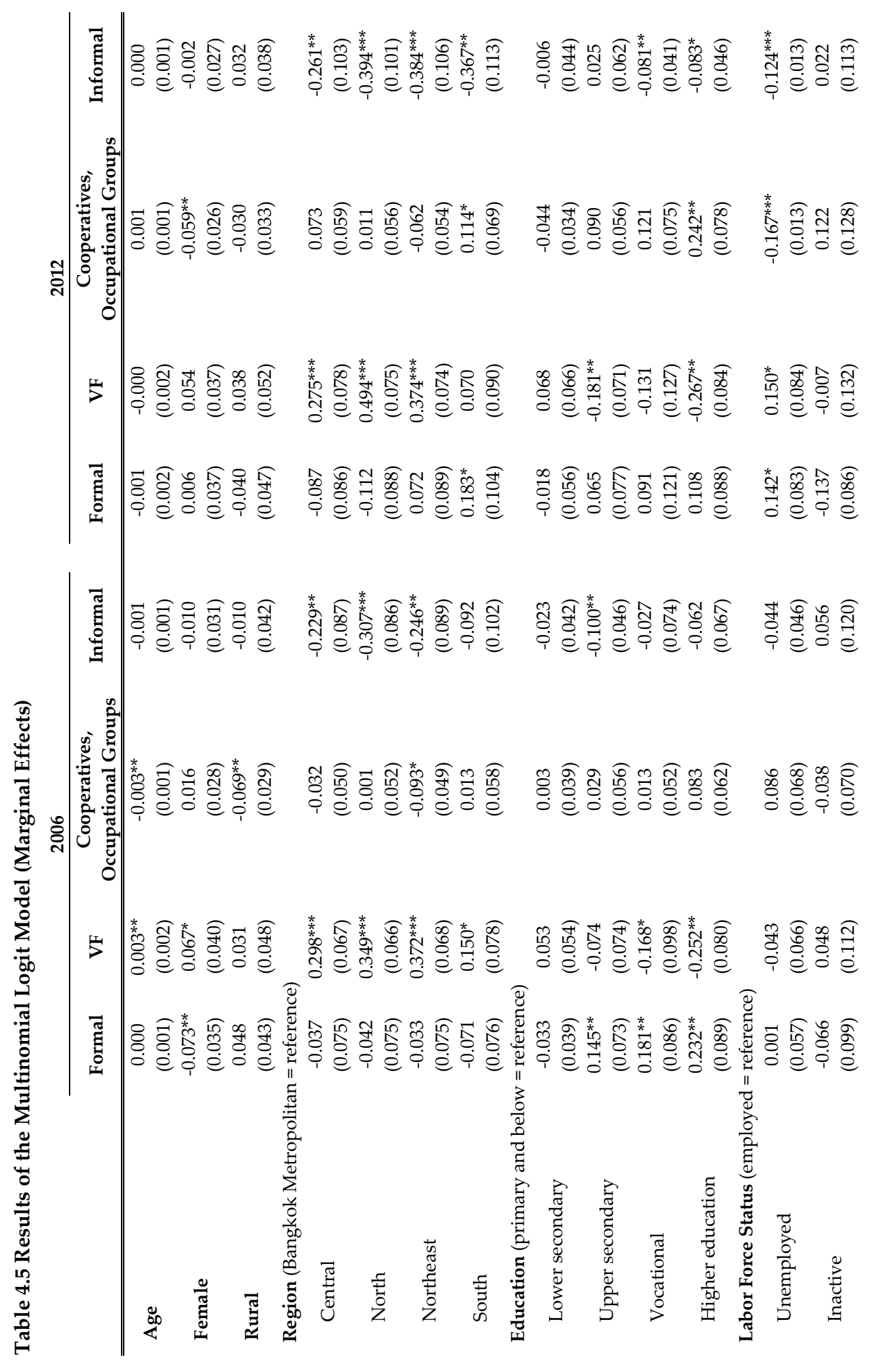




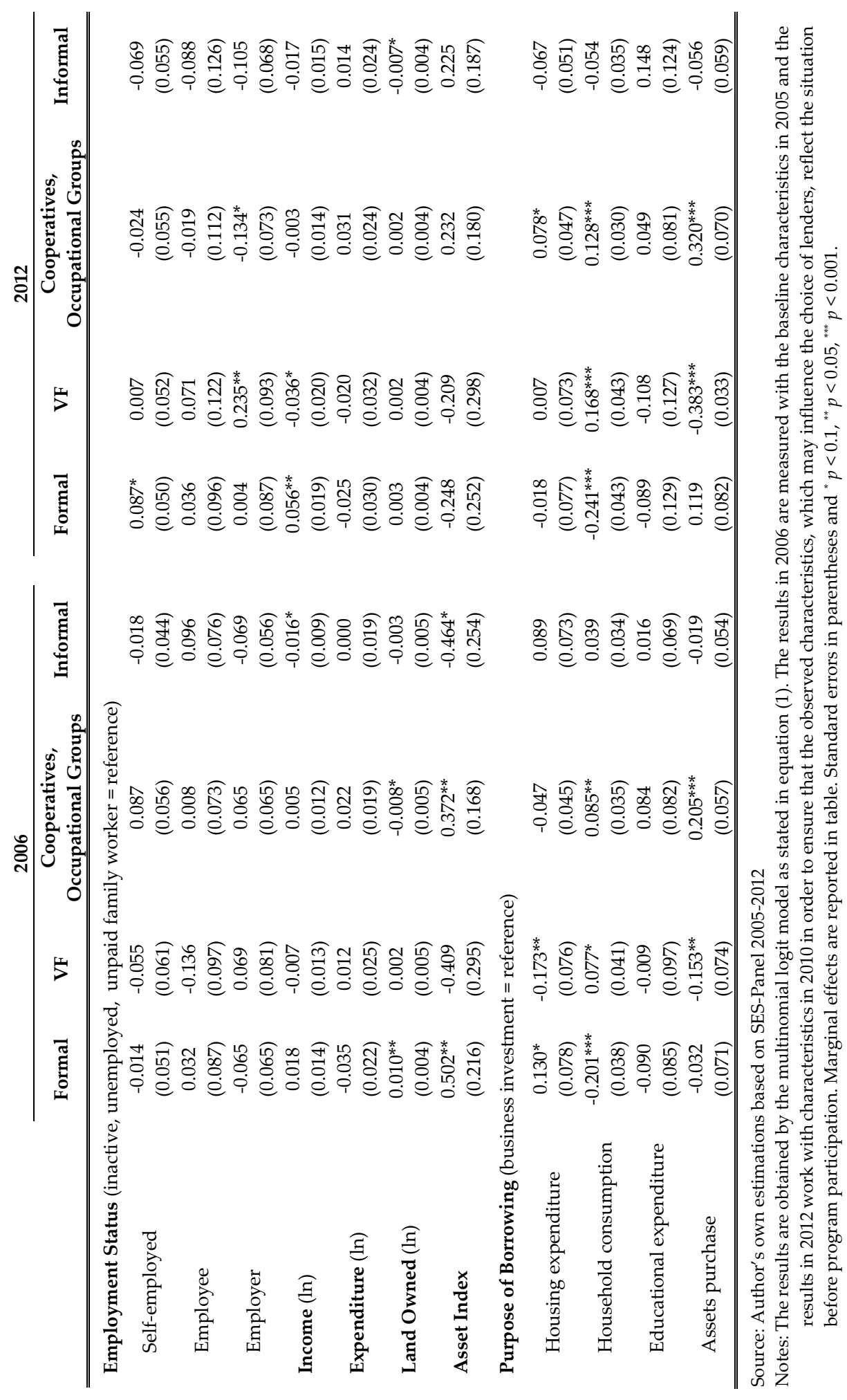




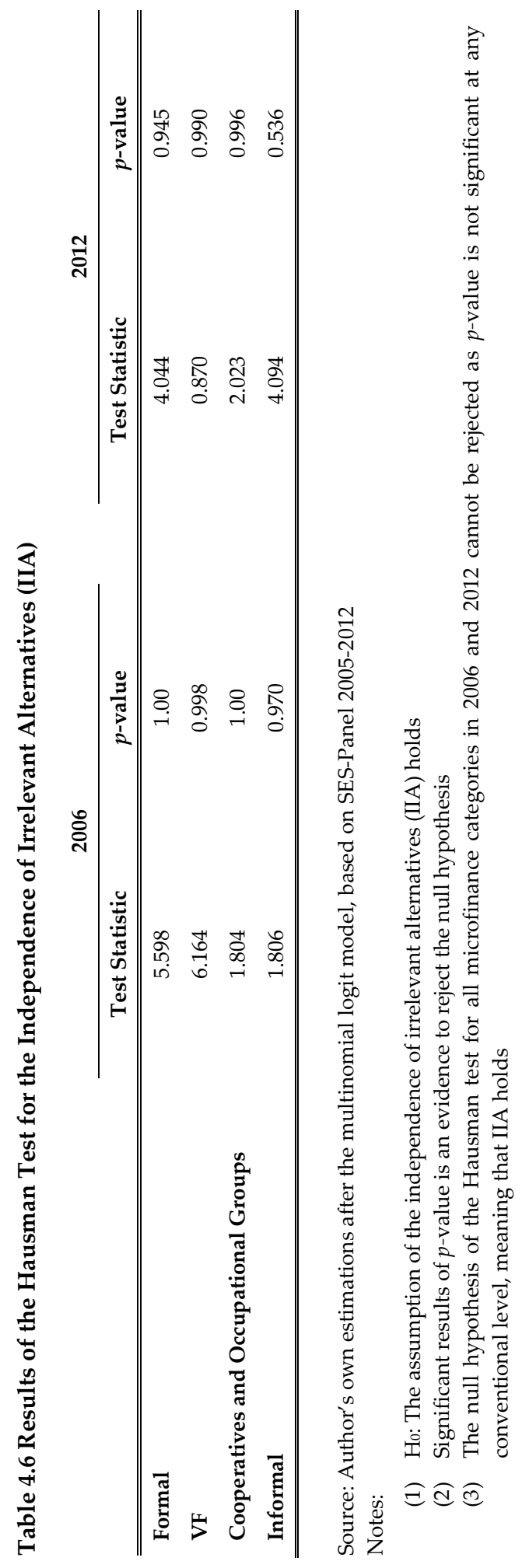




\subsubsection{Impacts of the VF}

In addition to characteristics of VF borrowers, this chapter also aims to give answers to questions: does the VF actually work? for whom does the VF work? and to what extent that larger loans result in better outcomes? Table 4.7 presents the impact of the VF on absolute and relative income, expenditure and asset mobility. Having non-borrowers as the control group, this study finds no significant impact of the VF on aggregate labor income and its components; wage, business income and agricultural income. Surprisingly, non-labor income including interest and dividends, rent income and public transfers, increases by 49.1 percent in the medium term and 68.6 percent in the long term, although it does not persist beyond five years after borrowing. Participation in the VF is also found to have no significant impact on household expenditure in any of the time duration. Another surprising result is found on non-consumption expenditure. It is observed that additional resources from the VF considerably increases payment on tax, insurance premium, contribution to social security, interest payment, lottery and gambling altogether in all time horizons by around 78-106 percent. This peculiar result found on non-consumption expenditure shall be discussed in the next section.

Similar impacts on income are found when VF borrowers are compared to those who obtain credit from other sources. This study does not observe any beneficial role of the VF on labor income and its components. The impact on non-labor income remains significant in the long run, although the medium-run impact is found to be insignificant. However, the positive effect on non-consumption expenditure vanishes in all time duration when non-VF borrowers are used as counterfactuals. With regard to the impact of the VF on relative income, expenditure and asset quintiles mobility, there is no credible evidence indicating that the VF are effective in moving their borrowers upward to a higher ranking in the income, expenditure and asset index distributions, regardless of which counterfactual is used.

Similarly, as presented in Table 4.8, the impact of the VF on upward labor mobility is also insignificant. The VF appears to have no impact on employment both in terms of quantity, as there is no effect on the transition to a better labor force status, and quality, as the transition to formal employment remains unchanged. Likewise, there is no evidence for new business creation implying that the VF are not effective in incentivizing people to become entrepreneur. The only significant impact of the VF on labor mobility is the impact on nonfarm business investment. The VF considerably increases non-agricultural business 
expenditure by almost 105 percent. However, this significant impact is only significant at the 10 percent level, materialized in 4-5 years after borrowing and does not persist beyond five years. Moreover, the impact also disappears when non-VF borrowers are considered as a control group.

As a robustness check, the results are estimated using other matching methods such as radius matching. Furthermore, difference in difference regressions stated in equation (2) and (3) are estimated with various specifications such as adding and removing control variables. It is found that most of the results are robust to different matching techniques and specifications. In addition, the analyses are additionally replicated using 2006 as baseline (instead of 2005) and 2007 as treatment (instead of 2006) to further verify the parallel trend assumption. It is found that the 2006-2007 results are nearly identical to the results based on 2005-2006 confirming that the short-term impacts are robust and the common trend assumption is plausible.

As guided by existing literature, this chapter examines the impact of the VF on a large number of mobility outcomes on a one-by-one basis. However, it might be the case that the significant effects of the VF on non-labor income, non-consumption expenditure and business expenditure are observed by chance among the whole set of outcomes that are being examined at the same time. Following Gibson, McKenzie and Stillman (2011) and Kling, Liebman and Katz (2007), the multiple hypothesis testing is thus conducted by calculating bootstrapped estimates of adjusted $p$-values using a modification of the free stepdown algorithm of Westfall and Young (1993).

Table 4.9 shows $p$-values and Westfall-Young adjusted $p$-values of the three outcomes for which the impact of the VF are significant when examined individually including non-labor income, non-consumption expenditure and business expenditure. The results suggest that the positive impact of the VF on non-labor income in the long run (2005-2010) remains significant while the medium-term impact remains marginally significant ( $\mathrm{p}$-value is equal to 0.1). At the same time, with the exception of 2005-2012, the effects of the VF on nonconsumption expenditure appear to be robust to the use of Westfall-Young adjusted $p$ values. These results confirm that borrowing from the VF increases non-labor income and non-consumption expenditure during the aforementioned period of time. However, the long-term impact (2005-2010) on business expenditure vanishes after accounting for multiple testing using the Westfall-Young adjustments. 


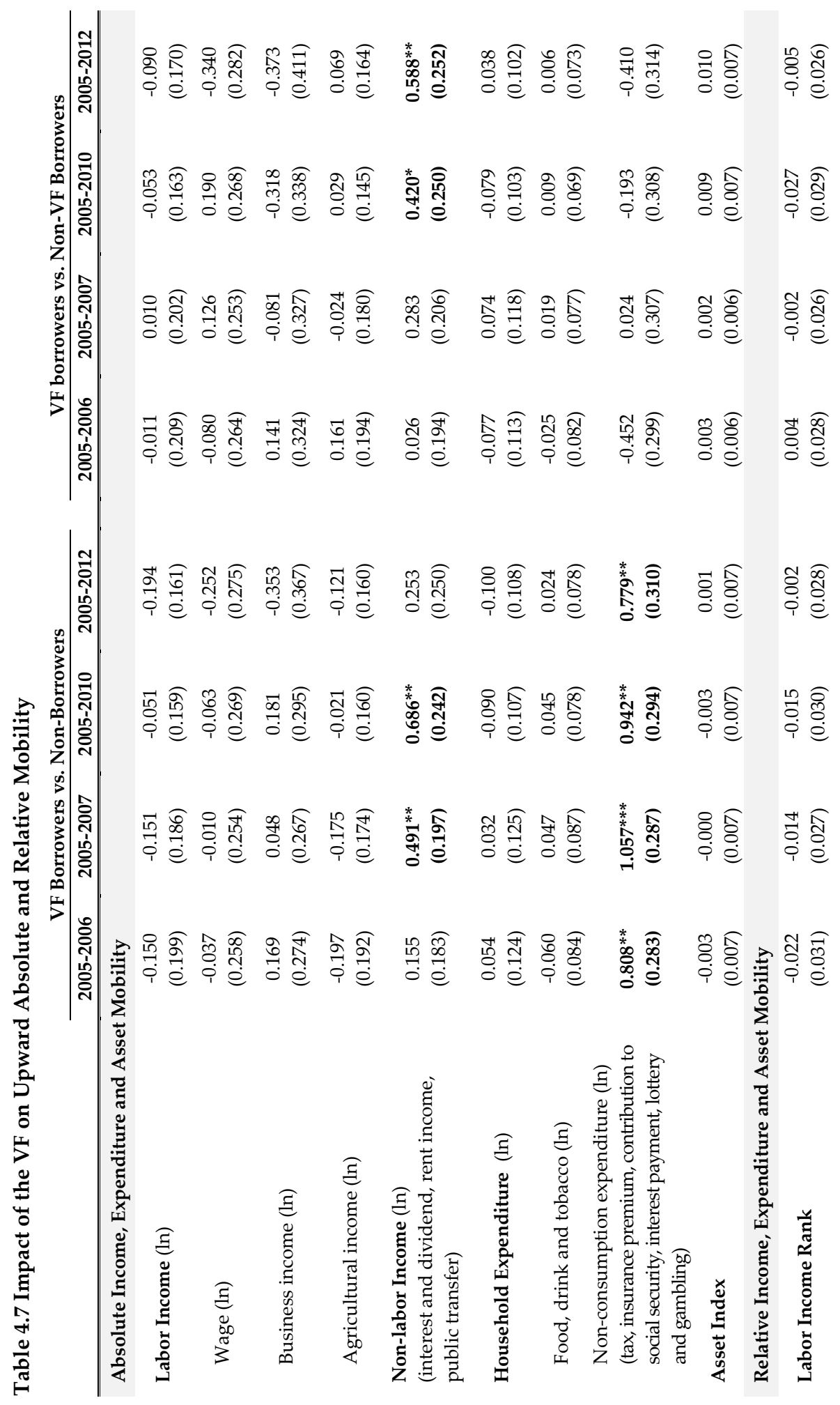




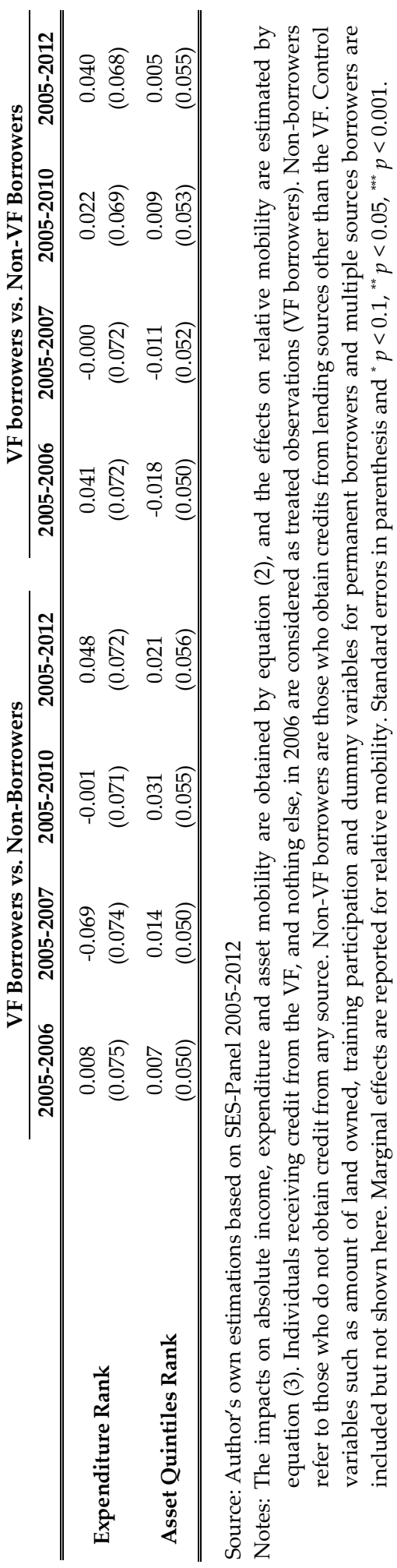




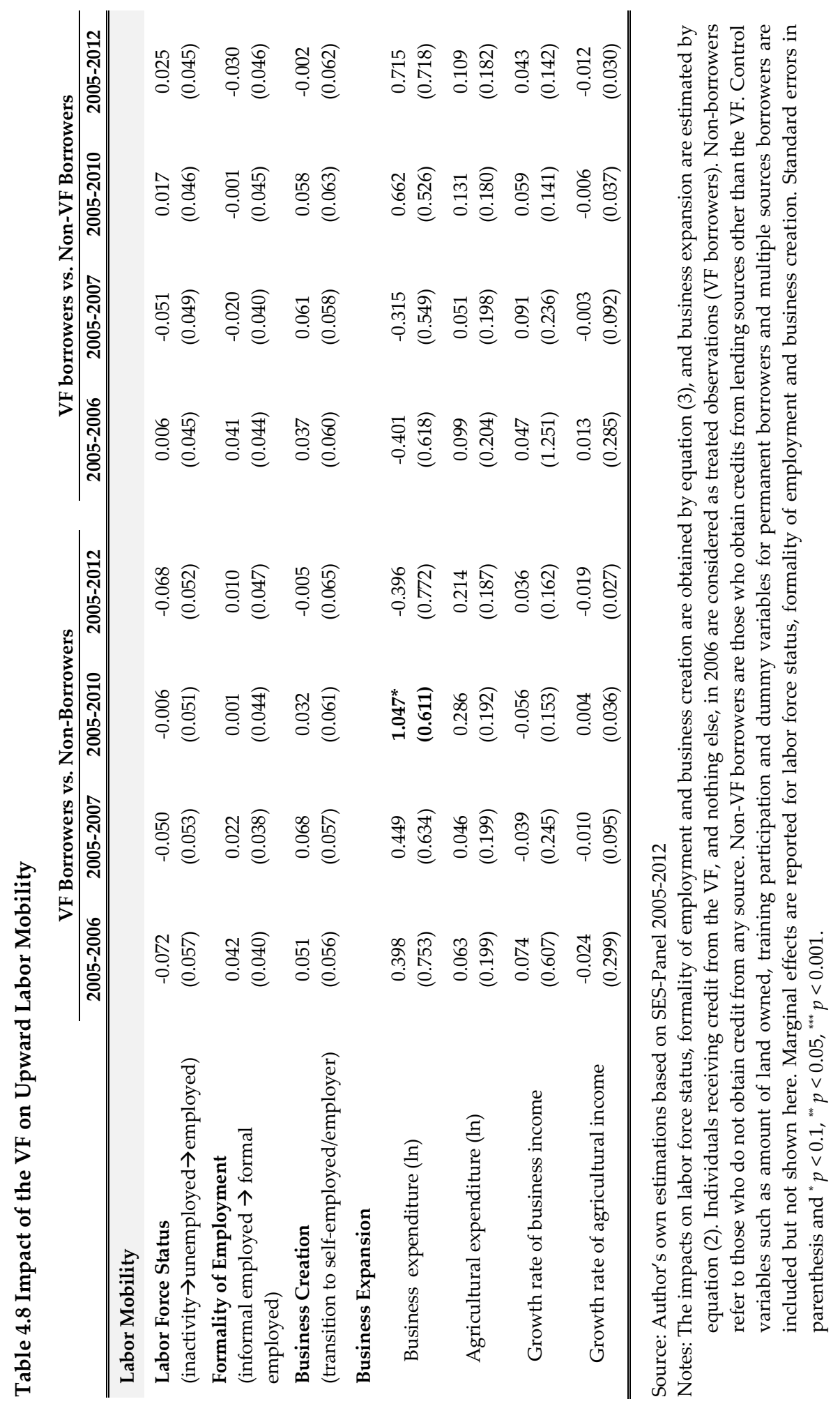




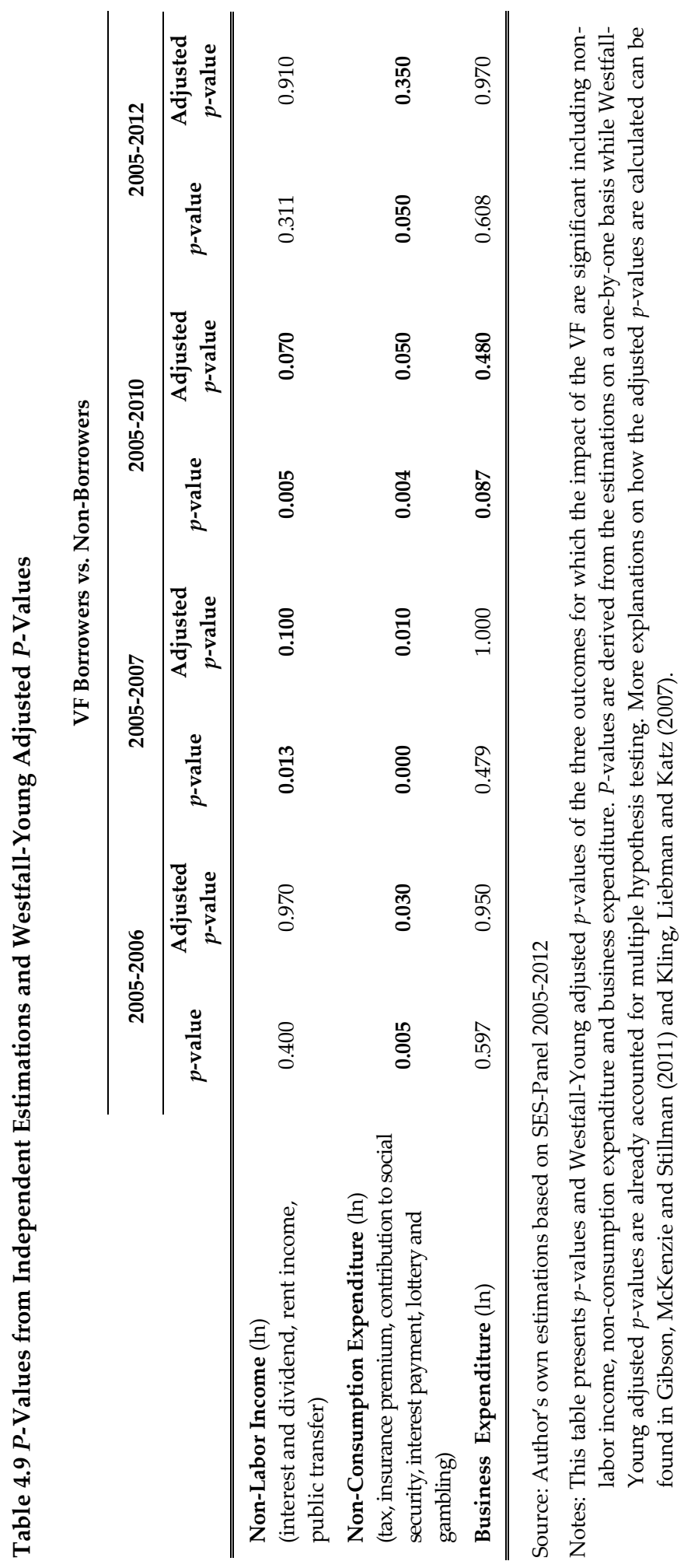


The results from the impact assessment suggest that the VF does not impact the borrowers this chapter studies along most outcome dimensions considered. This chapter then further analyzes whether it impacts particular groups of people by examining the impact heterogeneity on income, expenditure and asset mobility in female borrowers, trained borrowers and repeated borrowers. With regard to the impact heterogeneity by gender, a number of existing literatures on microcredit have suggested the different impact of microcredit on male and female borrowers. For example, Pitt and Khandker (1998) report the larger impact of the Grameen Bank and microcredit programs in Bangladesh on female borrowers. Similar findings are also presented in a more recent study by Khandker and Samad (2014). However, this study does not observe much variation between male and female borrowers. Moreover, the evidence is mixed, making it difficult to draw a conclusion for which gender the VF works better. As presented in Table 4.10, only heterogeneous impact on agricultural income, agricultural expenditure, household expenditure and asset index are found to be statistically significant. The results suggest that the impact of the VF is relatively larger on agricultural income and agricultural expenditure for female borrowers. Considering household expenditure and asset index, female borrowers are found to benefit less from the VF. However, these significant impacts are fitful as they are only realized at some points in time. This finding is somewhat in line with Kaboski and Townsend (2012), who also find no significant differential impact of the VF on female headed household.

In addition to impact heterogeneity by gender, this study also examines differential impact of individuals who attend both vocational training and the VF. According to existing literature on mobility, physical capital and human capital are important determinants of upward mobility (Fields, 2001; Woolard \& Klasen, 2005). Therefore, it is interesting to see whether or not there is a complementary effect between vocational training, aiming to augment human capital, and microcredit programs, which are supposed to promote investment in physical capital. Vocational training programs in Thailand are provided by the Department of Skill Development under the Ministry of Labor, Ministry of Agriculture and Cooperatives, and other local administrative units. The training courses offered cover a wide range of skills that can be useful for wage employment and self-employment activities. The impact of the vocational training program alone is presented in Chapter 3. 


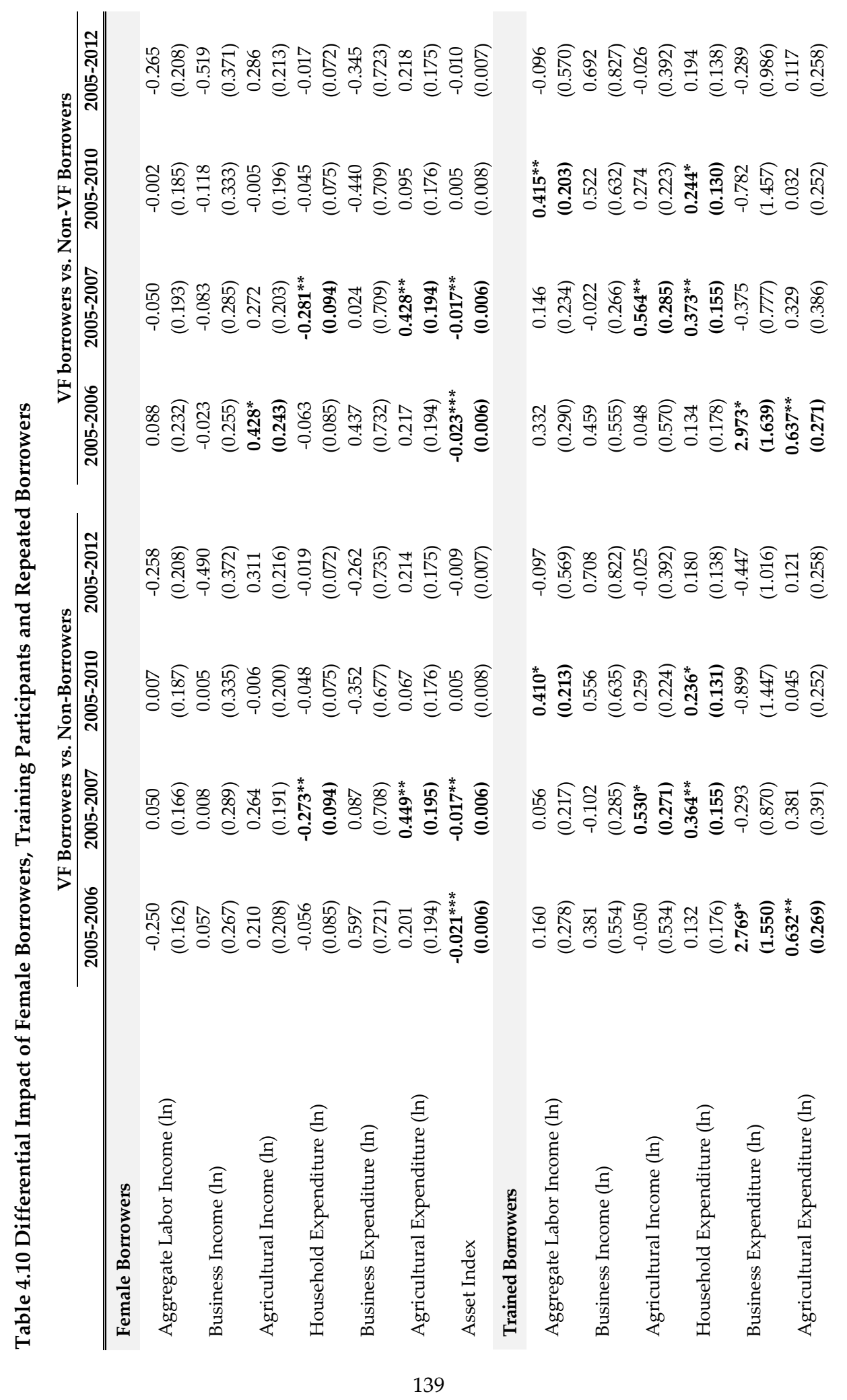




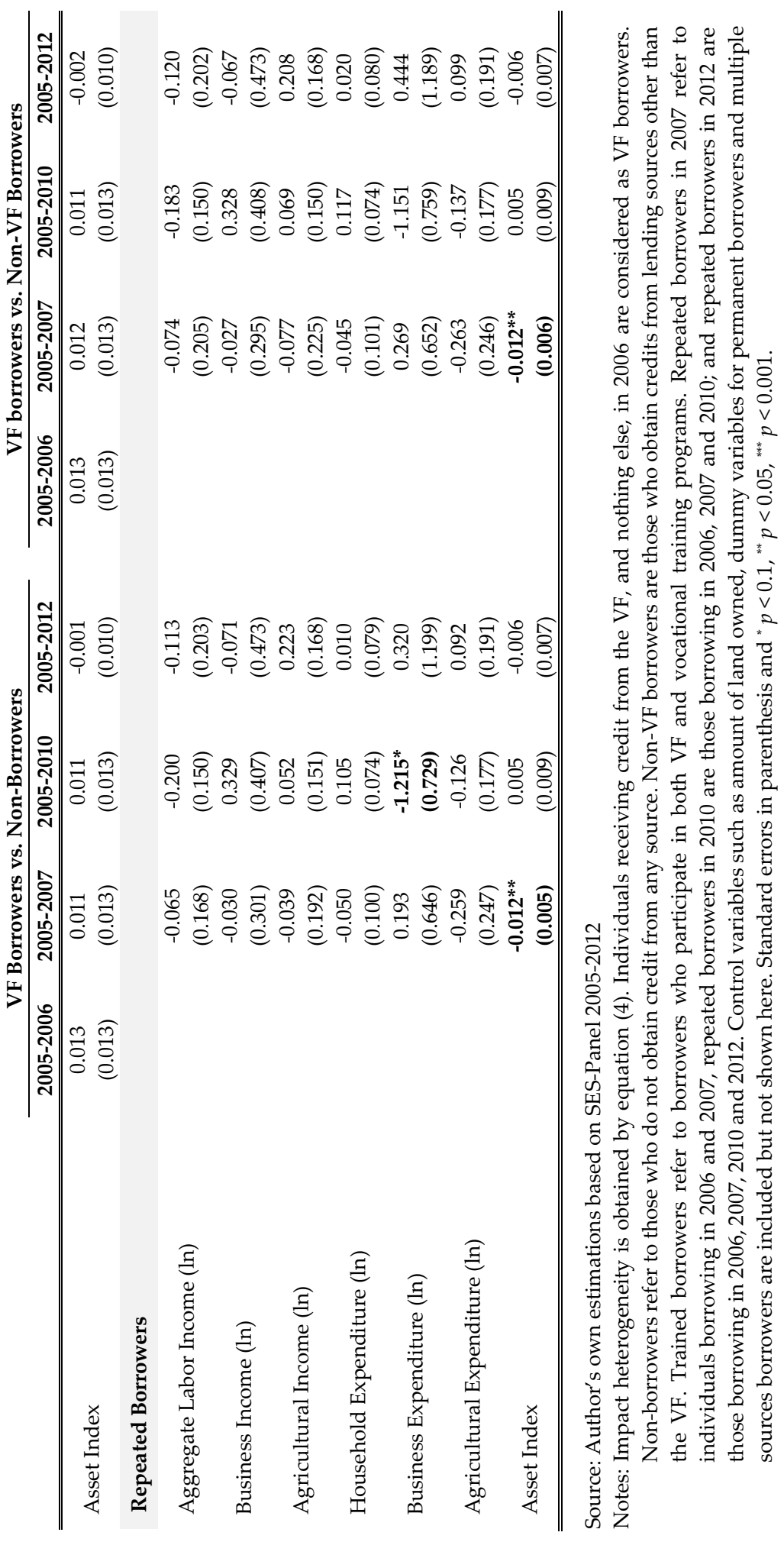


According to the results presented in Table 4.10, this study observes a significant heterogeneous impact between those attending the VF alone and those attending both vocational training and the $\mathrm{VF}$, on aggregate labor income in the long term. The complementary effect between microcredit and training also plays a role in agricultural business. It is found that trained VF borrowers invest more in farm business in the short term and generate higher agricultural income in the medium term. With regard to nonagricultural business, although training programs are found to have limited impact on business income of VF borrowers, trained VF borrowers invest in business considerably more than untrained borrowers in the short term. Moreover, the result also suggests that VF borrowers participating in training spend more on household expenditure, in comparison to their untrained counterparts. Nevertheless, there is no difference of impacts on asset index, no matter which control group is being considered.

Lastly, this chapter examines if repeated borrowers, or those who continue borrowing, are more effective than one-time borrowers. Studies on the differential impact of repeated borrowers are relatively scarce, compared to the heterogeneity by gender. Among the existing literature, several studies suggest a common conclusion that the impact on a number of development outcomes such as income, consumption and school enrollment are relatively larger for repeated borrowers (e.g. Barnes, 2001; Berhane \& Gardebroek, 2011; Chen \& Snodgrass, 2001). However, as presented in Table 4.10, this study does not observe a significant difference of repeated borrowers in a number of outcome variables especially on income, and its components, and household expenditure. The significant heterogeneity of repeated borrowers is only found on business expenditure in the medium term when nonborrowers are considered as controlled observations; and on asset index in the short term. Moreover, the impacts are negative meaning that repeated borrowers benefit less from the VF.

The impact of loan size on income, expenditure and productive activities, estimated empirically through Heckman Selection Models are presented in Table 4.11. There are some evidence supporting the widespread belief that larger loan size leads to better outcomes (Banerjee, 2013). According to the results, a one percent increase in the amount of the loan raises aggregate labor income by 0.4 percent in 2007 . However, the impacts of loan size on aggregate labor income in other years of estimations (2006, 2010 and 2012) are found to be insignificant. 


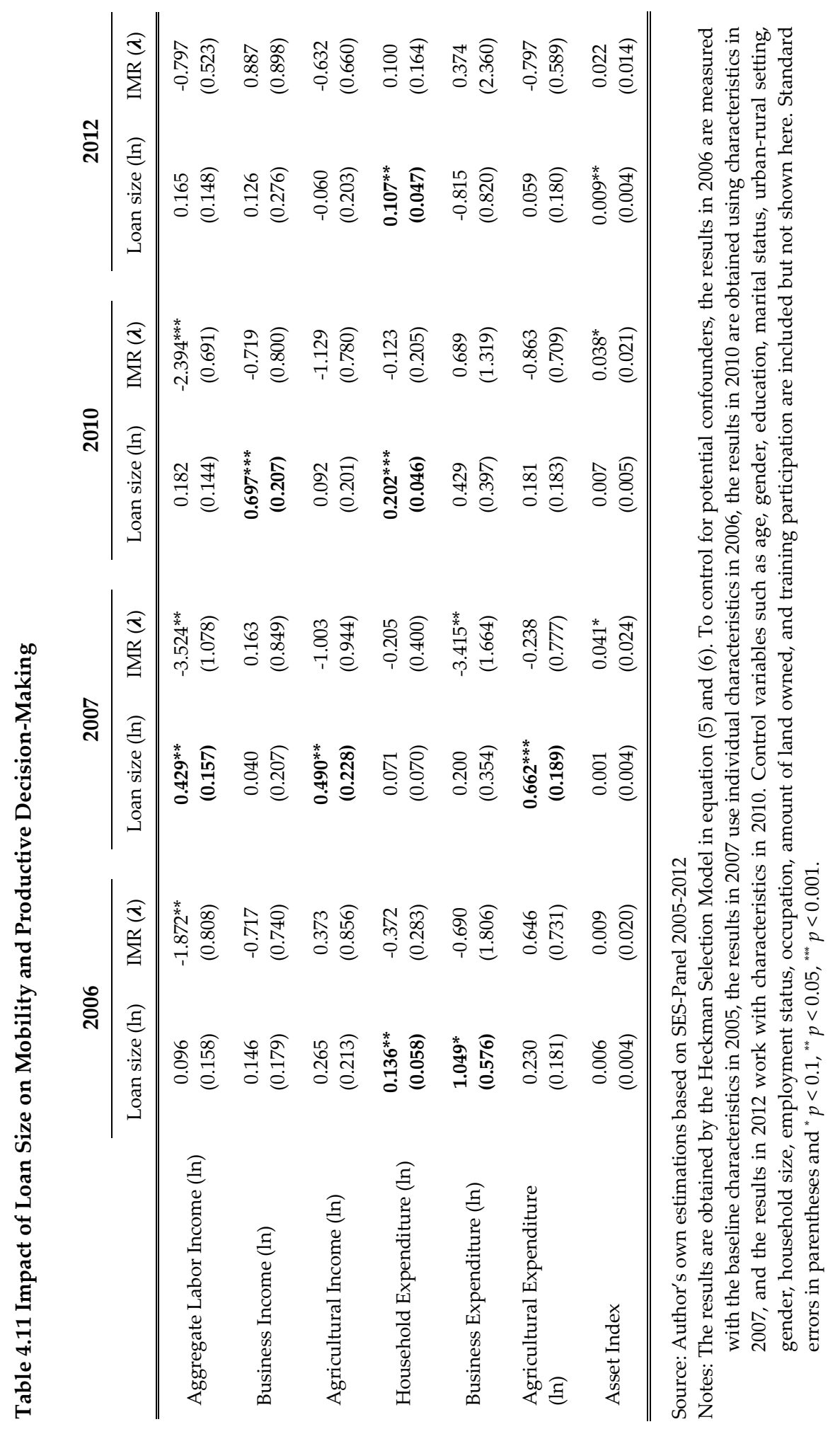


Likewise, the results show the positive impact of loan volume on non-farm income and farm income but the significant impact is only realized in 2010 and 2007, respectively. The role of loan size is more impressive in driving household expenditure. It is found that a larger loan size increases household expenditure in most years, with an exception in 2007. In addition, larger loan size also has a positive impact on business investment, both farm and non-farm. VF borrowers receiving larger credit are found to invest more on non-farm business by 1.1 percent in 2006 and farm business by 0.7 percent in 2007. Finally, the result from the Heckman selection models also indicates that larger loan size also result in higher asset acquisition in 2012.

\subsection{Conclusion and Discussion}

While vocational is an important social protection policy tool to increase human capital, microcredit is a common intervention to increase physical capital by allowing individuals/households to invest in productive assets and engage in income-generating activities. Despite the popularity of microcredit over the last decades, no clear evidence yet exists that microcredit actually improves the lives of borrowers. This chapter contributes to the ongoing discussion by providing new evidence from a novel data set which has never been used in other microcredit evaluations. The results from the multinomial logit model suggest that the VF borrowers are more likely to be women at greater age with low-income, low-education and living outside of Bangkok Metropolitan. This indicates that the VF is better able in reaching the poorer groups of the population, a finding that persists over time, though to a lesser degree in some characteristics. However, the effectiveness of the VF in fostering upward mobility is not promising. The significant impacts of the VF are observed only on non-labor income, non-consumption expenditure and business expenditure.

A number of potential explanations can be used to justify this unpromising result. First, people may borrow just to consume, not to invest (Barnes, 2001; Berhane \& Gardebroek, 2011; Chen \& Snodgrass, 2001). The success of microcredit in transforming the lives of borrowers depends on the extent to which microcredit has led to sustained increase in income and consumption. In other words, microloans should be used to finance investment and career development (Field, Holland, \& Pande, 2014). However, according to the descriptive statistics presented in Table 4.1, nearly 60 percent of VF borrowers report that the loan is used for household consumption. Moreover, the results from the multinomial logit model show that the VF borrowers are often those who borrow to consume rather than 
to invest. This may explain why only limited impacts on upward mobility are observed. Given that VF borrowers are normally the poor who may need to use extra money from microcredit to make ends meet before thinking about investment, complementary interventions such as cash transfers that help borrowers to fulfill their unmet basic needs might be necessary. Moreover, more effective training programs or public work programs that can inspire people to engage more in productive activities, promote labor participation and nurture entrepreneurial spirit might be potential solutions to this problem.

Second, even if borrowers aspire to invest, the design of loan contracts offered by the VF may not support them to do so. According to Banerjee (2013), a small loan size and short maturity loan are not useful for income-generating purposes. This is particularly the case for the VF from which only 20,000 baht (625 USD), on average, is granted and borrowers must pay the loan back within a year after borrowing. The results obtained from the Heckman selection model also confirm that larger loans are associated with better outcomes. Therefore, a more flexible loan contract is required to improve the effectiveness of the VF.

Third, the dominant role of government in microcredit market may discourage private sector participation and hence limit efficiency in the sector (Bird et al., 2011). Bateman and Chang (2009) argue that state intervention and local community engagement are potential solutions to reform microcredit models. However, on this issue, Bird et al. (2011) contend that a high degree of government involvement would limit private sector participation and impede efficiency and innovation of the credit market, which in turn adversely affect borrowers. They also report that Thailand is lagging behind its neighboring countries in providing quality and innovative financial services to low-income families. Therefore, a structural reform that ensures a fair competition among microloan providers and prioritizes benefits for the disadvantaged borrowers, is necessary (Bird et al., 2011).

The significant impact of the VF on non-labor income has some issues worth discussing. This study finds an increase in non-labor income in the medium and long term. A transfer received from the government is one of the components in this income category and may contribute to this result. In Thailand, public transfer programs such as social pensions, disability allowances as well as benefits from community welfare programs are generally based on self-registration. However, village leaders and welfare program committees have a crucial role in managing and encouraging community members to apply and receive transfers. These village leaders and welfare program committees are often take up the role as the VF committees (Nirathorn, 2009). Therefore, it is possible that the VF committees may act as an intermediary pointing people to other income sources offered by government 
transfer programs. It might be the case that public transfers targeted at the poor have increased during the period under study resulting in a higher transfers received by VF borrowers. However, it is found that the only major public transfer program implemented in Thailand during 2005-2012 is the universal Old Age Allowance (OAA) program which is a social pension for elderly (International Labour Organization, 2013). Under this OAA scheme, all elderly aged 60 or above who register themselves to this program are eligible for the transfer, regardless of their social and economic status. Therefore, it is unlikely that this transfer alone affects borrowers and non-borrowers differently. It is thus considered that community engagement through the VF and the role of the VF committees are the ones making the difference.

In addition to public transfer, rent income, interest and dividend are also included in nonlabor income. An increase in non-labor income thus implies that those who obtain credit from the VF may use money to purchase assets and rent it out or lend the money to others who do not obtain credit from the program. Although purchasing assets and lending are another form of investment, this might signify that there are people who are in need of credit but do not have access to the VF. In other words, the villages fund may not reach the poorest of the poor. Furthermore, this consequence may lead to more reliance on informal money lenders for those who do not have financial access. It is thus necessary to complement the VF with other additional support for the neediest.

Apart from non-labor income, the impact on non-consumption expenditure is also found to be significant. It is observed that non-consumption expenditure increases significantly in the short, medium and long term. The significant impact of the VF on non-consumption expenditure is also robust to the multiple hypothesis testing. Non consumption expenditure includes tax, insurance premium, contribution to social security, interest payment, lottery and gambling. As non-consumption expenditure is reported in one single variable, it is thus not possible to quantitatively examine which part of the expenditure driving this compelling result. However, it can be implied by relevant findings and information. First, according to the results, aggregate labor income and the transition to formal employment among VF borrowers remain unchanged. Hence, it is unlikely that tax payment and contribution to social security will be higher. Moreover, to my knowledge, there is no change in tax structure and social security regime during 2005-2012 that affected spending pattern of individuals. Therefore, there is no credible evidence supporting that higher payment on tax and social security contribute to the significant impact on non-consumption expenditure. 
Second, in Thailand, there is the Universal Health Care Coverage Scheme (UHCCS) which provides access to healthcare services free of charge. Considering that VF borrowers are normally those with lower socioeconomic status, according to the result from the multinomial logit model, VF borrowers may prefer to rely on the UHCCS as they may not be able to afford private insurance and spend more on insurance premium. Third, according to the summary report from the nationally representative cross-sectional household survey in 2010 and 2012 (National Statistical Office, 2012; 2014), expenditure on lottery and gambling account for only 8-9 percent of total household non-consumption expenditure. This is not surprising considering that survey respondents may feel reluctant to report their expenditure on lottery and gambling. Therefore, the amount of money spent on lottery and gambling might be too small to drive the significant result found on non-consumption expenditure.

Considering that payment on tax, social security, insurance premium, lottery and gambling may not be able to contribute to the substantial impact on non-consumption spending, it is most likely that interest payment is the expenditure driving the result. This argument is justified by the fact that the significant impact on non-consumption expenditure is only realized when VF borrowers are compared to non-borrowers, who are not subject to interest payment. Moreover, Chandoevwith and Ashakul (2008) who examine the impact of the VF on rural households also claim that the significant impact on non-consumption expenditure that they observed is driven by the higher expenditure on interest payment.

It is also interesting to see that although VF loans need to be repaid within one year, nonconsumption expenditure, or interest payment in particular, is found to be higher in all time horizons, even in 6-7 years after borrowing. This finding has several possible implications. On the one hand, it might be the case that credit received from the VF alone might be too small to invest and to generate profits. However, access to the VF might be used as a signal of borrower's creditworthiness which enables the VF borrowers to obtain larger amount of loans from other lending sources. This might also explain why the impact on business investment in found in the long run and why VF borrowers are able to invest more than the amount of loan received from the VF (104.7 percent). On the other hand, it is also possible that VF borrowers may borrow from other lending sources to pay off VF loan and repeat VF loan to repay the others. This rotation of money from one credit scheme to the next may eventually lead to a state of over-indebtedness which possibly explains the undesirable impact among repeated borrowers. Further research is needed to fully understand the impact of the VF on non-consumption expenditure and interest payment. 
The results on impact heterogeneities also provide interesting implications. According to the differential effect of trained borrowers, there is a complementary effect between training and the VF on some outcome variables such as aggregate labor income, agricultural income, household expenditure and investment in both farm and non-farm activities. However, none significant impact is found on agricultural income and asset index. The significant impact also appears only in some specific points of time. For example, it is found that trained VF borrowers tend to invest more in the short run and generate higher aggregate income in 4-5 years after borrowing and training. Several possible explanations may be used to justify this result such as the content and quality of training program. Nevertheless, this might be simply because the number of observations who attend both training and the VF in the SES-Panel data set are so small that the significant differences cannot be discerned. In addition, the differential impact of repeated borrowers is found to deviate from previous findings. As discussed, the incidence of over-indebtedness may explain the undesirable results among repeated borrowers observed in this chapter. However, these differential impacts of repeated borrowers might be confounded by the fact that the not-repeated borrowers might also borrow multiple times before 2005 during which the information cannot be captured by the SES-panel used in this study.

As mentioned before, another caveat of this chapter relates to the sample representativeness. Individuals with credit in 2005 are dropped from the analyses so that 2005 can be used as the pre-intervention baseline and the situation of treatment and control group before and after receiving credit from the VF can be compared. Those who do not borrow in 2006 but do borrow in subsequent years $(2007,2010$ or 2012) are also excluded from the analyses so that the causal inference of the effect of borrowing from the VF in 2006 can be derived. Although this choice of sample exclusion is chosen due to data constraints and methodological challenges, it is acknowledged that these sample exclusion steps may induce the sample selection bias to the results. Therefore, the results presented in this chapter should be considered with cautions. 


\section{References}

Akotey, J. O., \& Adjasi, C. K. D. (2016). Does Microcredit Increase Household Welfare in the Absence of Microinsurance? World Development, 77, 380-394.

https://doi.org/10.1016/j.worlddev.2015.09.005

Attanasio, O., Fitzsimons, E., Gomez, A., Gutiérrez, M. I., Meghir, C., \& Mesnard, A. (2010). Children's Schooling and Work in the Presence of a Conditional Cash Transfer Program in Rural Colombia. Economic Development and Cultural Change, 58(2), 181210. https://doi.org/10.1086/648188

Angelucci, M., Karlan, D., \& Zinman, J. (2015). Microcredit Impacts: Evidence from a Randomized Microcredit Program Placement Experiment by Compartamos Banco. American Economic Journal: Applied Economics, 7(1), 151-182. https://doi.org/10.1257/app.20130537

Attanasio, O., Augsburg, B., De Haas, R., Fitzsimons, E., \& Harmgart, H. (2015). The Impacts of Microfinance: Evidence from Joint-Liability Lending in Mongolia. American Economic Journal: Applied Economics, 7(1), 90-122. https://doi.org/10.1257/app.20130489

Augsburg, B., De Haas, R., Harmgart, H., \& Meghir, C. (2015). The Impacts of Microcredit: Evidence from Bosnia and Herzegovina. American Economic Journal: Applied Economics, 7(1), 183-203. https://doi.org/10.1257/app.20130272

Banerjee, A. (2013). Microcredit Under the Microscope: What Have We Learned in the Past Two Decades, and What Do We Need to Know? Annual Review of Economics, 5(1), 487-519. https://doi.org/10.1146/annurev-economics-082912-110220

Banerjee, A., Duflo, E., Glennerster, R., \& Kinnan, C. (2015). The Miracle of Microfinance? Evidence from a Randomized Evaluation. American Economic Journal: Applied Economics, 7(1), 22-53. https://doi.org/10.1257/app.20130533

Barnes, C. (2001). MICROFINANCE PROGRAM CLIENTS AND IMPACT: AN ASSESSMENT OF ZAMBUKO TRUST, ZIMBABWE. Retrieved from Management Systems International website: https://pdf.usaid.gov/pdf_docs/Pnacn576.pdf

Bateman, M., \& Chang, H.-J. (2009). The microfinance illusion. Available at SSRN 2385174. Retrieved from http://papers.ssrn.com/sol3/papers.cfm?abstract_id=2385174

Baulch, B., \& Quisumbing, A. R. (2011). Testing and Adjusting for Attrition in Household Panel Data [CPRC Toolkit Note]. Chronic Poverty Research Centre.

Berhane, G., \& Gardebroek, C. (2011). Does Microfinance Reduce Rural Poverty? Evidence Based on Household Panel Data from Northern Ethiopia. American Journal of Agricultural Economics, 93(1), 43-55. https://doi.org/10.1093/ajae/aaq126

Bird, K., Hattel, K., Sasaki, E., \& Attapich, L. (2011). Poverty, income inequality, and microfinance in Thailand. Asian Development Bank. Retrieved from https://www.adb.org/sites/default/files/publication/29271/poverty-incomeinequality-microfinance-thailand.pdf 
Boonperm, J., Haughton, J., \& Khandker, S. R. (2013). Does the Village Fund matter in Thailand? Evaluating the impact on incomes and spending. Journal of Asian Economics, 25, 3-16. https://doi.org/10.1016/j.asieco.2013.01.001

Caliendo, M., \& Kopeinig, S. (2008). SOME PRACTICAL GUIDANCE FOR THE IMPLEMENTATION OF PROPENSITY SCORE MATCHING. Journal of Economic Surveys, 22(1), 31-72. https://doi.org/10.1111/j.1467-6419.2007.00527.x

Canelas, C., \& Niño-Zarazúa, M. (2019). Schooling and Labor Market Impacts of Bolivia's Bono Juancito Pinto Program. Population and Development Review. https://doi.org/10.1111/padr.12270

Chandoevwit, W., \& Ashakul, B. (2008). The impact of the village fund on rural households. TDRI Quarterly Review, 23(2), 9-16.

Chen, M., \& Snodgrass, D. (2001). Managing Resources, Activities, and Risk in Urban India: The impact of SEWA Bank. Retrieved from Management Systems International website: http://www.wiego.org/sites/default/files/publications/files/Chen-Snodgrass-AIMSStudy-of-SEWA-Bank.pdf

Dichter, T., \& Harper, M. (Eds.). (2007). What's wrong with microfinance? London: Practical Action Publishers.

Fields, G. S. (2001). Distribution and Development: A New Look at the Developing World. MIT Press.

Fry, K., Firestone, R., \& Chakraborty, N. (2014). Measuring Equity with Nationally Representative Wealth Quintiles. Washington, DC: PSI.

Gibson, J., McKenzie, D., \& Stillman, S. (2011). The Impacts of International Migration on Remaining Household Members: Omnibus Results from A Migration Lottery Program. The Review of Economics and Statistics, 93(4), 1297-1318.

Heckman, J. J. (1976). The common structure of statistical models of truncation, sample selection and limited dependent variables and a simple estimator for such models. Annals of Economic and Social Measurement, 5, 475-492.

Heckman, J. J. (1979). Sample Selection Bias as a Specification Error. Econometrica, 47(1), 153. https://doi.org/10.2307/1912352

Ibrahim, A. H., \& Bauer, S. (2013). Access to Micro credit and its Impact on Farm Profit among Rural Farmers in Dryland of Sudan. Global Advanced Research Journal of Agricultural Science, 2(3), 088-102.

Imai, K. S., Gaiha, R., Thapa, G., \& Annim, S. K. (2012). Microfinance and Poverty-A Macro Perspective. World Development, 40(8), 1675-1689. https://doi.org/10.1016/j.worlddev.2012.04.013

International Labour Organization. (2013). Social protection assessment based national dialogue: Towards a nationally defined social protection floor in Thailand. Retrieved from http://www.ilo.org/wcmsp5/groups/public/---ed_protect/--soc_sec/documents/publication/wcms_213264.pdf 
Kaboski, J. P., \& Townsend, R. M. (2011). A Structural Evaluation of a Large-Scale QuasiExperimental Microfinance Initiative. Econometrica, 79(5), 1357-1406. https://doi.org/10.3982/ECTA7079

Kaboski, J. P., \& Townsend, R. M. (2012). The impact of credit on village economies. American Economic Journal: Applied Economics, 4(2), 98.

Karlan, D., \& Zinman, J. (2011). Microcredit in theory and practice: using randomized credit scoring for impact evaluation. Science, 332(6035), 1278-1284.

Khandker, S., Koolwal, G., \& Samad, H. (2010). Handbook on Impact Evaluation: Quantitative Methods and Practices. https://doi.org/10.1596/978-0-8213-8028-4

Khandker, S. R., Khalily, M. A. B., \& Samad, H. A. (2016). Beyond Ending Poverty: The Dynamics of Microfinance in Bangladesh. Directions in Development. Retrieved from https://openknowledge.worldbank.org/bitstream/handle/10986/24669/97814648089 44.pdf? sequence $=2 \&$ is Allowed $=y$

Khandker, S. R., \& Samad, H. A. (2014). Dynamic effects of microcredit in Bangladesh. World Bank Policy Research Working Paper, (6821). Retrieved from http://papers.ssrn.com/sol3/papers.cfm?abstract_id=2417519

Kling, J. R., Liebman, J. B., \& Katz, L. F. (2007). Experimental Analysis of Neighborhood Effects. Econometrica, 83-119.

Lewis, S., Tambunlertchai, K., Suesuwan, E., Adair, M., \& Hickson, R. (2013). Technical Assistance Consultant's Report: Microfinance Supply-Side Assessment Report [Technical Assistance Consultant's Report]. Retrieved from Asian Development Bank website: https://www.adb.org/sites/default/files/projectdocument/80376/45128-001-tacr-04.pdf

Menkhoff, L., \& Rungruxsirivorn, O. (2011). Do Village Funds Improve Access to Finance? Evidence from Thailand. World Development, 39(1), 110-122. https://doi.org/10.1016/j.worlddev.2010.09.002

Milana, C., \& Ashta, A. (2012). Developing microfinance: A survey of the literature. Strategic Change, 21(7-8), 299-330. https://doi.org/10.1002/jsc.1911

Moser, C., \& Felton, A. (2007). The Construction of an Asset Index Measuring Asset Accumulation in Ecuador. SSRN Electronic Journal. https://doi.org/10.2139/ssrn.1646417

National Statistical Office, Ministry of Information and Communication Technology. (2012). Summary report on Household Socioeconomic Survey 2010 (in Thai). Retrieved from http://service.nso.go.th/nso/nsopublish/pubs/pubsfiles/socPBook53.pdf

National Statistical Office, Ministry of Information and Communication Technology. (2014). Summary report on Household Socioeconomic Survey 2012 (in Thai).

National Village and Urban Community Fund Office. (2017). The Village and Urban Community Fund: Progress Report (in Thai). Presented at the Bangkok, Thailand. Bangkok, Thailand. 
Nirathorn, N. (2009). Social Integration through Social Protection Programmes: Some Considerations From Social Protection Scheme for Workers in the Informal Economy in Thailand. Presented at the An expert group meeting on "Policies to Advance Social Integration," United Nations Headquarters, New York. Retrieved from http://www.un.org/esa/socdev/social/meetings/egm09/docs/Nirathron.pdf

Panjaitan-Drioadisuryo, R. D. M., \& Cloud, K. (1999). Gender, self-employment and microcredit programs An Indonesian case study. The Quarterly Review of Economics and Finance, 39(5), 769-779. https://doi.org/10.1016/S1062-9769(99)00028-9

Pitt, M. M., \& Khandker, S. R. (1998). The impact of group-based credit programs on poor households in Bangladesh: does the gender of participants matter? Journal of Political Economy, 106(5), 958-996.

Rosenberg, R., Gaul, S., Ford, W., \& Tomilova, O. (2013). Microcredit Interest Rates and Their Determinants 2004-2011 (No. 7). CGAP.

Salia, P. J. (2014). The Effect of Microcredit on the Household Welfare (Empirical Evidences from Women Micro-entrepreneurs in Tanzania). International Journal of Academic Research in Business and Social Sciences, 4(5). https://doi.org/10.6007/IJARBSS/v4i5/853

Tambunlertchai, K. (2017). Financial Inclusion, Regulation, and Education: Asian Perspective. Retrieved from https://www.adb.org/sites/default/files/publication/350186/adbifinancial-inclusion-regulation-education-asian-perspectives.pdf\#page=286

Tarozzi, A., Desai, J., \& Johnson, K. (2015). The Impacts of Microcredit: Evidence from Ethiopia. American Economic Journal: Applied Economics, 7(1), 54-89. https://doi.org/10.1257/app.20130475

Van Rooyen, C., Stewart, R., \& de Wet, T. (2012). The Impact of Microfinance in Sub-Saharan Africa: A Systematic Review of the Evidence. World Development, 40(11), 2249-2262. https://doi.org/10.1016/j.worlddev.2012.03.012

Westfall, P., \& Young, S. (1993). Resampling-Based Multiple Testing: Examples and Methods for P-Value Adjustment. New York: Wiley.

Wichianlert, S. (2015). National Village and Urban Community Fund (in Thai). Thailand Parliament Budget Office, The Secretariat of The House of Representatives.

Woolard, I., \& Klasen, S. (2005). Determinants of Income Mobility and Household Poverty Dynamics in South Africa. Journal of Development Studies, 41(5), 865-897. https://doi.org/10.1080/00220380500145313

Wooldridge, J. M. (2010). Econometric Analysis of Cross Section and Panel Data (2nd ed.). Cambridge, Massachusettes: The MIT Press. 



\section{Chapter 5}

\section{Schooling Responses to Social Pensions:}

The Evidence from Thailand Old Age Allowance 


\subsection{Introduction}

Non-contributory pensions, also known as social pensions, have become increasingly important sources of support for older adults particularly those of low socioeconomic status. Such programs have been implemented in several developing countries in Latin America, Africa and Asia. Following the growing prevalence of social pensions, a good deal of research has been conducted to evaluate their impacts on poverty and vulnerability, physical and mental health status, and decisions to retire (see e.g. Case, 2001; Case \& Deaton, 1998; Chen \& Tan, 2018; Cheng, Liu, Zhang, \& Zhao, 2018; Galiani, Gertler, \& Bando, 2016). Moreover, since income from social pensions could be pooled within the household (Barrientos \& Lloyd-Sherlock, 2002), evaluation studies of social pension programs are also extended to measure the impact upon those living under the same roof such as nutritional status and school enrolment of children; migration and labor decisions of young adults; as well as wellbeing of the whole family (see e.g. Adamchak, 1995; Duflo, 2003; Kassouf \& Rodrigues de Oliveira, 2012).

Among a number of potential spillover effects, the impact on household investment in education is of particular interest. Additional income from social pensions can increase household financial resources, which in turn allow households to invest more in education of their offspring. As education is one of the key factors influencing income mobility and mobility in well-being (Narayan et al., 2018), social pensions could play a role in breaking the intergenerational transmission of poverty and fostering upward intergenerational mobility. There have been some studies trying to shed light on the schooling responses to social pensions. However, most studies are located in either Brazil (e.g. De Carvalho Filho, 2012; Ponczek, 2011) or South Africa (e.g. Case \& Deaton, 1998; Edmonds, 2006). Since the impact of social pensions tends to be contextual (Chen \& Tan, 2018), providing new evidence apart from these two countries would bring new insights into the literature of social pensions.

The Old Age Allowance (OAA) program in Thailand is an unconditional cash transfer program for Thai senior citizens at the age of 60 or above. This social pension scheme has been established since 1993 as a means-tested program targeting the poor before being expanded in 2009 to cover all Thai elderly persons, who are not covered by other pension programs (Sakunphanit \& Suwanrada, 2011; Suwanrada, Sukontamarn, \& Bangkaew, 2018). Despite being in operation for more than a decade, existing literature on the impact of the OAA remains limited (Paweenawat \& Vechbanyongratana, 2015; Suwanrada \& Leetrakul, 
2014). Moreover, most of the studies so far have focused only on the immediate effect of the OAA on beneficiaries. There is no impact evaluation study to date, to the best of my knowledge, that examines the potential spillover effects of the OAA upon their co-residents especially the impact on household investment in education.

The objective of this chapter is to fill these research gaps by evaluating to what extent additional resources from the OAA fosters intergenerational mobility by allowing households to invest more in education of their school-age members. This chapter utilizes 5 years of the nationally representative cross-sectional household surveys (SES), starting from the first year when the program was expanded to cover all Thai elderly in 2009 to the most recent year, in 2017, that the data set is available. As the OAA is a self-registration program, several empirical strategies are employed to account for the potential endogeneity. The chapter proceeds as follows. Section 5.2 provides theoretical background that motivates and frames this study. Section 5.3 summarizes previous findings of the spillover effects of social pension programs worldwide. Section 5.4 describes Thailand contexts, provides details of the OAA program and reviews existing studies on the impact of the program. Section 5.5 and 5.6 explains data and methodologies used in this study, respectively. Section 5.7 presents the empirical results and the last section (section 5.8) concludes and discusses the results.

\subsection{Theoretical Background}

Elderly people in developing countries tend to live in households consisting of more than two generations (Barrientos \& Lloyd-Sherlock, 2002). This multigenerational living arrangement is found either in the form of extended or skipped-generation family. Extended family is a household structure where three or more generations live together under the same roof (Peek, Im-em, \& Tangthanaseth, 2016). This household composition facilitates resource sharing and allows family members to support each other (Anderson \& Allen, 1984). Moreover, as summarized in Quisumbing (1997), the extended family structure makes it possible for members to smooth consumption, share risks, maximize gains from family farms and cultivate values of old age support in their children. However, in many cases, economic circumstances may give rise to the challenge of maintaining extended family structures as young adult members may have to migrate for better job opportunities and leave their children behind with the grandparents. This living arrangement where grandparents need to live and take care of their grandchildren alone, without other working-age members in the household refers to the skipped-generation household setting, 
which is becoming an increasingly common phenomenon in developing economies (Peek et al., 2016).

When considering multigenerational living arrangement, an insight into how households allocate resources among family members is of importance. Broadly speaking, intrahousehold allocation of resources can be explained by two main distinct theories: the unitary and the collective model. The unitary model assumes that a household acts as one single decision-making unit maximizing one single utility function (Alderman, Chiappori, Haddad, Hoddinott, \& Kanbur, 1995; Becker, 1981). Income, as well as other resources, from each and every member will be pooled and consumption allocation within the household is going to depend merely on the amount of these pooled resources, not the preference of those who receive it (Alderman et al., 1995; Browning, Bourguignon, Chiappori, \& Lechene, 1994). Therefore, the identification of the policy target group does not matter as the transfer will be shared within household no matter what. The unitary model appears to be attractive due to its simplicity; however, it ignores personal interests, which are likely to vary, and probably compete, among family members.

Unlike the unitary model, the collective model tries to aggregate different preferences through collective decision making. Under this collective approach, the ownership of resources affects the allocation of resources among household members (Alderman et al., 1995; Browning et al., 1994; Haddad, Hoddinott, \& Alderman, 1997; Pezzin \& Schone, 1997). In other words, the household decision to spend on different goods and services depends on the preference of the individual member who receives or owns the resources (Chiappori, 1992). According to the collective model, it is likely that pension income will be used directly in favor of the needs of elderly members receiving the pension such as healthcare and aged care services. However, there are economic theories suggesting motives why elderly may redistribute their resources to other members.

According to Becker (1974) and Becker and Tomes (1976), transfers among household members occur from altruism, which refers to selfless concerns and actions for the good of others. In the context of social pensions, grandparents may transfer a part of their pension income to other members without expecting anything in return because of their benevolence, caring and moral obligation towards their family members. On the other hand, intra-household transfers may also be motivated by self-interests. Transfers may be made in an exchange for other services (Bernheim, Shleifer, \& Summers, 1985; Cox, 1987). For example, parents may transfer to their children in exchange for their companionship (Cox \& Rank, 1992). Likewise, family members may consider transfers as an insurance against risk 
(Frankenberg, Lillard, \& Willis, 2002) or as a loan to other credit-constrained members (Cox, 1990). In the case of a social pension, pensioners may allocate their pension in exchange for companionship. Elderly members may also expect other members to take care of them or repay them when they earn income or acquire their own resources in the future.

Investing in education is one way by which social pensioners can redistribute their pension income to their grandchildren. According to Becker and Tomes (1979), in addition to the inheritability endowment, parents can increase the human capital of their children through an investment in education. Education has a close relationship with earning ability of individuals as well as other positive characteristics such as improved health status and greater longevity (Black \& Devereux, 2010; Ferreira et al., 2012; Narayan et al., 2018). Children from poor families that under-invest in education may not be able to acquire a higher income in the future (Checchi, 1997). Consequently, poverty and vulnerability in the current generation will be transmitted to the next generations (ibid). On the other hand, families that place a strong emphasis on educational investment are more likely to experience upward intergenerational mobility (Narayan et al., 2018). Therefore, if additional income from a pension is redistributed to education of co-residing children, either out of altruism or the exchange motive, then the social pension may have long-lasting benefits on upward mobility and poverty eradication.

\subsection{Spillover Effects of Social Pensions}

There is a large, and still growing, literature on the spillover effects of social pensions. Numerous studies clearly demonstrate an impact of the program on pensioners' coresidents. According to Barrientos and Lloyd-Sherlock (2002), a pension is a secure source of income, which enables households to invest in human, physical and social capital. These investments will in turn help households to break the intergenerational transmission of poverty and escape from the poverty trap. A number of empirical studies have supported this argument. For example, Duflo (2003) finds that the South-African pension program improves the anthropometric status of children, especially that of girls, living with female pensioners. Rodrigues de Oliveira, Kassouf and Aquino (2017) also observe a significant reduction in labor force participation of children living with pension recipients in Brazil.

In comparison to other spillover effects, research on schooling responses to social pensions is relatively limited. Many existing studies of social pensions suggest a positive impact on education of co-residing young members. The two studies of the rural pension system 
reform in Brazil are great examples. De Carvalho Filho (2012) analyzes 4 rounds (1989-1995) of the Brazilian household survey using triple differences and instrumental variables. He finds that a reduction in age eligibility of the rural pension program has led to an increase in school enrolment of girls co-residing with pension recipients by almost 10 percent. The impact on boys is, however, close to zero. Ponczek (2011) analyzes the same program using 6 rounds (1988-1995) of the same data set to measure the spillover effects on school achievements. He reports that the reformed pension program has a positive impact on child literacy especially for girls living with male beneficiaries.

The positive schooling responses to social pension are also proved to be valid in some other countries. Edmonds (2006) evaluates the impact of the old age pension program in South Africa on school attendance of children living with eligible elderly, in comparison to those living with nearly eligible ones. He concludes that additional income from social pensions relieves household credit constraints, reduces child labor and increases school attendance. Similarly, Waidler (2016) finds that income support from the South African Old Age Pension is spent in a way that benefits all household members particularly children. She concludes that an increase in the share of income from the Old Age Pension has led to higher household education expenditure. Martinez (2004) studies the impact of the BONOSOL program in Bolivia using regression discontinuity design with the difference in difference approach. He observes a 7-12 percentage point increase in the probability of school enrolment of children in beneficiary households. Likewise, a non-contributory pension program in India is found to correlate with an increase in household expenditure on education (Kaushal, 2014).

However, there are also some studies that observe no significant impact of social pension programs on education. Case and Deaton (1998) examine the redistributive effect of noncontributory programs in South Africa on various household expenditure categories such as food, transfers, savings and schooling. By using OLS and two-stage least squares regressions, they observe a negative but insignificant impact on household education expenditure implying that the elderly do not prefer educational investment to other household consumption categories. Kassouf \& Rodrigues de Oliveira (2012) also find that the BPC program, which is the social pension targeting the poor elderly in Brazil, contributes to a decrease in child labor, but has no impact on school attendance of children living with the program beneficiaries. 


\subsection{Thailand's Contexts and the Old Age Allowance}

\subsubsection{Pension System in Thailand}

Thailand is now in the population ageing era. According to a recent report by the United Nations Population Fund, the share of the elderly population in Thailand, those at the age of 60 or older, has considerably increased from 5.5 percent in 1960 to almost 13 percent in 2010 (Peek et al., 2016). By 2040, the elderly population is projected to increase to over 32 percent of the total population (ibid). This rapid demographic change has raised great concerns about various issues such as shortage of workforce, financial sustainability of pension funds, and insufficient resources of healthcare systems (National Economic and Social Development Board [NESDB], 2017b).

A study on Thai family and population reports that in 2013 almost 52 percent of the total population in Thailand live in an extended family (Peek et al., 2016). Most Thai elderly live with one or more adult children due to the longstanding norm and family solidarity (Knodel, Teerawichitchainan, Prachuabmoh, \& Pothisiri, 2015). Moreover, according to the 2014 Survey of Older Persons, 43 percent of the elderly population in Thailand co-reside with at least one grandchild (Knodel et al., 2015). The elderly usually receive support and assistance from other family members and in many cases, they also perform some services within households such as cooking and taking care of children in return (ibid).

This living arrangement, which is referred to as an extended or multigenerational family setting, has been the dominant household structure in Thailand (Peek et al., 2016). However, the number of skipped-generation families has been gradually increasing due the massive rural-urban migration in the past years. Statistics from the labor force survey show that in 2013, around 1.2 million children in Thailand live in households where parents are absent and grandparents are the only caretakers for them (Peek et al., 2016). A skipped-generation family is generally poor and lives in rural areas (ibid). Considering that the remittances from parents, who have been away for working, can be inadequate and inconsistent, this family structure may have negative effects on children's development outcomes.

With regard to Thailand's pension system, drawing on the classification of Brustad (2012), income security programs after retirement in Thailand can be broadly classified into two different systems. The first system is a pension scheme for formal employees. Government officials receive retirement benefits from the traditional civil service pension and the Government Pension Fund (GPF). The traditional service pension is a non-contributory 
defined benefit program financed by the government budget. The GPF is a compulsory defined contribution program under which a beneficiary and the government each contribute 3 percent of the beneficiary's monthly wage (Brustad, 2012; Suwanrada, 2009). The program covers several categories of government employees such as civil servants, teachers, police officers and military officers (Brustad, 2012). Other formal employees, especially those in private sectors, are required to subscribe to the Social Security Fund (SSF). Under the SSF, employees must contribute 3 percent of their monthly wage to the SSF's old-age benefit scheme. The contribution rates of employers and the government are 3 percent and 1 percent, respectively (ibid). The monthly wage used to calculate the contribution is capped at 15,000 baht (468.8 USD) (Suwanrada, 2009).

In addition to the SSF, some companies, especially the large ones in the stock market of Thailand, may also establish Provident Funds (PVD) to provide additional income support for their employees after retirement. These PVD schemes are voluntary. Those who participate have to contribute 2-15 percent of their monthly wage and the employer is required to contribute an amount at least equal to the contribution of their employees (Suwanrada, 2009). Besides, there are also Retirement Mutual Funds (RMF) which are operated by several private mutual fund management companies. RMFs provide an opportunity for both government officials and employees in private sectors to invest in mutual funds and receive benefits after retirement. Although informal employees are also able to invest in RMFs, most of RMFs investors are formal employees as investing in RMFs will receive favorable tax treatment from the government (Brustad, 2012)

The second pension scheme system refers to programs for informal employees including the OAA program, the Social Security Fund for informal workers (Article 40) and the National Saving Fund (NSF) (Brustad, 2012). The OAA program, which is of this chapter's particular interest, is a non-contributory pension program providing income support to all elderly at the age of 60 or above. Details of the OAA program are provided in section 5.4.2. The Social Security Fund for informal workers under the Article 40 of the Social Security Act is an extended social security scheme provided to informal workers who are not covered by the regular Social Security Fund. The program is voluntary and informal workers deciding to join the scheme are required to contribute 100 baht (3.1 USD) per month to this pension fund. The government will also contribute 50 baht (1.6 USD) a month to each and every participant to support their income security after retirement (Chantaramas \& Wiriyanupong, 2013). 
The National Savings Fund (NSF) was implemented in 2015. The objective of this voluntary pension scheme is to promote saving behavior and provide income security after retirement for informal workers (National Savings Fund, 2016). All Thai citizens aged 15-60 who are not covered by other contributory pension programs are entitled to apply for the NSF. The contribution does not need to be made on a monthly basis but participants must contribute at least 50 baht (1.6 USD) a year but not more than 13,200 baht (412.5 USD). The government will co-contribute according to participants' age range. For those aged 15-30 years, the government will grant 50 percent of the participants' contribution but not more than 600 baht (18.8 USD) per year. For participants aged 30-50 years, and 50 years or above, the government will contribute 80 percent but not more than 960 baht (30 USD), and 100 percent but not more than 1,200 baht (37.5 USD) a year, respectively (ibid).

The size of funds and the number of participants of the aforementioned pension programs are provided in Table 5.1.

Table 5.1 Number of Participants and Size of Pension Funds as of 2017

\begin{tabular}{|c|c|c|c|}
\hline & Program Features & $\begin{array}{r}\text { Number of } \\
\text { Participants }\end{array}$ & Fund Size \\
\hline \multicolumn{4}{|c|}{ Pension Programs for the Formal Sector } \\
\hline The Government Pension Fund & $\begin{array}{l}\text { - Compulsory } \\
\text { - Contributory }\end{array}$ & $1,028,961$ & $\begin{array}{r}\text { 825,135.2 Million Baht } \\
(25,785.5 \text { Million USD) }\end{array}$ \\
\hline The Social Security Fund & $\begin{array}{l}\text { - Compulsory } \\
\text { - Contributory }\end{array}$ & $14,564,682$ & $\begin{array}{r}\text { 1,541,699.5 Million Baht } \\
\text { (48,178.1 Million USD) }\end{array}$ \\
\hline The Provident Fund & $\begin{array}{l}\text { - Voluntary } \\
\text { - Contributory }\end{array}$ & $3,295,929$ & $\begin{array}{r}\text { 1,058,456.0 Million Baht } \\
(33,076.8 \text { Million USD) }\end{array}$ \\
\hline The Retirement Mutual Fund & - Voluntary & - & $\begin{array}{r}\text { 234,023.6 Million Baht } \\
(7,3132.2 \text { Million USD) }\end{array}$ \\
\hline \multicolumn{4}{|c|}{ Pension Programs for the Informal Sector } \\
\hline The OAA & $\begin{array}{l}\text { - Voluntary } \\
\text { - Non-contributory }\end{array}$ & $8,157,175$ & $\begin{array}{l}\text { 64,770.4 Million Baht } \\
\text { (2,024.0 Million USD) }\end{array}$ \\
\hline $\begin{array}{l}\text { The Social Security Fund } \\
\text { (Article 40) }\end{array}$ & $\begin{array}{l}\text { - Voluntary } \\
\text { - Contributory }\end{array}$ & $2,414,358$ & - \\
\hline The National Saving Fund & $\begin{array}{l}\text { - Voluntary } \\
\text { - Contributory }\end{array}$ & 529,633 & $\begin{array}{r}\text { 2,723.0 Million Baht } \\
\text { (85.0 Million USD) }\end{array}$ \\
\hline
\end{tabular}

Sources: Savings indicators report (Bureau of Savings and Investment Policy, 2018); Social and Quality of Life Database System on Income Security (NESDB, 2018a)

Notes: (1) Information on the traditional civil service pension is not available.

(2) The size of the Social Security Fund for informal employees (Article 40) is included in the fund size of the Social Security Fund for formal employees and thus cannot be shown separately.

(3) While the number of the OAA participants refers only to the number of elderly currently receiving pension benefit from the program, the number of participants of other pension 
programs reported in Table 5.1 also includes working-age members who are contributing to the pension fund and expect to receive benefit in the future. According to the Social Security Office (2018), there were 443,875 people receiving old-age benefit from the Social Security Fund in 2017.

(4) The OAA's fund size refers to the government budget as the OAA is non-contributory pension program fully financed by the central government.

\subsubsection{The Old Age Allowance Program}

In 1993, the Thai government introduced the old-age allowance system to provide cash transfer assistance to their disadvantaged old-age population (Jitapunkul \& Wivatvanit, 2009; Suwanrada \& Wesumperuma, 2013). The targeted population at that time were senior citizens at the age of 60 or older who were unable to meet basic needs, incapable to work, or abandoned by their family (Suwanrada \& Wesumperuma, 2013). The selection process was initially done by representatives of the central government and thereafter decentralized to local authorities and village committees (Sakunphanit \& Suwanrada, 2011; Suwanrada, 2009).

In October 2009, due to strong political support, failure of the targeting process, and persuasive advocacies from scholars, international organizations and relevant NGOs, the OAA was expanded from a poverty-targeted program to universal coverage. With the exception of those who are already covered by other contribution-based pension schemes, such as the government pension fund and social security, or live in public nursing homes, all Thai citizens at the age of 60 or over are entitled to receive this monthly allowance with no strings attached (Suwanrada \& Wesumperuma, 2012). The program is voluntary and the eligible elderly who is willing to receive the benefit only need to register with local authorities of their residence (Sakunphanit \& Suwanrada, 2011). With regard to the benefit amount, it was set at 200 baht (6.3 USD) a month per person at the beginning, before being increased to 500 baht (15.6 USD) in 2007 (Jitapunkul \& Wivatvanit, 2009). The transfer size was adjusted again in October 2011, from a uniform pension rate to a multiple rate system. Such multiple rate system has been used until present. Recipients aged of 60-69 receive 600 baht (18.8 USD) per person per month and those aged 70-79, 80-89 and 90 or above, receive 700 baht (21.9 USD), 800 baht (25 USD) and 1,000 baht (31.3 USD), respectively (Chandoevwit, 2013). The allowance can be received at the local authority office or transferred directly to the elderly or the authorized representative's bank account (Sakunphanit \& Suwanrada, 2011). 
The size of the OAA transfer is quite modest in comparison with similar social pension programs in other countries (Paweenawat \& Vechbanyongratana, 2015). The benefit amount is far below the national poverty line. In 2009, according to NESDB (2018b), the national poverty line was defined at 2,174 baht (67.9 USD) per person per month while the allowance benefit was only 500 baht (15.6 USD) in the same year. In 2011, although the benefit amount was adjusted to around 600-1,000 baht (18.8-31.3 USD), it was still much less than the poverty line, which was 2,415 baht (75.5 USD). Again, in 2017, the poverty line was increased to 2,686 baht (83.9 USD) but the benefit amount remains unchanged.

Despite the small transfer size, the allowance from the OAA has been an important source of income especially among poor elderly. Paweenawat and Vechbanyongratana (2015) find that during 2007-2011, financial support from the OAA accounted for 20-24 percent of per capita household income of the poorest 40 percent. ${ }^{18}$ Moreover, Knodel, Prachuabmoh and Chayovan (2013, pp. 47-49), based on the 2011 national Survey of Older Persons in Thailand, suggest that 11.4 percent of the elderly population considered the OAA allowance as their main source of income. Elderly living in rural areas relied even more on the OAA allowance as the study finds that 14 percent of rural elderly reported the allowance as their main source of income.

Figure 5.1 depicts the number of persons aged 60 or over, the number of the OAA pensioners and the government budget allocated to the OAA program during 2006-2017. As can be seen, the number of the OAA beneficiaries increased substantially in 2009 when the program was expanded to cover all Thai senior citizens. The budget spent on the OAA program increased gradually over time with a steep rise in 2012 since the transfer size was adjusted upward to a multiple rate system in late 2011. In 2017, around 70 percent of the population aged 60 or over in Thailand received a monthly allowance from the OAA, compared to only 17 percent in 2006, and the government allocated almost 65 billion baht (2 billion USD) to this program.

\footnotetext{
${ }^{18}$ The authors calculate the amount of the OAA monthly allowance relative to the average per capita household monthly income. For example, in 2007 the benefit level of the OAA is 500 baht (15.6 USD) per person per month while the mean per capita income of all households is 2,083 baht (65.1 USD) per person per month. Therefore, the OAA allowance accounts 24 percent which is obtained by dividing 500 by 2083 , the quotient is then multiplied by 100 to get the percentage.
} 


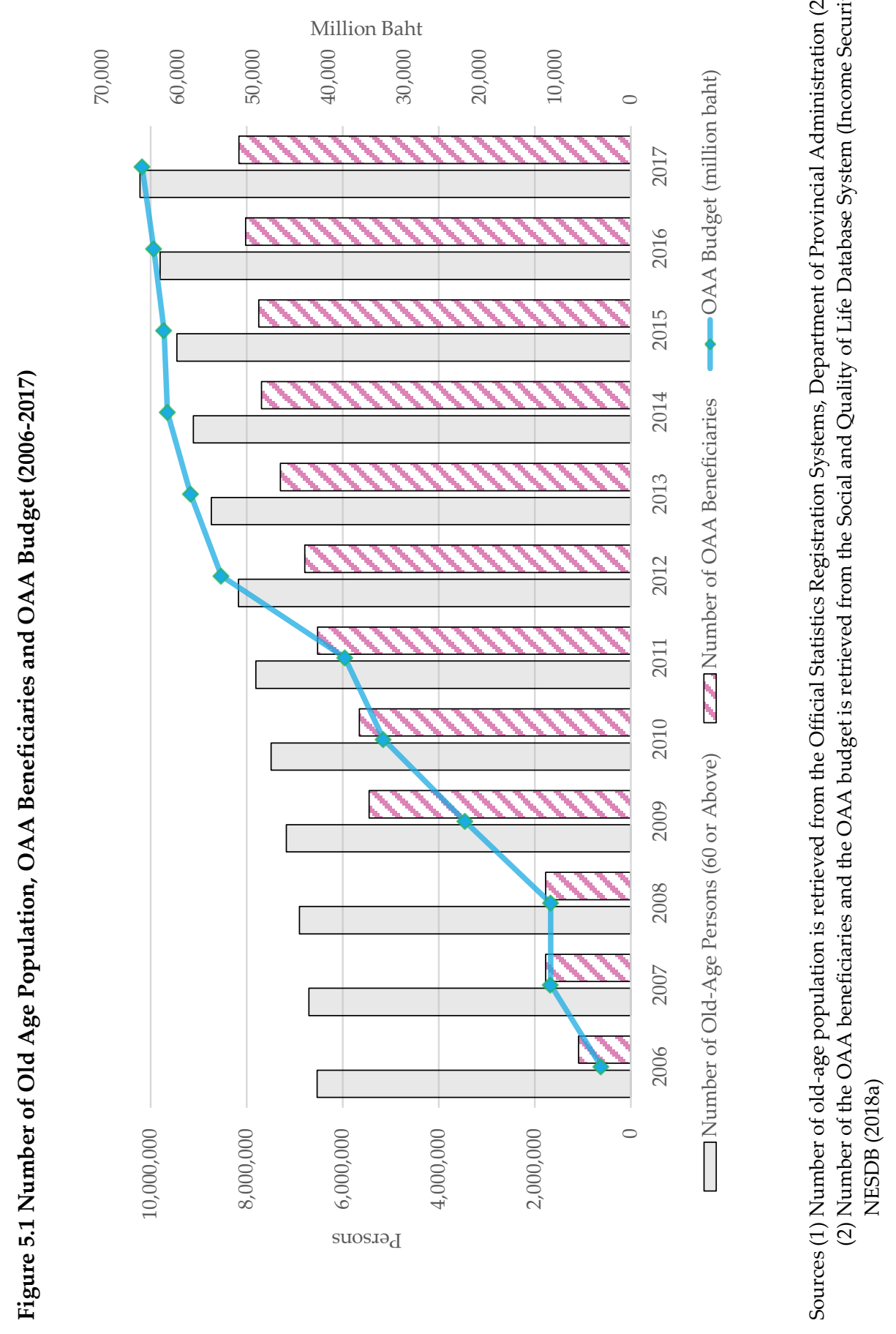


Despite being implemented for several years, the existing literature on the impact of the OAA remains scarce (Paweenawat \& Vechbanyongratana, 2015; Suwanrada \& Leetrakul, 2014). Almost all studies on the OAA mainly consider problems related to the administration and implementation process (Paweenawat \& Vechbanyongratana, 2015). Moreover, most quantitative analyses that try to assess the OAA impacts only use descriptive statistics to infer the results but do not spell out whether the impacts are actually from the program (see e.g. Suwanrada \& Leetrakul, 2014; Suwanrada \& Wesumperuma, 2012). To date, there are two studies, to the best of my knowledge, that attempt to employ econometric methods to draw causal impacts of the OAA. The first study uses Thailand's Household Socioeconomic Survey (SES) during 2006-2010 with the non-parametric difference-in-difference method to estimate the change in poverty rate among elderly due to the OAA benefit. The authors find that the expansion of the OAA in 2009 reduces the poverty rate of elderly recipients by 5.6 percent (Jitsuchon, Skoufias, \& Wiener, 2012). Second, Paweenawat and Vechbanyongratana (2015) merge three rounds (2007, 2009 and 2011) of the SES data to evaluate the impact of the universal OAA on labor supply decisions of elderly workers. By using a probit model and propensity score matching, they report that the receipt of the OAA benefit increases the probability of retirement among low-income elderly living outside of Bangkok by 6-7 percent.

The two aforementioned studies shed some light onto the immediate impact of the OAA on program beneficiaries. However, the spillover effects of the program upon pensioners' coresidents remain untested. There is no quantitative impact evaluation study to date that tries to figure out how the OAA benefit is redistributed to other members living in the same household. There is only some evidence from related literature suggesting that OAA pensioners allocate part of their pension income to other family members. For example, the results from the participatory qualitative research on social pension programs conducted in four countries including Thailand suggest that Thai elderly receiving benefit from the OAA spend part of their pension on education of their grandchildren, in addition to other expenses for household's daily necessities (Mujahid, Pannirselvam, \& Doge, 2008). Evidence from the Thai National Transfer Account (NTA) also confirms this result. National Transfer Account is the System of National Account (SNA) in which age dimension is added in order to display the reallocation of resources between age groups. According to the 2013 Thai NTA, in addition to the working-age members, elderly members aged 60 to 76 are also net contributors within the household meaning that they contribute to other members more than what they receive from them (Lowhachai, 2018). 


\subsubsection{Education System in Thailand}

Regarding Thailand's education system, the formal basic education system in Thailand consists of 15 years of education starting from 3 years for pre-primary school (for children at the age of 3 to 5 years old), 6 years for primary education, 3 years for lower secondary education, and 3 years for upper secondary education (Wongmonta \& Glewwe, 2017). Children are required to attend at least primary and lower secondary schools which form the compulsory educational level in Thailand (Ministry of Education, 2017; Wongmonta \& Glewwe, 2017). As investment in education is among the top priorities for the Thai government, the 15 years of basic education are provided free of charge (Pholphirul, 2017). In public schools, the government provides support in several expenditure categories including tuition fees, uniforms, textbooks, learning materials and extra-curricular activities (Ministry of Education, 2017). Private schools are also entitled to the subsidy. However, the government will only support as much as 70 percent of what is provided to the public schools (Wongmonta \& Glewwe, 2017). The private schools that are subsidized by the government will no longer be able to charge tuition fees higher than the remaining 30 percent that is not subsidized by the government (ibid).

Although most educational expenses are funded by the government, some expenses, such as meals, transportation costs and special learning/tutoring courses, remain uncovered. The transportation cost is actually burdensome in rural areas where students normally live far away from their school. Moreover, the recent study on challenging issues in Thai education reveals that students from the worse-off families may have to attend private schools, in which the tuition fees and other expenses are not fully funded, because they cannot compete with students from the better-off families in the school entrance exam (Cleesuntorn, 2016). The supply of public quality schools especially outside of the major cities is limited. Students thus need to compete for a place in their, or their parents', schools of choice. However, poorer students, in general, may not be able compete with wealthier students in getting into high-quality public schools and are forced to accept public schools with relatively lower quality and have less financial resources to subsidize and support students in addition to what is provided by the government. In some cases, poor parents may decide to send their children to private schools, which are generally more expensive, to ensure the quality of their children's education. 


\subsection{Data}

The Household Socioeconomic Survey (SES) is used in this analysis. The SES is a nationally representative cross-sectional survey conducted by the National Statistical Office of Thailand (NSO). This household survey was conducted every two years from 1988 until 2006. After that, it has been carried out on an annual basis. However, while information on household expenditure is collected every year, income-related variables are only available in the odd years. For example, the 2009 SES contains both household income and expenditure but the survey in 2010 covers only expenditure information. In addition to income and expenditure, SES also offers information on several characteristics of households and household members including gender, age, location of residence, education, occupation and participation in social protection programs such as the OAA and disability allowance. In each survey, around 40,000-50,000 households in all regions, both in urban and rural area, are interviewed.

In this chapter, the SES data are pooled across years in order to obtain a larger sample size. Moreover, since the OAA has been in operation for several years, drawing results merely from one specific year may obscure the real impact of the program. Accordingly, this chapter utilizes the surveys between 2009, when the OAA is firstly expanded to cover all Thai elderly, to 2017, which is the last year for which the data is available. As household income is needed for the estimations, only the survey in the odd years will be employed. These five years of surveys (2009, 2011, 2013, 2015 and 2017) are combined to obtain the pooled data set. The number of surveyed households in 2009, 2011, 2013, 2015 and 2017 are $43,844,42,083,42,738,43,400$ and 43,210, respectively.

The pooled data is then restricted by keeping only households that consist of at least one school-age member, those at the age of 3 up to and including 18, and one elderly member whose age is 55 years or above. The reason for restricting the sample only to households that have school-age members is that outcomes of interest in this analysis are related to education. It is thus legitimate to consider only households that are likely to invest in education and are subject to educational expenses. The age restriction of 3 to 18 corresponds to the pre-primary (3-5), primary (6-11), lower secondary (12-14) and upper secondary (1517) education level. Children at the age of 18 are also included into the analysis, although the upper secondary education is generally for children aged 15 to 17 , to address grade repetition and a delay in study. 
It might be the case that pension income is used to support children's education beyond the upper secondary level. However, as presented in Figure 5.2, the number of children who are still studying decreases substantially beyond 18 years of age. Moreover, the amount of OAA benefit might be too small to support higher education, the level at which the educational cost is normally not subsidized by the government. Hence, the school-age member is restricted to children at the age of 3 to 18 years only.

\section{Figure 5.2 The Distribution of Children Attending School by Age (0-24 years)}

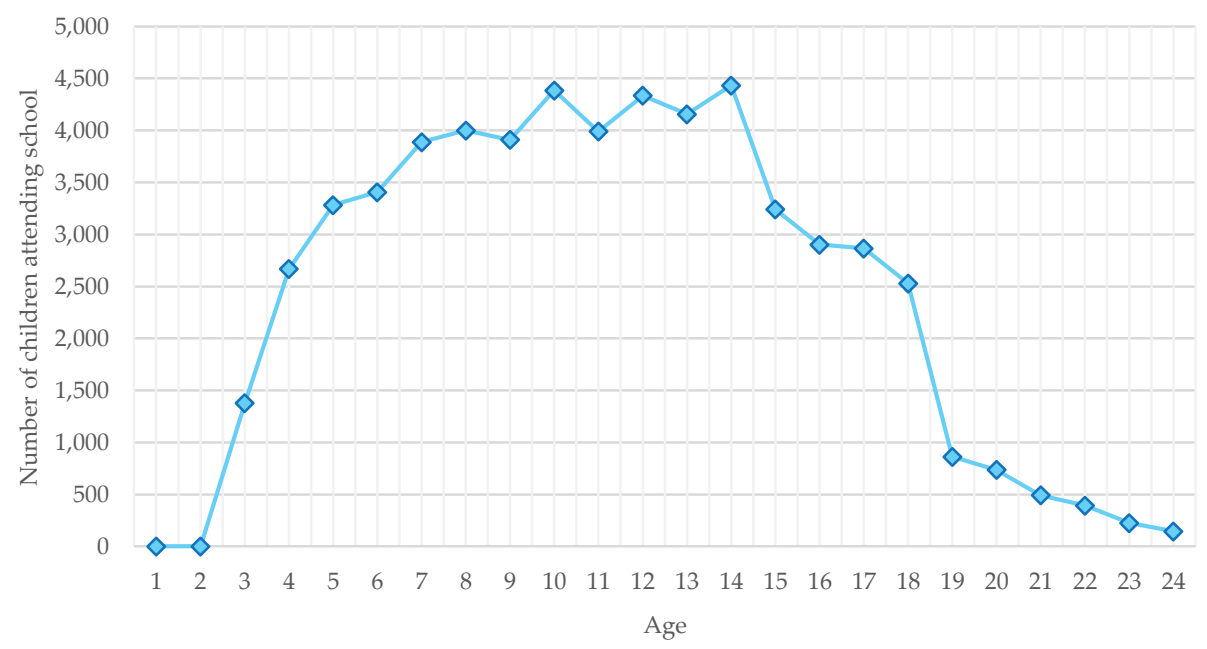

Source: Author's own estimation based on SES 2009, 2011, 2013, 2015 and 2017

Notes: The number of children attending schools is the total number (not annual basis) derived from all households in the pooled sample.

The presence of an elderly in the household may be associated with unobservables that also influence the outcomes such as the perception of the importance of education (Edmonds, 2006; Ponczek, 2011). Therefore, this study only considers households with at least one elderly member to reduce potential heterogeneity. As motivated by previous studies on social pension impacts such as Edmonds (2006) and Ponczek (2011), this analysis also includes the nearly-eligible elderly, those aged 55 to 59 years, instead of considering only those aged 60 or over, which is the age eligibility criteria for the OAA program. This is justified because households with nearly-eligible elderly members may face similar circumstances as those with eligible elderly members (Edmonds, 2006). The only factor making them different is the age of the elderly members. Therefore, the nearly-eligible households also make a good control group. Furthermore, households that receive pensions 
from the OAA together with the benefits from other pension programs are excluded from the sample to avoid potential confounding effects.

As presented in Table 5.2, there are 41,500 households remaining in the sample of which 25,258 households are the OAA beneficiaries. The other 16,242 households are nonparticipants, a group which consists of eligible non-participant households $(4,956$ households), non-eligible households (1,188 households) and nearly-eligible households (10,098 households). The eligible non-participant households refer to households with elderly members who are entitled to the OAA benefit but decided not to receive the benefit or having some delays in program registration. The non-eligible households are households whose elderly members were already covered by other contributory pension schemes such as the Government Pension Fund or the Social Security Fund. Lastly, the nearly-eligible households are households whose elderly members did not receive old-age benefit from other pension programs but were not old enough to be eligible to the OAA (an elderly between 55 to 59 years).

Table 5.2 Sample Size by Different Participant and Non-Participant Groups

\begin{tabular}{cr} 
& $\begin{array}{r}\text { Number of Households } \\
\text { from the Pooled Sample }\end{array}$ \\
\hline \hline Total sample size & $\mathbf{4 1 , 5 0 0}$ \\
OAA Beneficiary Households & $\mathbf{2 5 , 2 5 8}$ \\
Non-Beneficiary Households & $\mathbf{1 6 , 2 4 2}$ \\
Eligible non-participant households & 4,956 \\
Non-eligible households & 1,188 \\
Nearly-eligible households & 10,098 \\
\hline \hline
\end{tabular}

Source: Author's own estimation based on SES 2009, 2011, 2013, 2015 and 2017 and restricted by keeping only households that consist of at least on school-age member (3-18 years) and one elderly member (55 years or above).

It is worth noting that all variables related to income and expenditure in this analysis are deflated by the consumer price index (CPI) with the base year of 2015 obtained from Bureau of Trade and Economic Indices, Ministry of Commerce (2018). Summary statistics of participant and non-participant households are provided in Table 5.3. The summary statistics suggest that, in general, non-participant households are socioeconomically better off than participant households. Nearly-eligible households or households whose elderly members are not old enough to qualify for the OAA appear to be the most comparable counterparts in terms of household income and expenditure on education. 


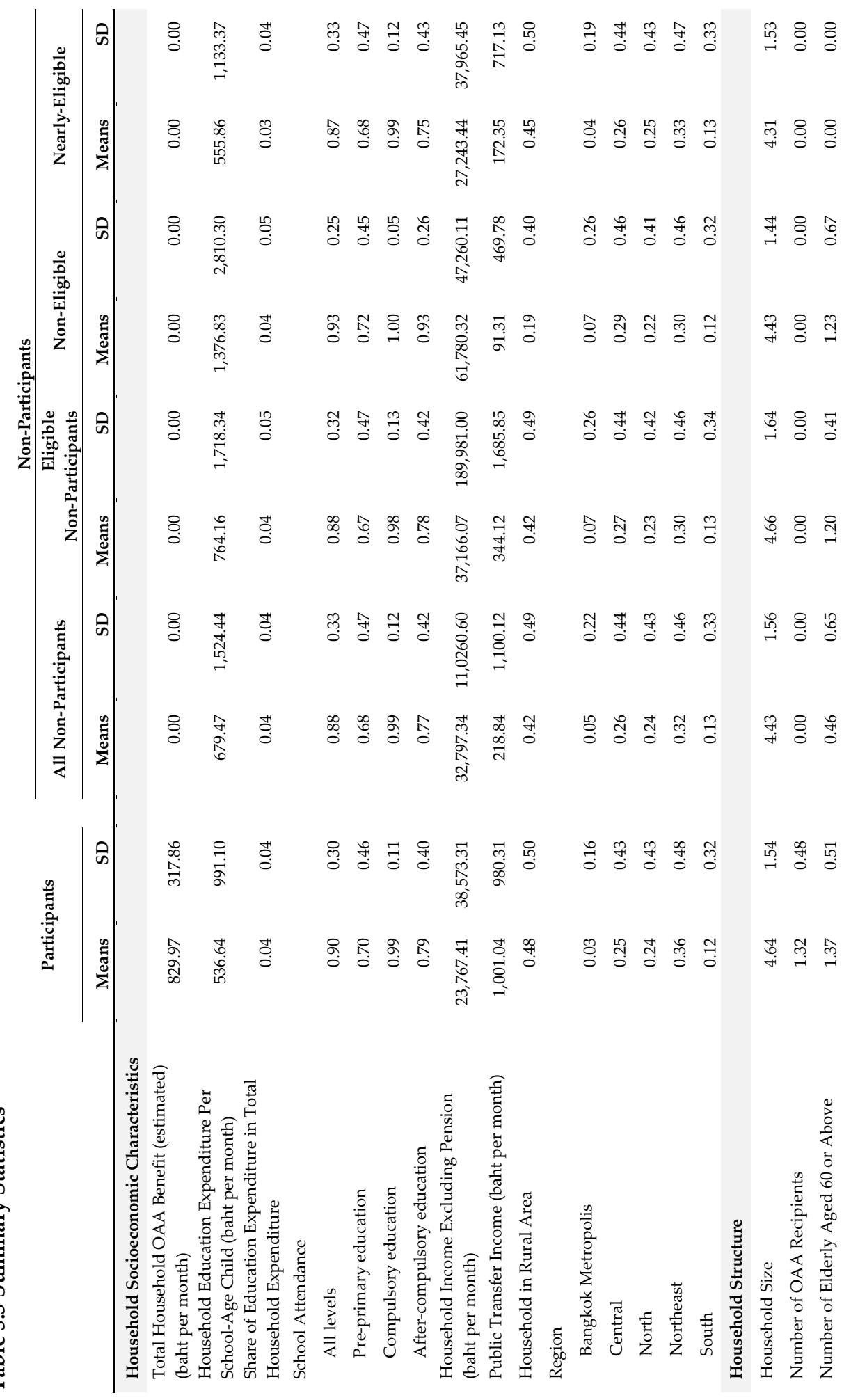




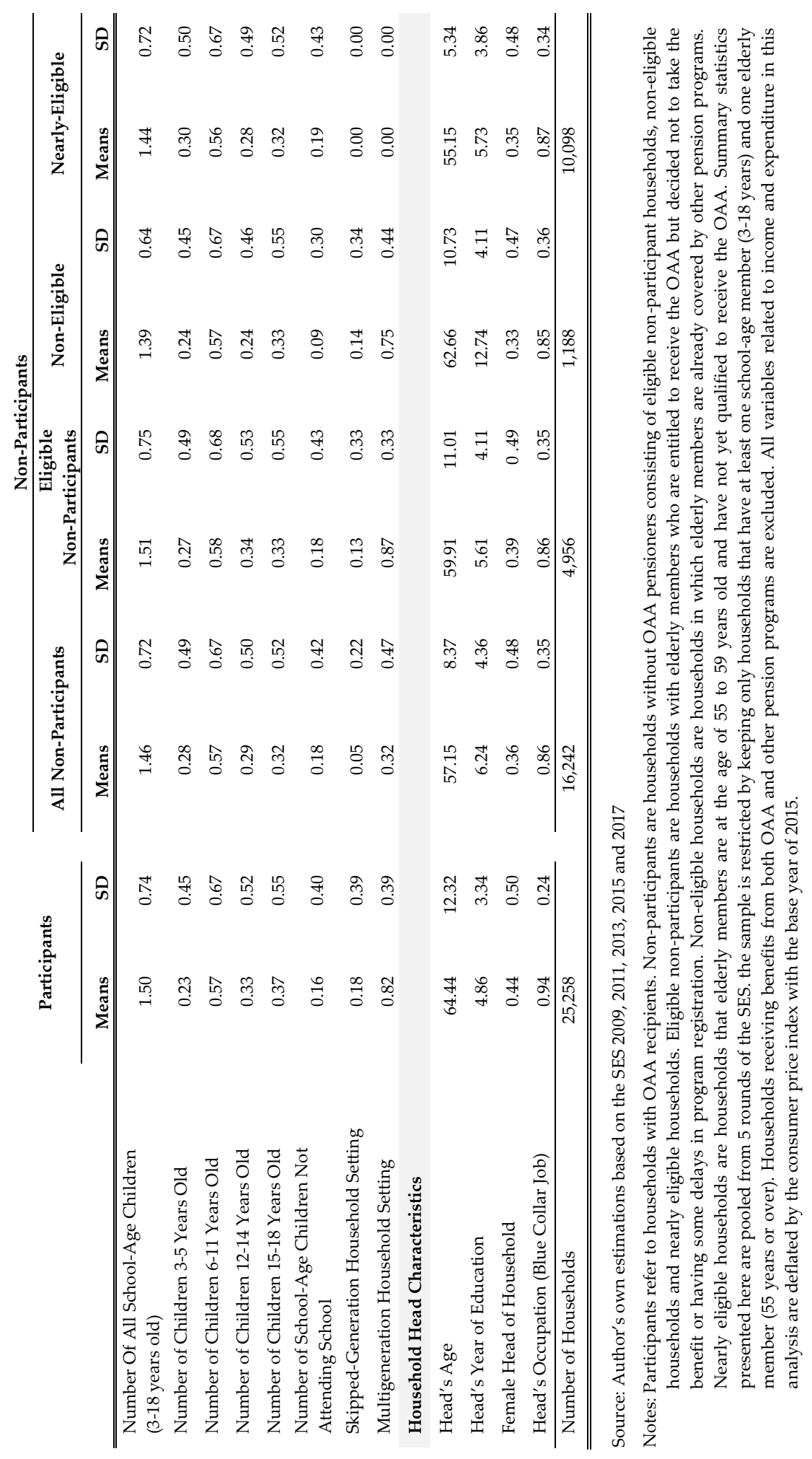




\subsection{Methods}

The main purpose of this study is to investigate the spillover effects of the OAA upon education of co-residing children. Since program participation rests on self-registration, naive estimations might be subject to a problem of endogeneity. For example, the elderly from rich families may not be willing to waste their time applying for the program just to receive a small amount of money, which is likely to be the case in this study. As can be seen from Table 5.3, participant households, on average, are socioeconomically worse off than the eligible non-participants. Considering that rich families may have a different preference for education, in comparison to the poorer ones, it is likely that this variation in preferences is an omitted variable that leads to endogeneity. On the other hand, it might be the case that people who are well aware of their right, and thus apply for the OAA program, are more likely to invest in education. Again, this omission of personal preferences may lead to biased results. Moreover, there might be a problem of simultaneity if households sign up for the OAA because they need to find additional income to finance education of their grandchildren. Therefore, the instrumental variables (IV) method is used to address the potential problem of endogeneity. This IV approach is also employed in previous literature such as Case and Deaton (1998) and Duflo (2003).

\subsubsection{Dependent Variables of Interest}

As aforementioned, the objective of this chapter is to examine the extent to which additional resources from the OAA foster intergenerational mobility by allowing households to invest more in education of their children. Two main dependent variables of interest are used to proxy educational investment including household education expenditure and school attendance. Household education expenditure in this study is household out-of-pocket payments on tuition fees, uniforms, books and other school-related supplies, transportation and special learning or tutoring courses. Both in-cash and in-kind expenses, converted in monetary terms, are included but forgone opportunity costs of schooling are not covered due to data limitations. According to the data, around 7.7 percent of households in the sample report zero expenditure on education. All households with zero education expenditure do not have children attending school. It is found that 47 percent of children not attending schools are at the age of 3 to 5 years, which is the school-age range for preprimary education, and 46 percent are at the age of 15 to 18 years, which corresponds to upper-secondary education. 
Table 5.4 Number and Percentage of School-Age Children Not Attending School by Age Group

\begin{tabular}{clcc} 
Age & Corresponding Educational Stage & Number of Children & Percent \\
\hline \hline 3 & Pre-Primary Education & 2,224 & 32.76 \\
4 & Pre-Primary Education & 754 & 11.11 \\
5 & Pre-Primary Education & 232 & 3.42 \\
$6-11$ & Primary Education (Compulsory) & 98 & 1.44 \\
$12-14$ & Lower Secondary Education (Compulsory) & 367 & 5.41 \\
15 & Upper Secondary Education & 437 & 6.44 \\
16 & Upper Secondary Education & 635 & 9.35 \\
17 & Upper Secondary Education & 836 & 12.32 \\
18 & Upper Secondary Education and Beyond & 1,205 & 17.75 \\
\hline \hline
\end{tabular}

Source: Author's own estimation based on SES 2009, 2011, 2013, 2015 and 2017

Notes: Statistics presented in the table are not on an annual basis but the total number derived from the whole sample of household with zero education expenditure. The sample is pooled from five rounds of the SES and restricted by keeping only households that have at least one school-age member (3-18 years) and one elderly member (55 years or over).

Both education expenditure per school-age child and share of education in total household expenditure are used to estimate households' education spending. Education expenditure per school-age child is calculated by the reported monthly expense on education of a household divided by the number of school-age members, aged 3 to 18 years, living in the household. This education spending per school-age child is then log-transformed and the natural logarithm of zero is replaced by zero. The share of education in total household expenditure refers to the proportion of household spending on education to total household expenditure, which includes consumption expenditure, both food and non-food, and nonconsumption expenditure. The share of education expenditure is coded as a fraction having a value between zero and one. Another outcome of interest is the probability of school attendance of school-age children co-residing with the old-age people. Unlike education expenditure, which is estimated at the household level, the unit of analysis for the impact on school attendance is at the individual child level. School attendance is defined as a dummy variable which is equal to one if that school-age member replies that he/she is studying to the question "are you currently attending school or not?" in the SES survey, and zero otherwise. 


\subsubsection{Endogenous Treatment Variables}

In line with the previous literature on the impact of social pensions (e.g. Case \& Deaton, 1998; De Carvalho Filho, 2012; Kassouf \& Rodrigues de Oliveira, 2012), the pension income that a household received from the OAA is used as an endogenous treatment variable in this study. This is justified by the fact that the amount of benefit was adjusted from the uniform to the multiple rate system since October 2011. Therefore, it might be likely that the variation in the OAA benefit also contributes to the differences in household education expenditure. Unfortunately, the SES data reports all public transfer income in one single variable. There is no separate information of OAA benefit in the data set. As a result, the amount of benefit needs to be calculated using the explicit rule of the benefit level of the program.

In the calculation, a benefit of 500 baht (15.6 USD) per person per month is assigned to OAA pensioners in 2009. In 2011, the uniform rate of 500 baht is applied to the first nine months (from January to September), the multiple rate system is used to the other three months (from October to December) and the monthly benefit per person is obtained by averaging over the year. The OAA benefit level in 2013 to 2017 is calculated with the multiple rate system. The per capita OAA benefit is then deflated by the CPI with the base year of 2015 and added up to household level to obtain the monthly household OAA benefit. As presented in Table 5.3, the amount of OAA benefit from this estimation, after being deflated by CPI, is approximately 830 baht (25.9 USD) per month. Not surprisingly, the estimated OAA benefit is less than the total public transfer income reported by respondents in the survey (1,001 baht or 31.3 USD for OAA recipients).

\subsubsection{Control Variables}

A number of control variables are included in the estimations to help spell out the impact of the OAA. The selection of control variables is motivated by several studies on determinants of education expenditure (see e.g. Alfonso, 2002; Knodel \& Wongsith, 1991; Tsang \& Kidchanapanish, 1992), existing literature on the impact of social pensions, and the availability of data. The first set of control variables is household characteristics. It has been well-studied that high income families normally invest more on education than their lowincome counterparts (Tilak, 2002). Hence, deflated household income (excluding pension) is included as a control variable. In the data, 128 households out of 41,500, or 0.3 percent, report negative household income due to business loss. These negative income responses 
are addressed by converting to zero. Household income is then transformed to natural logarithms and the natural logarithm of zero is replaced by zero. Moreover, rural households may have different spending patterns and educational preferences than urban households (Alfonso, 2002; Tsang \& Kidchanapanish, 1992). Accordingly, a dummy variable indicating area of residence, which equals one for individuals living in rural area and zero otherwise, is also included into the set of control variables. In addition to the rural-urban setting, differences in geographical region (Bangkok Metropolis, Central, North, Northeast and South) are also taken into account to control for variation in level of development and cost of living.

The second set of control variables is characteristics of household heads. A number of studies conclude that women are more likely to spend on goods and services that benefit children, in comparison to men (see e.g. Duflo, 2003; Haddad \& Hoddinott, 1994). Moreover, the level of education of the household head appears to significantly affect household investment in education (Tilak, 2002; Tsang \& Kidchanapanish, 1992; Vu Quang, 2012). Furthermore, the type of occupation of the household head, blue collar or white collar, is likely to influence household educational preferences (Alfonso, 2002; Tsang \& Kidchanapanish, 1992; Vu Quang, 2012). Therefore, characteristics of the household head namely gender, level of education and type of occupation are controlled for in this analysis. Gender of household head, in this study, is coded as a binary variable which is equal to one for female headed household. Education level of household head is measured by years of schooling. Type of occupation is also defined as a dummy variable which takes the value one if head of household is blue-collar and zero for a white-collar household head. ${ }^{19}$

Third, variation in household structure is also taken into consideration. According to Tilak (2002), the size of a household can indicate the demographic burden of the household. Likewise, Knodel and Wongsith (1991) conclude that family size is negatively associated with the prospect of school attendance among children in Thailand due to constraint of family resources. As a consequence, household size cannot be excluded from the set of control variables.

Following Case and Deaton (1998) and Vu Quang (2012), the number of household members aged 3 to 5,6 to 11,12 to 14 , and 15 to 18 which are the age group that officially corresponds

19 White-collar occupations in this study include legislators and government officials, corporate executives, professionals, associate professionals, technicians and clerks, while blue-collar occupations refer to service workers and sales workers, agricultural and fishery workers, craft workers, machine operators, armed forces and those working in elementary occupations such as street vendors, servants and garbage collectors. 
to pre-primary education level, primary education level, lower secondary level, and upper secondary leve ${ }^{20}$, respectively, are also included. Moreover, differences in family types may affect intra-household allocation of resources and spending pattern. This analysis therefore generates dummy variables for a skipped-generation household and multigeneration household and includes these two dummies in the estimations. The skipped-generation dummy is equal to one for a household where working-age members (aged 19 to 59 years) are absent, making elderly (aged 60 or above) the head of the household and the main caretaker for their grandchildren (aged no older than 18 years). In contrast to the skippedgeneration dummy, multigeneration dummy takes the value of one for a household where members of three generations (elderly, working-age members, and children) live in the same household.

In addition to the three aforementioned set of control variables, other factors which are likely to impact household investment in education are also included. According to the data, some households report zero education expenditure because their children do not attend school. The number of school-age children not going to school per household is thus generated and included in the regressions. With regard to types of schools, sending grandchildren or other children living in the same household to private schools may incur higher cost than to public ones, which is also evident in Alfonso (2002). This chapter thus employs the number of children going to private school as one of the covariates. Finally, it is necessary to take year effects into consideration since the cross-sectional data are pooled across years. The estimations thus include dummy variables for each of the years (2009, 2011, 2013, 2015 and 2017) to pick up trends and changes in one respective year that are not attributed to the OAA or other control variables.

\subsubsection{Estimation Methods}

This section explains estimations methods that are employed to measure the impact of the OAA on household education expenditure and school attendance. First, the following twostage least squares (2SLS) are conducted to examine the impact on household education expenditure per school-age child.

\footnotetext{
${ }^{20}$ The official school age for upper secondary education is 15-17 years. However, in the sample used in this study, 84 percent of 18 -years-old students are in upper secondary school. Therefore, children at the age of 18 are also included in the group of upper secondary education level.
} 


$$
\begin{gathered}
T_{i}=\alpha_{0}+\alpha_{1} Z_{i}+\alpha_{2} X_{i}+\mu_{i} \\
Y_{i}=\beta_{0}+\beta_{1} T_{i}+\beta_{2} X_{i}+\varepsilon_{i}
\end{gathered}
$$

As presented in equation (2), education expenditure per school-age child spent by a household i $\left(Y_{i}\right)$, in natural logarithm $(\ln )$, is a function of the amount of OAA pension that a household received from the OAA program $\left(T_{i}\right)$ (also log-transformed). Theoretically, eligibility criteria of the program can be used to construct IV as it is highly related to program participation but is unlikely to affect outcomes of interest (Khandker, Koolwal, \& Samad, 2010). Previous study on the spillover effects of social pension on co-residing members such as Duflo (2003) also uses the program eligibility to construct instruments. Therefore, the number of elderly members aged 60 or above, of household $i$, is used as an instrument $\left(Z_{i}\right)$ to predict $T_{i}$ as presented in equation (1). $X_{i}$ is a vector of aforementioned control variables including characteristics of household, household heads and household structure, as well as other factors potentially affecting household education expenditure namely the number of children not going to school, the number of children attending private schools and year dummies.

The validity of an instrument depends on the assumptions of instrument relevance and exclusion restriction (Stock \& Watson, 2011). For the instrument relevance, the high value of F-statistics (presented in the third last row of Table 5.5) and the strong correlations between the instrument and the instrumented endogenous treatment variable (presented in the second last row of Table 5.5) suggest that the 2SLS model does not have a problem of weak instrument. However, the exclusion restriction cannot be examined statistically since in this study, the number of endogenous regressor is equal to the number of instrument (Stock \& Watson, 2011). The analyses thus need to assume that the number of household member at the age of 60 or above is not directly related with household expenditure on education. This assumption is intuitive because the number of elderly should be more associated with other expenditure categories such as aged care and health care services, than education. Moreover, although the presence elderly in a household may associate with education expenditure, probably through unobserved preference, the association between education expenditure and the number of elderly itself should be minimal.

As discussed earlier, around 7.7 percent of households in the working sample reports zero education expenditure. Therefore, this chapter also conducts a tobit model with an endogenous regressor to address this problem of limited dependent variable due to a corner 
solution response (Wooldridge, 2009). Under the tobit model, equations (1) and (2) are reestimated by Maximum Likelihood assuming that $\left(\mu_{i}, \varepsilon_{i}\right)$ are normally distributed with mean zero, and a value of zero for education expenditure per school-age child $\left(Y_{i}\right)$ has a positive probability. Like in the 2SLS set up, $T_{i}$ refers to the amount of OAA pension received by household $\mathrm{i}$ which is endogenous and predicted by the instrument $Z_{i}$ or the number of elderly member aged 60 or above living in the household. The same set of control variables $\left(X_{i}\right)$ used in the 2SLS model is also applied in the tobit estimations. The expected value of education expenditure per school-age child $\left(Y_{i}\right)$ for overall households and the marginal effect of all explanatory variables (the endogenous treatment variable $T_{i}$ and control variables $\left(X_{i}\right)$ on the expected value of $Y_{i}$ are measured by equation (3) and (4) where $\sigma$ denotes standard deviation and $\beta_{k}$ refers to coefficients associated with endogenous treatment variable $\left(T_{i}\right)$ and control variables $\left(X_{i}\right)$.

$$
\begin{gathered}
E\left(Y_{i} \mid T_{i}, X_{i}\right)=\Phi\left(\frac{\beta_{1} T_{i}+\beta_{2} X_{i}}{\sigma}\right)\left(\beta_{1} T_{i}+\beta_{2} X_{i}\right)+\sigma \phi\left(\frac{\beta_{1} T_{i}+\beta_{2} X_{i}}{\sigma}\right) \\
\text { Marginal Effect }=\beta_{k} \Phi\left(\frac{\beta_{1} T_{i}+\beta_{2} X_{i}}{\sigma}\right)
\end{gathered}
$$

For the impact of the OAA on the fraction of household expenditure that is contributed to education, the fractional probit model with endogenous regressors is conducted to examine the results. Under this model, equation (1) and (2) are also estimated by the Maximum Likelihood Estimation method where $Y_{i}$ denotes the share of education in total household expenditure. $Y_{i}$ is coded as a fraction having a value between zero and one. The pair $\left(\mu_{i}, \varepsilon_{i}\right)$ is normally distributed with mean zero. The same set of endogenous treatment variable $\left(T_{i}\right)$, instrument $\left(Z_{i}\right)$ and control variables $\left(X_{i}\right)$ as in the 2SLS are also used in this fractional probit model.

In addition to education expenditure, the impact of OAA on school attendance is also examined. The analysis is conducted at the individual child level using the bivariate probit regression to obtain the results. Equation (1) and (2) are re-estimated assuming that $T_{j}$ and $Y_{j}$ are both a binary variable representing a child $\mathrm{j}$ co-residing with at least one OAA pensioner and school attendance of the child, respectively. The same instrument as the above 2SLS model is used so $Z_{j}$ denotes the number of household member aged 60 or over living with child $\mathrm{j}$. It is useful to note that the subscription is changed from $\mathrm{i}$ to $\mathrm{j}$ to reflect the change of the level of analysis from household $i$ to individual child $j$. The same set of control variables used in 2SLS model is also applied in the bivariate probit regression but the number of 
children not attending school and the number of children going to private school are excluded from the analysis. Moreover, age and gender of a child are also included as control variables. $\mu_{j}$ and $\varepsilon_{j}$ follow a bivariate normal distribution with variances equal to one and correlation coefficient equal to $\varrho$.

$$
\left(\begin{array}{c}
\varepsilon_{j} \\
\mu_{j}
\end{array}\right) \sim B V N\left(\left[\begin{array}{l}
0 \\
0
\end{array}\right],\left[\begin{array}{ll}
1 & \varrho \\
\varrho & 1
\end{array}\right]\right)
$$

The impact of the OAA on school attendance in all education levels is firstly examined. The impact in each education level including pre-primary education, compulsory education and upper secondary education is then estimated individually to examine the variations by levels.

\subsection{Results}

This section presents the results obtained from the estimations discussed in previous section. Table 5.5 presents the spillover effects of the OAA on household education expenditure per school-age child, using the amount of OAA pension received by a household, which is instrumented by the number of elderly members over the age of 60 , as the treatment variable. Column (1) estimates the impacts on beneficiary households, in comparison to all non-OAA participant households. According to the results, there is no credible evidence supporting that additional income from the OAA has a statistically significant role in increasing household education expenditure. Even when the nontreatment group is restricted to the eligible non-participants (column 3), non-eligible (column 5) and nearly eligible households (column 7), the impact of the OAA remains insignificant. Since consumption patterns may vary by income level, equation (1) and (2) are also replicated with merely households in the bottom 40 percent of the income distribution, as presented in Column (2), (4), (6) and (8). In line with the impact on the full sample, additional income from the OAA does not increase spending on education among the lowincome families.

The impact of the OAA on household education expenditure is also analyzed through the tobit model to address the corner solution response of an education expenditure variable, of which a number of observations have zero value. As presented in Table 5.6, it is found that the results obtained from the tobit model are similar to the ones obtained from the 2SLS model. The OAA pension does not lead to higher educational expenditure per school-age child, no matter which control group is being estimated. With regard to the relationship 
between household investment in education and other control variables, the 2SLS and the tobit model provide similar findings, which are also in line with previous studies on private spending on children's education (see e.g. Alfonso, 2002; Knodel \& Wongsith, 1991; Tsang \& Kidchanapanish, 1992).

For example, household income, education of household head and white-collar headed households are found to have a positive association with household education expenditure. The numbers of school-age children in the respective age groups are also positively associated with education spending but the coefficient of the variable representing the number of children aged 3-5 years appears to be smallest in magnitude. Besides, the number of children not attending school is found to have a highly negative relationship with household education expenditure as expected. The results on dummies for years also look interesting. The household education expenditure per school-age child in 2011 is found to be lower than that of 2009. The result is slightly higher in 2013 but remains negative, and only becomes positive in 2017.

While no significant impact of the OAA is found on household education expenditure, the beneficial role of the OAA on education is proved to be significant when the share of education in total household expenditure is used as the dependent variable of interest. However, the impact size is nearly negligible and not economically significant. Table 5.7 presents the impact of the OAA on the share of education expenditure analyzing through the fractional probit model. It is found that a one percent increase in income support from the OAA increases the share of education expenditure by approximately 0.00001-0.00003 percentage point depending on which control group is particularly considered (and 0.000020.00004 percentage point among the bottom 40 percent households).

The association between the share of education and control variables is generally in line with what is observed when the education expenditure per school-age child is used as the outcome variable. For instance, living arrangements of a household (being skippedgeneration households or multigeneration households) do not significantly influence household investment in education. However, different directions of relationship are found in some variables such as household income. In addition to the fractional probit model, a tobit model where a lower limit is set as zero and an upper limit is one, is also conducted to further examine the robustness of the results. The positive, significant but negligible impact of the OAA on the share of education expenditure observed from the fractional probit model is also found to be valid in the tobit estimation with the zero-to-one censoring limit. 


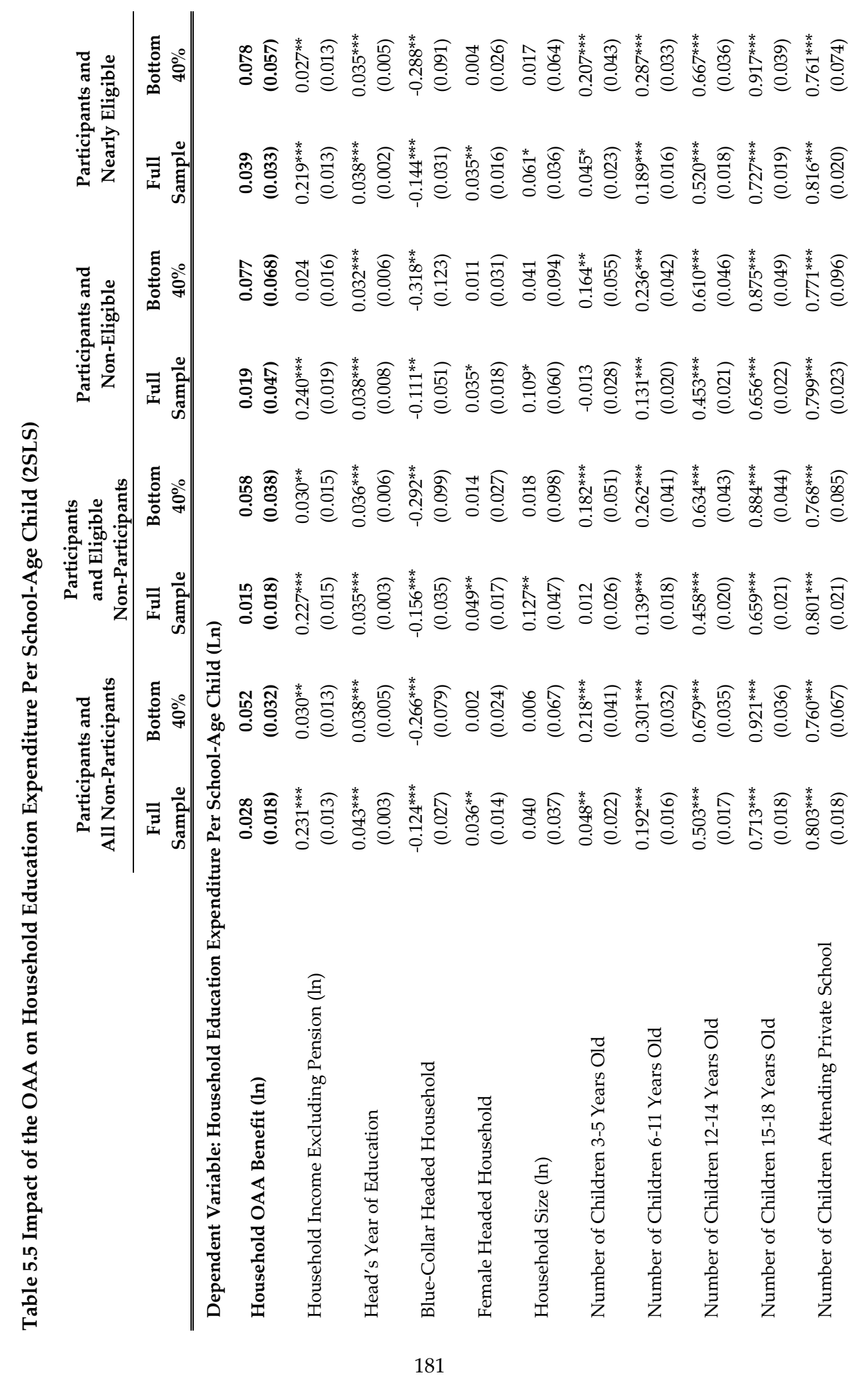




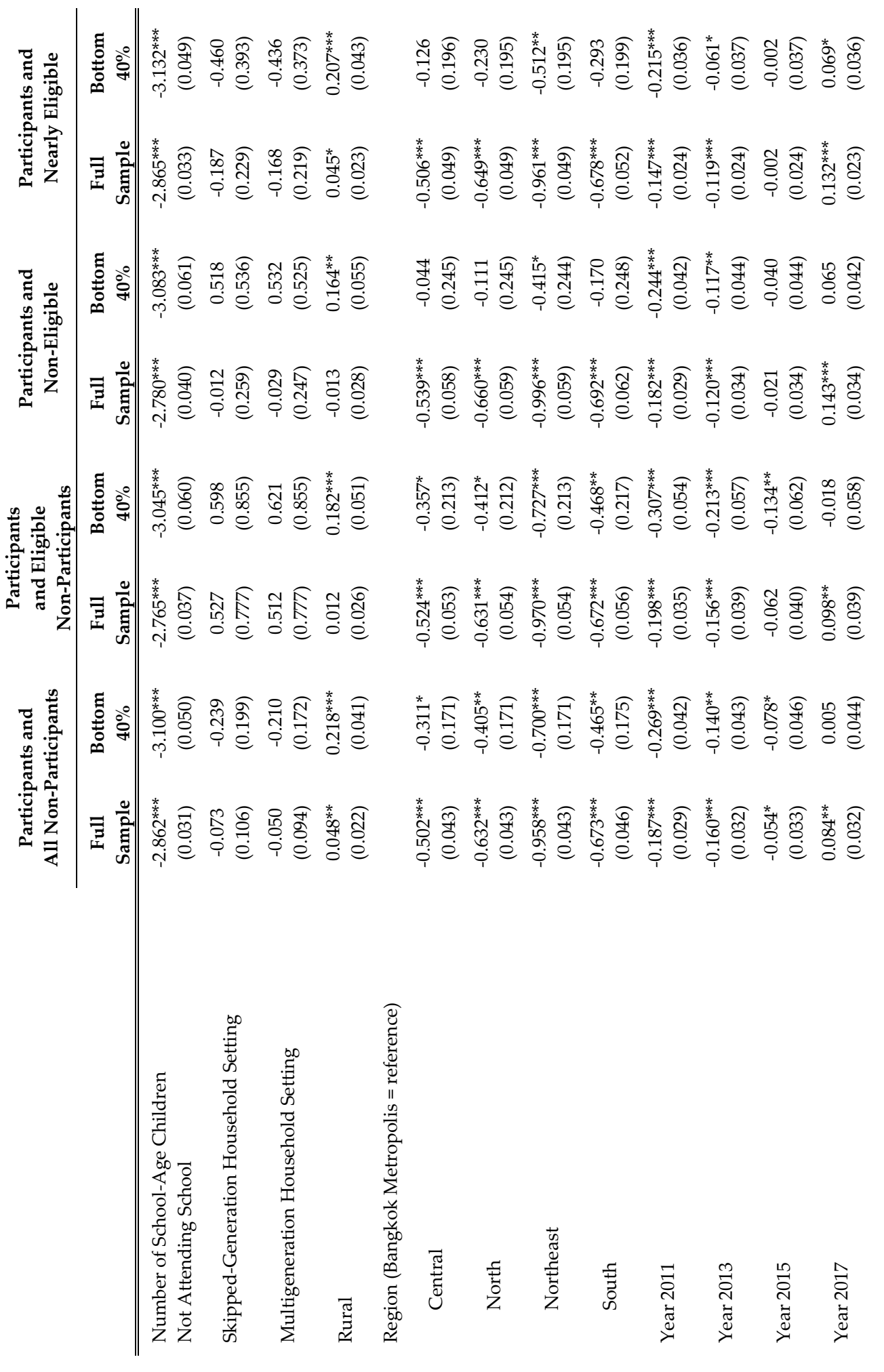




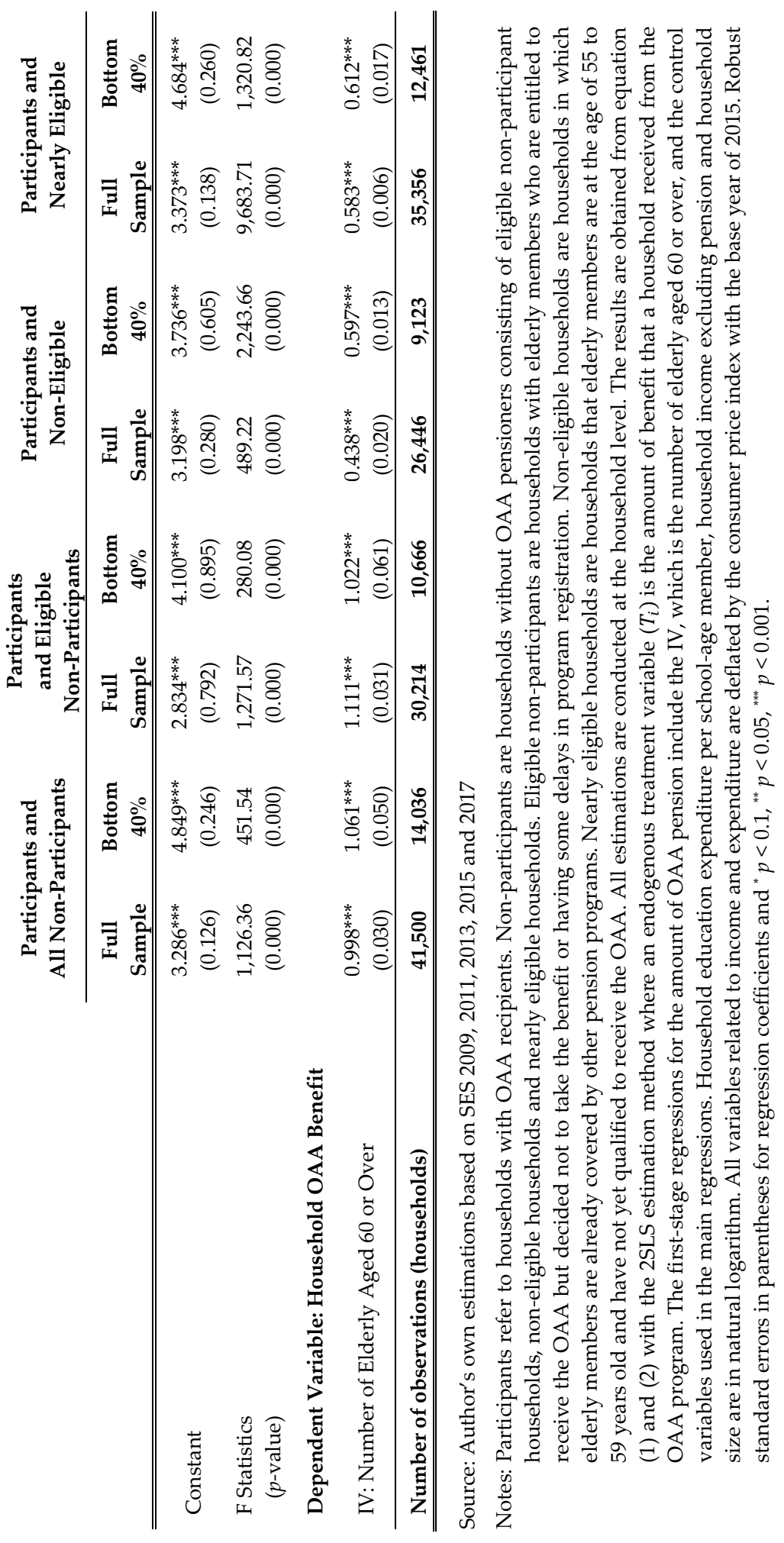




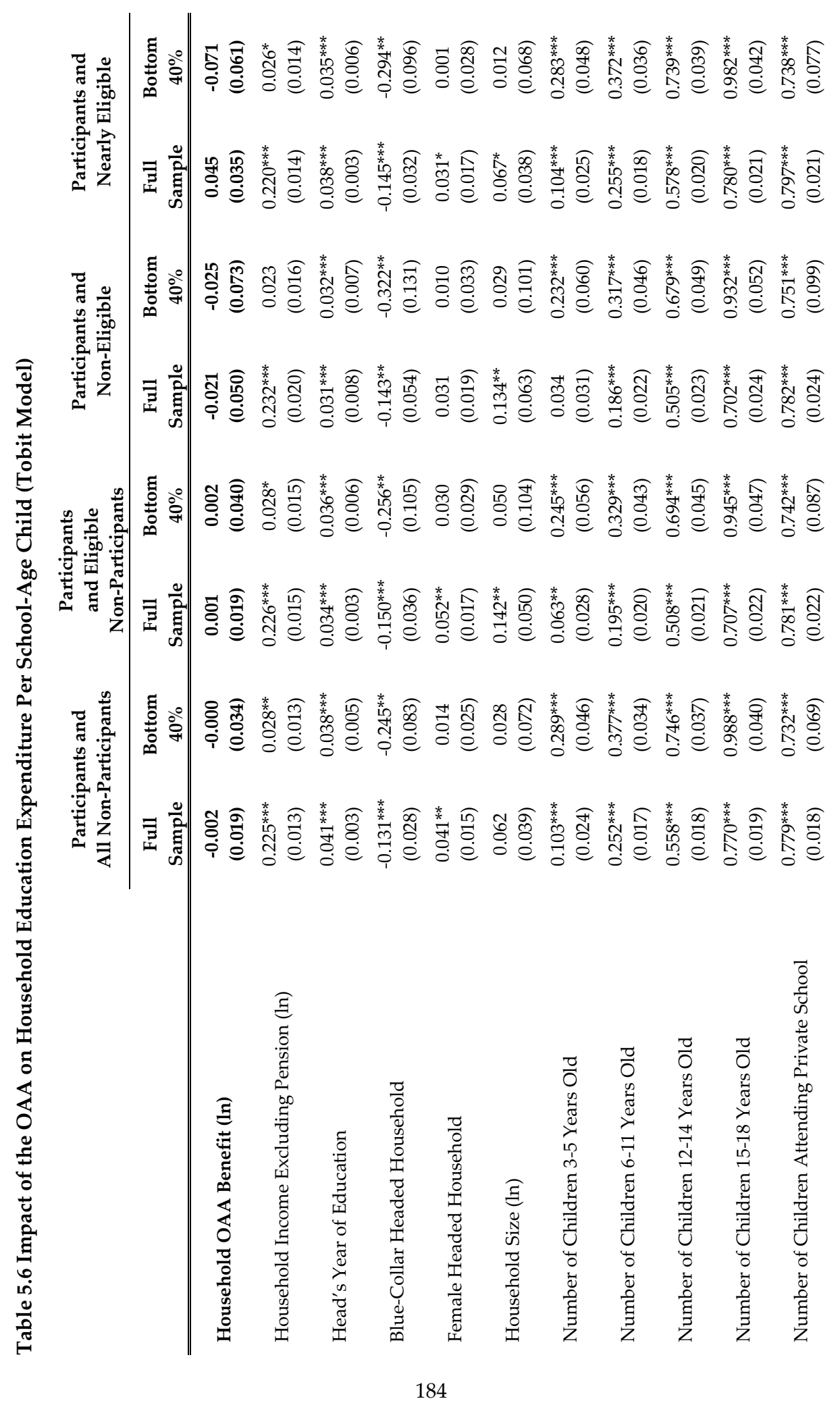




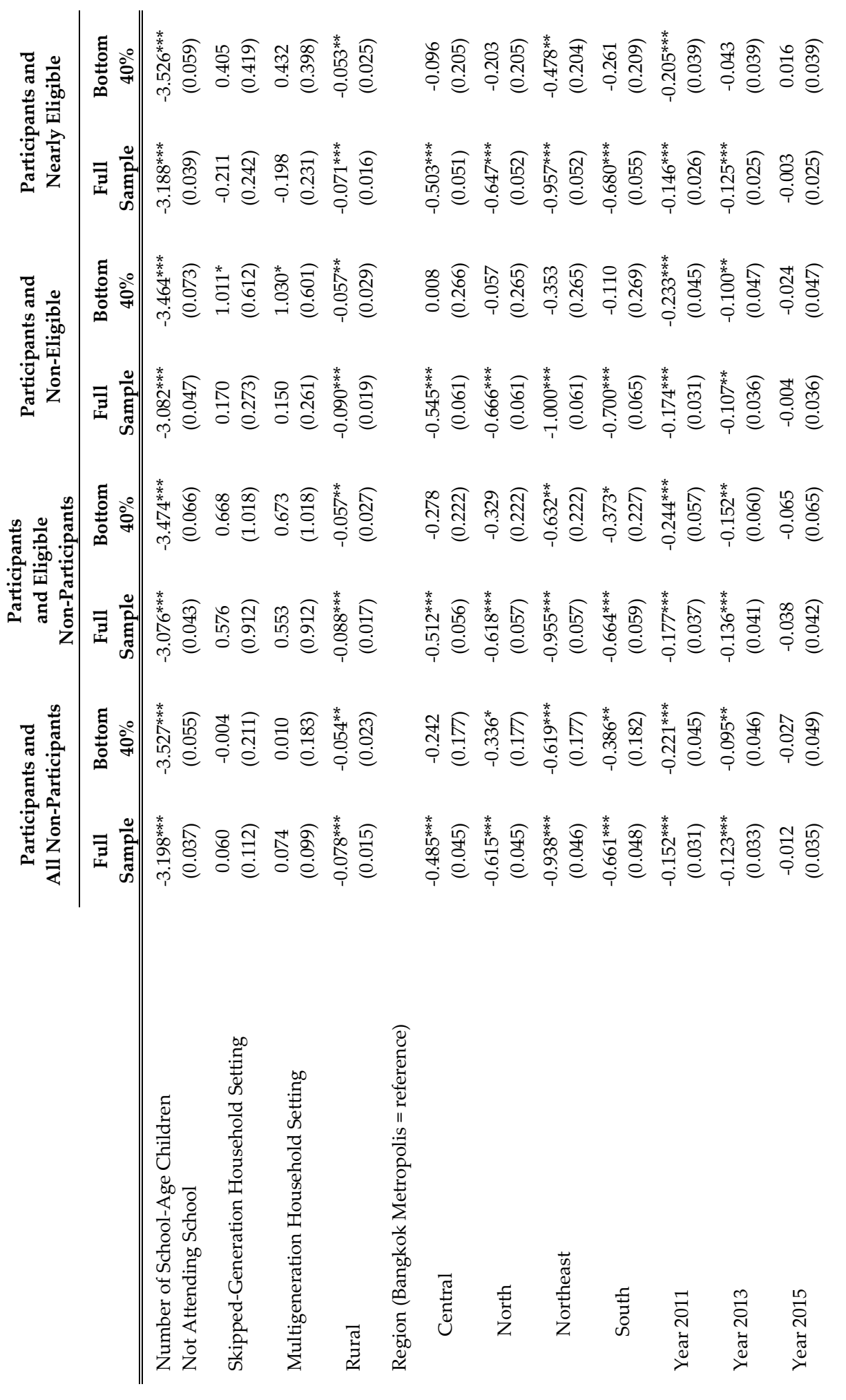




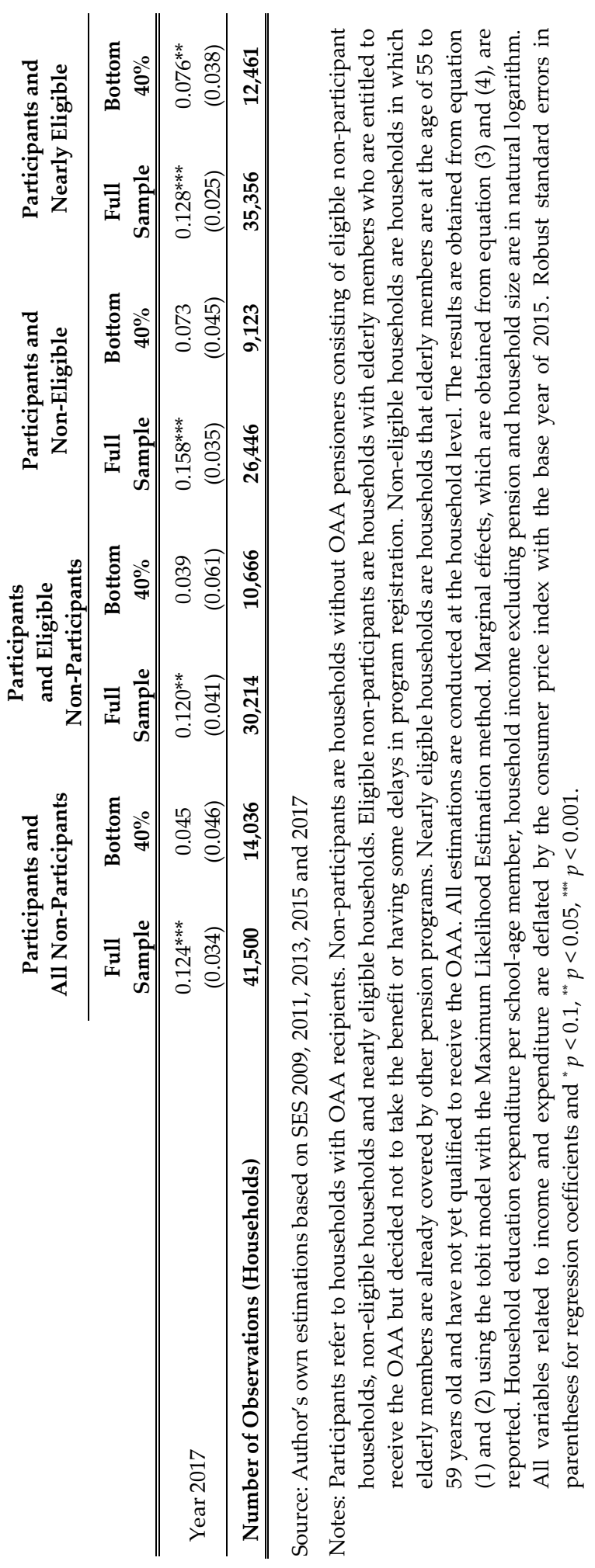




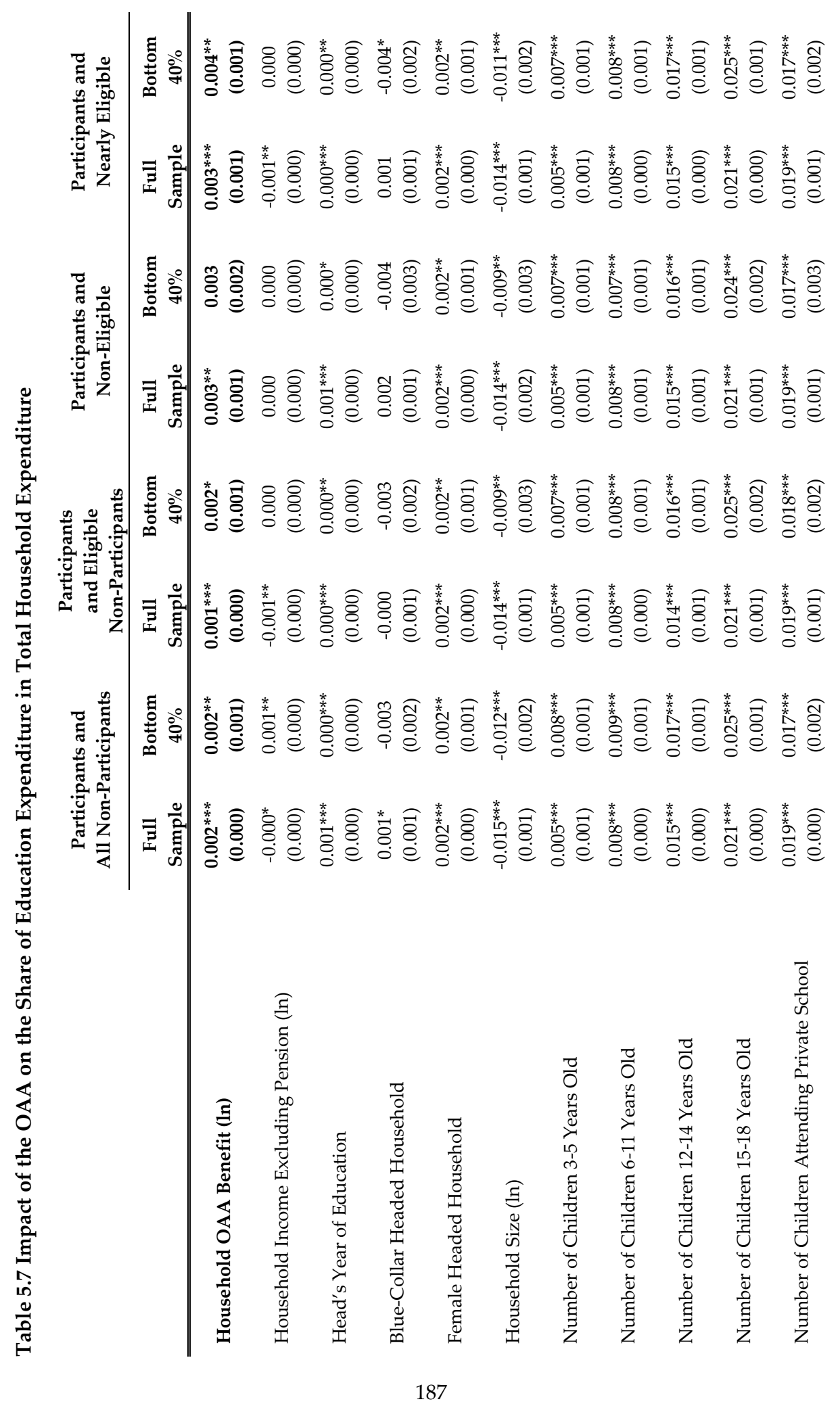




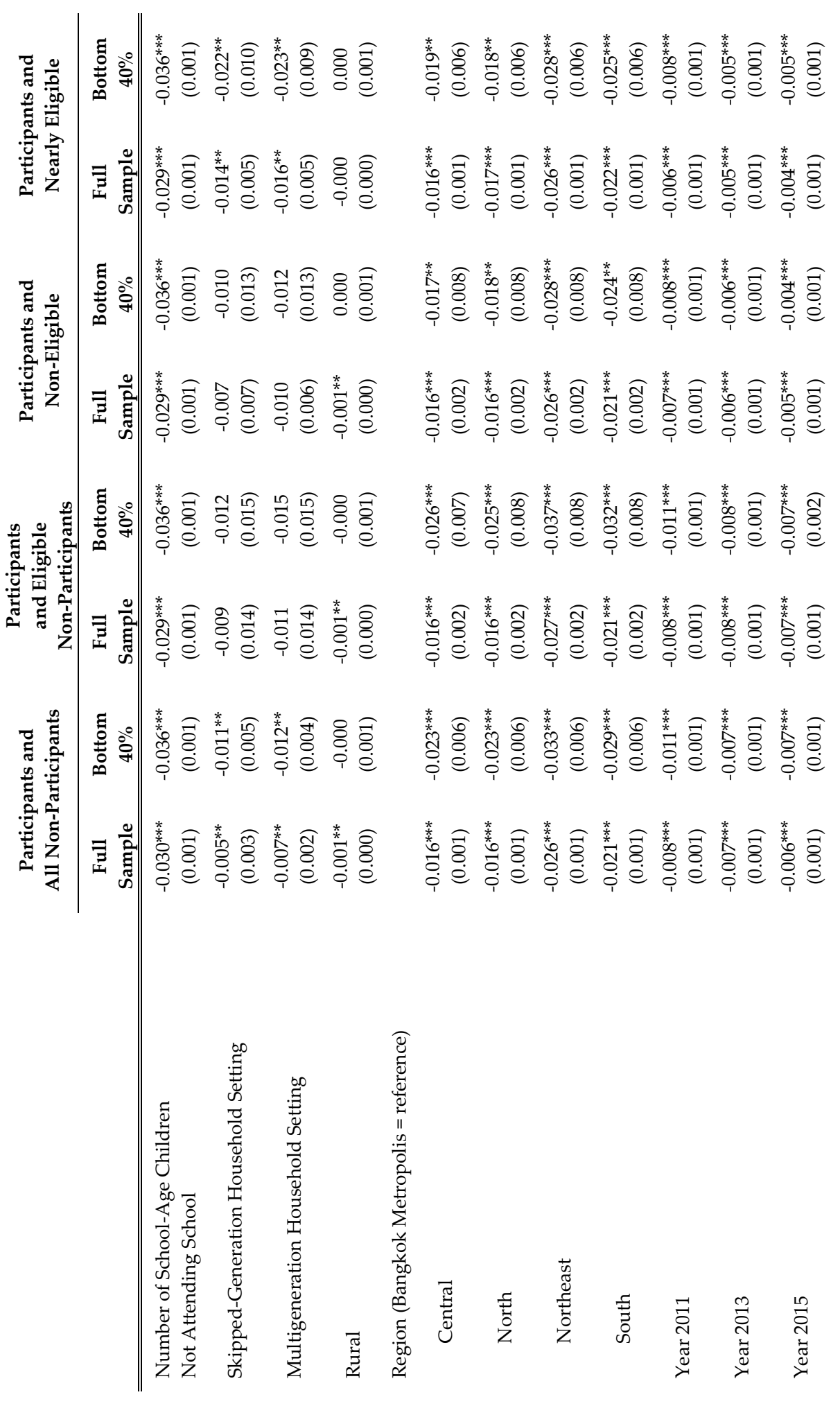




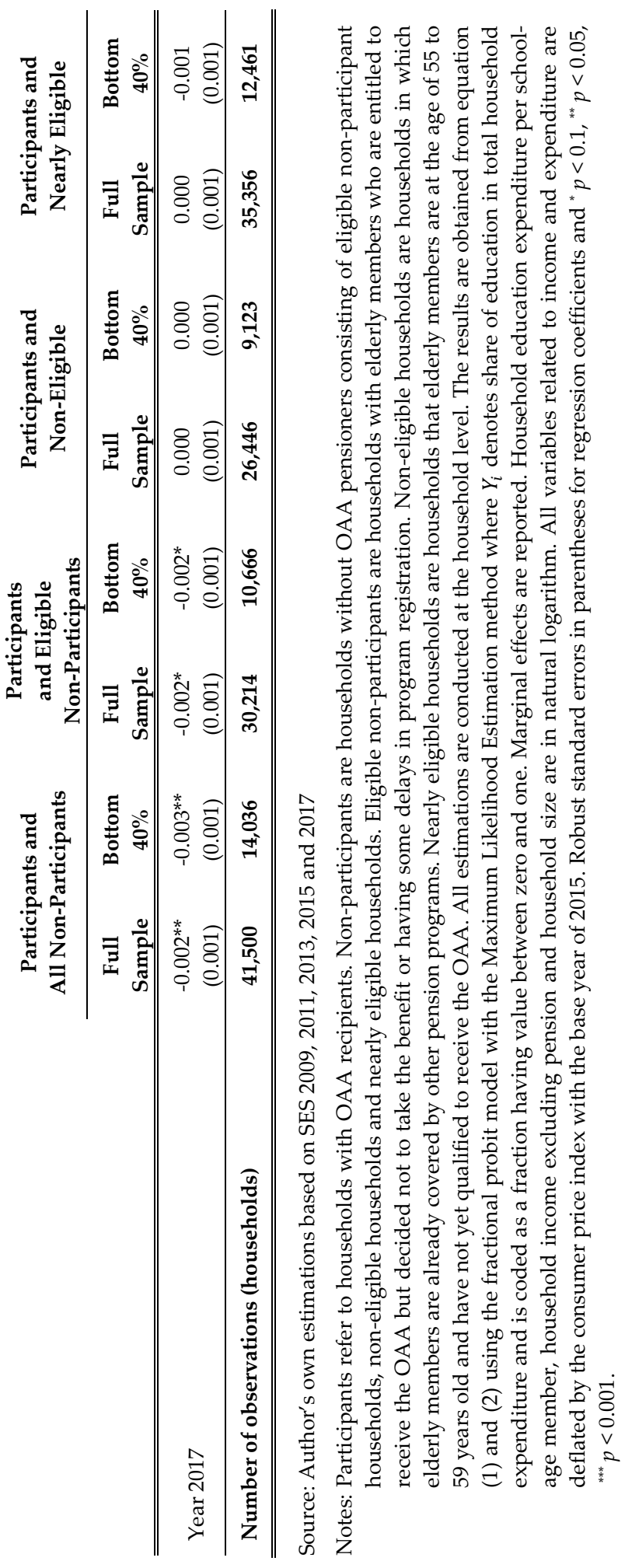




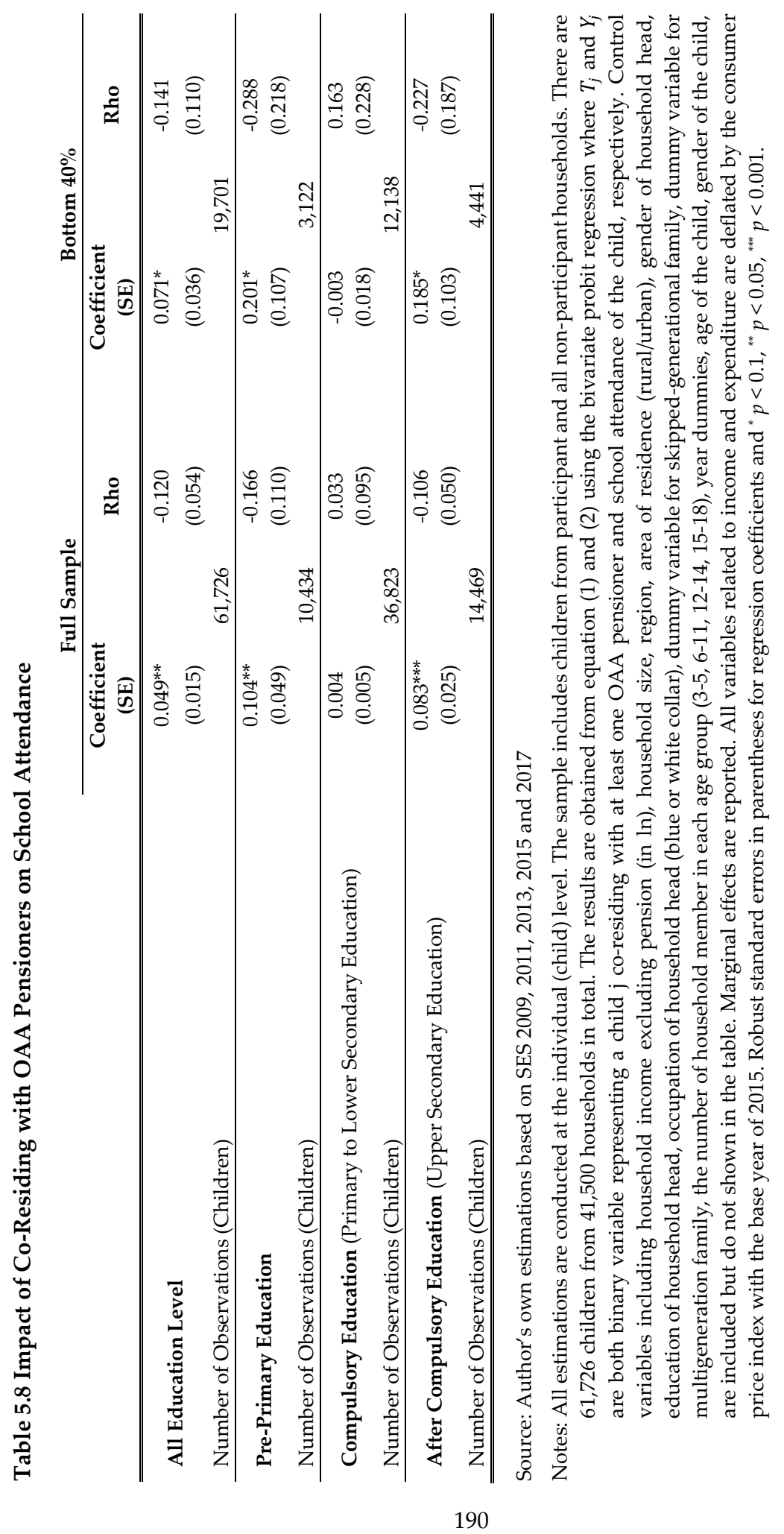


With regard to the impact of the OAA on school attendance, Table 5.8 presents the results of the bivariate probit model, using children from all non-beneficiary households as control group and schooling attendance as the dependent variable. The results suggest that income support from the OAA to the elderly members improves the probability of school attendance among school-age members. Children living with OAA pensioners are 4.9 percent more likely to attend school. The impact among children from the poorest 40 percent families is also positive and significant at the 10 percent level. The impact heterogeneity by educational level is also measured. It is found that co-residing with OAA recipients increases the likelihood of children attending pre-primary school and upper secondary education by 10.4 percent and 8.3 percent, respectively.

However, income support from the OAA does not promote compulsory school attendance. The impact of the OAA on school attendance among children from poorest 40 percent families also shows interesting results. It is found that living in beneficiary households is found to be beneficial for poor children of pre-primary and upper-secondary education school age (15-18 years old). The bivariate probit model also does not find the significant impact of co-residing with OAA pensioners in compulsory education implying that having OAA pensioners within a household do not help increasing the probability of sending children to compulsory school. These results obtained from the estimation with children from the bottom 40 percent households are quite in line with the ones obtained from the estimation with the full sample. However, the positive results of the bottom 40 percent households are only significant at the 10 percent level. ${ }^{21}$

\subsection{Conclusion and Discussion}

Social pension is an important income source especially in a country where more than half of employment is operating outside of the formal social security system. Additional income from social pensions could help enhance financial stability especially after retirement. Moreover, as discussed in Chapter 1, pension income can be used to invest in human capital and physical capital. A number of studies concludes that elderly people do not only spend

${ }^{21}$ As a robustness check, the impacts of the OAA on household education expenditure and school attendance are also examined using the wider age group (both 3-22 years and 3-24 years). It is found that the results are robust to the choice of the age group. The OAA still have a positive and significant impact on share of education expenditure and overall school attendance. However, when zoom in on the impact of the OAA on school attendance at tertiary level (which corresponds to 19-22 or 19-24 years of age), no significant impact is observed. 
their pension income on themselves but also redistribute it, either out of altruism or exchange motives, to other members in their family. Social pensions thus help promote intergenerational mobility. This positive spillover effect of social pension is empirically examined in this chapter.

The results from the 2SLS and the tobit models suggest that an increase in the amount of OAA benefit of the household does not significantly lead to an increase in household education expenditure per school-age child. The impact of the OAA is statistically significant when the share of education expenditures is employed as the dependent variable. However, the magnitude of the impact is minimal which can be attributable to the small transfer size of the OAA. With regard to the impact of the OAA on school attendance of co-residing children, it is observed that children co-residing with OAA pensioners are more likely to attend school, with an exception of the primary and lower secondary level in which school attendance is already mandatory.

Given the small impact of the OAA on school expenditure, it is interesting to consider which mechanism drives positive effects on school attendance. The first potential explanation is that the additional income from the OAA allows the elderly to retire and have more time to focus on the education of their grandchildren. This argument is supported by the recent study by Paweenawat and Vechbanyongratana (2015) who observe an increase in the probability of retirement among the low-income OAA beneficiaries. Moreover, it may be possible that the income support from the OAA reduces the incidence of child labor by making children co-residing with OAA pensioners feel less compelled to work in order to support their family. Children thus have the opportunity to attend school, instead of working. Although the impact of the OAA on child labor has not been examined, the significant causal relationship between social pensions and child labor is empirically evident in other countries such as Brazil (Rodrigues de Oliveira, Kassouf, \& Aquino, 2017). In addition, it might also be the case that the steady and reliable source of income from the OAA makes households less worried about their future financial circumstances and consequently send their grandchildren or children living in the same household to school. However, further analysis is needed to confirm these hypotheses and provide more insight into the mechanisms underlying the positive effect of the OAA on school attendance.

In this chapter, the spillover effects of the OAA among low-income families are also particularly examined. It is found that the impact of the OAA on household spending on education, measured by the share of education expenditure in total household expenditure, and school attendance are found to be positive and significant at the 5-10 percent level. Even 
though the magnitude of the effect is modest, the results are quite impressive considering that the amount of benefit is so small. Moreover, the result is quite surprising as it is expected that low-income families may favor other necessary expenditures over education because they have to meet basic needs before anything else. The OAA impact on the share of household expenditure that is contributed to education in each income decile up to the fourth group is hence further examined, as presented in Table 5.9, to test if the positive spillover effects onto education still exist among the poorest of the poor.

Not surprisingly, the results suggest that households in the two poorest groups (the first and second 10 percent income decile) do not spend additional income from the OAA on education, which is as expected, probably because they have to save the OAA income for other relatively more necessary or urgent expenditure. However, the positive impacts of the OAA on the share of education expenditure among households in the higher income deciles are still statistically significant. Probably this is because education is highly valued in Thailand and from the perspective of low-income families, investment in education of their offspring is among the promising ways to improve their living condition and escape from poverty.

In addition to the association between the OAA and education, the relationship between household investment in education and some other control variables, despite not being of central interest for the analysis, also provides interesting implications. First, the OAA pension income and income from other sources is found to have different effect on household education expenditure. As discussed, while the results suggest the small but significant impact of the OAA on the share of education expenditure in total household expenditure, the impact of the OAA on the absolute amount of education expenditure per school age child is found to be statistically insignificant. The reverse relationship is found on income excluding pension. It is found that income excluding pension of a household has a positive and significant association with household education expenditure but negative, or statistically insignificant, with the share of education in total household expenditure. 


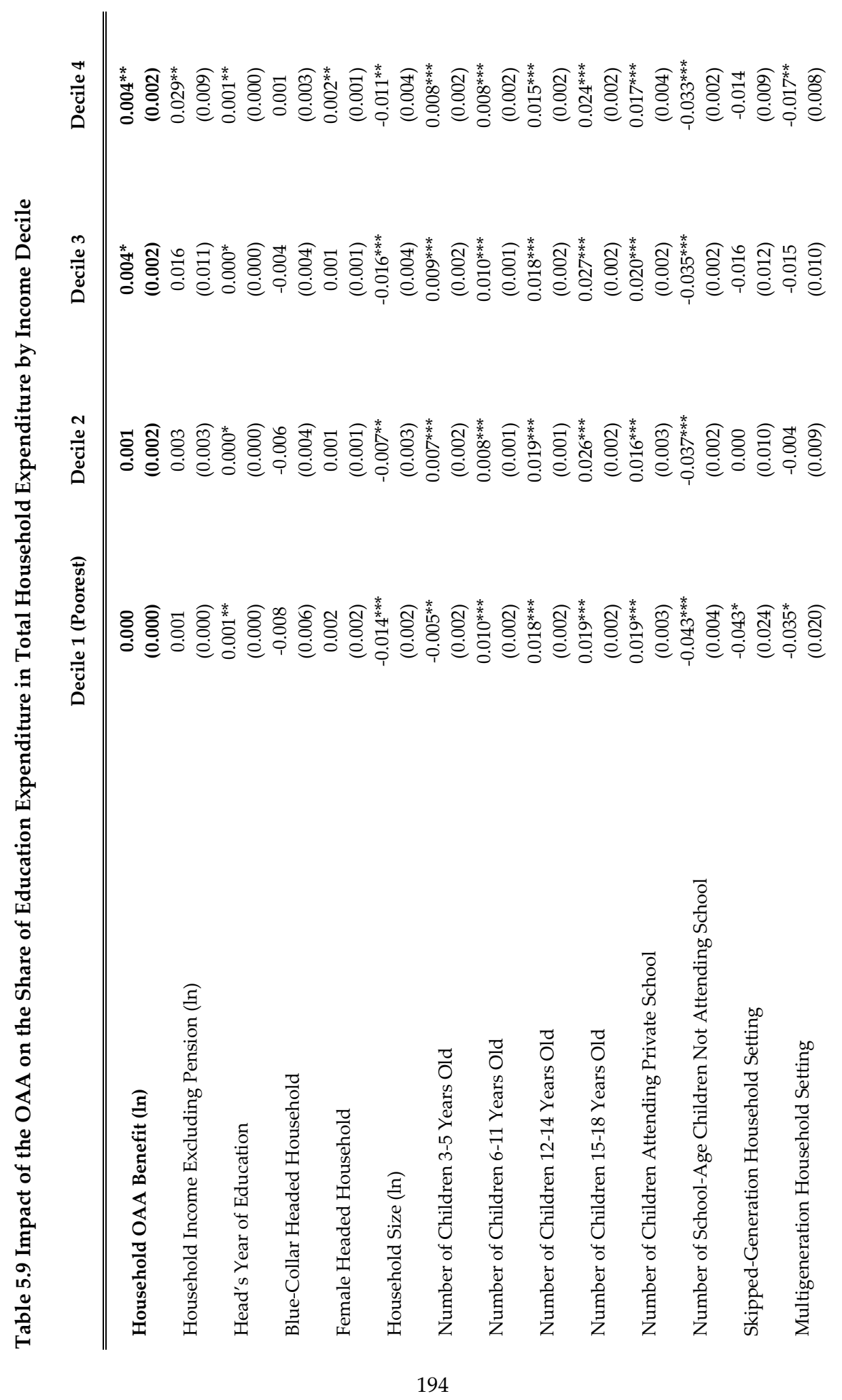




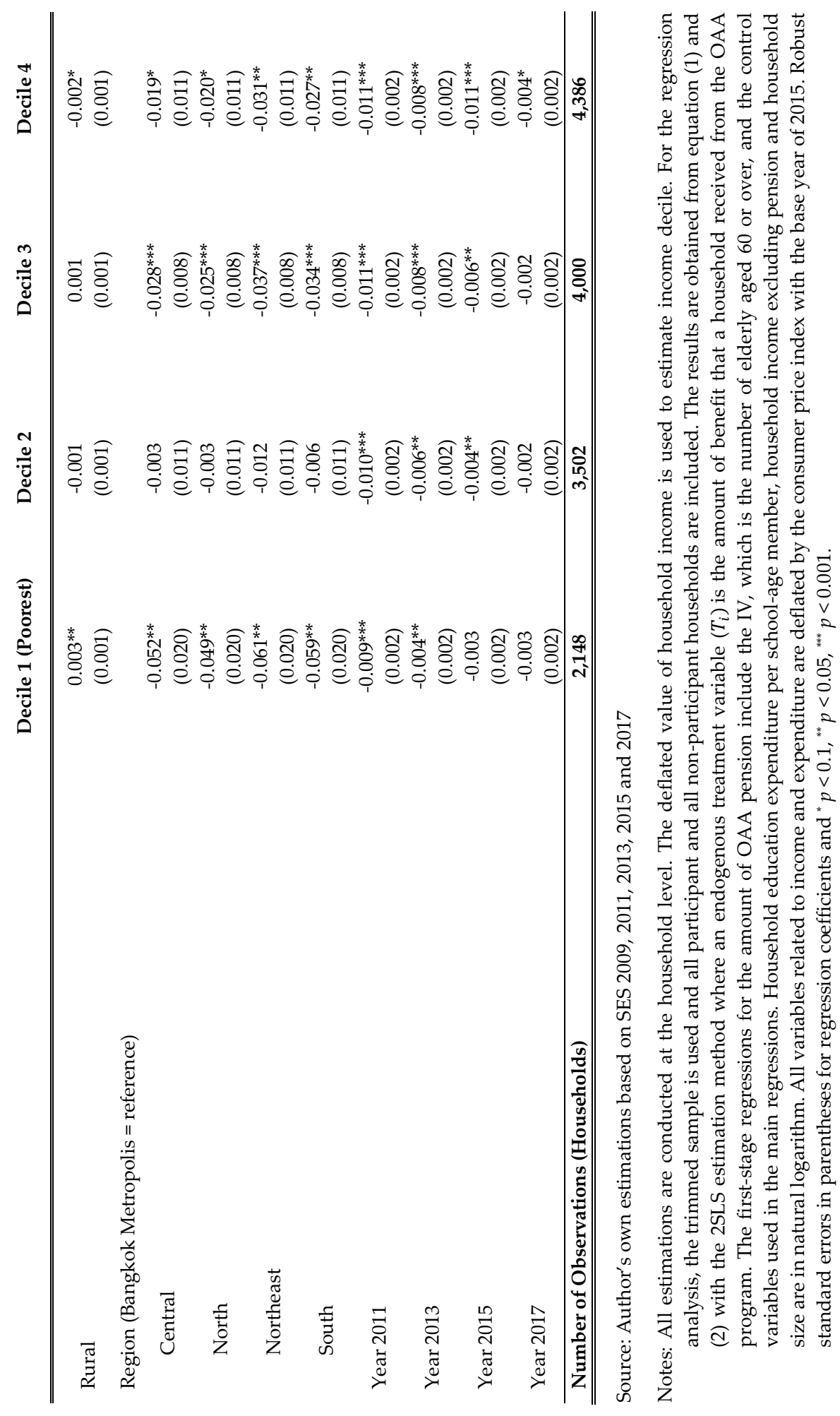


This finding possibly implies that OAA income is spent differently from other income. It might be possible that the significant part of OAA income is spent on children's schooling leading to a higher share of education spending relative to other expenditure categories. However, since OAA income is so small, it does not add much to the amount of education expenditure in comparison to non-beneficiary households who are generally better off. By contrast, a household may contribute only a small proportion of their income (excluding pension) to education. Nevertheless, as household income excluding the pension is much higher, it does make a difference on the amount of expenditure spent on education. Further research is needed to expand our insight into the behavioral effects of OAA income.

Second, the number of household members aged 3 to 5,6 to 11,12 to 14 , and 15 to 18 are also found to be associated with household investment in schooling, both in terms of amount and share of education expenditures. However, the coefficient representing the first group, 3 to 5 years, which officially corresponds to pre-primary education level is smallest in magnitude. It might be possible that the cost of pre-primary school is lowest in comparison to other education levels. Nevertheless, it might also be the case that households do not sufficiently invest in early-childhood education. In addition to the low awareness of earlychildhood development, the presence of early-age children in a household may lead to higher expenditure on age-specific goods and services such as nutrition and healthcare. The household thus has less money to spend on education. A number of studies have verified the long-term benefit of attending preschool such as cognitive skills, physical health and social skills. A recent study in Thailand indicates that preschool attendance has improved students' mathematic, reading and sciences test scores. These positive results are found to be stronger among low-income families (Pholphirul, 2017). Therefore, this finding raises concerns about the insufficient investment in early childhood development.

Third, the results of year dummies also provide interesting implications. According to the estimation results, year dummies are found to pick up a downward trend in household education expenditure in 2011 and 2013. When considering descriptive statistics of the SES, as depicted in the upper graph in Figure 5.3, it is found that both expenditure per school-age member and share of education in total household expenditure declined significantly in 2011. There was a slight increase in 2013 followed by a gradual increase in 2015 and 2017. This interesting trend may partly be explained by the extension of free basic education policy from 12 to 15 years, which was implemented in 2009 (Pholphirul, 2017; Wongmonta \& Glewwe, 2017). Households may gradually cut their education budget, in response to the policy, and slowly increase it afterwards. 
Figure 5.3 Education Expenditure (2009-2017)

Household Education Expenditure from The Household Socioeconomic Survey (SES)

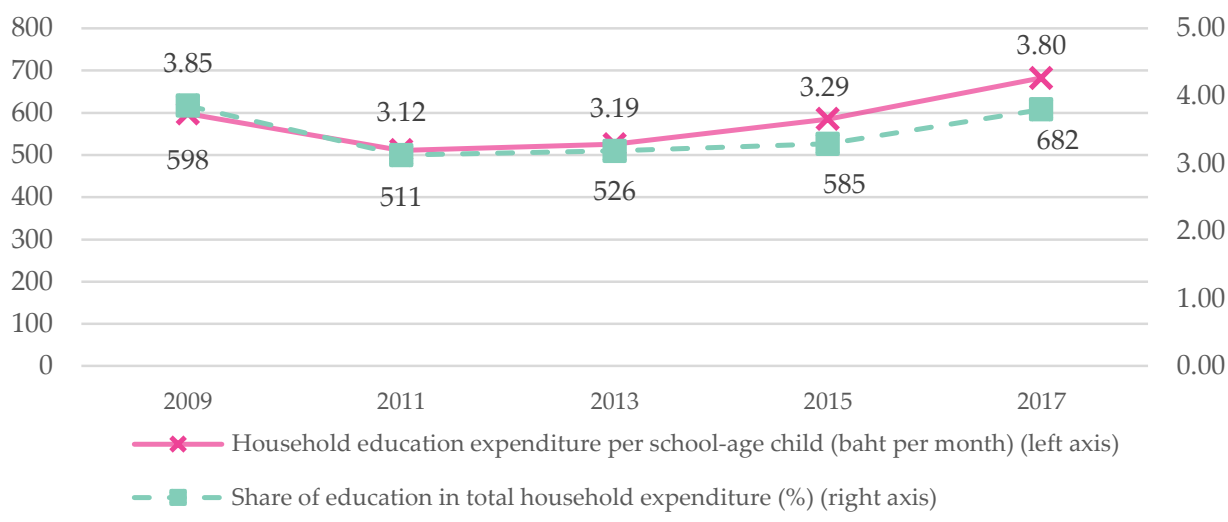

Government and Private Consumption Expenditure on Education from Thailand's National Account

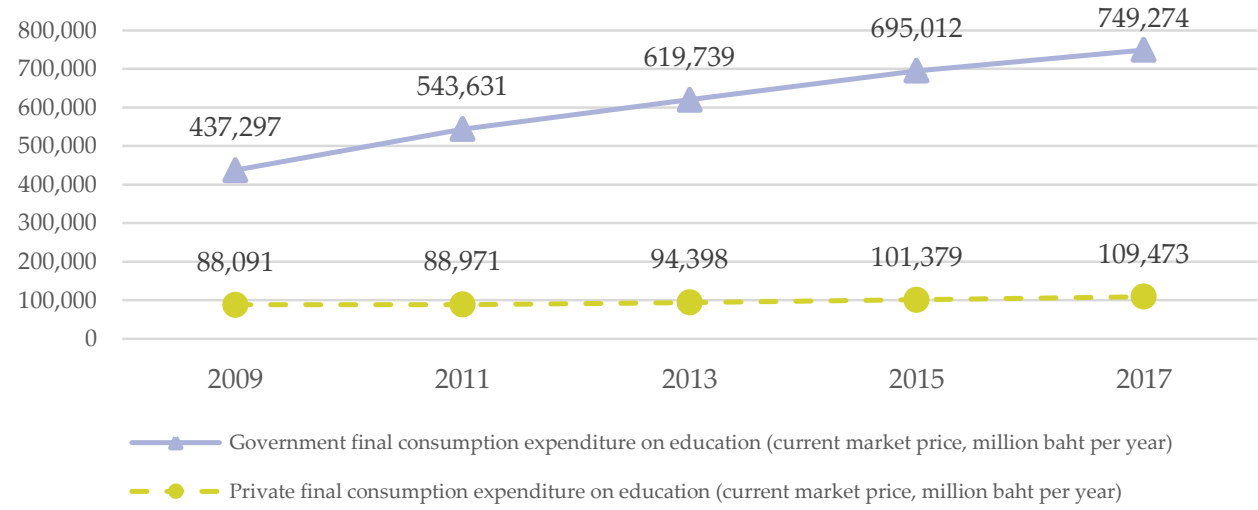

Sources: The upper graph is drawn from authors' own estimations based on the Household Socioeconomic Survey (SES) 2009, 2011, 2013, 2015 and 2017

The lower graph makes use of the data from Thailand's National Account by National Economic and Social Development Board (2017a; 2018c)

However, according to the statistics from the National Accounts, as presented in the lower graph in Figure 5.3, while government spending on education exhibits a rising trend after 2009, private consumption on education appears to be quite stable during the same period. Therefore, further analysis, which is beyond the scope of this research, is needed for more in-depth explanation of this compelling trend in household education expenditure. 
The demographic transition toward population ageing implies that the number of pension receivers, (old age people) will be substantially higher while the number of taxpayers (working-age population) who actually fund the program will be considerably lower. This projected population ageing has caused growing concern over the financial stability of the social pension program. Therefore, the convincing evidence to justify why the government needs to keep allocating the budget to this program is of importance for policy makers. Previous studies on the OAA have brought convincing evidence that additional resources from the program help reduce poverty, vulnerability and allow poor elderly to retire (Jitsuchon et al., 2012; Paweenawat \& Vechbanyongratana, 2015). This study sheds further light on the beneficial role of the OAA program.

When other sources of income are sporadic, a constant and reliable cash transfer from the OAA helps increase the likelihood of school attendance and, though small in magnitude, the share of expenditure that is contributed to education. Therefore, the contribution of the OAA is not only limited to poverty reduction among elderly but also the intergenerational poverty which would remain if children were not educated. Moreover, investment in human capital of children, through education, leads to a higher productivity of the future workforce. As a consequence, the positive spillover effects of the OAA may lessen concerns about population ageing as the declining number of working-age population may be compensated by the higher productivity of prospective labor.

Although, in this study, the OAA is empirically proved to be helpful in allowing household to invest more in education, there is still room for improvement. The first and foremost issue is to improve the adequacy of the benefit amount. Most studies on the OAA have suggested the government to increase the benefit level to ensure that the elderly have sufficient income support for their living (see e.g. Suwanrada \& Leetrakul, 2014; Suwanrada \& Wesumperuma, 2012). Moreover, according to the results obtained in this chapter, the higher pension income leads to the higher share of education expenditure for co-residing children. Therefore, the amount of benefit should be augmented to further enhance the impact of the program on education.

Second, in addition to the current system in which the benefit level is discriminated merely by age range, the government should attempt to allocate the amount of benefit according to the recipients' needs. Increasing the benefit amount across the board may lead to excessive financial burden. The targeting approach may thus be useful in deciding for whom and to what extent the benefit should be increased. The available data sets, such as the basic minimum needs data $(\mathrm{BMN})$ and the administrative data from the Welfare Smart Card 
project, which cover income information, poverty status, and the unique personal identifier, would be useful for the target identification process and the differentiation of the benefit level. Third, the government should consider providing additional non-monetary benefit together with the cash transfer such as long-term care services for elderly and quality child care services for the skipped-generation families, which can alleviate the burden of elderly as single-handed caretakers. Considering that the elderly recipients sacrifice their own benefit for co-residents, these additional in-kind benefits will reassure the adequate standard of living of the elderly which is the main objective of the OAA program.

The results presented in this study are derived from justified impact evaluation methods which are appropriate for the program context and data availability. However, it is acknowledged that the findings are subject to some limitations. First, this study could only examine the spillover effects generated within the households. However, the OAA recipients may possibly allocate their pension income to other family members who do not live under the same roof. Hence, the impact of the OAA cannot be captured by the current analyses. This limitation may partly explain why only a modest impact is observed in this study.

Second, the positive schooling responses observed in this study is considered as the evidence for the impact of social pensions in fostering upward intergenerational mobility due to the well-documented linkage between education and positive characteristics such as greater earning ability, better health status. Nevertheless, the thesis acknowledges that the higher spending on education and school attendance is not necessarily associated with higher schooling outcomes which also matters for upward income mobility (Narayan et al., 2018). Moreover, there are a number of factors, such as quality of education and return to education, affecting the relationship between education and upward mobility (ibid). Therefore, the positive impact of the OAA on educational spending and school attendance observed in this chapter does not necessarily translate into upward intergenerational mobility. 


\section{References}

Adamchak, D. J. (1995). Pensions and household structure of older persons in Namibia. Southern African Journal of Gerontology, 4(2), 11-15.

https://doi.org/10.21504/sajg.v4i2.81

Alderman, H., Chiappori, P.-A., Haddad, L., Hoddinott, J., \& Kanbur, R. (1995). Unitary Versus Collective Models of The Household: Is it time to shift the burden of proof? The World Bank Research Observer, 10(1), 1-19.

Alfonso, M. (2002, March 9). Private Spending on Primary and Secondary Education in Peru. Presented at the The 46th Annual Meeting of the Comparative and International Education Society, Orlando, FL, USA. Retrieved from https://www.researchgate.net/profile/Mariana_Alfonso/publication/237736270_Priv ate_Spending_on_Primary_and_Secondary_Education_in_Peru/links/544686680cf2 f14fb80f4e86.pdf

Anderson, K. L., \& Allen, W. R. (1984). Correlates of Extended Household Structure. Phylon (1960-), 45(2), 144-157. https://doi.org/10.2307/274476

Barrientos, A., \& Lloyd-Sherlock, P. (2002). Non-contributory pensions and social protection. Social Protection Sector, International Labor Office Geneva, Discussion paper 12, 31.

Becker, G. S. (1974). A Theory of Social Interactions. Journal of Political Economy, 82(6), $1063-$ 1093.

Becker, G. S. (1981). A Treatise on the Family. Cambridge, Massachusettes: Havard University Press.

Becker, G. S., \& Tomes, N. (1976). Child Endowments and the Quantity and Quality of Children. Journal of Political Economy, 84(4), S143-S162.

Becker, G. S., \& Tomes, N. (1979). An Equilibrium Theory of the Distribution of Income and Intergenerational Mobility. The Journal of Political Economy, 87(6), 1153-1189.

Bernheim, B. D., Shleifer, A., \& Summers, L. (1985). The Strategic Bequest Motive. Journal of Political Economy, 93(6), 1045-1076.

Black, S. E., \& Devereux, P. J. (2010). Recent Developments in Intergenerational Mobility. NBER Working Paper Series. Retrieved from https://www.nber.org/papers/w15889

Browning, M., Bourguignon, F., Chiappori, P.-A., \& Lechene, V. (1994). Income and Outcomes: A Structural Model of Intrahousehold Allocation. Journal of Political Economy, 102(6), 1067-1096. https://doi.org/10.1086/261964

Brustad, O. D. (2012). Thailand: pension system overview and reform directions. In D. Park (Ed.), Pension Systems and Old-Age Income Support in East and Southeast Asia. Asian Development Bank. 
Bureau of Savings and Investment Policy, Fiscal Policy Office, Ministry of Finance. (2018). Savings Indicators (December 2017). Retrieved from

http://www2.fpo.go.th/FPO/index2.php?mod=Content\&file=contentview\&contentI $\mathrm{D}=\mathrm{CNT} 0019172 \&$ categoryID $=\mathrm{CAT} 0001570$

Bureau of Trade and Economic Indices, Ministry of Commerce. (2018). Thailand Consumer

Price Index. Retrieved from

http://www.price.moc.go.th/price/cpi/index_new_all.asp

Case, A. (2001). Does money protect health status? Evidence from South African pensions [NBER Working Paper 8495]. Retrieved from National Bureau of Economic Research website: http://www.nber.org/papers/w8495

Case, A., \& Deaton, A. (1998). Large Cash Transfers to the Elderly in South Africa. The Economic Journal, 108(450), 1330-1361. https://doi.org/10.1111/1468-0297.00345

Chandoevwit, W. (2013). Social and Economic Aspects of the Elderly in Thailand. Malaysian Journal of Economic Studies, 50(2), 15.

Chantaramas, S., \& Wiriyanupong, N. (2013). Pension System in Thailand (in Thai). Retrieved from Bureau of Savings and Investment Policy, Ministry of Finance website: http://www2.fpo.go.th/S-I/Source/Article/Article146.pdf

Checchi, D. (1997). Education and Intergeneration Mobility in Occupations: A Comparative Study. American Journal of Economics and Sociology, 56(3). Retrieved from https://onlinelibrary.wiley.com/doi/abs/10.1111/j.1536-7150.1997.tb03364.x

Chen, Y., \& Tan, Y. J. (2018). The effect of non-contributory pensions on labour supply and private income transfers: evidence from Singapore. IZA Journal of Labor Policy, 7(1). https://doi.org/10.1186/s40173-018-0099-3

Cheng, L., Liu, H., Zhang, Y., \& Zhao, Z. (2018). The health implications of social pensions: Evidence from China's new rural pension scheme. Journal of Comparative Economics, 46(1), 53-77. https://doi.org/10.1016/j.jce.2016.12.002

Chiappori, P.-A. (1992). Collective Labor Supply and Welfare. Journal of Political Economy, 100(3). Retrieved from https://www.journals.uchicago.edu/doi/abs/10.1086/261825

Cleesuntorn, A. (2016). Education in Thailand and the Challenging Issues. Retrieved from Graduate School of eLearning, Assumption University website: http://www.en.moe.go.th/index.php?option=com_content\&view=article\&id=3660:e ducation-in-thailand-and-the-challenging-issues\&catid=23:article

Cox, D. (1987). Motives for Private Income Transfers. Journal of Political Economy, 95(3), 508546.

Cox, D. (1990). Intergenerational Transfers and Liquidity Constraints. The Quarterly Journal of Economics, 105(1), 187. https://doi.org/10.2307/2937825

Cox, D., \& Rank, M. R. (1992). Inter-Vivos Transfers and Intergenerational Exchange. The Review of Economics and Statistics, 74(2), 305. https://doi.org/10.2307/2109662 
De Carvalho Filho, I. E. (2012). Household Income as a Determinant of Child Labor and School Enrollment in Brazil: Evidence from a Social Security Reform. Economic Development and Cultural Change, 60 Number 2, 399-435.

Department of Provincial Administration. (2018). Official Statistics Registration Systems Official Number of Population in Thailand Classified by Age. Retrieved from http://stat.dopa.go.th/stat/statnew/upstat_age_disp.php

Duflo, E. (2003). Grandmothers and Granddaughters: Old-Age Pensions and Intrahousehold Allocation in South Africa. The World Bank Economic Review, 17(1), 1-25. https://doi.org/10.1093/wber/lhg013

Edmonds, E. V. (2006). Child labor and schooling responses to anticipated income in South Africa. Journal of Development Economics, 81(2), 386-414. https://doi.org/10.1016/j.jdeveco.2005.05.001

Ferreira, F. H., Messina, J., Rigolini, J., López-Calva, L.-F., Lugo, M. A., Vakis, R., \& Ló, L. F. (2012). Economic mobility and the rise of the Latin American middle class. World Bank Publications.

Frankenberg, E., Lillard, L., \& Willis, R. J. (2002). Patterns of Intergenerational Transfers in Southeast Asia. Journal of Marriage and Family, 64(3), 627-641. https://doi.org/10.1111/j.1741-3737.2002.00627.x

Galiani, S., Gertler, P., \& Bando, R. (2016). Non-contributory pensions. Labour Economics, 38, 47-58. https://doi.org/10.1016/j.labeco.2015.11.003

Haddad, L., \& Hoddinott, J. (1994). Women's Income and Boy-Girl Anthropometric Status in the Côte d'Ivoire. World Development, 22(4), 543-553.

Haddad, L., Hoddinott, J., \& Alderman, H. (Eds.). (1997). Introduction: The Schope of Intrahousehold Resource Allocation Issues. In Intrahousehold Resource Allocaiton in Developing Countries: Models, Methods, and Policy (pp. 1-16). Retrieved from https://pdfs.semanticscholar.org/341b/a3bdc46bc7f083780479f3a4fabf3698d2f1.pdf\# page $=53$

Jitapunkul, S., \& Wivatvanit, S. (2009). National Policies and Programs for the Aging Population in Thailand. Ageing International, 33(1-4), 62-74. https://doi.org/10.1007/s12126-009-9027-6

Jitsuchon, S., Skoufias, E., \& Wiener, M. (2012). Reducing Elderly Poverty in Thailand: The Role of Thailand's Pension and Social Assistance Programs. https://doi.org/10.1596/26767

Kassouf, A. L., \& Rodrigues de Oliveira, P. (2012). Impact Evaluation of the Brazilian NonContributory Pension Program Benefício de Prestação Continuada (BPC) on Family Welfare. Partnership for Economic Policy Working Paper, No. 2012-12. Retrieved from https://papers.ssrn.com/sol3/papers.cfm?abstract_id=2374388\#\#

Kaushal, N. (2014). How Public Pension affects Elderly Labor Supply and Well-being: Evidence from India. World Development, 56, 214-225. https://doi.org/10.1016/j.worlddev.2013.10.029 
Khandker, S., Koolwal, G., \& Samad, H. (2010). Handbook on Impact Evaluation: Quantitative Methods and Practices. https://doi.org/10.1596/978-0-8213-8028-4

Knodel, J., Prachuabmoh, V., \& Chayovan, N. (2013). The Changing Well-being of Thai Elderly: An Update from the 2011 Survey of Older Persons in Thailand. Population Studies Center, Research Report 13-793, 96.

Knodel, J., Teerawichitchainan, B., Prachuabmoh, V., \& Pothisiri, W. (2015). The Situation of Thailand's Older Population: An updates based on the 2014 Survey of Older Persons in Thailand (Population Studies Center Research Reports No. 15-847). Retrieved from Population Studies Center, University of Michigan website: https://www.psc.isr.umich.edu/pubs/pdf/rr15-847.pdf

Knodel, J., \& Wongsith, M. (1991). Family Size and Children's Education in Thailand: Evidence from a National Sample. Demography, 28(1), 119-131.

Lowhachai, S. (2018). The National Transfer Accounts 2013 (in Thai). Bangkok, Thailand: National Economics and Social Development Board, Office of the Prime Minister.

Martinez, S. (2004). Pensions, Poverty and Household Investments in Bolivia. Retrieved from https://eml.berkeley.edu/ webfac/bardhan/e271_f04/martinez.pdf

Ministry of Education. (2017). Thai Education in Brief: Education as a Spearhead to Break through the Middle-Income Trap. Retrieved from

http://www.en.moe.go.th/enMoe2017/index.php/policy-and-plan/thai-educationin-brief

Mujahid, G., Pannirselvam, J., \& Doge, B. (2008). The Impact of Social Pensions: Perceptions of Asian Older Persons. Bangkok, Thailand: United Nations Population Fund.

Narayan, A., Van der Weide, R., Cojocaru, A., Lakner, C., Redaelli, S., Mahler, D. G., ... Thewissen, S. (2018). Fair Progress? Economic Mobility across Generations around the World. Retrieved from https://elibrary.worldbank.org/doi/abs/10.1596/978-1-4648$1210-1$

National Economic and Social Development Board, Office of the Prime Minister. (2017a). Thailand's National Account: National Income of Thailand 2016 Chain Volume Measures. Retrieved from https://www.nesdb.go.th/nesdb_en/main.php?filename=national_account

National Economic and Social Development Board, Office of the Prime Minister. (2017b). The 12th National Economics and Social Development Plan (2017-2021). Retrieved from http://www.nesdb.go.th/ewt_news.php?nid=6420\&filename=develop_issue

National Economic and Social Development Board, Office of the Prime Minister. (2018a). Social and Quality of Life Database System - Income Security. Retrieved from http://social.nesdb.go.th/SocialStat/StatReport_Final.aspx?reportid=175\&template= 1R2C\&yeartype $=$ M\&subcatid $=47$

National Economic and Social Development Board, Office of the Prime Minister. (2018b). Social and Quality of Life Database System - Poverty and Income Distribution. Retrieved from 
http://social.nesdb.go.th/SocialStat/StatReport_Final.aspx?reportid=854\&template= 2R1C\&yeartype $=$ M\&subcatid $=59$

National Economic and Social Development Board, Office of the Prime Minister. (2018c).

Thailand's National Account: National Income of Thailand 2017 Chain Volume Measures. Retrieved from

https://www.nesdb.go.th/nesdb_en/main.php?filename=national_account

National Savings Fund. (2016). Introduction to the National Savings Fund (in Thai). Retrieved from http://www.nsf.or.th/images/nsf/pr/knowledge/IntroduceNSF_25590907.pdf

Paweenawat, S. W., \& Vechbanyongratana, J. (2015). The Impact of a Universal Allowance for Older Persons on Labor Force Participation: The Case of Thailand. Sociological Demography Press, 54, 53-68.

Peek, C., Im-em, W., \& Tangthanaseth, R. (2016). The State of Thailand's Population 2015: Features of Thai Families in the Era of Low Fertility and Longevity. Retrieved from The United Nations Population Fund Thailand and The Office of The National Economic and Social Development Board website: https://thailand.unfpa.org/sites/default/files/pubpdf/State\%20of\%20Thailand\%20Population\%20report\%202015Thai\%20Family_en.pdf

Pezzin, L. E., \& Schone, B. S. (1997). The Allocation of Resources in Intergenerational Households: Adult Children and Their Elderly Parents. The American Economic Review, 87(2), 6 .

Pholphirul, P. (2017). Pre-primary education and long-term education performance: Evidence from Programme for International Student Assessment (PISA) Thailand. Journal of Early Childhood Research, 15(4), 410-432. https://doi.org/10.1177/1476718X15616834

Ponczek, V. (2011). Income and bargaining effects on education and health in Brazil. Journal of Development Economics, 94(2), 242-253. https://doi.org/10.1016/j.jdeveco.2010.01.011

Quisumbing, A. R. (1997). Better Rich, or Better There? Grandparent Wealth, Coresidence, and Intrahousehold Allocation. International Food Policy Research Institute, Discussion Paper No.23, 54.

Rodrigues de Oliveira, P., Kassouf, A. L., \& Aquino, J. M. de. (2017). Cash transfers to the elderly and its spillover effects: Evidences from a non-contributory program in Brazil. Journal of Economic Studies, 44(2), 183-205. https://doi.org/10.1108/JES-042015-0059

Sakunphanit, T., \& Suwanrada, W. (2011). 500 Baht Universal Pension Scheme. In Sharing Innovative Experiences: Vol. Successful Social Protection Floor Experiences (pp. 401-415). Retrieved from http://www.ilo.org/secsoc/information-resources/publications-andtools/books-and-reports/WCMS_SECSOC_20840/lang--en/index.htm

Social Security Office, Ministry of Labour. (2018). The Number of Beneficiaries of the Social Security Fund 2009-2017. Bangkok, Thailand. 
Stock, J. H., \& Watson, M. W. (2011). Introduction to Econometrics (3rd International Edition). Pearson.

Suwanrada, W. (2009). Poverty and Financial Security of the Elderly in Thailand. Ageing International, 33(1-4), 50-61. https://doi.org/10.1007/s12126-009-9030-y

Suwanrada, W., \& Leetrakul, P. (2014). The Impact of the Old Age Allowance on the Lives of Older People and the Local Economy in Thailand. Retrieved from Foundation for Older Persons' Development website: http://ageingasia.org/the-impact-of-the-old-ageallowance-on-the-lives-of-older-people-and-the-local-economy-in-thailand/

Suwanrada, W., Sukontamarn, P., \& Bangkaew, B. (2018). Who supports intergenerational redistribution policy? Evidence from old-age allowance system in Thailand. The Journal of the Economics of Ageing, 12, 24-34. https://doi.org/10.1016/j.jeoa.2017.11.004

Suwanrada, W., \& Wesumperuma, D. (2012). Development of the Old-Age Allowance System in Thailand: Challenges and Policy Implications. In S. W. Handayani \& B. Babajanian (Eds.), Social Protection for Older Persons: Social Pensions in Asia. Retrieved from https://www.adb.org/publications/social-protection-older-personssocial-pensions-asia

Suwanrada, W., \& Wesumperuma, D. (2013). The Challenges of the Old-age Allowance System in Thailand (One Pager No. 217). International Policy Centre for Inclusive Growth, Asian Development Bank.

Tilak, J. B. G. (2002). Determinants of Household Expenditure on Education in Rural India. National Council of Applied Economic REsearch, Working Paper Series No.88.

Tsang, M. C., \& Kidchanapanish, S. (1992). Private resources and the quality of primary education in Thailand. International Journal of Educational Research, 17(2), 179-198. https://doi.org/10.1016/0883-0355(92)90007-S

Vu Quang, H. (2012). Determinants of educational expenditure in Vietnam. International Journal of Applied Economics, 9(1), 59-72.

Waidler, J. (2016). On the Fungibility of Public and Private Transfers: a Mental Accounting Approach. UNU-MERIT Working Papers, 2016-60.

Wongmonta, S., \& Glewwe, P. (2017). An analysis of gender differences in household education expenditure: the case of Thailand. Education Economics, 25(2), 183-204. https://doi.org/10.1080/09645292.2016.1168363

Wooldridge, J. M. (2009). Introductory Econometrics: A Modern Approach (Fourth Edution). South-Western Cengage Learning. 



\section{Chapter 6}

Conclusion 


\subsection{Introduction}

Economic mobility indicates the extent to which opportunity exists in society and thus can be considered as a policy objective in its own right. However, research on this subject in developing countries remains limited due to the lack of longitudinal data. Among the scarce studies on mobility, many of them reveal that the opportunities for people, especially those in the bottom of the spectrum, to move upward become increasingly sparse. This phenomenon goes not only against moral principles but also leads to long-term economic inefficiency, persistence of inequality and disruption of social harmony. This stalled mobility, therefore, must be tackled to ensure that equal opportunity to succeed remains achievable for all members of society.

This thesis brings economic mobility, which is a different but complementary perspective to traditional static inequality, into the discussion of income distribution. The primary objective is to examine the patterns and factors fostering mobility as well as the role that social protection programs may have played in promoting upward economic mobility in the context of developing economies. The impact of three major programs in Thailand implemented at the national level, namely vocational training, the Village Fund (VF) and the Old Age Allowance (OAA), are estimated and discussed by means of various impact evaluation methods which are appropriate for the available data, objectives of the study and contexts of the estimations using both cross-sectional and panel data sets at the national coverage level.

This final chapter recapitulates the key results obtained and discussed in this thesis (section 6.2). The chapter further offers wider policy implications derived from all the evidence gathered in this work (section 6.3). Moreover, contributions to the existing body of knowledge and the impacts that this research may have on public policies aiming to promote economic mobility are presented (section 6.4). Furthermore, the major shortcomings that this thesis encounters as well as the potential directions for future research are discussed (section 6.5). The thesis ends by providing concluding remarks (section 6.6). 


\subsection{Key Findings}

This section summarizes key findings drawn from each chapter in this thesis. With an exception of the first key finding which is based on the introductory chapter (Chapter 1), each key finding also contains specific policy implications which derived from the results found in the respective chapter. The five key findings, corresponding to the five previous chapters, are as follows

Key Finding 1: Theoretical and empirical studies substantiate that economic mobility is driven by human capital and physical asset. Social protection programs, which are expected to facilitate such investment in human and physical capital, are thus considered as a potential intervention to foster upward mobility.

Chapter 1, the introductory chapter, provides the background concepts of mobility as well as existing theoretical and empirical findings with regard to drivers of mobility. Four main economic theories including the theory of cumulative advantage, the theory of poverty traps, the theory of skilled-biased technological change and the theory of regression to the mean conclude that the extent of income mobility depends considerably on the productive capacity of economic agents (individuals or households), which is, in turn, determined by human capital and physical capital accumulation. This theoretical concept is increasingly supported by empirical findings. The chapter also elaborates on the potential contribution of social protection programs in facilitating investment in human and physical capital and hence in fostering upward mobility. As discussed in the chapter, skill training programs could improve human capital of participants whereas microcredit programs relieve credit constraints and allow borrowers to accumulate physical assets. Moreover, it is becoming increasingly evident that regular and reliable income sources from social transfer programs could promote mobility both within and between generations by enabling productive investment in human and physical capital.

Key Finding 2: Although poor households appear to experience upward absolute income mobility, the opportunity for them to climb up to higher income positions is still limited. The share of earners in a household and the possession productive assets are found to be the most important factors that could foster income mobility.

Chapter 2 finds that the degree of absolute non-directional income mobility in Thailand is high by international standards but the country appears to be one of the most immobile countries when the direction of income change is taken into consideration. The results from absolute income mobility estimation suggest that poor households experience upward 
absolute income movement during the period under study. However, the results from the transition matrices exhibit a low degree of relative income mobility particularly at the lower tail and the upper tail of the income distribution implying that there is a sticky floor at the bottom and sticky ceiling at the top. In this chapter, an attempt is also made to identify factors driving income mobility. It is found that the share of earners within a household and the productive assets that the household accumulates are positively associated with both absolute and relative income mobility. This finding is in line with the existing theoretical and empirical studies discussed in Chapter 1, which substantiate that human capital and physical assets are the most crucial facilitating factors of income mobility. The results call for interventions that could improve ability of household members to generate income and facilitate household investment in productive assets. In turn, this policy implication sets the scene for the social protection programs of interest evaluated in the next chapters.

\section{Key Finding 3: There is no credible evidence for the positive impact of vocational training program in Thailand on upward mobility in terms of earning and employment, both in absolute and relative terms.}

Chapter 3 evaluates the impact of vocational training programs in Thailand on various mobility indicators including wage, income, expenditure, and a transition to higher labor market status. Although a training program is expected to increase human capital and foster upward mobility of participants in theory, the impact of the program is disappointing in practice. Thailand's vocational training has no significant effect on wages and incomes, and the probability of wage and income rank change. The impact on labor mobility is also unpromising as participation in training does not lead to formal employment, higher labor force status and better employment positions.

In addition to the overall impact of vocational training, the chapter also examines the heterogeneity of effects with respect to individual and program characteristics to answer the questions for whom the training works and which type of training works best. Answers to these questions deepen the understanding of the impact of Thailand's training programs and are informative for the design of policies aiming to enhance the positive impact of training on upward mobility. The results suggest that women, rural residents, youth (aged 15-24) and elderly (aged 60 or above), low-educated workers, and economically inactive people, benefit less from the program. These findings necessitate a more tailored training program that take into consideration the dissimilarity of conditions, needs and preferences of participants such as a female-friendly training programs, age-specific training programs and training programs for low-educated participants. Complementary policies and services 
such as quality education, employment counseling and job search assistance are also necessary to improve the effectiveness of training in fostering upward mobility.

With regard to heterogeneity by type of training, it is found that computer training courses, training offered by private institutions, a cooperation of government and private agencies, and training financed by employers are associated with better outcomes. Policy implications drawn from these findings thus call for training programs that offer skills suitable for the specific context of the country and that keep up with the demand for labor such as computer training. Moreover, the cooperation between public and private sectors in designing and delivering skills training programs should be more encouraged.

Key Finding 4: VF borrowers tend to have lower socioeconomic status, in comparison to borrowers of other lending sources. However, borrowing from the VF does not translate into upward absolute and relative income, expenditure, and productive asset mobility. Its impacts on labor mobility and business creation are also disappointing.

Chapter 4 identifies the common characteristics of individuals willing to apply and managing to receive credit from the VF. It is found that VF borrowers tend to be older women with low-income, low-education and living outside of the capital city. This result implies that the VF is better than other lending sources in reaching and providing credit to the disadvantaged groups. The chapter also examines the impact of the VF on mobility outcomes of borrowers. The VF aims to address credit constraints, increase physical capital investment, promote income-generating activities and hence promote upward mobility. However, according to the results from the impact assessments, there is no credible evidence indicating that the program does deliver such promise.

As presented in Chapter 4, the results suggest that the VF does not foster upward income, expenditure and productive asset mobility, both in absolute and relative terms. The impact on labor mobility is also undesirable as employment status and business creation remain unchanged. Although the VF is found to promote business expansion in the long run, the positive impact is weakly significant and vanishes after five years. However, the chapter reports the surprising result that the VF increases income on rent, interest, dividend and public transfers in the long run. Non-consumption expenditure also appears to increase in the short, medium and long term which is likely to be driven by higher spending on interest payments. With regard to the heterogeneity of impact by population subgroups, the complementary effect between microcredit and training programs is found to materialize as trained borrowers have higher mobility outcomes than their untrained counterparts. 
However, the results do not show significant differences between male and female borrowers nor between one-time borrowers and repeated borrowers. Finally, the chapter examines the role of loan size on mobility. It is found that a larger amount of loan leads to better mobility outcomes in general.

A number of explanations are brought forward to justify the disappointing impacts of the VF. The explanations discussed in the chapter include the use of credit which is likely to be for consumption rather than for productive investment, the design of loan contracts such as small loan size and short maturity which is not conducive for investment purposes, and the dominant role of government in microcredit market, which limits private sector participation and thus impedes the development of the market as a whole. The chapter suggests a number of policy implications based on these findings. For example, social assistance such as cash transfers to the poor might be necessary to allow low-income borrowers to make ends meet and be able to use credit for more productive purposes. The loan contract might also need to be re-designed to be more opportune for income-generating activities. Moreover, the structure of the microcredit system in Thailand should be reformed to encourage fair competition among microcredit providers, located both in the public and private sectors.

Key Finding 5: The secure source of income from the OAA promotes school attendance and, though small in magnitude, increases the share of education expenditure.

Chapter 5 provides the first evaluation of spillover effects of a social pension program in Thailand. The chapter examines the extent to which the OAA fosters intergenerational mobility by allowing households to invest more into the education of their school-age members. The results suggest that pension income from the OAA does not lead to an increase in household education expenditure per school-age child, in comparison to nonparticipant households. The impact of the OAA is significant when the share of total household expenditure that is contributed to education is used as the outcome of interest. However, the magnitude of the impact is negligible and not economically significant. The chapter also substantiates that the OAA promotes school attendance among co-residing children. The positive impacts of the OAA on school attendance also materialize among the poorest 40 percent families.

The chapter also zooms in on school attendance at each level of education. The largest effect of the OAA is found for the pre-primary education, followed closely by the aftercompulsory level (or upper secondary level). The chapter presents policy options derived 
from the finding that further strengthen the effectiveness of the OAA. First and foremost, the amount of the benefit should be increased. However, to avoid the excessive financial burden, additional benefit should be only given to those who need it most. This can be accomplished through an effective targeting system using the available data that could identify the target beneficiaries and allocate benefits optimally. Moreover, additional nonmonetary benefits such as long-term care services for the elderly and quality child care services for skipped-generation families might also be useful to improve the standard of living of the elderly and the upward mobility of the next generations.

\subsection{Policy Implications}

The key findings of this thesis imply that Thailand still needs to overcome several challenges to transform the country into an inclusive and dynamic society where people from all walks of life have the opportunity to progress. In theory, social protection programs appear to be an obvious mobility-enhancing intervention to address this problem. However, in practice, two out of the three programs evaluated in this study do not seem to be working as the evidence shows. This may explain why inequality remains a challenge even though a number of social protection programs have been introduced. This ineffectiveness of the current system leaves plenty of room for better policy formulation and implementation to foster economic mobility. This section discusses policy implications derived from the evidence emerging from the chapters of this thesis.

The first policy implication is to improve the efficacy and efficiency of social protection programs. The Thai government has implemented a number of social protection programs over the past several years. However, questions remain regarding the performance of the programs in promoting livelihoods and transforming lives of beneficiaries. The results obtained from this thesis suggest a number of possible avenues to improve the quality of the existing programs. For example, vocational training needs to be tailored to specific needs and characteristics of participants and keep up with changes in country context and labor market demand whereas the loan contract of the VF might benefit from being more flexible and conducive to productive investments. The improvement in the program's quality has the potential to unlock the effectiveness of social protection policies in promoting productive capacity and fostering upward mobility of participants.

Second, a significant effort should be made to integrate all individual programs into a more coherent social protection system under the common umbrella. Although almost all social 
protection programs in Thailand are institutionalized in the national legislation and budget, they are rather fragmented and lack harmonization. Each program is operated individually by different government authorities. The vocational training program is located under the Ministry of Labour, the VF is operated by the National Village and Urban Community Fund Committee whereas the OAA is run by the Ministry of Social Development and Human Security. Moreover, there has been no coordination between programs neither at the policy nor administrative level. This isolation system has impeded the complementarity between programs. As discussed in Chapter 4, trained borrowers benefit more from the VF. This positive complementary effect between vocational training and the VF would even be higher under a harmonized system. Vocational training could be more useful for VF borrowers by equipping them with work skills, financial literacy and good business practices as well as encouraging an entrepreneurial spirit if such coordination was in place. By the same token, with the effective coordination between the two programs, credit from the VF could be used to finance productive activities of training participants such as job search, business creation and business expansion.

Furthermore, the integration of isolated programs would make it possible for the government to identify coverage gaps and redundancies in the existing social protection, which is highly useful for policy decisions on investment priorities. In addition, the integrated social protection system also supports the graduation model to social protection. The graduation model requires a series of intensive social protection interventions in order to promote sustainable change in the lives of the poor. Also, it is now an increasingly commonly held belief that a transformative impact is hardly achieved by a single intervention. Instead, a transition to sustainable self-reliance needs to be backed up by a holistic package of supports (Devereux \& Sabates-Wheeler, 2015). Therefore, reducing fragmentation between social protection programs is considered as another possible avenue to strengthen the role of social protection in fostering upward mobility.

Third, policies to foster mobility should not only be confined to social protection programs. Other quality public services alongside social protection should be provided or improved. For example, investment in quality education should continue to be prioritized. In Chapter 2 , the level of education is found to be one of the significant factors associated with upward absolute income mobility. Higher level of education also increases the probability of positive income rank change among the poorest 20 percent households. Moreover, the strong complementarity between education and vocational training is evident in Chapter 3 . It is observed that participants with higher education benefit more from the vocational training 
program. At the same time, the results from Chapter 5 reveal that a part of OAA income is spent on education of co-residing children implying that the current government subsidy in education may not be sufficient. Therefore, greater investment efforts together with the more effective spending on education are needed to level the playing field. Furthermore, improvement of the quality of education should receive more attention since it has a direct impact on productive capacity, which largely determines whether individuals can climb up the ladder.

In addition to investment in education, the quality of jobs also needs to be improved. The analysis of mobility determinants in Chapter 2 reveals that the number of income earners within a family is the most important factor underlying positive income mobility, both in absolute and in relative terms. Hence, a policy to promote mobility needs to ensure job opportunities, particularly decent ones. However, despite the exceptional low rate of unemployment, the quality of employment has been one of the biggest challenges of Thailand. More than half of the employment in Thailand is operated informally without the provision of social security and unemployment insurance. Moreover, approximately a third of people working in the private sector and more than half of the young and low-skilled workers get paid less than the minimum wage (OECD, 2018). These unsatisfactory working conditions are unlikely to enhance economic prospects. Therefore, Thailand must also make efforts to create more quality jobs.

Putting together the second and third policy implication, it is essential to emphasize that social protection policies should be considered as an integral part of the wider system of support, under which social protection programs as well as other basic services are interconnected with the common objectives to enhance productive capacity and promote sustainable livelihoods.

Finally, in order to improve the efficiency and effectiveness of social protection programs in fostering economic mobility, it is essential to conduct program evaluations on a regular basis and to expand the coverage, both in terms of waves and details, of the panel data set to support these evaluations. Impact evaluations of social protection programs in Thailand are scarce. The analysis presented in Chapter 3, to my knowledge, is the first impact evaluation of vocational training program in Thailand, even if the program has been implemented for decades. Likewise, there are only two existing studies to date that examine the impact of the OAA using econometric impact evaluation methods (see Jitsuchon, Skoufias, \& Wiener, 2012; Paweenawat \& Vechbanyongratana, 2015). This is mainly because program assessments in Thailand have solely focused on the monitoring part, which uses the simple 
descriptive statistics to reveal the number of participants, report the budget, and explain the implementation challenges, administrative issues and general situation of the program. Although this remains relevant, more credible evidence based on rigorous impact evaluation studies about what works, what does not work and why it does (not) work are important to improve the quality of social protection programs.

The evaluation of social protection programs requires quality data, particularly panel data if the outcome of interest is related to mobility indicators. To my knowledge, the SES-Panel used in this thesis is the only nationally representative panel survey available in Thailand. The SES-Panel contains rich detailed information with respect to the information of households and household members. However, much information about participation in social protection programs such as the OAA is missing. Moreover, although the seven-year SES-Panel data makes it possible to examine the long-term effects of certain programs, it is not long enough to allow the direct estimation of intergenerational mobility, which requires exceptionally long panel data that allows for the comparison of parents' and children's socioeconomic status. Furthermore, the last wave of the SES-Panel was executed as far back as 2012. The outdated data is not favorable to regular program evaluations in order to reveal the performance of social protection programs in a timely fashion. Therefore, it is important to expand the surveyed questions to cover more detailed information regarding participation in social protection programs; and to regularly re-survey the existing SESPanel. This improvement would allow the SES-Panel to better support the program evaluation system which in turn would ameliorate program quality.

\subsection{Contributions}

This thesis seeks to provide answers to the two primary research questions: (1) To what extent does income mobility take place in Thailand and what are the underlying factors determining income mobility? (2) To what extent and under what conditions do social protection programs - namely vocational training, the VF and the OAA - contribute to upward mobility? By doing so, the thesis contributes to the current state of knowledge in several ways.

This thesis contributes to the few existing studies that employ both macro and micro mobility approaches to analyze economic mobility in a developing economy context. The macro mobility approach measures the extent of economic mobility of the entire economy, whereas the micro mobility approach aims to study the pattern of mobility by examining 
who moves up, who lags behind, why and by how much (Fields, 2008). As can be noticed, both mobility approaches are addressed in the two research questions mentioned above. Considering that the study of economic mobility has been restricted to developed and a few developing economies (Brand-Weiner \& Francavilla, 2015; Fields, Hernández, Freije, \& Puerta, 2007), the results obtained in this thesis enrich the understanding of economic mobility in several dimensions.

The thesis also contributes to the empirical impact evaluation research by explicitly using both absolute and relative mobility as the main outcomes of interest, employing a number of treatment effect methods to examine the impact of social protection programs and drawing conclusions from the panel data set that has never been used in any impact evaluation studies. The impact of social protection programs on economic mobility has not been sufficiently explored. In particular, relative economic mobility has rarely been used as an impact of interest in program evaluations. Using relative mobility to indicate the impact is essential because people tend to compare themselves to their neighbors when assessing the living conditions (Pavlopoulos, 2007). Moreover, evaluating the role of social protection programs in transforming the lives of participants (transformative role) involves assessing a change of participants in relation to others in society (Devereux \& McGregor, 2014). The different results between absolute and relative expenditure mobility obtained in Chapter 3 emphasizes the importance of using both absolute and relative mobility indicators in program evaluations.

Besides, the three social protection programs studied in this thesis did not consider and prepare for the evaluation process prior to the implementation. This implies that the experimental methods are not feasible and that there is no data specifically collected for a potential evaluation of the program. Moreover, the programs are subject to selection bias as participation in the programs is voluntary. As a result, this thesis has to employ several treatment effect methods, with exogenous and endogenous treatments, that are appropriate for the respective program settings and the objective of the study to examine the impact of the program. The thesis hence contributes to the strand of impact evaluation literature by providing concrete examples of how to use econometric models to estimate the program effects when the program contexts, both in terms of data and implementation, may not be conducive to the process of impact evaluation. Furthermore, most of the analyses conducted in this thesis are drawn from the SES-Panel, a nationally representative panel data set, which has never been used in prior studies on income mobility and program evaluation. Therefore, the thesis provides fresh and novel information based on this data set. 
In addition, each analytical chapter fills existing knowledge gaps in its respective strand of literature. For example, Chapter 2 provides the first empirical study of income mobility in Thailand that examines movements of households, both in rural and urban areas, along the entire distribution of income using a nationally representative household panel data set. Chapter 3 adds to the strand of vocational training literature by providing evidence from an empirical impact evaluation from a developing country outside LAC which remains relatively scarce in the literature compared to the evidence from advanced countries. The results obtained in this chapter also capture changes that occurred in the informal sector by making use of household survey data instead of social security records or official administrative data that are often used in other training evaluations. Moreover, the chapter examines the heterogeneity of the impacts with respect to participants and programs characteristics which has rarely been explored in previous research.

Although a number of microcredit evaluations have been carried out, the existing evidence remains mixed and contentious. Chapter 4 contributes to the ongoing debate by providing new evidence from the VF, a large-scale microcredit program initially funded by the Thai government and operated by the local communities, which is different from other microcredit models both in terms of size and design. The analysis also makes use of the novel nationally representative panel data set which has never been used in any microcredit evaluation studies. Finally, Chapter 5 provides the first empirical evidence based on an analysis of spillover effects of the social pension program in Thailand. This adds to the limited amount of existing literature of the spillover effects of a social pension program implemented in a developing country other than South Africa and Brazil.

With regard to policy relevance, this thesis advocates for the inclusion of economic mobility, which is a complementary perspective to the traditional static inequality index such as the well-studied Gini coefficient, into the policy discussions on income distribution. Moreover, the thesis sheds light on the productive role of social protection programs in promoting economic mobility, which is instrumental for policy decisions. Furthermore, a deeper insight regarding the program impacts and the impact heterogeneities obtained from this thesis could be used to formulate policies aiming to enhance the effectiveness of social protection programs. All these contributions to policies would allow the government to better respond to the rising inequality and come up with more effective strategies to ensure that all members of the society could equally benefit and contribute to economic growth without regard to their family backgrounds. 


\subsection{Limitations and Future Research}

The central interest of this thesis is to establish a causal linkage between social protection programs and economic mobility. However, deriving such causality is always complicated. A number of impact evaluation methods used in this thesis such as propensity score matching with difference in difference, endogenous switching regressions and instrumental variables have the potential to deal with endogeneity and are justified given the current data availability and the objectives of the respective analyses. Nevertheless, the methods themselves are also subject to some limitations and rely on some strong methodological assumptions for the accuracy of the causal inference. If endogeneity is not fully addressed, the results can only indicate the association between social protection and economic mobility at best. Therefore, the results regarding the program impacts obtained in this thesis should be interpreted with cautions.

In addition to the methodological challenges, the analyses in this work are also limited by the currently available data. In Chapter 3, for example, the number of observations in the treatment group (or training participants) is small, which may partly explain the insignificant effect of the training programs. This is not so surprising as the SES-Panel is the general household survey which is not specifically designed to collect information on training or any other social protection programs in the first place. The choice of using this data set is motivated by the interest in capturing changes that take place in the informal sector which has been ignored in previous training evaluation studies. Moreover, there is no specific data for this program available that can be employed for impact assessments whereas other administrative data such as social security and tax records are not accessible for researchers.

A similar problem occurs in Chapter 4 when analyzing the complementary effects between human capital development, achieved by training participation, and the possession of physical assets, facilitated by the VF. The number of observations attending both vocational training and the VF are so small that the analysis could not detect any significant change. In the same vein, the lack of panel data that is long enough to cover detailed information of both parents and children is the main reason why intergenerational mobility in Thailand, as well as in many other countries, could not be directly estimated. Chapter 5 thus needs to proxy upward intergenerational economic mobility by household investment in education. It is widely believed that greater investment in education is associated with higher economic capacity, which in turn promotes upward economic mobility. However, this research 
acknowledges that there are a number of factors that may negatively affect this relationship, particularly the quality of education.

With regard to the avenues for future research, more evidence from other case studies of developing countries, preferably ones with a richer panel data set, could help verifying the external validity of the results obtained in this research and further enrich the understanding of the pattern of economic mobility and the productive role of social protection policies in the context of developing economies. Moreover, if richer and more comprehensive panel data is available, future research should also pay more attention to the policy complementarities, not only between social protection programs but also social protection and other public services such as education and healthcare. This would shed further light on the role of social protection as an integral part of the holistic system of support discussed in section 6.3. Furthermore, this thesis mainly focuses on the supply-side policies without taking into account personal aspirations, which may also play a key part in driving mobility through productive behavior. Therefore, more evidence on aspirations as well as the complementarity between aspirations and program participation would contribute to a refined understanding of economic mobility from both supply and demand side.

In addition, future research can also benefit from the analyses of the relationship between social protection programs (or public policies at large), social and political conflict and socioeconomic upward mobility in Thailand. Thailand's democratic trajectory is not beautiful. After the revolution in 1932, which brought an end to the absolute monarchy, Thailand's political regime has been shaped by several coups, constitutional changes, and political conflicts. At a glance, these political changes do not seem to interrupt government investment in social protection. Both democratically-elected government and military government have attempted to use social protection programs, many of which are thought to be "pro-poor policies" (such as the VF, the OAA, the UHCCS, the Child Support Grant and the Welfare Smart Card) to gain political support from people especially those at the lower end of the spectrum. These programs are supposed to reduce inequality and foster upward socioeconomic mobility which in turn resolve social and political conflicts. And yet, some studies claim that the implementation of these pro-poor programs is among the main reasons behind Thailand's political polarization that took place since 2006 as it represents the shift of political power from the middle class toward the poor (Jenmana, 2018). Therefore, more in-depth analyses would be of great value to deepen our understanding of 
these complex linkages and the contribution of social protection to inequality and socioeconomic mobility in time of political crises.

\subsection{Concluding Remarks}

In a fair and open society, people are able to prosper to their full potential through their own talents and efforts. People can rise to the higher economic classes regardless of what class they were born into because the opportunity to succeed is equally provided to everyone who is prepared. This is how a society should function and a basic social contract that governments should offer to their citizens. Yet when examined more closely, an increasing number of studies find that the opportunity gaps between individuals from more privileged backgrounds and those from less-advantageous backgrounds have widened. Wealth and income are getting more concentrated in the hands of few people from rich families while people growing up in poor families find that no matter how hard they work, it is never enough. This circumstance will eventually lead to several undesirable consequences such as persistence of inequality, long-term economic inefficiency and disruption of social harmony. The government thus needs to do what is necessary to ensure that economic opportunity remains attainable for all members of society particularly the ones at the bottom of the income spectrum.

This thesis enriches our understanding of economic mobility, the topic that has been understudied in the context of developing countries due to the lack of appropriate data. Economic mobility traces dynamic improvement of households and individuals and could thus indicate the extent of opportunity that the society has offered. This information cannot be provided by mainstream static inequality indices. The results reveal that upward economic mobility, especially in relative terms, has been limited in Thailand. Drawing from the existing literature on economic mobility and social protection programs, this thesis shows that in theory, social protection has a great potential to remove obstacles to upward economic mobility and foster sustainable welfare improvement among program participants. However, according to the results gathered from several empirical impact evaluations conducted in this work, the thesis finds that in practice, the productive role of social protection programs in driving upward economic mobility is not guaranteed and not automatic.

The implementation of social protection programs alone does not necessary help leveling the playing field. The government needs to commit greater efforts in order to activate the 
productive role of the programs in fostering economic capacity and thus economic mobility of beneficiaries. As the evidence in this thesis has shown, the efficiency and effectiveness of social protection must be improved. This quality improvement process must be supported by a rigorous impact evaluation framework that is undertaken on a regular basis and based on evidence from comprehensive panel data. Moreover, the integration of fragmented social protection programs is necessary to identify policy gaps and redundancies and maximize the complementarities between programs. Finally, this thesis argues that social protection must be treated as an integral part of the wider system of social and economic support aiming to enhance productive capacity, unleash economic opportunity and foster sustainable mobility to higher economic status for all citizens. All these efforts would pave the way toward an inclusive society where everyone has an opportunity to succeed on an equal basis. 


\section{References}

Brand-Weiner, I., \& Francavilla, F. (2015). Income mobility in times of economic growth: The case of Vietnam. OECD Working Paper No.328. Retrieved from http://www.oecdilibrary.org/development/income-mobility-in-times-of-economicgrowth_5jrp0hz8thjl-en

Devereux, S., \& Sabates-Wheeler, R. (2015). Graduating from Social Protection? Editorial Introduction. IDS Bulletin, 46(2), 1-12. https://doi.org/10.1111/1759-5436.12124

Fields, G. S. (2008). A brief review of the literature on earnings mobility in developing countries. Cornell University ILR School Working Paper. Retrieved from http://digitalcommons.ilr.cornell.edu/workingpapers/101

Fields, G. S., Hernández, R. D., Freije, S., \& Puerta, M. L. S. (2007). Intragenerational income mobility in Latin America. Economía, 7(2), 101-154.

Jenmana, T. (2018). Income Inequality, Political Instability, and the Thai Democratic Struggle. The Paris School of Economics.

Jitsuchon, S., Skoufias, E., \& Wiener, M. (2012). Reducing Elderly Poverty in Thailand: The Role of Thailand's Pension and Social Assistance Programs. https://doi.org/10.1596/26767

OECD. (2018). Multi-dimensional Review of Thailand: Volume 1. Initial Assessment. OECD Development Pathways, OECD Publishing, Paris. https://doi.org/10.1787/9789264293311-en

Pavlopoulos, D. (2007). Wage Mobility Patterns in Europe (Tilburg University). Retrieved from https://pure.uvt.nl/portal/en/publications/wage-mobility-patterns-ineurope(916ddc9e-ef9c-45ad-bc4b-4cb6e6cbad99).html

Paweenawat, S. W., \& Vechbanyongratana, J. (2015). The Impact of a Universal Allowance for Older Persons on Labor Force Participation: The Case of Thailand. Sociological Demography Press, 54, 53-68. 



\section{Valorisation Addendum}

In compliance with article 22.5 of the "Regulations for obtaining the doctoral degree at Maastricht University" adopted by the Board of Deans, dated 1 September 2018, this addendum discusses the valorisation opportunities of this thesis with regard to the social and economic relevance of the thesis, the potential target audiences to whom the research results might be of interest and the innovativeness of the thesis in comparison with existing literature.

Reduction of inequality has been declared as the $10^{\text {th }}$ Sustainable Development Goal (SDGs) that the United Nations, along with governments, has set for 2030. This thesis is relevant to this ongoing global policy agenda by expanding the understanding on economic mobility. The study of economic mobility traces dynamic improvements of individuals/households and indicates the level of inclusiveness and the degree to which equal opportunities exist in the society. This information cannot be explored by mainstream static inequality indices. Given that mobility is the complementary perspective to inequality, a better insight into mobility is a valuable piece of knowledge for the design of policies to reduce inequality.

More specifically, Target 10.4 under the SDGs calls for the adoption of social protection policies to achieve greater equality. Empirical evidence found in this thesis suggests that the implementation of social protection programs alone does not necessarily remove binding constraints for individuals/households to get ahead. Program design and implementation matter. The thesis substantiates that the effectiveness of the programs must be improved. Moreover, in the fight against inequality, social protection policies should be regarded as an integral part of the wider system of social and economic support seeking to promote sustainable upward mobility especially among people from disadvantaged backgrounds.

Chapters 3, 4 and 5 evaluate the effectiveness of three different policies in Thailand, including vocational training, microcredit and social pensions. They provide recommendations that feed into the Thai policy discourse and may be of interest for policy makers, international organizations and responsible government agencies in improving the quality of the aforementioned programs. For example, Chapter 3 suggests more customized training programs that take into account personal circumstances of participants and the rapid changes in the demand for labor. Chapter 4 proposes more flexible loan contracts that are conducive to productive activities, a complementary social transfer for the poor and the structural reform of the credit market system to improve development outcomes of 
borrowers. In Chapter 5, it is suggested that a higher benefit amount and additional nonmonetary services might be useful to improve elderly's welfare and foster upward intergenerational mobility.

The results presented in this thesis are original as most of the analyses is based on panel household survey data (Panel-SES) which has never been used in former economic mobility and impact evaluation literature (Chapter 2, 3 and 4). This novel data set is analyzed through several econometric methods suitable for the respective analysis. Although Chapter 5 makes use of the long-established household survey (SES), the spillover effect of the Old Age Allowance program in Thailand has never been explored in previous literature.

The main target of the thesis is policy makers in Thailand as well as in other developing countries. Moreover, the thesis might be useful for a wider audience including scholars and readers who are interested in the issues of socioeconomic inequality, mobility and social protection but have no grounding in the subject. With regard to the dissemination of the results, the main findings of this thesis have been disseminated at several seminars and international conferences. In particular, the main results presented in Chapter 3 have been presented at the Asian Development Bank Institute and Asian Growth Research Institute Workshop on Public and Private Investment in Human Capital and Intergenerational Transfers in Asia which was held in Kitakyushu, 2017 and the IZA World Labor Conference in Berlin, 2018. The key findings from Chapter 4 have been shared and discussed at the Asian and Australasian Society of Labour Economics or AASLE in Seoul, 2018. The evidence found in Chapter 5 has been presented at the Nordic Conference on Development Economics in Copenhagen, 2019 and the 34th Annual Congress of the European Economic Association in Manchester, 2019. In addition, the results obtained in Chapter 3 have already been published as a UNU-MERIT working paper. The findings from Chapter 3, 4 and 5 are also aimed to be published in peer-reviewed journals. Furthermore, some of the key evidence reported in this thesis have been shared or will be shared with the National Economic and Social Development Board (NESDB) which is the national planning agency providing recommendations on social, economic and other development issues to the prime minister and cabinet of Thailand. 


\section{About the Author}

Patima Chongcharoentanawat was born and raised in Bangkok, Thailand. She obtained a Bachelor's degree in Economics from Chulalongkorn University, Thailand (First Class Honors) and a Master's degree in Applied Economics from the University of Michigan, USA. After four years serving as a plan and policy analyst at the National Economic and Social Development Board (NESDB), the national planning agency under the Office of the Prime Minister in Thailand, she was awarded a scholarship from the Royal Thai Government to pursue her PhD at UNU-MERIT, Maastricht University in 2015. Her research interests lie in the broad area of socioeconomic inequality, active labor market policies, social protection programs and impact evaluation. In her $\mathrm{PhD}$ dissertation, she particularly focuses on socioeconomic mobility and the role of social protection programs in fostering mobility. During her time as a PhD fellow at UNU-MERIT, Patima also worked as a tutor (teaching assistant), a Master thesis supervisor and a second reader (co-evaluator) for a number of theses in the MSc in Public Policy and Human Development program (MPP). After the end of her PhD journey, Patima will return to her job at NESDB in Thailand where she plans to broaden, deepen and share her knowledge and expertise in the aforementioned areas. 



\section{UNU-MERIT/MGSoG Dissertation Series}

2019

\section{Patima Chongcharoentanawat}

Beyond Static Inequality: Public

Policies and Economic Mobility in

Thailand

UNU-MERIT/MGSoG Dissertation

Series № 238

\section{Charlotte Guillard}

Rethinking economic growth

and structural change.

The role of boundaries and linkages

between industries

UNU-MERIT/MGSoG Dissertation

Series № 237

\section{Nicolas Echarti}

Employment Effects or Vocational

Rehabilitation in Germany:

A quantitative analysis

UNU-MERIT/MGSoG Dissertation

Series № 236

\section{Shellie E. Solomon}

Neighborhoods Matter:

Crime, collective efficacy and

foreclosures in Miami

UNU-MERIT/MGSoG Dissertation

Series № 235

\section{Michał Kazimierczak}

Regional Innovation and

Entrepreneurship

Patents, trade marks, entry and

entrants' growth in European

manufacturing industries

UNU-MERIT/MGSoG Dissertation

Series № 234

\section{Fernanda Soares}

The Influence of Within School and Across Schools' Collaborative Practices on Student Learning and Teaching Outcomes in West Africa

UNU-MERIT/MGSoG Dissertation Series № 233

\section{Mira Bierbaum}

New Mindsets to Innovate Activation UNU-MERIT/MGSoG Dissertation

Series № 232

\section{Norman Dytianquin}

Technology in the Asian Miracle and

Crisis Debates: Applications of and Insights from the Field of Influence Approach to Input-Output Analysis UNU-MERIT/MGSoG Dissertation Series № 231 


\section{Nga Le}

The implications of health insurance for the labour market and patient satisfaction with medical care in Vietnam

UNU-MERIT/MGSoG Dissertation Series № 230

\section{Jinhyuck Park}

Intellectual Property right protection and cross-border RED investments by multinational enterprises

UNU-MERIT/MGSoG Dissertation Series № 229

\section{Richard de Groot}

Show me the Money:

Essays on the Impact of Cash Transfers on Child Nutrition and the Role of Intra-Household Dynamics UNU-MERIT/MGSoG Dissertation Series № 228

\section{Catie Lott}

Diamonds are a Women's Best Friend Broadening Measures of Women's Access to Formal Political DecisionMaking

UNU-MERIT/MGSoG Dissertation Series № 227

\section{Ana Cristina Calderon Ramirez}

Public Management Reforms

Three stories about public procurement agencification in Latin America UNU-MERIT/MGSoG Dissertation Series № 226

\section{Camilo Nicanor Carrillo Purin}

Teachers' in-service training and student achievement:

The effect of in-service training of Peruvian teachers on student achievement

UNU-MERIT/MGSoG Dissertation Series № 225

\section{Hugo Confraria}

Developing scientific capacity in the

Global South

UNU-MERIT/MGSoG Dissertation Series № 224

\section{Alison Cathles}

Educational Pathways and Skills:

Past, Present, and Future

UNU-MERIT/MGSoG Dissertation

Series № 223

\section{Ibrahima Sory Kaba}

Aggregate Fluctuations and

Development: Essays on

Macroeconomic Volatility and

Economic Growth

UNU-MERIT/MGSoG Dissertation

Series № 222

\section{Charlotte Keijser}

Firm Participation, Learning and Innovation in Heterogenous Value Chains of IT-enabled Services UNU-MERIT/MGSoG Dissertation Series № 221 


\section{Salih Çevikarslan}

Innovation Strategies and Their

Implications for Technological Change

and Market Outcomes:

An Evolutionary Multi-Agent Based

Modelling Approach

UNU-MERIT/MGSoG Dissertation

Series № 220

\section{Wondimagegn Mesfin Tesfaye}

Essays on the Impacts of Climate-

Smart Agricultural Innovations on

Household Welfare

UNU-MERIT/MGSoG Dissertation

Series № 219

\section{Tatevik Poghosyan}

How Board Networks Affect Firm

Performance and Innovation Incentives in Transition Economies: The Case of Armenia

UNU-MERIT/MGSoG Dissertation

Series № 218

\section{Arip Muttaqien}

Essays on Inequality and Polarization:

Empirical Studies in Developing Asia

UNU-MERIT/MGSoG Dissertation

Series № 217

2018

\section{Katrin Marchand}

Essays on Forced Migration and

Labour Market Participation in

Developing Countries

UNU-MERIT/MGSoG Dissertation

Series № 216

\section{Ortrun Merkle}

The Myth of Gender Neutral Power:

Corruption and Gender Norms

UNU-MERIT/MGSoG Dissertation

Series № 215

\section{Biljana Meshkovska}

Life after Trafficking:

(re)integration processes of women that have been trafficked for the purpose of sexual exploitation in Europe

UNU-MERIT/MGSoG Dissertation

Series № 214

\section{Vincenzo Vinci}

The Relevance of Institutions and

People's Preferences for Social

Protection

UNU-MERIT/MGSoG Dissertation

Series № 213

\section{Silke Heuser}

The Effectiveness of Environmental Policies on Reducing Deforestation in the Brazilian Amazon

UNU-MERIT/MGSoG Dissertation

Series № 212

\section{Jennifer Waidler}

Social Assistance and Remittances and Their Role in the Fight Against

Poverty

UNU-MERIT/MGSoG Dissertation

Series № 211

\section{Choolwe Muzyamba}

The role of community mobilization in the promotion of maternal health of women living with HIV in Zambia UNU-MERIT/MGSoG Dissertation Series № 210 
Juan Carlos A. Castillo Sánchez

Assessing the Role of the Export Sector in Mexican Economic

Development,1965-2014

UNU-MERIT/MGSoG Dissertation

Series № 209

\section{Tareq Abuelhaj}

Food Security Policy Impact Analysis:

The Econometrics of Cash and Food

Assistance Cost Effectiveness

UNU-MERIT/MGSoG Dissertation

Series № 208

Marta Férnandez de Arroyabe

Arranz

Essays on MEAS and Innovation

UNU-MERIT/MGSoG Dissertation

Series № 207

\section{Clotilde Mahé}

Essays on Migration and Occupational

Choice

UNU-MERIT/MGSoG Dissertation

Series № 206

\section{Simone Sasso}

Talent on the move. Essays on Human

Capital, Graduate Mobility and

Economic Development

UNU-MERIT/MGSoG Dissertation

Series № 205

\section{Khaled Walid Rajab}

Strategic Planning under Fragility

UNU-MERIT/MGSoG Dissertation

Series № 204

\section{Mutinta Hambayi Nseluke}

A Tall Order: Improving Child Linear

Growth

UNU-MERIT/MGSoG Dissertation

Series № 203

\section{Elvis Korku Avenyo}

Innovations and Firm Performance

in sub-Saharan Africa: Empirical

Analyses

UNU-MERIT/MGSoG Dissertation

Series № 202

\section{Ni Zhen}

Employment Dynamics, Firm

Performance and Innovation

Persistence in the Context of

Differentiated Innovation Types:

Evidence from Luxembourg

UNU-MERIT/MGSoG Dissertation

Series № 201

\section{Caroline Wehner}

Too Scared to Achieve: The Relation

Between Neuroticism,

Conscientiousness

and Socioeconomic Outcomes

UNU-MERIT/MGSoG Dissertation

Series № 200

\section{Stefania Innocenti}

On Institutional Persistence

UNU-MERIT/MGSoG Dissertation

Series № 199

\section{Hassen Abda Wako}

Economic Globalization, Institutions and Development: Essays on Aid, Foreign Direct Investment and Trade UNU-MERIT/MGSoG Dissertation Series № 198 


\section{Michael Verba}

Hans-Erik Edsand

Winds of Change

UNU-MERIT/MGSoG Dissertation

Series № 197

\section{Ana Patricia Silva Vara}

Redressing the Gender Gap

UNU-MERIT/MGSoG Dissertation

Series № 196

\section{Andrés Iván Mideros Mora}

Essays on the Economic Effects of Noncontributory Social Protection

UNU-MERIT/MGSoG Dissertation Series № 195

\section{Tobias Broich}

New Actors in the Global Economy

UNU-MERIT/MGSoG Dissertation

Series № 194

\section{Bernard Nikaj}

From No-government to E-government

UNU-MERIT/MGSoG Dissertation

Series № 193

\section{Ali Safarnejad}

Prioritizing the HIV Response

UNU-MERIT/MGSoG Dissertation

Series № 192

\section{Clovis Freire}

Diversification and Structural

Economic Dynamics

UNU-MERIT/MGSoG Dissertation

Series № 191
Innovation and Knowledge Dynamics:

Essays on the Knowledge Economy

UNU-MERIT/MGSoG Dissertation

Series № 190

\section{Pui Hang Wong}

The Hearts and Minds in Conflict and

Peace: The Economics of

Counterinsurgency and the Psychology of Reconstruction

UNU-MERIT/MGSoG Dissertation

Series № 189

\section{Brenda Yamba}

Schooling Despite All Odds: Evidence from Lesotho on Female Child Carers who Stayed in School

UNU-MERIT/MGSoG Dissertation

Series № 188

\section{Sheng Zhong}

Moving towards An Energy Efficient

Future: Essays on Energy Efficiency,

Technology and Development

UNU-MERIT/MGSoG Dissertation

Series № 187

\section{Julieta Marotta}

Access to Justice and Legal

Empowerment of Victims of Domestic

Violence through Legal Organizations

in the City of Buenos Aires: A

Qualitative Empirical Legal Study

UNU-MERIT/MGSoG Dissertation

Series, № 186 


\section{Andrea Franco-Correa}

On the Measurement of

Multidimensional Poverty as a Policy

Tool: Empirical Applications to Chile,

Colombia, Ecuador and Peru

UNU-MERIT/MGSoG Dissertation

Series, № 185

2016

Yesuf Awel

Insurance for Growth: Empirical

Essays on Insurance Demand and

Impacts in Africa

UNU-MERIT Dissertation Series,

№ 108

\section{Tigist Mekonnen Melesse}

Grow More Food using Fewer

Resources: Agricultural Technology

Adoption and Innovation Practices for

Inclusive and Sustainable

Development

UNU-MERIT Dissertation Series,

№ 107

\section{Eleni Yitbarek}

Getting Ahead or left Behind? Essays on Poverty Dynamics and Social

Mobility in Africa

UNU-MERIT Dissertation Series, № 106

\section{Thuy Dieu Nguyen}

Firm-Level Theory and Evidence of

Corruption

UNU-MERIT Dissertation Series, № 105

\section{Raquel Tsukada Lehman}

Essays on Household Production with

Labor-Saving Technology

UNU-MERIT Dissertation Series,

№ 104

\section{Eva Barteková}

Multi-Problem Challenges for a

Renewable Future: Empirical Studies

on Competitive Disadvantages from

Electricity Price Differentials and

Mineral Supply Risk in an Open

Economy

UNU-MERIT Dissertation Series,

№ 103

\section{Jocelyn Olivari}

Entrepreneurial Traits and Innovation:

Evidence from Chile

UNU-MERIT Dissertation Series,

№ 102

\section{Muhammad Shafique}

Essays on the role of knowledge, RED, and Technology-based Firms in the

Evolution of Socio-techno-economic

System

UNU-MERIT Dissertation Series,

№ 101

\section{Serdar Türkeli}

Governance of Innovation Policy:

Empirical Studies on Applied Political

Economy by Multi-Methods Analysis

UNU-MERIT Dissertation Series,

№ 100 


\section{Ayokunu Adedokun}

Pathways to Sustainable Peace

building in Divided Societies: Lessons

and Experiences from Mozambique

MGSoG Dissertation Series, № 75

\section{Luiz Rothier Bautzer}

Organizing Concurrent Engineering

through ICT Platforms

Blueprinting Product Lifecycle

Management Platforms across

Disciplinary Agencies

MGSoG Dissertation Series, № 74

\section{Natalia Popova}

Migration in the Periphery of the

European Union:

Determinants of Successful and

Sustainable Labour Market Integration of Return Migrants in Albania, Egypt, Moldova and Tunisia

MGSoG Dissertations Series, № 73

\section{Richard A. Martina}

Uncertainty and Resource Constraint in the Small Island Developing States:

Essays in Entrepreneurial Cognition

MGSoG Dissertations Series, № 72

\section{Cécile Cherrier}

The Expansion of Basic Social

Protection in Low-income Countries:

An Analysis of Foreign Aid Actors'

Role in the Emergence of Social

Transfers in Sub-Saharan Africa

MGSoG Dissertations series, № 71

\section{Paul Caldron}

The Tacit Bargain in Short-Term

Medical Missions: Why U.S.

physicians go and what it costs

MGSoG Dissertation Series, № 70

\section{Mahmut Kobal}

Customs \& Excellence: A Comparative Approach on Administrative and Regulatory Compliance Perspectives of the EU-Turkey Customs Union

MGSoG Dissertation Series, № 69

\section{Craig Loschmann}

Essays on Conflict-related Migration

and Development in the Case of

Afghanistan

MGSoG Dissertations Series, № 68

\section{Andrea Milan}

Rural Livelihoods, Location and

Vulnerable Environments: Approaches

to Migration in Mountain areas of

Latin America

MGSoG Dissertation Series, № 67

\section{Farida Lada}

On Guarding the Welfare of Clinical

Trial Subjects While Promoting Novel

Drug Innovation

A Game Theoretical Approach

MGSoG Dissertation Series, № 66

2015

\section{Hibret Belete Maemir}

Dissecting Aggregate Productivity:

International Integration and Growth

with Heterogeneous Firms

UNU-MERIT Dissertation Series, № 96 


\section{Giorgio Triulzi}

Looking for the Right Path: Technology

Dynamics, Inventive Strategies and

Catching-up in the Semiconductor Industry

UNU-MERIT Dissertation Series, № 95

\section{Abdul Baseer Qazi}

Knowledge flows and networks in the

ICT sector: The case of Pakistan

UNU-MERIT Dissertation Series,

№ 94

\section{Ajay Thutupalli}

Technology Paradigm Shifts in

Agriculture: Drivers of Sustainability

and Catch up

UNU-MERIT Dissertation Series, № 93

\section{Eduardo Urias}

Improving access to HIV/AIDS

treatment in Brazil: When are

Compulsory Licenses effective in Price

Negotiations?

UNU-MERIT Dissertation Series, № 92

\section{Francesca Guadagno}

Why have so few Countries

Industrialised?

UNU-MERIT Dissertation Series, № 91

\section{Daniel Opolot}

The Evolution of Beliefs and Strategic

Behaviour

UNU-MERIT Dissertation Series, № 90
Alejandro Lavopa

Structural Transformation and

Economic Development: Can

Development Traps be Avoided

UNU-MERIT Dissertation Series, № 89

\section{Jinjin Zhao}

Urban water management reform: The

Case of China

UNU-MERIT Dissertation Series,

№ 88

\section{Simona Vezzoli}

Borders, Independence and Post-

colonial Ties: the Role of the State in

Caribbean Migration

MGSoG Dissertation Series, № 65

\section{Silvia Consuelo Gómez Soler}

Civil Conflict and Education: How

Does Exposure to Civil Conflict Affect

Human Capital Accumulation?

Evidence from Standardized Exit

Exams in Colombia

MGSoG Dissertation Series, № 64

\section{Paula Nagler}

Occupational Choice in the Developing

World

MGSoG Dissertation Series, № 63

\section{Jasmin Kientzel}

Determinants of Professional

Commitment to Environmental

Sustainability

MGSoG Dissertation Series, № 62 


\section{Mehmet Güney Celbiş}

Regional Policies: Convergence, Trade, and the Allocation of Public Capital

MGSoG Dissertation Series, № 61

\section{Florian Henning}

Living Up to Standard:

Interoperability Governance and

Standards Adoption in Government

Information Networks

MGSoG Dissertation Series, № 60

Niels P. Groen

The Never-Ending Project

Understanding E-Government Project

Escalation

MGSoG Dissertation Series, № 59

\section{Derek Copp}

Teacher-Based Reactivity to Provincial

Large-scale Assessment in Canada

MGSoG Dissertation Series, № 58

\section{Michaella Vanore}

Family-Member Migration and the

Psychosocial Health Outcomes of

Children in Moldova and Georgia

MGSoG Dissertation Series, № 57

\section{Sonja Fransen}

The Economic and Social Effects of

Remittances and Return Migration in

Conflict-Affected Areas: The Case of

Burundi

MGSoG Dissertation Series, № 56

\section{Ibrahim Khalil Conteh}

The Impact of Floods on Primary

School Education in Zambia

MGSoG Dissertation Series, № 55

\section{Richard Bluhm}

Growth Dynamics and Development

Essays in Applied Econometrics and

Political Economy

MGSoG Dissertation Series, № 54

\section{Nevena P. Zhelyazkova}

Work-Family Reconciliation and Use of Parental Leave in Luxembourg:

Empirical Analysis of Administrative

Records

MGSoG Dissertation Series, № 53

2014

\section{Dirk Crass}

The Impact of Brands on Innovation and Firm Performance: Empirical Evidence from Germany

UNU-MERIT Dissertation Series, № 87

\section{Samyukta Bhupatiraju}

The Geographic Dimensions of Growth and Development

UNU-MERIT Dissertation Series, № 86

\section{François Lafond}

The Evolution of Knowledge Systems UNU-MERIT Dissertation Series, № 85 


\section{Annalisa Primi}

Promoting Innovation in Latin

America: What Countries Have

Learned (and What They Have Not) in

Designing and Implementing

Innovation and Intellectual Property

Policies

UNU-MERIT Dissertation Series, № 84

\section{Fatoumata Lamarana Diallo}

Evaluation of Meal and Deworming

Programs for Primary Schools in Rural

Senegal

UNU-MERIT Dissertation Series, № 83

\section{Sachin Kumar Badkas}

Metachoice and Metadata: Innovating with Environmental Policy Analysis in Europe

MGSoG Dissertation Series, № 52

\section{Irina S. Burlacu}

An Evaluation of Tax-Benefit Systems Impact on the Welfare of Frontier Worker:

The Case of Luxembourg and Belgium MGSoG Dissertation Series, № 51

\section{Özge Bilgili}

Simultaneity in Transnational

Migration Research: Links Between

Migrants' Host and Home Country

Orientation

MGSoG Dissertation Series, № 50

\section{Yulia Privalova Krieger}

Reshaping the Big Agenda:

Transnational Politics and Domestic

Resistance Financial crisis and social protection reform in Bosnia and

Herzegovina

MGSoG Dissertation Series, № 49

\section{Marieke van Houte}

Moving Back or Moving Forward?

Return migration after Conflict

MGSoG Dissertation Series, № 48

\section{Oxana Slobozhan}

Global Governance in the Management of Natural Resources: The Case of the Extractive Industries Transparency Initiative (EITI)

MGSoG Dissertation Series, № 47

\section{Luis Bernardo Mejia Guinand}

The Changing Role of the Central

Planning Offices in Latin America: A

Comparative Historical Analysis

Perspective (1950-2013)

MGSoG Dissertation Series, № 46

\section{Cheng Boon Ong}

Ethnic Segregation in Housing, Schools and Neighbourhoods in the

Netherlands

MGSoG Dissertation Series, № 45

\section{Luciana V. Cingolani}

Bureaucracies for Development:

Oxymoron or Reality? Studies on State

Capacity in Challenging Governance

Contexts

MGSoG Dissertation Series, № 44 


\section{Carlos Cadena Gaitán}

Green Politics in Latin American

Cities - Sustainable Transport Agendas

MGSoG Dissertation Series, № 43

\section{Katie Kuschminder}

Female Return Migration and

Reintegration Strategies in Ethiopia

MGSoG Dissertation Series, № 42

\section{Metka Hercog}

Highly-Skilled Migration and New

Destination Countries

MGSoG Dissertation Series, № 41

\section{Margaret Agaba Rugadya}

Can Remittances Influence the Tenure and Quality of Housing in Uganda?

MGSoG Dissertation Series, № 40

\section{Ilire Agimi}

New Governance Under Limited

Statehood: The Case of Local

Government Reform in Kosovo

MGSoG Dissertation Series, № 39

2013

\section{Anant Kamath}

Information Sharing through Informal

Interaction in Low-Tech Clusters

UNU-MERIT Dissertation Series, № 82

\section{Flavia Pereira de Carvalho}

What we talk about when we talk about Brazilian Multinationals: An Investigation on Brazilian FDI, Economic Structure, Innovation and the Relationship between them UNU-MERIT Dissertation Series, № 81

\section{Jun Hou}

Complementarity in Innovation and Development: A Cross-country

Comparison

UNU-MERIT Dissertation Series, № 80

\section{Rufin Baghana}

Impacts of Government Incentives to $R \mathcal{E D}$, Innovation and Productivity: A Microeconometric Analysis of the Québec Case

UNU-MERIT Dissertation Series, № 79

\section{Lilia I. Stubrin}

High-Tech Activities in Emerging Countries: A Network perspective on the Argentinean Biotech Activity UNU-MERIT/MGSoG Dissertation Series, № 78

\section{Kristine Farla}

Empirical Studies on Institutions, Policies and Economic Development MGSoG Dissertation Series, № 38 
Marina Petrovic

Social Assistance and Activation in the Pursuit of Happiness: Shedding New

Light on Old Policy Solutions to Social Exclusion

MGSoG Dissertation Series, № 37

\section{Laura Torvinen}

Assessing Governance Assessments:

The Case of Mozambique: Governance

Assessments in the Context of Aid

Effectiveness Discourse

MGSoG Dissertation Series, № 36

\section{Biniam Egu Bedasso}

Institutional Change in the Long

Shadow of Elite: Essays on

Institutions, Human Capital and

Ethnicity in Developing Countries

MGSoG Dissertation Series, № 35

\section{Sepideh Yousefzadeh Faal}

Deghati

Childhoods Embargoed: Constructing

and Reconstructing Multidimensional

Child Poverty in Iran 1984-2009

MGSoG Dissertation Series, № 34

\section{Robert Bauchmüller}

Investing in Early Childhood Care and Education: The Impact of Quality on Inequality

MGSoG Dissertation Series, № 33

\section{Martin Rehm}

Unified Yet Separated: Empirical

Study on the Impact of Hierarchical

Positions within Communities of

Learning

MGSoG Dissertation Series, № 32
2012

\author{
Abdul Waheed \\ Innovation Determinants and \\ Innovation as a Determinant: Evidence \\ from Developing Countries \\ UNU-MERIT Dissertation Series, \\ № 77
}

\section{Bilal Mirza}

Energy Poverty and Rural Energy

Markets in Pakistan

UNU-MERIT Dissertation Series, № 76

\section{Benjamin Engelstätter}

Enterprise Software and Video Games:

An Empirical Analysis

UNU-MERIT Dissertation Series,

№ 75

\section{Fulvia Farinelli}

Natural Resources, Innovation and Export Growth: The Wine Industry in Chili and Argentina

UNU-MERIT Dissertation Series

\section{Rodolfo Lauterbach}

Innovation in Manufacturing: From

Product Variety and Labor

Productivity Growth to Economic

Development in Chile

UNU-MERIT Dissertation Series

\section{Kirsten Wiebe}

Quantitative Assessment of

Sustainable Development and Growth in Sub-Saharan Africa

UNU-MERIT Dissertation Series, № 74 


\section{Julio Miguel Rosa}

Organizational Strategies, Firms'

Performance and Spatial Spillovers:

The Canadian Case in Research and

Development.

UNU-MERIT Dissertation Series,

№ 73

Johannes Wilhelmus Marie Boels

Joseph Schumpeter, Honderd Jaar

Economische Ontwikkeling: Een

Historisch-theoretische Beschouwing.

UNU-MERIT Dissertation Series

\section{Dorcas Mbuvi}

Utility Reforms and Performance of the

Urban Water Sector in Africa

MGSoG Dissertation Series, № 31

\section{Lina Salanauskaite}

Distributional Impacts of Public

Policies: Essays in Ex-Ante and Ex-

Post Evaluation

MGSoG Dissertation Series, № 30

\section{Esther Schüring}

To Condition or not - is that the

Question?

An Analysis of the Effectiveness of ExAnte and Ex-Post Conditionality in

Social Cash Transfer Programs

MGSoG Dissertation Series, № 29

\section{Joe Abah}

Strong Organisations in Weak States:

Atypical Public Sector Performance in

Dysfunctional Environments

MGSoG Dissertation Series, № 28

\section{Zina Samih Nimeh}

Social Citizenship Rights: Inequality

and Exclusion

MGSoG Dissertation Series, № 27

2011

\section{Daniel Vertesy}

Interrupted Innovation: Emerging

Economies in the Structure of the

Global Aerospace Industry

UNU-MERIT Dissertation Series,

№ 72

\section{Tina Saebi}

Successfully Managing Alliance

Portfolios: An Alliance Capability

View

UNU-MERIT Dissertation Series,

№ 71

\section{Nora Engel}

Tuberculosis in India: A Case of

Innovation and Control

UNU-MERIT/MGSoG Dissertation

Series, № 70

\section{Evans Mupela}

Connectivity and growth in Sub-

Saharan Africa: The Role of

Communication Satellites

UNU-MERIT Dissertation Series, № 69

\section{Nantawan Kwanjai}

Cross Cultural Intelligence amid

Intricate Cultural Webs: A Tale of the

UnDutchables in the Land of 1002

Smiles

UNU-MERIT Dissertation Series, № 68 


\section{Lina Sonne}

Innovation in Finance to Finance Innovation: Supporting Pro-poor Entrepreneur-based Innovation UNU-MERIT Dissertation Series, № 67

\section{Lenka Eisenhamerová}

Legitimacy of 'Humanitarian Military

Intervention'

MGSoG Dissertation Series, № 26

\section{Sonila Tomini}

Informal Payments for Health Care

Services in Albania

MGSoG Dissertation Series, № 25

\section{Jinjing Li}

Dynamic Microsimulation in Public

Policy Evaluation

MGSoG Dissertation Series, № 24

\section{Aziz Atamanov}

Rural Nonfarm Employment and International Migration as

Alternatives to Agricultural

Employment: The Case of Kyrgyzstan

MGSoG Dissertation Series, № 23

\section{Frieda Vandeninden}

Poverty Alleviation: Aid and Social

Pensions

MGSoG Dissertation Series, № 22

\section{Juliana Nyasha Tirivayi}

The Welfare Effects of Integrating AIDS Treatment with Food Transfers:

Evidence from Zambia

MGSoG Dissertation Series, № 21

\section{Agnieska Ewa Sowa}

Who's Left Behind? Social Dimensions of Health Transition and Utilization of Medical Care in Poland

MGSoG Dissertation Series, № 20

\section{Emmanaouil Sfakianakis}

The Role of Private Actors in the

Provision of Public Goods with

Applications to Infrastructure and

Financial Stability

MGSoG Dissertation Series, № 19

\section{Siu Hing Lo}

White Collars Green Sleeves: An Interorganizational Comparison of Determinants of Energy-Related Behaviors among Office Workers MGSoG Dissertation Series, № 18

\section{Treena Wu}

Constraints to Human Capital Investment in Developing Countries: Using the Asian Financial Crisis in Indonesia as a Natural Experiment MGSoG Dissertation Series, № 17

\section{Henry Espinoza Peña}

Impact Evaluation of a Job-Training

Programme for Disadvantaged Youths:

The Case of Projoven

MGSoG Dissertation Series, № 16 


\section{Asel Doranova}

Fernando Santiago

Human Resources Management

Practices and Learning for Innovation

in Developing Countries:

Pharmaceutical Firms in Mexico

UNU-MERIT Dissertation Series, № 66

\section{Zakaria Babutsidze}

Essays on Economies with

Heterogeneous Interacting Consumers

UNU-MERIT Dissertation Series, № 65

\section{Bertha Vallejo}

Learning and Innovation Under

Changing Market Conditions: The

Auto Parts Industry in Mexico

UNU-MERIT Dissertation Series,

№ 64

\section{Donatus Ayitey}

Technical Change, Competitiveness and Poverty Reduction: A Study of the Ghanaian Apparel Industry

UNU-MERIT Dissertation Series, № 63

\section{Sergey Filippov}

Multinational Subsidiary Evolution:

Corporate Change in New EU Member States

UNU-MERIT Dissertation Series, № 62
Technology Transfer and Learning

under the Kyoto Regime: Exploring the Technological Impact of CDM Projects in Developing Countries

UNU-MERIT Dissertation Series, № 61

\section{Florian Tomini}

Between Family and Friend:

Understanding the Interdependency of Private Transfers

MGSoG Dissertation Series, № 15

\section{Michał Polalowski}

The Institutional Transformation of

Social Policy in East Central Europe:

Poland and Hungary in Comparative and Historical Perspective

MGSoG Dissertation Series, № 14

\section{Maha Ahmed}

Defining, Measuring and Addressing

Vulnerability: The Case of Post

Conflict Environments

MGSoG Dissertation Series, № 13

\section{Pascal Beckers}

Local Space and Economic Success:

The Role of Spatial Segregation of

Migrants in the Netherlands

MGSoG Dissertation Series, № 12

\section{Victor Cebotari}

Conflicting Demands in Ethnically

Diverse Societies: Ethno political

Contention and Identity Values in

Europe

MGSoG Dissertation Series, № 11 
Dennis Gyllensporre

Competing and Complementary

Perspectives on the EU as a Crisis

Management Actor:

An Examination of the Common

Security and Defence Policy through

the Lenses of Idealism and Realism

MGSoG Dissertation Series, № 10

\section{Judit Vall Castello}

Business Cycle and Policy Effects on Labour Market Transitions of Older and Disabled Workers in Spain

MGSoG Dissertation Series, № 9

\section{Keetie Roelen}

False Positives or Hidden Dimensions:

The Definition and Measurement of

Child Poverty

MGSoG Dissertation Series, № 8

\section{Denisa Maria Sologon}

Earning Dynamics in Europe

MGSoG Dissertation Series, № 7

\section{Melissa Siegel}

Money and Mobility: Migration and

Remittances

MGSoG Dissertation Series, № 6

\section{Jessica S. Hagen-Zanker}

Modest Expectations: Causes and

Effects of Migration on Migrant

Households inSource Countries

MGSoG Dissertation Series, № 5
2009
Alexis Habiyaremye
From Primary Commodity Dependence
to Diversification and Growth:
Absorptive Capacity and Technological
Catch Up in Botswana and Mauritius.
UNU-MERIT Dissertation Series,
№ 60

\section{Yoseph Getachew}

The Role of Public Capital in Economic

Development

UNU-MERIT Dissertation Series, № 59

\section{Sandra Leitner}

Embodied Technological Change and

Patterns of Investment in Austrian

Manufacturing

UNU-MERIT Dissertation Series,

№ 58

\section{Semih Akçomak}

The Impact of Social Capital on

Economic and Social Outcomes

UNU-MERIT Dissertation Series, № 57

\section{Abraham Garcia \\ The Role of Demand in Technical \\ Change \\ UNU-MERIT Dissertation Series, № 56}

\section{Saurabh Arora}

Coherence in Socio-technical Systems:

A Network Perspective on the Innovation Process

UNU-MERIT Dissertation Series, № 55 


\section{Mirtha R. Muniz Castillo}

Human Development and Autonomy in Project Aid: Experiences from four bilateral projects in Nicaragua and El Salvador

MGSoG Dissertation Series, № 4

\section{Christiane Arndt}

Governance Indicators

MGSoG Dissertation Series, № 3

\section{Britta Augsburg}

Microfinance: Greater Good or Lesser

Evil?

MGSoG Dissertation Series, № 2

2008

\section{Rutger Daems}

Medicines for the Developing World UNU-MERIT Dissertation Series, № 54

\section{Johannes Hanel}

Assessing Induced Technology:

Sombart's Understanding of Technical Change in the History of Economics UNU-MERIT Dissertation Series, № 53

\section{Rifka Weehuizen}

Mental Capital: the Economic Significance of Mental Health UNU-MERIT Dissertation Series, № 52

\section{Danielle Cloodt}

The Relationship between RED

Partnership Formation, Social

Embeddedness and Innovative

Performance

UNU-MERIT Dissertation Series, № 51

\section{Sabine Fuss}

Sustainable Energy Development under Uncertainty

UNU-MERIT Dissertation Series,

№ 50

\section{Geranda Notten}

Measuring and Managing Poverty

Risks

MGSoG Dissertation Series, № 1

2007

\section{Tobias Kronenberg}

Reconciling Environmental

Conservation with Economic

Prosperity: The Feasibility of Double

Dividends in the Short and Long Run UNU-MERIT Dissertation Series, № 49

\section{Viktoria Kravtsova}

Assessing the Impact of Foreign Direct Investment in Transition Economies UNU-MERIT Dissertation Series, № 48 


\section{Suhail Sultan}

The Competitive Advantage of Small and Medium Sized Enterprises: The Case of Jordan's Natural Stone Industry

UNU-MERIT Dissertation Series, № 47

2006

\section{Bulat Sanditov}

Essays on Social Learning and Imitation

UNU-MERIT Dissertation Series, № 46

\section{Mamata Parhi}

Dynamics of New Technology

Diffusion: A Study of the Indian

Automotive Industry

UNU-MERIT Dissertation Series, № 45

\section{Andreas Reinstaller}

Social Structures and the Innovation Process: Their Role in the Demand of Firms and Consumers

UNU-MERIT Dissertation Series, № 44

\section{Rose Kiggundu}

Innovation systems and Development:

The Journey of a Beleaguered Nile

Perch Fishery in Uganda

UNU-MERIT Dissertation Series, № 43

\section{Thomas Pogue}

The Evolution of Research

Collaboration in South African Gold Mining: 1886-1933

UNU-MERIT Dissertation Series, № 42

\section{Geoffrey Gachino}

Foreign Direct Investment, Spillovers and Innovation: The Case of Kenyan Manufacturing Industry

UNU-MERIT Dissertation Series, № 41

\section{Önder Nomaler}

Technological Change, International Trade and Growth: An Evolutionary, Multi-Agents-Based Modeling

Approach

UNU-MERIT Dissertation Series, № 40

2005

\section{Samia Satti Osman Mohamed-}

Nour

Change and Skill Development in the Arab Gulf Countries

UNU-MERIT Dissertation Series, № 39

\section{Elad Harison}

Intellectual Property Rights:

Economics and Policy Analysis

UNU-MERIT Dissertation Series, № 38 


\section{Daniel Dalohoun}

Learning to innovate: agricultural innovation and entrepreneurship: the case of Songhaï farmers in Benin UNU-MERIT Dissertation Series, № 37

\section{Müge Ozman}

Networks, Organizations and

Knowledge

UNU-MERIT Dissertation Series, № 36

\section{Bas Straathof}

Product Variety and Economic

Growth: The Counteracting Effects of Scale and Idiosyncrasy

UNU-MERIT Dissertation Series, № 35

\section{Wilfred Schoenmakers}

Knowledge Flows between

Multinational Companies: A Patent

Data Analysis

UNU-MERIT Dissertation Series, № 34

\section{Myriam Cloodt}

Mergers and Acquisitions ( $M$ and As) in High-Tech Industries: Measuring the Post-M and A Innovative

Performance of Companies

UNU-MERIT Dissertation Series, № 33
2004

\section{Paola Criscuolo}

$R \mathcal{E D}$ Internationalisation and

Knowledge Transfer: Impact on MNEs and their Home Countries

UNU-MERIT Dissertation Series, № 32

\section{Maarten Verkerk}

Trust and Power on the Shop Floor UNU-MERIT Dissertation Series, № 31

\section{Gottfried Leibbrandt}

Adoption, Harmonization and Succession of Network Technologies across Countries

UNU-MERIT Dissertation Series, № 30

\section{Mark Sanders}

Skill Biased Technical change: Its

Origins, the Interaction with the

Labour Market and Policy Implications

UNU-MERIT Dissertation Series,

№ 29

2003

\section{Nadine Roijakkers}

Inter-firm Cooperation in High-tech Industries: a Study of R\&D

Partnerships in Pharmaceutical

Biotechnology

UNU-MERIT Dissertation Series, № 28 
Viki Sonntag

Speed, Scale and Sustainability

UNU-MERIT Dissertation Series, № 27

\section{Masaru Yarime}

From End-of-Pipe Technology to Clean Technology

UNU-MERIT Dissertation Series, № 26

\section{Stéphane Malo}

The Combinatorial Chemistry Revolution: Sustaining a Superior

Performance Position through

Technological Learning

UNU-MERIT Dissertation Series,

№ 25

\section{2}

\section{Annelies Hogenbirk}

Determinants of Inward Foreign

Direct Investment: the Case of the

Netherlands

UNU-MERIT Dissertation Series, № 24

\section{Bastiaan Johan terWeel}

The Computerization of the Labour Market

UNU-MERIT Dissertation Series
2001

\section{John Adeoti}

Technology Investment in Pollution Control in Sub-Saharan Africa: The Case of the Nigerian Manufacturing Industry

UNU-MERIT Dissertation Series, № 23

\section{Edward Huizenga}

Innovation Management: How

Frontrunners Stay Ahead: An

Empirical Study on Key Success

Factors in the ICT sector

UNU-MERIT Dissertation Series, № 22

2000

\section{Machiel van Dijk}

Technological Change and the

Dynamics of Industries: Theoretical Issues and Empirical evidence from Dutch Manufacturing UNU-MERIT Dissertation Series, № 21

\section{9}

\section{Jan Cobbenhagen}

Managing Innovation at the Company Level: A Study on Non-Sector-Specific Success Factors

UNU-MERIT Dissertation Series, № 20 
Marjolein Caniëls

Regional Growth Differentials: The

Impact of Locally Bounded Knowledge

Spillovers

UNU-MERIT Dissertation Series, № 19

1998

\section{Aldo Geuna}

Resource Allocation and Knowledge production: Studies in the Economics of University Research

UNU-MERIT Dissertation Series, № 18

1996

\section{Reinoud Joosten}

Dynamics, Equilibria, and Values

UNU-MERIT Dissertation Series,

№ 17

\section{Hugo Kruiniger}

Investment, $R \mathcal{E} D$, and the Financing

Decisions of the Firm

UNU-MERIT Dissertation Series, № 16

\section{5}

\section{Hans van Meijl}

Endogenous Technological Change:

The Case of Information Technology,

Theoretical Considerations and

Empirical Results

UNU-MERIT Dissertation Series, № 15

\section{René Kemp}

Environmental Policy and Technical

Change: A Comparison of the

Technological Impact of Policy

Instruments

UNU-MERIT Dissertation Series,

№ 14

\section{Rohini Acharya}

The Impact of New Technologies on

Economic Growth and Trade: A Case

Study of Biotechnology

UNU-MERIT Dissertation Series,

№ 13

\section{Geert Duysters}

The Evolution of Complex Industrial Systems: The Dynamics of Major IT Sectors

UNU-MERIT Dissertation Series, № 12

\section{Marjan Groen}

Technology, Work and Organisation: A Study of the Nursing Process in Intensive Care Units

UNU-MERIT Dissertation Series, № 11

\section{4}

\section{Huub Meijers}

On the Diffusion of Technologies in a Vintage Framework: Theoretical Considerations and Empirical Results UNU-MERIT Dissertation Series, № 10 
Theon van Dijk

The Limits of Patent Protection: Essays on the Economics of Intellectual

Property Rights

UNU-MERIT Dissertation Series, № 9

\section{Hans Voordijk}

Naar Integrale Logistiek in

Bedrijfsketens: Ontwikkelingen in de Bouw

UNU-MERIT Dissertation Series, № 8

1993

\section{Paul Diederen}

Technological Progress in Enterprises and Diffusion of Innovation:

Theoretical Reflections and Empirical

Evidence

UNU-MERIT Dissertation Series, № 7

\section{Ben Dankbaar}

Economic Crisis and Institutional

Change: The Crisis of Fordism from the Perspective of the Automobile Industry UNU-MERIT Dissertation Series, № 6

\section{Hanno Roberts}

Accountability and Responsibility: The Influence of Organisation Design on Management Accounting UNU-MERIT Dissertation Series, № 5
1992

\section{Bart Verspagen}

Uneven Growth between

Interdependent Economies: An

Evolutionary View on Technology

Gaps, Trade and Growth

UNU-MERIT Dissertation Series,

№ 4

\section{Sjoerd Romme}

A Self-organization Perspective on

Strategy Formation

UNU-MERIT Dissertation Series, № 3

\section{9}

\section{John Spangenberg}

Economies of Scale, and Atmosphere in Research Organisations

UNU-MERIT Dissertation Series, № 2

1988

\section{John Hagedoorn}

Evolutionary and Heterodox

Innovation Analysis: A Study of

Industrial and Technological

Development in Process Control and

Information Technology

UNU-MERIT Dissertation Series, № 1 